\title{
Protein-protein and protein-membrane interactions in prothrombin activation
}

Citation for published version (APA):

Riemslag-Govers, J. W. (1994). Protein-protein and protein-membrane interactions in prothrombin activation. [Doctoral Thesis, Maastricht University]. Rijksuniversiteit Limburg. https://doi.org/10.26481/dis.19940610jr

Document status and date:

Published: 01/01/1994

DOI:

10.26481/dis.19940610jr

Document Version:

Publisher's PDF, also known as Version of record

\section{Please check the document version of this publication:}

- A submitted manuscript is the version of the article upon submission and before peer-review. There can be important differences between the submitted version and the official published version of record.

People interested in the research are advised to contact the author for the final version of the publication, or visit the DOI to the publisher's website.

- The final author version and the galley proof are versions of the publication after peer review.

- The final published version features the final layout of the paper including the volume, issue and page numbers.

Link to publication

\footnotetext{
General rights rights.

- You may freely distribute the URL identifying the publication in the public portal. please follow below link for the End User Agreement:

www.umlib.nl/taverne-license

Take down policy

If you believe that this document breaches copyright please contact us at:

repository@maastrichtuniversity.nl

providing details and we will investigate your claim.
}

Copyright and moral rights for the publications made accessible in the public portal are retained by the authors and/or other copyright owners and it is a condition of accessing publications that users recognise and abide by the legal requirements associated with these

- Users may download and print one copy of any publication from the public portal for the purpose of private study or research.

- You may not further distribute the material or use it for any profit-making activity or commercial gain

If the publication is distributed under the terms of Article $25 \mathrm{fa}$ of the Dutch Copyright Act, indicated by the "Taverne" license above, 


\section{PROTEIN-PROTEIN AND PROTEIN-MEMBRANE INTERACTIONS IN PROTHROMBIN ACTIVATION}

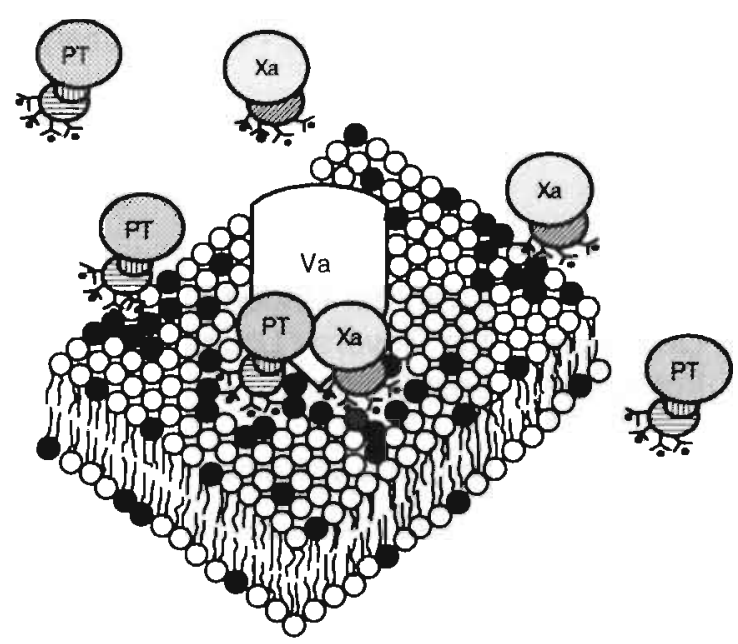


Govers-Riemslag, Josepha Wilhelmina Philomena

Protein-protein and protein-membrane interactions in prothrombin activation Josepha Wilhelmina Philomena Govers-Riemslag - Maastricht:

Thesis Maastricht - With. ref. - With summary in Dutch.

ISBN: 90-9007223-3

Subject headings: prothrombin / blood coagulation.

Omslag: Louis van der Linden

Ontwerp - Robin Govers / Louis van der Linden

Fotografie - Joost Govers

Druk: Hub. Tonnaer b.v. Kelpen 


\section{PROTEIN-PROTEIN AND \\ PROTEIN-MEMBRANE INTERACTIONS \\ IN PROTHROMBIN ACTIVATION}

\section{PROEFSCHRIFT}

ter verkrijging van de graad van doctor aan de Rijksuniversiteit Limburg te Maastricht, op gezag van de Rector Magnificus, Prof. Dr. H. Philipsen, volgens het besluit van het College van Dekanen, in het openbaar te verdedigen op vrijdag 10 juni 1994 om 14.00 uur

door

Josepha Wilhelmina Philomena Govers-Riemslag 
Promotor

Co-promotor

Beoordelingscommissie : Prof. Dr. G.J. van der Vusse, voorzitter Prof. Dr. M.P. van Dieijen-Visser

Prof. Dr. J.F.M. Smits

Dr. K.F. Stocker

Prof. Dr. H.M. Verheij

Financial support by the Netherlands Heart Foundation and by the Foundation Dr. Ir. J.H.J. v.d. Laar for the publication of this thesis is gratefully acknowledged. 
Where we are going is how we get there.

If where we are going is how we get there,

we are where we are going.

If we are where we are going, we have nowhere to go.

If we have nowhere to go, may we be where we are.

\section{Robert Fripp}

Ter herinnering aan mijn vader Voor mijn moeder Voor Frans, Pim en Birgit 
The experimental chapters of this thesis are based on the following articles:

- Tans G., Govers-Riemslag J.W.P., van Rijn J.L.M.L. and Rosing J. (1985) Purification and properties of a prothrombin activator from the venom of Notechis scutatus scutatus, J. Biol. Chem. 260, 9366-9372 [Chapter 4]

- Govers-Riemslag J.W.P., Knapen M.J.H., Tans G., Zwaal R.F.A. and Rosing J. (1987) Structural and functional characterization of a prothrombin activator from the venom of Bothrops neuwiedi, Biochim. Biophys. Acta 916, 388-401 [Chapter 3]

- Gerads I., Govers-Riemslag J.W.P., Tans G., Zwaal R.F.A. and Rosing J. (1990) Prothrombin activation on membranes with anionic lipids containing phosphate, sulfate, and/or carboxyl groups, Biochemistry 29, 7967-7974

[Chapter 6 and 7]

- Govers-Riemslag J.W.P., Janssen M.P., Zwaal R.F.A. and Rosing J. (1992) Effect of membrane fluidity and fatty acid composition on the prothrombinconverting activity of phospholipid vesicles, Biochemistry 31, 10000-10008 [Chapter 8]

- Govers-Riemslag J.W.P., Janssen M.P., Zwaal R.F.A. and Rosing J. (1994) Prothrombin activation on dioleoylphosphatidylcholine membranes, Eur. J. Biochem. 220, 131-138

[Chapter7] 


\section{Contents}

Chapter 2 Snake venom prothrombin activators.

A division according to structural and functional properties

Chapter $3 \quad$ Structural and functional characterization of a prothrombin activator from the venom of Bothrops neuwiedi

Chapter $4 \quad$ Purification and properties of a prothrombin activator from the venom of an Australian elapid snake, Notechis scutatus scutatus

Chapter 5 Membranes and blood coagulation

Chapter 6

The prothrombin-converting activity of membranes with varying polar headgroups

Chapter $7 \quad$ Prothrombin activation on

dioleoylphosphatidylcholine membranes

Chapter $8 \quad$ Effect of membrane fluidity and fatty acid composition on the prothrombin-converting activity of phospholipid vesicles

Chapter $9 \quad$ Summary and concluding remarks

Samenvatting en slotopmerkingen

List of publications

Curriculum vitae 


\section{Abbreviations}

PL

diC 18 -ether PC

DMPC

DMPS

DOPA

DOPC

DOPG

DOPS

DPPC

$P A$

$P C$

PE

PG

PLac

PS

MePA

SF

\section{FII / PT}

Ila

FVa

FVII

FIX

FXa

TF

Gla

S2238

$\mathrm{S} 2337$

CBS 31.39

I2581

dansyl-GGACK

p-NPGB

RVV-X

AT-III

HSA

STI phospholipid

dioctadecyl phosphatidyicholine

dimyristoyl-sn-glycero-3-phosphocholine

dimyristoyl-sn-glycero-3-phosphoserine

dioleoyl-sn-glycero-3-phosphate

dioleoyl-sn-glycero-3-phosphocholine

dioleoyl-sn-glycero-3-phosphoglycerol

dioleoyl-sn-glycero-3-phosphoserine

dipalmitoyl-sn-glycero-3-phosphocholine

phosphatidic acid

phosphatidylcholine

phosphatidylethanolamine

phosphatidylglycerol

phosphatidyl- $\beta$-lactate

phosphatidylserine

phosphatidylmethanol (phosphatitic acid monomethylester)

sulfatide

prothrombin

thrombin

activated coagulation factor $V$

coagulation factor $\mathrm{VII}$

coagulation factor IX

activated coagulation factor $X$

tissue factor

gamma-carboxyglutamic acid

H-D-phenyl-alanyl-L-pipecolyl-L-arginine-p-nitroanilide.

$\mathrm{N}$-benzoyl-L-isoleucyl-L-glutamyl-(piperidyl)-glycyl-L-arginylp-nitroanilide hydrochloride

$\mathrm{CH}_{3} \mathrm{SO}_{2}$-D-leucyl-glycyl-L-arginine-p-nitroanilide $\mathrm{N}$-dansyl-(p-guanidino)phenylalaninepiperidide

hydrochloride

dansyl-L-glutamylglycyl-L-arginine chloromethyl ketone

dihydrochloride

p-nitrophenyl p-guanidinebenzoate

purified factor $X$ activator from Russell's viper venom

antithrombin III

human serum albumin

soybean trypsin inhibitor 
SDS

Tris

EDTA

KdXava

Q10

TLC

$\mathrm{Mr}$ sodium dodecyl sulfate

tris(hydroxy-methyl)aminomethane

ethylenediaminetetraacetic acid

dissociation constant for factor XaVa-complex

the ratio of the rate constants of a reaction for each $10^{\circ} \mathrm{C}$ rise in temperature.

thin-layer chromatography

molecular weight 
Chapter 1

\section{Haemostasis and Prothrombin Activation}




\section{General}

The blood vessel wall is luminally lined by a layer of endothelial cells, which separates coagulation factors and platelets from subendothelial vascular structures. After injury, components from the subendothelium and connective tissue are exposed to the blood and initiate the haemostatic process that causes the impedance or the arrest of bleeding. During haemostasis, components from the blood (e.g. blood platelets and coagulation factors) act in close cooperation with the subendothelium of the damaged vessel wall [1]. Circulating resting platelets come in contact with collagen and become activated, which among others results in a release of several different platelet proteins. The activated platelets subsequently adhere via receptors to the subendothelium with the aid of adhesive proteins such as von Willebrand factor, fibronectin, thrombospondin and different types of collagen, which may be either present on the vessel wall or adsorbed from plasma [1-3]. The adhering platelets then aggregate and form the so-called primary haemostatic plug. Simultaneously the extrinsic pathway of blood coagulation is initiated by the exposure of the integral membrane protein, tissue factor, at the site of vascular injury [4,5]. Tissue factor [6] forms an efficient enzyme complex with the circulating coagulation factor $\operatorname{VII}(a)[7,8]$. This complex converts coagulation factor $X$ into the active serine protease factor $\mathrm{Xa}$, which on its tum converts prothrombin (factor II) into thrombin (factor Ila). The final reaction of the highly ordered coagulation process is the conversion of soluble fibrinogen into an insoluble cross-linked fibrin network by thrombin. Fibrin consolidates the fragile primary haemostatic plug of aggregated platelets and a stable thrombus is formed [see for a review on blood coagulation refs. 9-11].

This thesis deals with a study of one reaction of blood coagulation, namely the activation of prothrombin by the prothrombinase complex. The remaining part of this introduction is therefore focused on the coagulation system and especially on prothrombin activation.

\section{Modern view of the coagulation cascade}

In plasma blood coagulation factors are present as inactive precursors (zymogens) of active serine proteases. In 1964 the reaction sequence of blood coagulation was presented in a cascade model, which consisted of the so-called intrinsic and extrinsic pathways $[12,13]$. Initiation of coagulation 
through the intrinsic pathway (contact activation) starts with the activation of factor XII by prekallikrein in the presence of high molecular weight kininogen $[14,15]$. This pathway is no longer considered to play an important role in haemostasic plug formation. The classical coagulation cascade is consequently reduced to the extrinsic pathway and involves the reactions depicted in Figure 1.

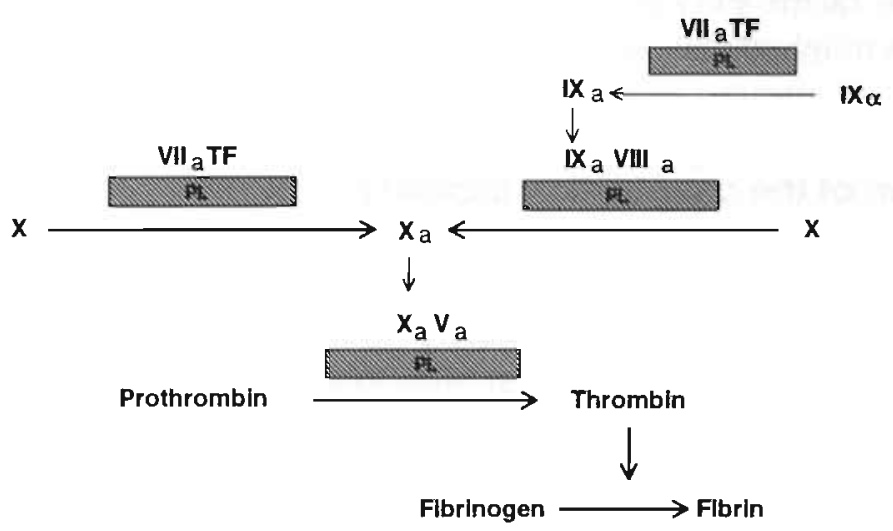

Figure 1. Schematic representation of the extrinsic pathway of the blood coagulation. Roman numerals indicate coagulation factors and the activated forms are designated by subscipt "a", i.e. $\mathrm{VII}_{\mathrm{a}}, \mathrm{IX}_{\mathrm{a}}, \mathrm{X}_{\mathrm{a}}$, etc.; $\mid \mathrm{X}_{\alpha}$ is a nonenzymatic intemediate. Each serine protease is shown in association with the appropriate cofactor protein on the membrane surface. TF is the abbreviation for tissue factor and PL refers to the procoagulant phospholipid surface.

The first proteolytic event in the extrinsic coagulation cascade is the conversion of the zymogen factor $\mathrm{X}$ into the serine protease factor $\mathrm{Xa}$. In the initial phase, this reaction is catalyzed by a complex between tissue factor and factor VII or factor VIla $[16,17]$. With respect to the initiation there are two possibilities: (a) either factor VII itself possesses proteolytic activity [18] or (b) a small fraction of factor VII circulates in plasma in an activated form (factor VIla). Circulating factor VIla may in itself be harmless, since in the absence of tissue factor, factor VIla is a very poor enzyme. In any event, factor $X a$ formed in the initial phase of coagulation stimulates further factor $X$ activation by the conversion of factor VII into factor VIla. Factor Xa also converts factor IX into the nonenzymatic intermediate factor IX $\alpha$, which is a good substrate for the tissue factor-VIla complex by which it is converted into factor IXa [19]. Factor $\mathrm{Xa}$ is able to form trace amounts of thrombin from the zymogen prothrombin and these early formed thrombin molecules can activate factor VIII and factor V. FVIIIa and factor Va are cofactors that lack 
enzymatic activity, but which enormously stimulate blood coagulation by accelerating factor $X$ and prothrombin activation, respectively. Although thrombin is the principal activator of Factor $V$ and factor VIII, factor Xa can also activate both these factors [20-22]. As soon as factor $\mathrm{Va}$ and factor VIII a are generated, the coagulation cascade becomes a very efficient process. Factor $X$ is not only activated by the tissue factor-VIla complex, but also by the factor VIIIa-IXa complex and the activation of prothrombin by factor $\mathrm{Xa}$ is tremendously enhanced by the presence of Factor Va.

\section{Regulation of the coagulation cascade}

The sequence of reactions that constitutes the coagulation cascade requires a unique and sophisticated regulatory system. On the one hand these reactions must be initiated as a response to vascular injury, but on the other hand the growth of the haemostatic plug must be strictly limited to the site of vessel wall damage. In the blood there are anticoagulant systems, which may counterbalance the procoagulant pathway and prevent undesired thrombus formation.

Thrombin not only enhances its own formation, by activating the protein cofactors factor $\mathrm{Va}$ and factor VIIIa, but indirectly also exhibits an anticoagulant effect. On intact endothelium, thrombin forms a complex with the membrane glycoprotein thrombomodulin [23]. This cell-bound thrombinthrombomodulin complex initiates the anticoagulant coagulation pathway by converting protein $C$ into activated protein $C$ (APC) [23-25]. APC is able to convert factor $\mathrm{Va}[26,27]$ and factor VIIIa [28] into inactive cofactors by limited proteolysis. Via this reaction sequence, which has the characteristics of negative feedback, thrombin also inhibits its own formation [for a review paper see ref. 29].

Blood also contains a number of naturally occurring inhibitors that among others act on thrombin and consequently slow down the generation of fibrin. Antithrombin III appears to be the primary plasma inhibitor of thrombin [30], but the inhibitory action of antithrombin III is also directed to factor IXa and factor Xa [31]. The formation of the one to one antithrombin III-enzyme complex is greatly enhanced by heparin. The action of antithrombin III together with heparin results in a complete block of fibrin formation.

Another control mechanism is fibrinolysis, an enzyme system which is capable of dissolving blood clots by degradation of the fibrin clot. Plasminogen, which is the proenzyme of the fibrinolytic enzyme system, is 
converted into the active enzyme plasmin by several different types of plasminogen activators [for a review see ref 32].

\section{The prothrombinase complex and the formation of thrombin}

Thrombin plays a key role in the process of blood coagulation. It is formed after proteolytic cleavage of the zymogen prothrombin by the so-called prothrombinase complex. This macromolecular enzyme complex is composed of the serine protease factor $\mathrm{Xa}$ and the nonenzymatic protein cofactor factor $\mathrm{Va}$, which are reversibly associated on a membrane surface in the presence of calcium ions.

Prothrombin (factor II) has a molecular weight of approximately 72,000 and is one of the six vitamin K-dependent proteins, which are involved in blood coagulation [11,33]. Prothrombin circulates in plasma as a singlechain glycoprotein at a concentration of approximately $3 \mu \mathrm{M}$. The complete amino acid sequence is known [34]. In the prothrombin molecule three functional domains can be recognized. Two of these domains are present in the large activation peptide region of prothrombin. This part of the prothrombin molecule exhibits a great affinity towards the accessory components of the prothrombinase complex. The amino-terminal fragment 1 region contains $10 \gamma$-carboxyglutamic acid residues (Gla residues) [35], which are involved in the $\mathrm{Ca}^{2}+$-dependent interaction of prothrombin with phospholipid membranes [36-38] while the fragment 2 region is thought to interact with the cofactor factor $V a[39,40]$ and can bind to $\alpha$-thrombin [41].The third domain is the carboxyl-terminal region and this domain, which is homologous to other serine proteases, contains the active site.

The enzyme, factor $\mathrm{Xa}$ is a vitamin K-dependent glycoprotein with a molecular weight of 44,000 that consists of a heavy chain $(\mathrm{Mr} 27,000)$ and a light chain ( $\mathrm{Mr} 18,000$ ) linked together via a disulfide bridge [42,43]. Factor $\mathrm{Xa}$ belongs to the class of serine proteases and contains $12 \gamma$ carboxyglutamic acid residues within the first 40 amino acids of the light chain $[44,45]$. The active site of factor $X a$ is located on the heavy chain $[46,47]$.

The protein cofactor factor $\mathrm{Va}$ is a two subunit glycoprotein ( $\mathrm{Mr} 180,000)$, which is composed of a heavy chain (Mr 105,000) and a light chain ( $\mathrm{Mr}$ $74,000)[48,49]$ associated via a calcium ion [50]. Factor $\mathrm{Va}$ can bind to a membrane surface via the light chain in a calcium-independent manner. The heavy chain of factor $\mathrm{Va}$ has affinity for prothrombin and factor $\mathrm{Xa}$. 
The procoagulant membrane surface consists of a bilayer of phospholipid molecules. When membranes contain negatively charged phospholipid molecules (e.g. phosphatidylserine or phosphatidic acid) the stimulation of prothrombin activation is greatly enhanced [for a review see chapter 5]. The binding of the vitamin K-dependent coagulation factors, prothrombin and factor $\mathrm{Xa}$, is $\mathrm{Ca}^{2+-d e p e n d e n t ~ a n d ~ t h e ~ i n t e r a c t i o n s ~ a r e ~ m e d i a t e d ~ b y ~} \gamma$ carboxyglutamic acid residues [discussed in more detail in chapter 2]. Factor $\mathrm{Va}$ binds to the membrane surface via the light chain through both ionic and hydrophobic interactions.

The conversion of prothrombin into thrombin is the result of cleavage of the Arg274-Thr275 and Arg323-lle324 bonds in the prothrombin molecule. Two potential pathways of thrombin generation exist and, depending upon the order of peptide bond cleavage in prothrombin, two intermediates (prethrombin 2 and meizothrombin) can be formed during prothrombin activation. The amounts of prethrombin 2, meizothrombin, and thrombin, generated during the initial phase of prothrombin activation are strongly dependent on the reaction conditions used under which prothrombin activation is studied [for a review see ref. 51].

The rate of prothrombin activation by factor $\mathrm{Xa}$ is 1000 -fold increased, in the presence of the accessory components factor $\mathrm{Va}$ or phospholipids plus $\mathrm{Ca} 2+$-ions. Optimal stimulation of prothrombin activation (280,000-fold) is observed when both factor $\mathrm{Va}$ and a procoagulant membrane surface plus calcium ions are present. The protein cofactor $\mathrm{Va}$ performs two main functions in prothrombin activation: (1) it promotes binding of factor $\mathrm{Xa}$ to procoagulant membranes [9,52], and (2) it increases the catalytic activity of factor Xa. The latter effect is thought to be caused by a factor Va-induced conformational change of factor $\mathrm{Xa}$ which converts it into a better enzyme [53]. The main function of the phospholipid membrane is to provide a surface that promotes assembly of the factor Xa-factor $\mathrm{Va}$ complex and that subsequently supports the interaction of the substrate prothrombin with factor Xa /or with the factor XaVa-complex [10]. The major effects of the accessory components are: (1) an increase of the $k_{c a t}$ of prothrombin activation by factor $\mathrm{Va}$ and (2) a decrease of the $\mathrm{K}_{\mathrm{m}}$ for prothrombin by phospholipids plus calcium ions [54].

The mechanism and interactions involved in prothrombin activation serve as a model for the activation of other vitamin K-dependent coagulation factors (factor VII, factor IX, factor $X$ and protein $\mathrm{C}$ ). All these coagulation factors are activated by a serine protease, which interacts with a protein cofactor on a membrane surface and rapidly activates the specific substrate. 
However, unlike most other protease zymogens, the prothrombin molecule contains a very large activation peptide region. About half of the prothrombin molecule is removed as activation peptide during activation. In contrast to the other vitamin $\mathrm{K}$ related proteinases, there are no disulfide bridges, which after activation connect the Gla-containing region of prothrombin to the active site-containing polypeptide chain. The enzyme thrombin may therefore dissociate from the activation complex and diffuse to its different substrates, whereas other vitamin $\mathrm{K}$ proteinases remain bound to the phospholipid surface in a calcium-dependent manner mediated by the $\gamma$ carboxyglutamic acid residues.

\section{The present investigation}

A wide variety of snake species contain potent prothrombin activators [discussed in chapter 2]. Prothrombin activation by the snake venom prothrombin activators is of special interest, since studies on such activators may add information to our current knowledge of the mechanism of prothrombin activation.

The purpose of this investigation is to gain more insight into the mechanism of action of the prothrombinase complex by making use of snake venom enzymes as prothrombin activators. In Chapter 2 a short review is presented on snake venoms which contain activators of prothrombin. In Chapter 3 and Chapter 4 the purification, characterization and biochemical properties of two snake venom prothrombin activators are reported.

The influence of the phospholipid component of the prothrombinase complex on the assembly and catalytic activity is investigated by varying parts of the phospholipid molecules and so change the properties of the membrane. An introduction to this theme is presented in Chapter 5. The effects of certain membrane alterations on the assembly and the expression of the activity of the prothrombinase complex are described in Chapters 6-8.

Chapter 6 concerns a study on the procoagulant properties of membranes composed of mixtures of phosphatidylcholine and (phospho)lipid molecules, with different polair headgroups.

The stimulation of prothrombin activation by membranes solely composed of the neutral phospholipid phosphatidylcholine is described in chapter 7 .

Chapter 8 summarizes the results of prothrombin activation on procoagulant membranes with different physical properties (membrane fluidity and packing density of the membrane). 


\section{References}

1. De Groot P.G. and Sixma J.J. (1993) Platelet-vessel wall interaction, Vascular Medicine Review 4, 83-93

2. Girma J.P, Meyer D., Verweij C.L., Pannekoek H. and Sixma J.J. (1987) Structurefunction relationship of human von Willebrand factor, Blood 70, 605-611

3. Ruggeri Z.M.and Zimmerman T.S. (1987). Von Willebrand factor and von Willebrand disease, Blood 70, 895-904

4. Weiss H.J., Turitto V.T., Baumgartner H.R., Nemerson Y. and Hoffman T. (1989) Evidence for the presence of tissue factor activity on subendothelium, Blood 73, 968-975

5. Wilcox J.N., Smith K.M., Schwartz S.M. and Gordon D. (1989) Localization of tissue factor in the normal vessel wall and in the atherosclerotic plaque, Proc. Natl. Acad. Sci. 86, 2839-2843

6. Edgington T.S., Mackman N., Brand K. and Ruf W. (1991) The structural,biology of expression and function of tissue factor, Thromb. Haemost. 66, 67-79

7. Osterud B. and Rapaport S. (1977) Activation of factor IX by the reaction product of tissue factor and factor VII: additional pathway for initiating blood coagulation, Proc. Natl. Acad. Sci. 74, 5260-5264

8. Krishnaswamy S. (1992) The interaction of human factor Vlla with tissue factor, $J$. Biol. Chem. 267, 23696-23706

9. Mann K.G., Jenny R.J. and Krishnaswamy S. (1988) Cofactor proteins in the assembly and expression of blood clotting enzyme complexes, Ann. Rev. Biochem. 57, 915-956

10. Mann K.G., Nesheim M.E., Church W.R., Haley P. and Krishnaswamy S. (1990) Review article: surface-dependent reactions of the vitamin K-dependent enzyme complexes, Blood 76, 1-16

11. Davie E.W., Fujikawa K. and Kisiel W. (1991) The coagulation cascade: Initiation, maintenance, and regulation, Biochemistry 30, 10363-10370

12. Macfarlane R.G. (1964) A cascade mechanism for blood coagulation, Nature 202, 498-499

13. Davie E.W., Ratnoff O.D. (1964) Waterfall sequence for intrinsic blood clotting, Science 145, 1310-1312

14. Griffin J.H. and Cochrane C.G. (1976) Mechanism for involvement of high molecular weight kininogen in surface-dependent reactions of Hageman factor (coagulation factor XII), Proc. Nall. Acad. Sci. 73, 2554-2558

15. Ratnoff O.D. and Saito H. (1979) Interactions between Hageman factor, plasma prekallikrein, high molecular weight kininogen, and plasma thromboplastin antecedent, Proc. Natl. Acad. Sci. 76, 958-961

16. Nelsestuen G.L., Kisiel W. and DiScipio R.G. (1978) Interaction of vitamin K dependent proteins with membranes, Biochemistry 17, 2134-2138

17. Nemerson Y. (1988) Tissue factor and hemostasis, Blood 71, 1-8

18. Zur M., Radcliffe R.D., Oberdick J. and Nemerson Y. (1982) The dual role of factor VII in blood coagulation. Initiation and inhibition of a proteolytic system by a zymogen, J. Biol. Chem. 257, 5623-5631

19. Lawson J.H. and Mann K.G. (1991) Cooperative activation of human factor IX by human extrinsic pathway of blood coagulation, J. Biol. Chem. 266, 11317-11327 
20. Foster W.B., Nesheim M.E. and Mann K.G. (1983) The factor Xa-catalyzed activation of factor V, J. Biol. Chem. 258, 13970-13977

21. Monkovic D.D. and Tracy P. (1990) Activation of human factor $V$ by factor $X a$ and thrombin, Biochemistry 29, 1118-1128

22. Lollar P., Knutson G.J.and Fass D.N. (1985) Activation of porcine factor VIII:C by thrombin and factor $\mathrm{Xa}$, Biochemistry 24, 8056-8064

23. Esmon C.T. and Owen W.G. (1981) Identification of an endothelial cofactor for thrombin-catalyzed activation of protein C, Proc. Natl. Acad. Sci. 78, 2249-2252

24. Owen, W.G. and Esmon, C.T. (1981) Functional properties of an endothelial cell cofactor for thrombin-catalyzed activation of protein C, J. Biol. Chem. 256, 55325535

25. Esmon N.L., Owen W.G. and Esmon C.T. (1982) Isolation of a membrane bound cofactor for thrombin-catalyzed activation of protein C, J. Biol. Chem. 257, 859-864

26. Kisiel W., Canfield W.M., Ericsson L.H. and Davie E.W (1977) Anticoagulant properties of bovine plasma protein $\mathrm{C}$ following activation by thrombin, Biochemistry 16, 5824-5831

27. Marlar R.A., Kleiss A.J. and Griffin J.H. (1982) Mechanism of action human activated protein $\mathrm{C}$, a thrombin-dependent anticoagulant enzyme, Blood 59, 10671072

28. Vehar G.A. and Davie E.W. (1980) Preparation and properties of bovine factor VIII (antihemophilic factor), Biochemistry 19, 401-410

29. Esmon C.T. (1989) The roles of protein $C$ and thrombomodulin in the regulation of blood coagulation, J. Biol. Chem. 264, 4743-4746

30. Rosenberg R.D. and Damus P.S. (1973) The purification and mechanism of action of human anti-thrombin-heparin cofactor, J. Biol. Chem. 248, 6490-6505

31. Kurachi K., Fujikawa K., Schmer G. and Davie E.W (1976) Inhibition of bovine factor IXa and factor Xaß by antithrombin III, Biochemistry 15, 373-377

32. Collen D. (1980) On the regulation and control of fibrinolysis, Thromb. Haemostas. 43, 77-89

33. Suttie J.W. and Jackson C.M. (1977) Prothrombin structure, activation and biosynthesis, Physiol. Rev. 57, 1-70

34. Magnusson S., Petersen T.E., Sottrup-Jenssen L. and Claeys H. (1975) Complete primary structure of prothrombin: Isolation, structure and reactivity of ten carboxylated glutamic acid residues and regulation of prothrombin activation by thrombin. in Proteases and Biological Control, Reich E., Rifkin D.B. and Shaw W.(Eds.), Cold Spring Harbor Laboratory, Cold Spring Harbor, N.Y., pp. 123-149

35. Soriano-Garcia M., Park C.H., Tulinsky A., Ravichandran K.G. and SkrzypczakJankun W. (1989) Structure of $\mathrm{Ca}^{2+}$ prothrombin fragment 1 including the conformation of the Gla domain, Blochemistry 28, 6805-6810

36. Jobin F. and Esnouf M.P. (1967) Studies on the formation of the prothrombinconverting complex, Biochem. J. 102, 666-674

37. Barton P.G. and Hanahan D.J. (1969) Some lipid-protein interactions involved in prothrombin activation, Biochim. Biophys. Acta 187, 319-327

38. Bull R.K., Jevons S. and Barton P.G. (1972) Complexes of prothrombin with calcium ions and phospholipids, J. Biol. Chem. 247, 2747-2754

39. Esmon C.T. and Jackson C.M. (1974) The conversion of prothrombin to thrombin. IV. The function of the fragment 2 region during activation in the presence of factor V, J. Biol. Chem. 249, 7791-7797 
40. Seegers W.H., Novoa E., Walz D.A., Andary T.J. and Hassouna H.I. (1976) Effects of prothrombin fragments on thrombin, on thrombin formation and separation from Ac-globulin (factor V), Thromb. Res. 8, 83-97

41. Myrmel K.H., Lundblad R.L. and Mann K.G. (1976) Characteristics of the association between prothrombin fragment 2 and $\alpha$-thrombin, Biochemistry 15 , 1767-1773

42. Fujikawa K., Titani K. and Davie E.W. (1975) Activation of bovine factor X (Stuart factor): Conversion of factor Xa-alpha to factor Xa-beta, Proc. Natl. Acad. Sci. 72 , 3359-3363

43. Jesty J., Spencer A.K., Nakashima Y., Nemerson Y., and Konigsberg W. (1975) The activation of coagulation factor $X$. Identity of cleavage sites in the altemative activation pathways and characterization of the $\mathrm{COOH}$-terminal peptide, J. Biol. Chem. 250, 4497-4504

44. Howard J.B. and Nelsestuen G.L. (1975) Isolation and characterization of vitamin K-dependent region of bovine blood clotting Factor X, Proc. Natl. Acad. Sci. 72 , $1281-1285$

45. Bucher D., Nebelin, E., Thomson J. and Stenflo, J. (1976) Identification of $\gamma$ carboxyglutamic acid residues in bovine factor $\mathrm{IX}$ and $\mathrm{X}$ and in a new vitamin $\mathrm{K}$ dependent protein, FEBS Letters 68, 293-296

46. Leveson J.E. and Esnouf M.P. (1969) The inhibition of activated Factor $X$ with diisopropylfluorophosphate, Brit. J. Haematol. 17, 173-178

47. Radcliffe R.D. and Barton P.G. (1972) The purification and properties of activated factor X, J. Biol. Chem. 247, 7735-7742

48. Nesheim M.E. and Mann K.G. (1979) Thrombin-catalyzed actvation of single chain bovine factor V, J. Biol. Chem. 254, 1326-1334

49. Esmon C.T. (1979) The subunit structure of thrombin-activated factor $V$. Isolation of activated factor $\mathrm{V}$, separation of subunits and reconstitution of biological activity, J. Biol. Chem. 254, 964-973

50. Hibbard L.S. and Mann K.G. (1980) The calcium binding properties of bovine factor V, J. Biol. Chem. 255, 638-645

51. Rosing J. and Tans G. (1988) Meizothrombin, a major product of factor Xacatalyzed prothrombin activation, Thromb. Haemostas. 60, 355-360

52. Lindhout T., Govers-Riemslag J.W.P., van de Waart P., Hemker H.C. and Rosing J. (1982) Factor Va-factor $\mathrm{Xa}$ interaction. Effects of phospholipid vesicles of varying composition, Biochemistry 21 5494-5502

53. Walker R.K. and Krishnaswamy S. (1993) The influence of factor Va on the active site of factor Xa, J. Biol. Chem. 268, 13920-13929

54. Rosing J., Tans G., Govers-Riemslag J.W.P., Zwaal R.F.A. and Hemker H.C. (1980) The role of phospholipids and factor $\mathrm{Va}$ in the prothrombinase complex, $J$. Biol. Chem. 255, 274-283 


\section{Chapter 2}

\section{Snake Venom Prothrombin Activators A Division According to Structural and Functional Properties}




\section{Introduction}

Snake venoms are highly complex toxins that contain several biological active substances. The nonenzymatic polypeptides such as neurotoxins and cardiotoxins have been thoroughly characterized $[1,2]$. Neurotoxins, some of which act together with snake venom phospholipases, affect the nervous system and cardiotoxins depolarize heart muscle cells. The venoms of several snake species also contain enzymes which interfere with the blood coagulation mechanism, either via procoagulant, anticoagulant or fibrinolytic effects (for a review see Pirkle and Markland, 1988 [3]) and [4]. Platelet functions may also be affected by snake venom proteins, since some venoms induce platelet aggregation and release reactions [5], whereas others contain potent inhibitors of platelet aggregation [6].

The lethality of a venom appears to be due to the combined actions of several of its components. It is of interest that snake bites with the highest mortality rate always cause coagulation disorders [7].

There are many reports on snake venoms, that can activate coagulation factors. During the last decades venom prothrombin activators from different snake families have been intensively studied. Prothrombin activators have been purified from the venoms of Elapidae [8], Crotalidae (Bothrops species [9] ), Viperidae (Echis species [10]), and Colubridae (Dispholidus typus $[11,12]$ and Thelotornis kirtlandi $[13,14])$.

Also venom prothrombin activators have been characterized, which cleave peptide bonds in prothrombin, but which do not generate an active enzyme. These venoms often contain one or more thrombin-like enzymes.

Thrombin-like enzymes have been purified from the venoms of Bothrops species (BATROXOBIN or REPTILASE [15-17] and THROMBOCYTIN [18-20]), from the venoms of Agkistrodon caliginous [21] and Crotalus atrox [22], Agkistrodon acutus (ACUTIN) [23] and Bitis gabonica (GABONASE) [24].

It has become clear that the various snake venom prothrombin activators activate prothrombin via different pathways $[3,4,25,26]$. The purpose of this chapter is to make a division of venom prothrombin activators according to their structural and functional properties and compare them with the mammalian enzymes factor $X a$ and thrombin. 


\section{Prothrombin activation and the prothrombinase complex}

The conversion of prothrombin to its active form thrombin is an essential event in the process of blood coagulation. Under physiological conditions this activation is catalyzed by the prothrombinase complex, that comprises the serine protease factor $\mathrm{Xa}$, the nonenzymatic protein cofactor $\mathrm{Va}, \mathrm{a}$ procoagulant membrane and calcium ions.

Although Factor $\mathrm{Xa}$ slowly activates prothrombin, the activation rate increases 280,000 fold when the full prothrombinase complex is assembled. To illustrate this difference, sixty molecules of thrombin are formed by the complete prothrombinase complex in one second, while factor $\mathrm{Xa}$ alone needs more than three days to produce one thrombin molecule. The presence of the so-called accessory components appears to be very important for efficient prothrombin activation since they greatly accelerate the activation of prothrombin by the serine protease factor $\mathrm{Xa}$. The properties of prothrombin and the components of the prothrombinase complex are discussed in more detail in chapter 1.

\section{Different pathways of prothrombin activation}

There are several peptide bonds in prothrombin that are susceptible to proteolytic cleavage. Two peptide bonds in prothrombin can be cleaved by the enzyme factor Xa and these are at position Arg274-Thr275 (site 2) and Arg323-lle324 (site 3) [27] (Figure 1).

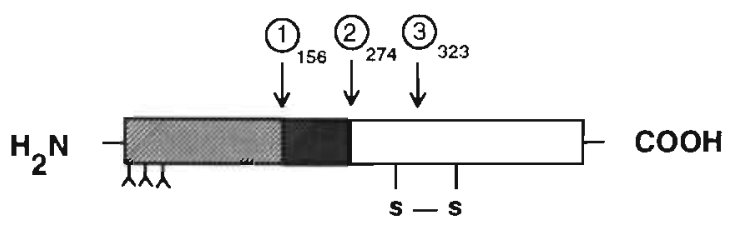

\section{Prothrombin}

Figure 1. Schematic structure of prothrombin. The three peptide bonds susceptible to proteolytic cleavage are indicated. The thombin or meizothrombin site is illustrated by - (Arg 156-Ser 157), and the factor Xa cleavage sites are designated by 2 (Arg274-Thr275) and $\mathbf{3}$ (Arg323-Ile324). $\lambda$ is $\gamma$-carboxyglutamic acid.

When prothrombin is activated by factor $\mathrm{Xa}$ these peptide bonds can be cleaved in random order and a combination of products can thus be formed. 
The actual product generation and the order of peptide bond cleavage depends on the reaction conditions used (see below and ref. [28]).

The peptide bond Arg156-Ser157 (site 1, Figure 1) in the activation peptide region of prothrombin can be cleaved by the feedback action of thrombin or meizothrombin (an intermediate in thrombin formation) and is inhibited by Ca2+-ions $[27,29,30]$. In thrombin at least two more bonds can be cleaved at the carboxyl-terminus of this molecule by autocatalysis, which results in thrombin derivatives with reduced procoagulant activity $[31,32]$.

The different peptide bond cleavages in the prothrombin molecule are separately described below and the physiological prothrombin activators factor Xa and thrombin will be compared with the snake venom prothrombin activators with respect to their activities in catalyzing the different peptide bond cleavages.

\section{The cleavage of the $\operatorname{Arg}_{156}-S^{-S_{157}}$ peptide bond of prothrombin}

The cleavage of peptide bond Arg156-Ser157 is catalyzed by thrombin or thrombin-like enzymes and results in the formation of fragment 1 and prethrombin 1 (Figure 2).
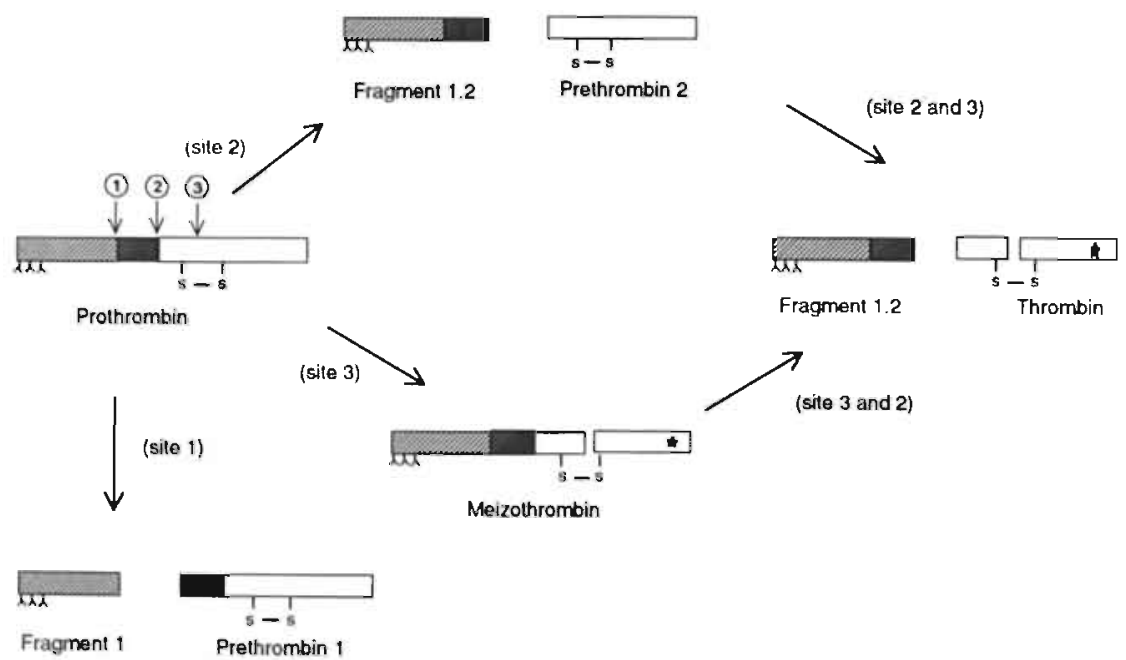

Figure 2. Different pathways of prothrombin activation. The result of peptide bond cleavages in prothrombin at different sites is shown and the name of the products formed is given. $\uparrow$ is $\gamma$-carboxyglutamic acid and is indicates active site exposure. 
Fragment 1 contains the Gla residues and prethrombin 1 contains fragment 2 and the active site domain, but is not yet catalytically active. Prethrombin 1 lacks $\gamma$-carboxyglutamic acid residues and is therefore a poor substrate for the prothrombinase complex. Thus, the conversion of prothrombin into prethrombin 1 slows down the activation of prothrombin and can be regarded as a negative feedback reaction, which may reduce thrombin formation in purified systems. However, this feedback reaction is presumably not important under physiological conditions [30]. Thrombin not only catalyzes the feedback reaction on prothrombin, but also acts on other proteins that participate in blood coagulation e.g. factor V, factor VIII, factor XIII, protein $\mathrm{C}$ and fibrinogen.

There are many reports on snake venoms that contain thrombin-like activities, especially in snake venoms that belong to the Crotalidae families [9]. Depending on their activity towards prothrombin, snake venom thrombinlike enzymes can be divided in two groups: group 1 with two distinct thrombin-like enzymes in one venom that together mimic the activity of thrombin but individually exhibit only a part of its activity and group 2 with one thrombin-like enzyme which possesses only a part of the thrombin activity.

According to the above-mentioned division Bothrops venoms belong to group 1. Many papers have been published on the thrombin-like activity of Bothrops venoms, among which the two thrombin-like enzymes of Bothrops atrox, BATROXOBIN Or REPTILASE [15-17] and THROMBOCYTIN [18-20], have been the most extensively studied. The biological significance of distributing essential functions of thrombin over two different protein molecules in snake venoms is not understood. BATROXOBIN readily clots fibrinogen, but it does not activate factor XIII or platelets [15]. TнномвосүтIN causes platelet aggregation, activates factor XIII and cleaves fragment 1 from prothrombin, but has a low fibrinogen clotting activity [19]. THROMBOCYTIN and BATROXOBIN are single chain glycoproteins with molecular weights of 36,000 and 32,000 , respectively, and both belong to the serine proteases $[16,20]$.

Other snake venoms of the Crotalidae family contain one thrombin-like enzyme and belong to group 2, Agkistrodon acutus (ACUTIN) [33,34], Agkistrodon contortrix [35], Agkistrodon rhodostoma (ANCROD) [36] and Crotalus adamanteus (CROTALASE) [37]. These proteases are able to perform thrombin-like activity on prothrombin and have no influence on any other coagulation factor except fibrinogen. These venom serine proteases are single chain proteins with a molecular weight of approximately 35,000 . 
ACUTIN can also cleave the Lys44-Tyr45 peptide bond of prothrombin and converts prothrombin into a molecule without Gla-domain [33,34].

The venom of Bitis gabonica (belonging to the Viperidae) contains one thrombin-like enzyme which compared to other venom enzymes has a unique combination of thrombin-like activities. The thrombin-like enzyme from the venom of Bitis gabonica (GABONASE, a single chain protein with a molecular weight of 30,600 ) not only releases both fibrinopeptides $A$ and $B$ from fibrinogen, but similar to thrombin, it also activates factor XIII [24]. This combined action has so far not been observed for any other thrombin-like venom enzyme. However, no experiments have been described on the ability of this thrombin-like enzyme to cleave peptide bonds in prothrombin.

\section{Venoms that catalyze the cleavage of the Arg274-Thr275 peptide bond of prothrombin}

The exclusive cleavage of the Arg274-Thr275 bond (site 2) of prothrombin by factor Xa results in the formation of two products: (1) prethrombin 2, which is an intermediate in thrombin formation with the same molecular weight as thrombin $(36,000)$, but which is not catalytically active, and (2) the activation peptide fragment 1.2 , which contains the $\gamma$-carboxyglutamic acid residues in the fragment 1 and the factor $\mathrm{Va}$ binding site in the fragment 2 region of the molecule (Figure 2).

Prethrombin 2 was only observed as a reaction product during prothrombin activation by its physiological activator $\mathrm{Xa}$ in the absence of the protein cofactor factor $\mathrm{Va}$ [38].

There are only a few examples in literature of snake venom prothrombin activators whose action on prothrombin is restricted to peptide bond 2 and hence give rise to prethrombin 2 formation. Proteolysis of prothrombin by enzymes isolated from the venoms of Crotalus adamanteus (CROTALASE) [35] and from Agkistrodon acutus (ACUTIN) [33,34], results in the formation of prethrombin 2 as endproduct [33-35]. Both venom prothrombin activators are also able to cleave the Arg156-Ser157 peptide bond of prothrombin (described in the section above) and they are present in the group of venoms, which contain one thrombin-like enzyme. It is remarkable that these thrombin-like enzymes catalyze the cleavage of the peptide bond in prothrombin at position Arg274-Thr275, since this peptide bond is normally not cleaved by thrombin, but by factor $X a$. Both venoms can be very useful in the preparation and purification of prethrombin 1 and prethrombin 2, which 
occur as activation intermediates during thrombin formation by the physiological activator factor Xa.

The crude venom of another Agkistrodon species, Agkistrodon halys halys and the crude venom of Naja naja oxiana also generate prethrombin 2 when incubated with prothrombin [39]. Since these venoms contain a number of procoagulant activities and the enzymes responsible for the peptide bond cleavage in prothrombin have not yet been purified, no conclusions can yet be made about their enzymatic nature.

\section{Venoms that catalyze the cleavage of the Arg323-Ile 324 peptide bond of prothrombin}

The cleavage of the Arg323-lle324 bond (site 3) of prothrombin by factor $\mathrm{Xa}$ gives rise to the formation of meizothrombin and results in exposure of the active site (Figure 2). Meizothrombin has the same molecular weight as prothrombin $(72,000)$, but due to the peptide bond cleavage it is a two-chain molecule that consists of the so-called F1.2-A (fragment $1.2+$ A chain of thrombin, $\mathrm{Mr} 41,000)$ and $\mathrm{B}$-chain domains $(\mathrm{Mr} 31,000)$ linked via a disulfide bridge. It has the capacity to split small oligopeptide substrates specific for thrombin, but has a greatly reduced enzymatic activity on macromolecular thrombin substrates such as fibrinogen or factor $V$ [40-43].

A number of snake venoms only cleave prothrombin at site 3 . These enzymes are different from the physiological activator factor $\mathrm{Xa}$ and belong to another class of enzymes, namely the metalloproteases. The most intensively studied prothrombin activator of this group is that from the venom of Echis caninatus, $[29,40,44-48]$. The venom prothrombin activators from other Echis species [39,49], from Dispholidus typus [11,12], Thelotornis kirtlandi $[13,14]$ as well as two Bothrops species, Bothrops atrox $[50]$ and Bothrops neuwiedi [51] also belong to this group. The structural and functional properties of these four activators strongly resemble those reported for the venom prothrombin activator from Echis carinatus. The purification, and characterization of the snake venom prothrombin activator from Bothrops neuwiedi is described in Chapter 3 of this thesis. 


\section{Venoms that cleave both the $\mathrm{Arg}_{274}-\mathrm{Thr}_{275}$ and $\mathrm{Arg}_{323}-\mathrm{Ile}_{324}$ peptide bonds of prothrombin}

After cleavage of both the peptide bonds 2 and 3 prothrombin is converted into two products i.e. the activation peptide fragment 1.2 and thrombin (Figure 2). Thrombin consists of an A chain (49 residues) and a B chain (259 residues) that are attached to each other via a disulfide bond. Thrombin is a very potent enzyme (serine protease) with a key position in haemostasis. Apart from catalyzing the conversion of fibrinogen into fibrin, it also activates factor V, factor VIII, protein C, factor XIII, blood platelets, and a variety of other cells.

Depending on the order of bond cleavage, there are two pathways to form thrombin from the zymogen prothrombin, i.e. via the intermediate prethrombin 2 or via meizothrombin. Thrombin is subsequently formed when factor Xa cleaves the second bond in either activation intermediate. The major reaction product in the initial stage of prothrombin activation by factor $\mathrm{Xa}$ is prethrombin 2, whereas meizothrombin is the major reaction product when prothrombin is activated by the factor XaVa-complex $[28,38]$.

The snake venom prothrombin activators that have the capacity to cleave both peptide bonds all belong to the Australian Elapidae and are serine proteases, like factor $X$. Prothrombin activation by venom activators from the Australian Elapidae also appears to be stimulated by the accessory components of the prothrombinase complex (phospholipids and factor $\mathrm{Va}$ ). Depending upon the effects of factor $\mathrm{Va}$ and/or phospholipids on venomcatalyzed prothrombin activation, the snake venom prothrombin activators, which can cleave prothrombin at site 2 and site 3 , can be classified in two groups. The Notechis-like prothrombin activators (e.g. Notechis scutatus, Notechis ater niger, Notechis ater humphreysi,Tropidechis carinatus, Pseudechis porphyriacus and Hoplocephalus stephensii) [52-54] strongly resemble the physiological activator factor $\mathrm{Xa}$. Prothrombin activation by Notechis-like prothrombin activators is stimulated by both factor $\mathrm{Va}$ and phospholipids. The Oxyuranus-like prothrombin activators (e.g. Oxyuranus scutellatus, Oxyuranus microlepidotus and Pseudonaja textilis) [8,55-58] are much larger proteins with molecular weights of approximately $\mathrm{Mr} 300,000$. Prothrombin activation by these venoms is only stimulated by the presence of phospholipids and the rate of prothrombin activation is not further enhanced by factor $\mathrm{Va}$. It is shown that Oxyuranus-like activators consist of a catalytic and a cofactor unit with properties identical to that of the factor $\mathrm{XaVa}$ complex. In Chapter 4 of this thesis the purification and 
characterization of the prothrombin activator from Notechis scutatus scutatus is described and this venom activator is compared with a representative prothrombin activator (i.e. the activator from Oxyuranus scutellatus) from the Oxyuranus group.

\section{Concluding remarks}

Procoagulant snake venoms are useful tools for the analysis of the mechanism of the coagulation process. The use of snake venom enzymes in fundamental haemostatic research has contributed significantly to the understanding of the mechanism of coagulation factor activation. Only a small part of the present knowledge of snake venoms is reviewed in this chapter, namely the venom components that catalyze the cleavage of peptide bonds in prothrombin. The purpose of this chapter is to outline the mechanism of the different pathways of prothrombin activation and to compare the venom prothrombin activators, that are responsible for the different cleavages in the prothrombin molecule, with the physiological enzymes.

From this inventory it appears that there are several classes of snake venom prothrombin activators. Only two venom activators, that catalyze peptide bond cleavages in prothrombin at the same sites as factor $\mathrm{Xa}$, are further discussed in this thesis (Chapter 3 and Chapter 4).

\section{References}

1. Gosh B.N., DE S.S. and Chaudhuri D.K. (1941) Separation of the neurotoxin from the crude cobra venom and study of the action of a number of reducing agents on it, Ind. Jour. Med. Res. 29, 367-373

2. Sarkar N.K. (1947) Isolation of cardiotoxin from cobra venom (Naja tripudians, monocellate variety), J. Ind. Chem. Soc. 24, 227-232

3. Pirkle H. and Markland Jr, F.S. (1988) Hemostasis and animal venoms, New York, Basel: Marcel Dekker, Inc.

4. Kornalik F. (1985) The influence of snake venom enzymes on blood coagulation, Pharmac. Ther. 29, 353-405

5. Davey M.G., Lüscher E.F. (1965) Actions of some coagulant snake venoms on blood platelets, Nature 207, 730-732

6. Chao B.H., Jakubowski J.A., Savage B., Chow E.P., Marzec U.M., Harker L.A. and Maraganore J.M. (1989) Agkistrodon piscivorus piscivorus platelet aggregation inhibitor: A potent inhibitor of platelet aggregation, Proc. Natl. Acad. Sci. 86, 80508054 
7. Jiménez-Porras J.M. (1970) Biochemistry of snake venoms, Clin. Toxicol. 3, 389431

8. Marshall L.R. and Herrmann R.P. (1983) Coagulant and anticoagulant actions of australian snake venoms, Thromb. Haemostas. 50, 707-711

9. Nahas L., Kamigutti A.S. and Barros M.A.R. (1979) Thrombin-like and factor Xactivator components of Bothrops snake venoms, Thromb. Haemost. 41, 314-328

10. Nahas L., Denson K.W.E. and Macfarlane R.G. (1964) A study of the coagulant action of eight snake venoms, Thromb. Diath. Haemorm. 12, 355-367

11. Mackay N., Ferguson J.C., Ashe J., Bagshawe A., Forrester A. and McNicol G.P. (1969) Venom of boomslang (dispholidus typus) in vivo and in vitro studies, Thromb. Diath. Haemorrh. 21, 234-244

12. Guillin M.C., Bezeaud A. and Menache D. (1978) The mechanism of activation of human prothrombin by an activator isolated from Dipholidus typus venom, Biochim. Biophys. Acta 537, 160-168

13. Kornalik F. and Taborska E. (1978) Procoagulant and defibrinating potency of the venom gland extract of Thelotomis kirtlandi, Thromb. Res. 12, 991-1001

14. Kornalik F., Taborska E.and Mebs D. (1978) Pharmacological and biochemical properties of a venom gland extract from the snakes Thelotornis kittlandi, Toxicon $16,535-542$

15. Stocker K. and Egberg N. (1973) Reptilase as a defibrinogenating agent, Thromb. Diath. Haemorh. 1, 361-370

16. Stocker K. and Barlow G.H. (1976) The coagulant enzyme from Bothrops atrox venom (Batroxobin), Methods Enzymol. 45, 214-223

17. Holleman W.H. and Weiss L.J. (1976) The thombin-like enzyme from Bothrops atrox snake venom. Properties of the enzyme purified by affinity chromatography on p-aminobenzamidine-substituted agarose, J. Biol. Chem. 251, 1663-1669

18. Niewiarowski S., Kirby E.P. and Stocker K. (1977) Thrombocytin, a novel platelet activating enzyme from Bothrops atrox venom, Thromb. Res. 10, 863-869

19. Niewiarowski S., Kirby E.P., Brudzynski T.M. and Stocker K. (1979) Thrombocytin, a serine protease from Bothrops atrox. Interaction with platelets and plasma clotting factors, Biochemistry 18, 3570-3577

20. Kirby E.P., Niewiarowski S., Stocker K., Kettner C., Shaw E. and Brudzynski T.M. (1979) Thrombocytin a serine protease from Bothrops atrox venom. Purification and characterization of the enzyme, Biochemistry 18, 3564-3570

21. Suzuki T. and Takahashi H. (1984) Purification of two thrombin-like enzymes from the venom of Agkistrodon caliginosus (kankokumamushi), Toxicon 22, 29-38

22. Pirkle $H_{.}$, Theodor I. and Lopez R. (1989) Catroxobin, a weakly thrombin-like enzyme from the venom of Crotalus atrox. $\mathrm{NH}_{2}$-terminal and active site amino acid sequences, Thromb. Res. 56, 159-168

23. Ouyang C., Hong J.S. and Teng C.M. (1971) Purification and properties of the thrombin-like principle of Agkistriodon acutus venom and its comparison with bovine thrombin, Thromb. Diath. Haemorn. 26, 224-234

24. Pirkle H., Theodor I., Miyada D. and Simmons G. (1986) Thrombin-like enzyme from the venom of Bitis gabonica. Purification, properties, and coagulant actions, $J$. Biol. Chem. 261, 8830-8835

25. Rosing J., Zwaal R.F.A. and Tans G. (1988) Hemostasis and animal venoms (Pirkle, H. and Markland, F.S., eds.), pp 1-25, New York, Basel: Marcel Dekker, Inc. 
26. Rosing J. and Tans G. (1991) Inventory of exogenous prothrombin activators, Thromb. Haemostas. 65, 627-630

27. Suttie J.W. and Jackson C.M. (1977) Prothrombin structure, activation and biosynthesis, Physiol. Rev. 57, 1-70

28. Rosing J. and Tans G. (1988) Meizothrombin, a major product of factor Xacatalyzed prothrombin activation, Thromb. Haemostas. 60, 355-360

29. Rhee M.J., Morris S. and Kosow D.P. (1982) Role of meizothrombin and meizothrombin (des $\mathrm{F} 1$ ) in the conversion of prothrombin to thrombin by the Echis carinatus venom coagulant, Biochemistry 21, 3437-3443

30. Silverberg S.A. (1979) Proteolysis of prothrombin by thrombin. Determination of kinetic parameters and demonstration and characterization of an unusual inhibition by $\mathrm{Ca} 2+$ ions, J. Biol. Chem. 254, 88-94

31. Workman E.F. and Lundblad R.L. (1980) CRC Handbook Series in Clinical Laboratory Science, Sect. I: Hematology, R.M. Schmidt (ed), CRC Press, Boca Raton, FL, pp 149-169.

32. Mann K.G., Elion J., Butkowski R.J., Downing M. and Nesheim M.E. (1981) Prothrombin, Methods. Enzymol. 80, 286-302

33. Seegers W.H., Teng C-M and Novoa E. (1980) Preparation of bovine prethrombin 2. Use of acutin and activation with prothrombinase or ecarin, Thromb. Res. 19, 11 . 20

34. Teng C-M. and Seegers W.H. (1980) Production of prothrombin fragment 1-44 with acutin and some effects on thrombin generation, Thromb. Res. 20, 271-279

35. Pirkle H., Markland F.S. and Theodor J. (1976) Thrombin-like enzymes of snake venoms -action on prothrombin, Thromb. Res. 8, 619-627

36. Esnouf M.P. and Tunnah G.W. (1967) The isolation and properties of the thrombinlike activitiy from Agkistrodon modostoma venom, Brit. J. Haemat. 13, 581-590

37. Markland F.S. and Damus P.S. (1971) Purification and properties of a thrombin-like enzyme from the venom of Crotalus adamanteus, J. Biol. Chem. 246, 6460-6473

38. Rosing J., Tans G., Govers-Riemslag J.W.P., Zwaal R.F.A. and Hemker H.C. (1980) The role of phospholipids and factor $\mathrm{Va}$ in the prothrombinase complex, J. Biol. Chem. 255, 274-283

39. Yukelson L.Ya., Tans G., Thomassen M.C.L.G.D., Hemker H.C. and Rosing, J. (1991) Procoagulant activities in venoms from central asian snakes, Toxicon 29, 491-502

40. Franza R.B., Aronson D.L. and Finlayson J.S. (1975) Activation of human prothrombin by a procoagulant fraction from venom of Echis carinatus, J. Biol. Chem. 250, 7057-7068

41. Kornalik F. and Blombäck B. (1975) Prothrombin activation induced by Ecarin. A prothrombin converting enzyme from Echis carinatus venom, Thromb. Res. 6, 5363

42. Morita T., Iwanaga S. and Suzuki T. (1976) The mechanism of activation of bovine prothrombin by an activator isolated from Echis carinatus venom and characterization of the new active intermediates, J. Biochem. 79, 1089-1108

43. Rosing J., Zwaal R.F.A. and Tans G. (1986) Formation of meizothrombin as an intermediate in factor Xa-catalyzed prothrombin activation, J. Biol. Chem. 261, 4224-4228 
44. Schieck A., Kornalik F. and Habemann E. (1972) The prothrombin activating principle from Echis carinatus venom. I. Preparation and biochemical properties, Naunyn-Schmiedeberg's Arch. Exp. Path.Pharmac. 272, 402-416

45. Schieck A., Habermann E. and Kornalik F. (1972) The prothrombin activating principle from Echis carinatus venom. II. Coagulation studies in vitro and in vivo, Naunyn-Schmiedeberg's Arch. Exp. Path.Pharmac. 274, 7-17

46. Morita T., Iwanaga S. and Suzuki T. (1976) Activation of bovine prothrombin by an activator isolated from Echis carinatus venom, Thromb. Res. 8, 59-76

47. Morita T. and Iwanaga S. (1978) Purification and properties of prothrombin activator from the venom of Echis carinatus, J. Biochem. 83, 559-570

48. Fortova H., Dyr J.E., Vodrazka Z. and Kornalik F. (1983) Isolation of the prothrombin-converting enzyme of Echis carinatus venom by chromatographic and electrophoretic methods, J. Chromat. 259, 473-479

49. Gitter S., Levi G., Kochwa S., De Vries A., Rechnic A. and Casper J. (1960) Studies on the venom of Echis colorata, Am. J. Trop. Med. Hyg. 9, 391-399

50. Hofmann $H$. and Bon C. (1987) Blood coagulation induced by the venom of Bothrops atrox. 1. Identification, purification and properties of a prothrombin activator, Biochemistry 26, 772-780

51. Govers-Riemslag J.W.P., Knapen M.J.H., Tans G., Zwaal R.F.A. and Rosing J. (1987) Structural and functional characterization of a prothrombin activator from the venom of Bothrops neuwiedi, Biochim. Biophys. Acta 916, 388-401

52. Chester A. and Crawford G.P.M. (1982) In vitro coagulant properties of venoms from australian snakes, Toxicon 20,501-504

53. Tans G., Govers-Riemslag J.W.P., van Rijn J.L.M.L. and Rosing J. (1985) Purification and properties of a prothrombin activator from the venom of Notechis scutatus scutatus, J. Biol. Chem. 260, 9366-9372

54. Williams $V$. and White J. (1989) Purification and properties of a procoagulant from peninsula tiger snake (Notechis ater niger) venom, Toxicon 27, 773-779

55. Pirkle H., McIntosh M., Theodor J.and Vemon S. (1972) Activation of prothrombin with Taipan snake venom, Thromb. Res. 1, 559-568

56. Walker F.J., Owen W.G. and Esmon C.T. (1980) Characterization of the prothrombin activator from the venom of Oxyuranus scutellatus scutellatus (Taipan venom), Biochemistry 19, 1020-1023

57. Speijer H., Govers-Riemslag J.W.P., Zwaal R.F.A. and Rosing J. (1986) Prothrombin activation by an activator from the venom of Oxyuranus scutellatus (Taipan snake), J. Biol. chem. 261, 13258-13267

58. Masci P.P., Whitaker A.N. and DeJersey J. (1988) Purification and characterization of a prothrombin activator from the venom of the Australian brown snake, Pseudonaja textilts textilis, Biochem. Int. 17, 825-835 


\section{Chapter 3}

\section{Structural and Functional}

Characterization of a Prothrombin Activator from

the Venom of Bothrops neuwiedi 


\section{Summary}

A prothrombin activator from the venom of Bothrops neuwiedi was purified by gel filtration on Sephadex G-100, ion-exchange chromatography on DEAE-Sephacel and affinity chromatography on a $\mathrm{Zn} 2+$-chelate column. The overall purification was about 200 -fold, which indicates that the prothrombin activator comprises about $0.5 \%$ of the crude venom. The venom activator is a single-chain protein with an apparent molecular weight of 60,000 . It readily activated bovine prothrombin with a $\mathrm{K}_{\mathrm{m}}$ of $38 \mu \mathrm{M}$ and a $V_{\max }$ of $120 \mu \mathrm{mol}$ prothrombin activated per min per $\mathrm{mg}$ of venom activator. Venom-catalyzed prothrombin activation was not accelerated by the so-called accessory components of the prothrombinase complex, phospholipids plus $\mathrm{Ca}_{2}^{2+}$ and Factor Va. Gel-electrophoretic analysis of prothrombin activation indicated that the venom activator only cleaved the Arg323-Ile324 bond of bovine prothrombin, since meizothrombin was the only product of prothrombin activation. The activator did not hydrolyze commercially available $p$ nitroanilide substrates and its prothrombin-converting activity was not inhibited by benzamidine, phenylmethylsulfonylfluoride, dansyl-Glu-Gly-Argchloromethyl ketone and soy-bean trypsin inhibitor. However, chelating agents such as EDTA, EGTA and o-phenanthroline rapidly destroyed the enzymatic activity of the venom activator. The activity of chelator-treated venom activator could be partially restored by the addition of an excess $\mathrm{CaCl}_{2}$. These results indicate that the venom activator remarkably differs from Factor $\mathrm{Xa}$ and that the enzyme is not a serine proteinase, but likely belongs to the metalloproteinases. The structural and functional properties of the venom prothrombin activator from Bothrops neuwiedi are similar to those reported for the venom activator from Echis carinatus.

\section{Introduction}

Many snake venoms have been identified to contain one or more procoagulant activities. In the literature, there are several reports on venom enzymes with fibrinolytic, thrombin-like activity, kallikrein-like activity as well as on snake venoms that contain activators of prothrombin or factor $\mathrm{X}$ (for review papers see Ref. [1] ). Activators of prothrombin have been isolated from the venoms of a wide variety of snake species. There are, however, large differences between the mechanisms by which these venom activators activate prothrombin [2]. 
It has been reported that the venoms of Bothrops species contain several proteins with procoagulant activities [3]. The venom from Bothrops atrox contains thrombin-like enzymes (BATROXOBIN, THROMBOCYTIN; [4,5]), a factor $X$ activator [6] and a prothrombin activator [7]. Our interest was to determine the molecular properties of the Bothrops prothrombin activator and its mode of action in prothrombin activation. In this chapter, we describe the purification and the structural and functional characterization of the prothrombin activator from Bothrops neuwiedi, a Bothrops species whose venom was reported to contain a considerable amount of prothrombinconverting activity [3].

\section{Experimental procedures}

- Reagents. S2238, S2337, S2222, S2302, S2366 and 12581 were purchased from AB Kabi Diagnostica. Chromozym TH was from Boehringer-Mannheim, and $\mathrm{CH}_{3} \mathrm{OCO}-\mathrm{D}-\mathrm{CHG}-\mathrm{Glu}-\mathrm{Gly}$-Arg-pNa. AcOH (a factor Xa substrate) was purchased from Pentapharm, Basel. Dansyl-Glu-Gly-Arg- $\mathrm{CH}_{2} \mathrm{Cl}$ was from Calbiochem. Heparin (USP activity 175 units/ mg) was purchased from Organon. Ovalbumin, human serum albumin (fatty acid free), bovine serum albumin, SBTI, EGTA, benzamidine- $\mathrm{HCl}, \mathrm{N}$-ethylmaleimide, PMSF, prestained molecular weight markers, lyophilized crude venom from Bothrops neuwiedi and 1,2-dioleoyl-sn-glycero-3phosphocholine were obtained from Sigma. EDTA, 2-mercaptoethanol and Triton $\mathrm{X}-100$ were from Merck. Agarose was from Kochlight. o-Phenanthroline was from Baker. lodoacetamide was from Janssen Pharmaceutica. DEAE-Sephacel, Sepharose 4B, Sephadex G-100 and calibration kits for gel electrophoresis were purchased from Pharmacia. All reagents used were of the highest grade commercially available.

$\mathrm{Zn} 2+$-chelate-Sepharose was prepared by coupling iminodiacetic acid to Sepharose 4B according to the method of Porath et al. [8] followed by saturating the material with $\mathrm{ZnCl}_{2}(1 \mathrm{mg} / \mathrm{ml})$ and extensive washing with $50 \mathrm{mM}$ Tris- $\mathrm{HCl}(\mathrm{pH}$ 8.3)/ $400 \mathrm{mM} \mathrm{NaCl}$.

- Proteins. Bovine prothrombin was purified according to the method of Owen et al. [9]. Thrombin was purified as described earlier [10], and bovine factor $X$ was purified according to Fujikawa et al. [11]. Factor $X a$ was prepared from factor $X$ after activation by RW-X [12]. Bovine antithrombin III was purified according to Thaler and Schmer [13]. Factor $V$ and factor $V a$ were obtained as described by Lindhout et al. [14]. The protein preparations were stored at $-80^{\circ} \mathrm{C}$ in $50 \mathrm{mM}$ Tris$\mathrm{HCl}(\mathrm{pH} 7.9), 175 \mathrm{mM} \mathrm{NaCl}, 0.5 \mathrm{mg} / \mathrm{ml}$ human serum albumin. Factor $\mathrm{Va}$ was stored in the same buffer containing $5 \mathrm{mM} \mathrm{CaCl} 2$. Purified preparations of the venom prothrombin activator were stored in a $50 \mathrm{mM}$ Mes $(\mathrm{pH} 6.0)$ buffer containing $400 \mathrm{mM} \mathrm{NaCl}$. 
- Protein concentrations. The molar concentration of thrombin was determined by active-site titration with $p$-PNGB [15]. Prothrombin concentrations were determined by the same method after complete activation with Echis carinatus venom. Factor $\mathrm{Va}$ concentrations were determined by kinetic analysis [14]. The protein concentration of the purified prothrombin activator from Bothrops neuwiedi was determined according to Sedmak et al. [16] using bovine serum albumin as a standard.

- Phospholipids and phospholipid vesicle preparations. Phosphatidylserine was prepared from phosphatidylcholine by enzymatic synthesis [17]. Single bilayer vesicles were prepared by sonication of mixtures of $25 \mathrm{~mol} \%$ phosphatidylserine and 75 mol\% phosphatidylcholine as described before [10]. Phospholipid concentrations were determined by phosphate analysis [18].

- Assay system for measurement of prothrombin activation. The activation of prothrombin by the venom activator from Bothrops neuwiedi was followed by measuring the generation of amidolytic activity (meizothrombin plus thrombin) towards the chromogenic substrate S2238. Prothrombin was preincubated for 5 min at $37^{\circ} \mathrm{C}$ in a buffer containing $50 \mathrm{mM}$ Tris- $\mathrm{HCl}(\mathrm{pH} 7.9), 175 \mathrm{mM} \mathrm{NaCl}$, and $0.5 \mathrm{mg} / \mathrm{ml}$ human serum albumin. When cofactors (phospholipid vesicles, factor $\mathrm{Va}$ or $\mathrm{CaCl}_{2}$ ) were present, they were included in the preincubation mixture. Prothrombin activation was started with the addition of appropriate dilutions of the venom activator in the same buffer. After different time intervals, samples were transferred to disposable cuvettes (1 cm pathlength) containing $235 \mu \mathrm{M}$ S2238 in $50 \mathrm{mM}$ Tris- $\mathrm{HCl}(\mathrm{pH} 7.9), 175 \mathrm{mM} \mathrm{NaCl}, 20 \mathrm{mM}$ EDTA, and $0.5 \mathrm{mg} / \mathrm{ml}$ ovalbumin. From the rate of change of the difference between the absorbance at 405 and 500 $\mathrm{nm}(\triangle \mathrm{A} \quad 405-500 / \mathrm{min})$, determined on a SLM Aminco DW2-C spectrophotometer operating in the dual-wavelength mode, the amount of prothrombin activated (i.e., thrombin plus meizothrombin formed) was calculated using a calibration curve made with known amounts of active-site-titrated thrombin. In order to specifically determine meizothrombin, the amidolytic activity was also measured with $4 \mathrm{nM}$ antithrombin $\mathrm{III}$ and $10 \mu \mathrm{g} / \mathrm{ml}$ of heparin in the cuvette (cf. Ref. 19). In that case, samples from the prothrombin activation mixture were incubated for $1 \mathrm{~min}$ in the cuvette with antithrombin III and heparin to inhibit thrombin prior to the addition of S2238.

During its purification, the prothrombin activator from Bothrops neuwiedi was routinely assayed in reaction mixtures that contained $1 \mu \mathrm{M}$ prothrombin, $5 \mathrm{mM}$ $\mathrm{CaCl}_{2}$, and appropriate dilutions of samples containing venom activator. Prothrombin activation was determined by measuring the amidolytic activity of reaction aliquots taken after $3 \mathrm{~min}$ of activation time. In that case, the prothrombin-converting activity of the venom prothrombin activator was expressed in units, 1 unit being the amount of activator that activates $1 \mu \mathrm{mol}$ of prothrombin in $1 \mathrm{~min}$ at $37^{\circ} \mathrm{C}$ under the assay conditions described above.

- Assay system for measurement of factor $X$ activation. During the purification of the prothrombin activator from Bothrops neuwiedi, column fractions were also tested for the presence of a factor $X$ activator. $3.3 \mu \mathrm{M}$ Factor $X$ was preincubated for $5 \mathrm{~min}$ at $37^{\circ} \mathrm{C}$ in a buffer containing $50 \mathrm{mM}$ Tris- $\mathrm{HCl}(\mathrm{pH} 7.9), 175$ $\mathrm{mM} \mathrm{NaCl}, 10 \mathrm{mM} \mathrm{CaCl} 2$, and $0.5 \mathrm{mg} / \mathrm{ml}$ human serum albumin. Factor $\mathrm{X}$ 
activation was started with the addition of appropriate dilutions of venom activator in the same buffer. After $3 \mathrm{~min}$, the amount of factor Xa formed was determined in a sample from the reaction mixture that was transferred to a cuvette containing $193 \mu \mathrm{M}$ S2337 in $50 \mathrm{mM}$ Tris- $\mathrm{HCl}(\mathrm{pH} 7.9), 175 \mathrm{mM} \mathrm{NaCl}, 20 \mathrm{mM}$ EDTA, and 0.5 $\mathrm{mg} / \mathrm{ml}$ ovalbumin. The absorbance change determined at 405 minus $500 \mathrm{~nm}$ is a measure for the amount of factor Xa present. The factor X-converting activity was expressed in units, 1 unit being the amount of activator that activates $1 \mu \mathrm{mol}$ of factor $X$ in $1 \mathrm{~min}$ at $37^{\circ} \mathrm{C}$ under the assay conditions described above.

- Assay system for measurement of thrombin-like activity. The thrombin-like activities of Bothrops neuwiedi were determined with the chromogenic substrate S2238 in cuvettes that contained $50 \mathrm{mM}$ Tris- $\mathrm{HCl}(\mathrm{pH} 7.9), 175 \mathrm{mM} \mathrm{NaCl}, 20 \mathrm{mM}$ EDTA, $0.5 \mathrm{mg} / \mathrm{ml}$ ovalbumin, and $235 \mu \mathrm{M}$ S2238. The rate of $p$-nitroaniline formation was calculated from the absorbance change at 405 minus $500 \mathrm{~nm}$, using a molar absorption coefficient of $1.04 .10^{4} \mathrm{~mol}^{-1} . \mathrm{I} . \mathrm{cm}^{-1}$ for $p$-nitroaniline. 1 unit thrombin-like activity was defined as the amount of enzyme that forms $1 \mu \mathrm{mol}$ of $p$ nitroaniline in $1 \mathrm{~min}$ at $37^{\circ} \mathrm{C}$ under the assay conditions described above

- Gel-electrophoretic techniques. Gel electrophoresis of the purified prothrombin activator was carried out in the presence of SDS [20] on tube- or slab gels containing $10 \%$ acrylamide. Gel-electrophoretic analysis of prothrombin cleavage by the purified prothrombin activator was carried out in the presence of SDS on $10 \%$ polyacrylamide slab gels according to Laemmli [20]. Further experimental details are given in the legends to the figures. The prothrombin converting activity of the purified Bothrops activator could be directly detected in the SDS-polyacrylamide gels using an agarose overlay method based upon the procedure of Granelli-Piperno and Reich [21] and Wagner et al. [22]. The activity of the venom activator in the gel was restored by removing the SDS from the gel with a wash in distilled water containing $2.5 \%$ Triton X-100 followed by washing out the Triton X-100 with distilled water only. Protein bands with prothrombinconverting activity were detected by overlaying the gel with a 1 -mm-thick agarose gel layer $(1.25 \%(w / v)$ agarose in $15 \mathrm{mM}$ Tris $(\mathrm{pH} 7.9) / 50 \mathrm{mM} \mathrm{NaCl} / 5 \mathrm{mM} \mathrm{CaCl}$ ) containing $0.5 \mu \mathrm{M}$ prothrombin and $750 \mu \mathrm{M}$ S2238. Prothrombin activator bands became visible as yellow zones in the agarose indicator-gel and were photographed under dark ground illumination.

\section{Results}

\section{Purification of the prothrombin activator from Bothops neuwiedi}

The prothrombin activator from Bothrops neuwiedi was purified from the crude venom by gel filtration on Sephadex G-100 (Figure 1), ion-exchange chromatography on DEAE-Sephacel (Figure 2) and affinity chromatography on a $\mathrm{Zn} 2+$-chelate column (Figures $3 \mathrm{~A}$ and $3 \mathrm{~B}$ ). All purification steps were carried out in the presence of benzamidine in order to prevent possible proteolytic degradation of the venom activator. The prothrombin activator 


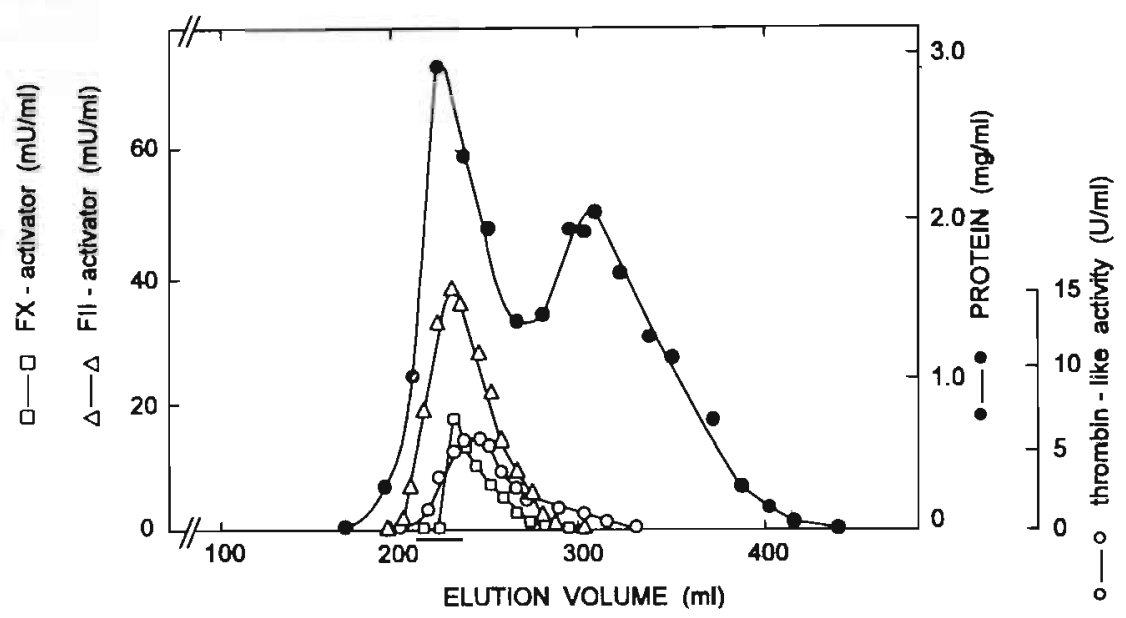

Figure 1. Sephadex G-100 elution profile of Bothrops neuwiedi venom. Crude venom $(1 \mathrm{~g})$ was dissolved at $4^{\circ} \mathrm{C}$ in $30 \mathrm{ml} 50 \mathrm{mM}$ Hepes $(\mathrm{pH} \mathrm{7.0)}, 500 \mathrm{mM} \mathrm{NaCl}$ and $10 \mathrm{mM}$ benzamidine. A small precipitate was removed by centrifugation for $15 \mathrm{~min}$ at $10,000 \mathrm{~mm}$ in a Beckman centrifuge. The supematant was chromatographed in two $15 \mathrm{ml}$ portions, on a Sephadex G-100 column $(2.5 \times 100 \mathrm{~cm})$ at a flow rate of $20 \mathrm{ml} / \mathrm{h}$ at $4^{\circ} \mathrm{C}$. Elution of protein was monitored at $280 \mathrm{~nm}(\bullet)$. The eluted fractions were tested for their ability to activate prothrombin $(\Delta)$ or factor $X(\square)$ and to hydrolyze $S 2238(0)$ as described in Experimental Procedures. The fractions indicated by the solid bar were pooled and subjected to further purification.

Table 1. Purification of the prothrombin activator from the venom of Bothrops neuwiedi

$\begin{array}{llcc}\text { Total } & \text { Spec. act. } & \text { Recovery } & \text { Purifi- } \\ \text { protein } & \text { (munits per } & (\%) & \text { cation } \\ (\mathrm{mg}) & \text { mg venom) } & & \end{array}$

\begin{tabular}{lrrrr}
\hline $\begin{array}{l}\text { Crude venom } \\
\text { Sephadex G-100 }\end{array}$ & 624 & 7 & 100 & 1 \\
$\begin{array}{l}\text { DEAE-Sephacel } \\
\text { Zn2+-chelate- } \\
\text { Sepharose I }\end{array}$ & 117 & 11 & 29 & 2 \\
$\begin{array}{l}\text { Zn2+-chelate- } \\
\text { Sepharose II }\end{array}$ & 1.1 & 44 & 20 & 6 \\
& 0.6 & 781 & 20 & 112 \\
\hline $\begin{array}{l}\text { Total protein was determined according to Sedmak et al. [16] using bovine serum } \\
\text { albumin as standard. Prothrombin activation was determined as descnibed in } \\
\text { Experimental Procedures. }\end{array}$
\end{tabular}


eluted from the Sephadex G-100 column almost simultaneously with an activator of factor $X$ and with the thrombin-like activity also present in the venom. In order to remove the major part of the latter activities, only a small fraction of the prothrombin activator was pooled and subjected to further purification. This explains the rather low yield of the prothrombin activator after gel permeation chromatography (Table 1). The prothrombin activator did adhere to DEAE-Sephacel at low ionic strength and could be eluted from the column with a linear salt gradient (Figure 2). The prothrombin-converting activity eluted just in front of the factor $X$ activator and the thrombin-like enzyme (Figure 2). The fractions containing prothrombin activator were pooled and applied to a $\mathrm{Zn}^{2+}$-chelate column. Both the prothrombin activator and the factor $X$ activator did bind to the $\mathrm{Zn} 2+$-chelate column at $\mathrm{pH}$ 8.3, whereas the thrombin-like enzyme did not adhere. The prothrombin

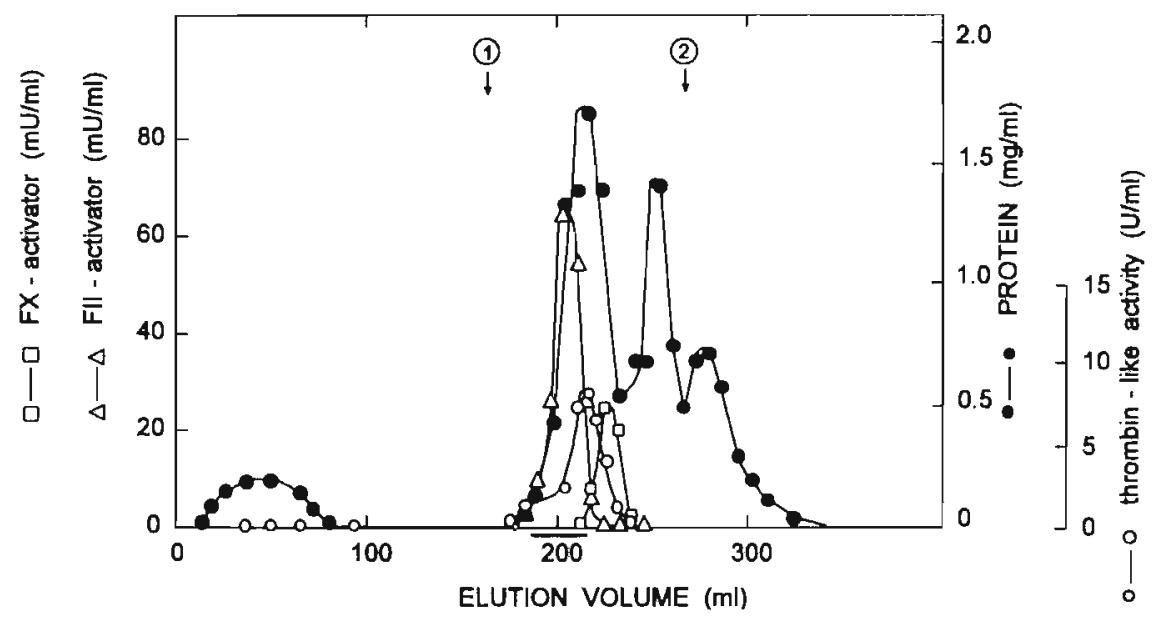

Figure 2. DEAE-Sephacel column chromatography of the prothrombin activator from Bothrops neuwiedi. The pooled fractions containing prothrombin activator from the Sephadex G-100 column (67 ml) were dialyzed against a $10 \mathrm{mM}$ Tris- $\mathrm{HCl}(\mathrm{pH} 7.5)$ buffer containing $10 \mathrm{mM}$ benzamidine and subsequently applied to a DEAE-Sephacel column $(1 \times 20 \mathrm{~cm})$ at a flow rate of $7 \mathrm{ml} / \mathrm{h}$ at $4^{\circ} \mathrm{C}$ and washed with the same buffer. At the arrows indicated in the figure bound protein was eluted with a linear gradient of $(2 \times$ $60 \mathrm{ml}$ ) with starting buffer in the front chamber and the same buffer containing $200 \mathrm{mM}$ $\mathrm{NaCl}$ in the distal chamber (arrow 1) after which elution was finished with an additional volume of the buffer with $200 \mathrm{mM} \mathrm{NaCl}$ (arrow 2). The eluted fractions were tested for the presence of protein (๑), prothrombin activator $(\Delta)$, factor $X$ activator $(\square)$, and thrombin-like activity $(O)$, as described in Experimental Procedures. The prothrombin activator eluted between $25 \mathrm{mM} \mathrm{NaCl}$ and $70 \mathrm{mM} \mathrm{NaCl}$. These fractions (indicated by the solid bar) were pooled and dialyzed against $50 \mathrm{mM} \mathrm{Tris}-\mathrm{HCl}(\mathrm{pH} 8.3) / 400 \mathrm{mM} \mathrm{NaCl}$. 

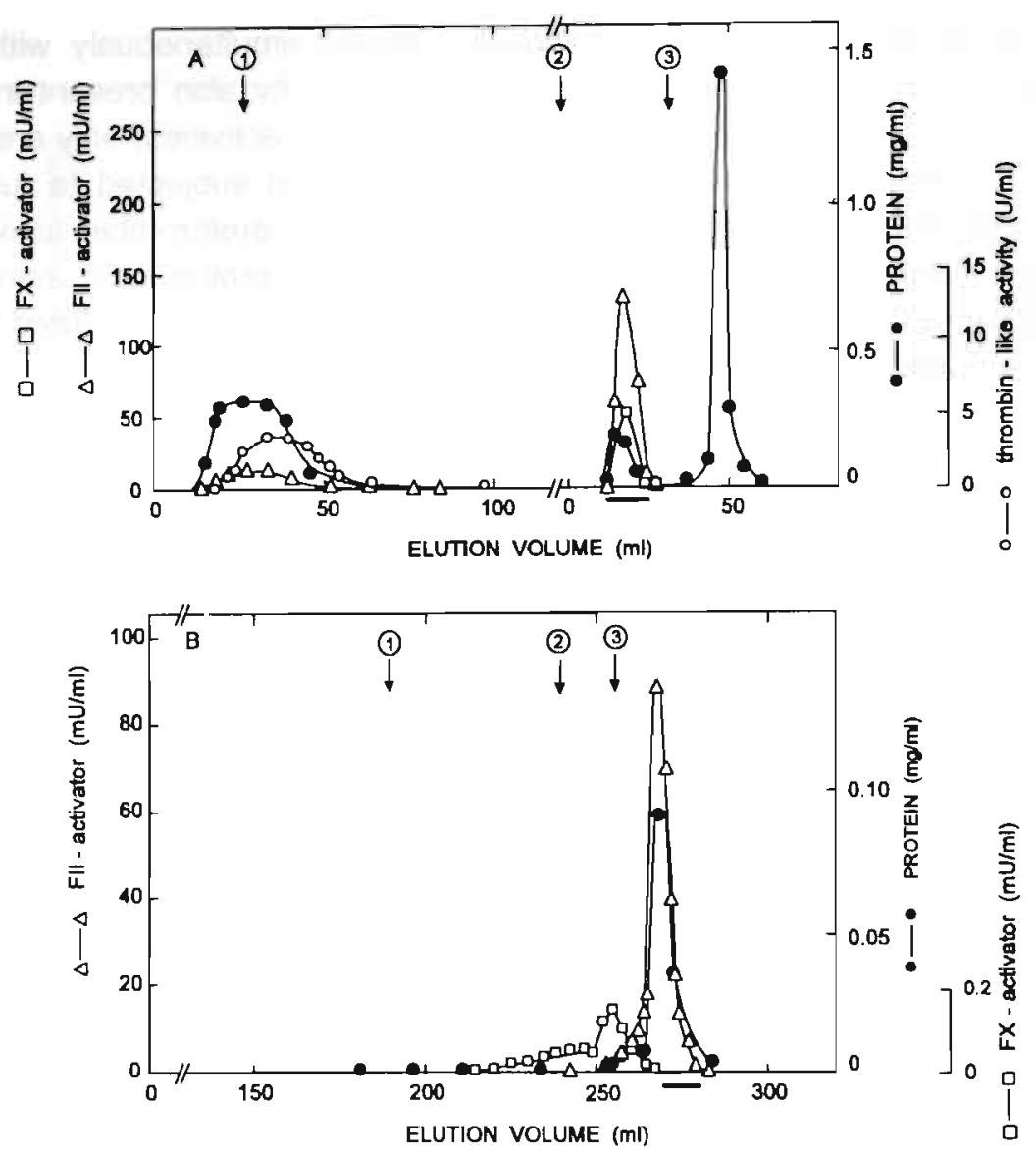

Figure 3. Affinity chromatography of the prothrombin activator of Bothrops neuwiedi on $\mathrm{Zn}^{2+-c h e l a t e-S e p h a r o s e . ~ P a n e l ~ A: ~ T h e ~ p o o l e d ~ f r a c t i o n s ~ c o n t a i n i n g ~ t h e ~}$ prothrombin activator from the DEAE-Sephacel column (see Figure 2) were applied to $\mathrm{Zn}^{2+}$-chelate-Sepharose $(1 \times 12 \mathrm{~cm})$ at a flow rate of $5 \mathrm{ml} / \mathrm{h}$ at $4^{\circ} \mathrm{C}$ in $50 \mathrm{mM}$ Tris- $\mathrm{HCl}$ $(\mathrm{pH} 8.3) / 400 \mathrm{mM} \mathrm{NaCl}$. The column was subsequently washed (arrow 1) with starting buffer followed by stepwise elution of bound protein with $50 \mathrm{mM}$ Mes (pH 6.0)/ $400 \mathrm{mM}$ $\mathrm{NaCl}$ (arrow 2) and washing with the same buffer containing $50 \mathrm{mM}$ EDTA to remove all bound material (arrow 3). The eluted fractions were tested for their protein content (0) according to Sedmak et al. [16], the prothrombin activator $(\Delta)$, the factor $X$ activator $(\square)$, and thrombin-like activity $(O)$. The prothrombin activator containing fractions were pooled as indicated by the solid bar. Panel $\mathrm{B}$ : The pooled fractions were dialyzed against $50 \mathrm{mM}$ Tris ( $\mathrm{pH} \mathrm{8.3)/400} \mathrm{mM} \mathrm{NaCl}$ and reapplied to $\mathrm{Zn} 2+$-chelate-Sepharose $(1-12 \mathrm{~cm}$ ) at a flow rate of $5 \mathrm{ml} / \mathrm{h}$ at $4^{\circ} \mathrm{C}$. Elution was performed stepwise with buffers of decreasing $\mathrm{pH}$. No protein eluted with $50 \mathrm{mM}$ Tris ( $\mathrm{pH} 8.3$ ), $50 \mathrm{mM}$ Tris ( $\mathrm{pH} 7.5$ ) or $50 \mathrm{mM}$ Hepes (pH 7.2). Subsequently, the column was washed with $50 \mathrm{mM}$ Hepes (pH 6.8, arrow 1) $50 \mathrm{mM}$ Mes ( $\mathrm{pH} \mathrm{6.4,} \mathrm{arrow} \mathrm{2)} \mathrm{and} 50 \mathrm{mM}$ Mes ( $\mathrm{pH} \mathrm{6.0,} \mathrm{arrow} \mathrm{3)} \mathrm{all} \mathrm{containing} 400 \mathrm{mM} \mathrm{NaCl}$. The fractions were tested for their protein content (0), for the presence of the prothrombin activator $(\triangle)$, and the factor $X$ activator $(\square)$. 
activator and the factor $X$ activator were eluted and separated by stepwise elution with buffers of decreasing $\mathrm{pH}$ (Figures $3 \mathrm{~A}$ and $3 \mathrm{~B}$ ). A summary of the purification of the prothrombin activator from Bothrops neuwiedi is shown in Table 1. The purification was approximately 200 -fold with an overall yield of $20 \%$. The purified activator did not contain the thrombin-like protein or the factor $X$ activator, since it was not possible to detect either of these activities in the final prothrombin activator preparations. From the increase in specific activity, it can be calculated that the prothrombin activator comprises about $0.5 \%$ of the crude venom.

\section{Structural properties of the prothrombin activator from Bothrops neuwiedi}

SDS-gel electrophoresis of the purified prothrombin activator under nonreducing conditions showed one major protein band with an apparent molecular weight of 60,000 (Figure 4).

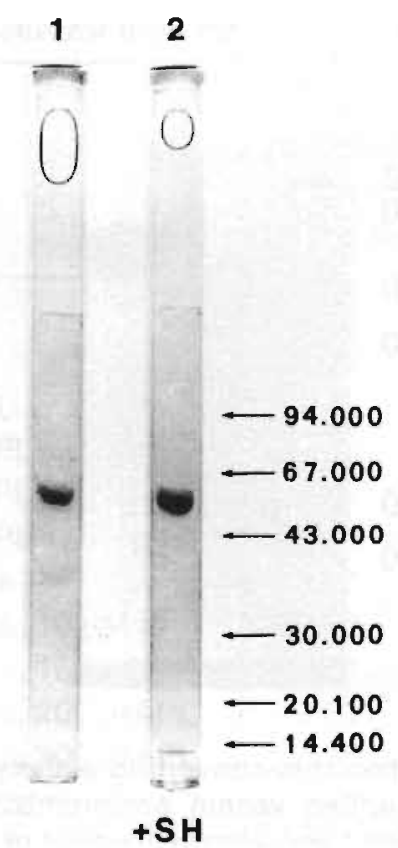

Figure 4. Polyacrylamide gel electrophoresis of the purified prothrombin activator from the venom of Bothrops neuwiedi. Gel electrophoresis of $20 \mu \mathrm{g}$ of activator was carried out on $10 \%$ gels in the presence of sodium dodecyl sulfate according to Laemmli [20]. 5\% 2-mercaptoethanol was present in the reduced sample (lane 2). The gels were stained with Coomassie brilliant blue R250. The migration distance of molecular weight markers, electrophoresed under the same conditions, is indicated in the figure. 
Upon reduction with 2-mercaptoethanol, the latter band migrated at the same position. The protein band with a molecular weight of 60,000 contained the prothrombin-activating activity as shown by a direct autographic method shown in Figure 5. The activity of the venom activator in the SDS slab gel was restored by removing the SDS from the gel with a wash in distilled water containing $2.5 \%$ Triton $X-100$ followed by washing out the Triton X-100 with distilled water only. The prothrombin activator was subsequently detected by overlaying the gel with an agarose-indicator gel containing prothrombin and the thrombin substrate, S2238. At those places where prothrombin is activated in the indicator gel, $\mathbf{S} 2238$ will be converted and a yellow band becomes visible. When photographed against a dark background, the yellow band becomes visible as a dark band in the agarose.

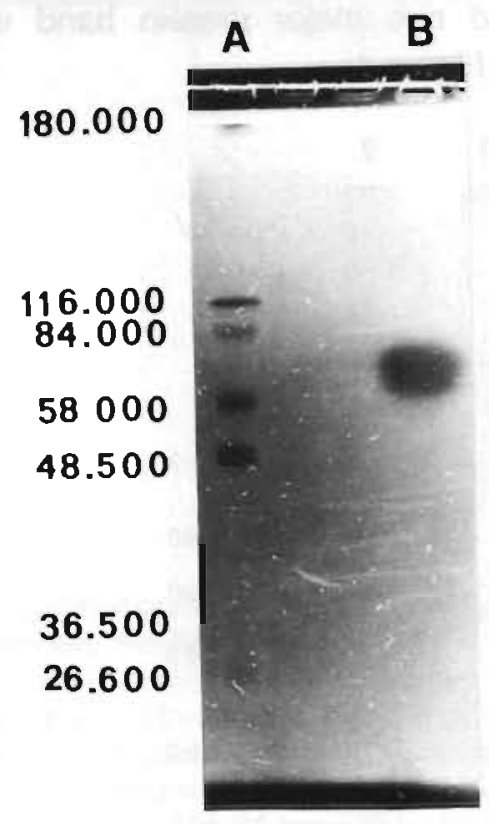

Figure 5. Localization of prothrombin-converting activity after SDS-polyacrylamide gel electrophoresis of the purified venom prothrombin activator from Bothrops neuwiedi. Purified venom activator was electrophoresed on a $10 \%$ acrylamide slab gel. After electrophoresis, the SDS was removed from the polyacrylamide gel and the prothrombin-converting activity was localized with an agarose-indicator gel containing prothrombin, $\mathrm{Ca} 2+$ and $\mathrm{S} 2238$ as described in Experimental Procedures. Lane A: prestained molecular weight markers; lane B: $0.3 \mu \mathrm{g}$ purified venom activator. The polyacrylamide slab gel overlayed with the agarose-indicator gel was photographed under dark ground illumination. Molecular weights of the prestained markers are indicated in the figure. 
Figure 5 shows that the prothrombin-converting activity migrated at 60,000 apparent molecular weight. A control overlay in which prothrombin was omitted from the indicator gel showed no yellow bands. Since the prothrombin-converting activity comigrated with the $\mathrm{Mr} 60,000$ protein band visible on the stained gels, we conclude that these proteins are one and the same. Gradient gel electrophoresis under non-reducing conditions in the absence of SDS and fast protein liquid chromatography (FPLC) on a Superose 12 column confirmed the molecular weight of 60,000 (data not shown). Therefore, the purified venom prothrombin activator from Bothrops neuwiedi is a single subunit enzyme with a molecular weight of 60,000 .

\section{Catalytic properties of the purified venom activator}

The purified venom activator readily activated prothrombin in the absence of accessory components of the prothrombinase complex (Table 2).

Table 2. The effects of phospholipid, Ca2+, EDTA and factor $\mathrm{Va}$ on prothrombin activation by the purified activator from the venom of Bothrops neuwiedi

Prothrombin activator

$\mathrm{V}$

( $\mu$ mol prothrombin activated/min

per $\mathrm{mg}$ venom)

\begin{tabular}{|c|c|c|}
\hline Venom, EDTA & 1.85 & 0.63 \\
\hline Venom, $\mathrm{Ca}^{2+}$ & 2.94 & 1.00 \\
\hline Venom, $\mathrm{Ca}^{2+}, 10 \mu \mathrm{MPL}$ & 2.95 & 1.00 \\
\hline Venom, $\mathrm{Ca}^{2+}, 100 \mu \mathrm{MPL}$ & 2.40 & 0.82 \\
\hline Venom, $\mathrm{Ca}^{2+}, 200 \mu \mathrm{MPL}$ & 2.29 & 0.78 \\
\hline Venom, $\mathrm{Ca}^{2+}, 300 \mu \mathrm{MPL}$ & 2.29 & 0.79 \\
\hline Venom, $\mathrm{Ca}^{2+}$, Factor Va & 2.95 & 1.00 \\
\hline Venom, $\mathrm{Ca}^{2+}$, Factor $\mathrm{Va}, 10 \mu \mathrm{M} \mathrm{PL}$ & 3.02 & 1.03 \\
\hline Venom, $\mathrm{Ca}^{2+}$, Factor $\mathrm{Va}, 100 \mu \mathrm{M} \mathrm{PL}$ & 2.61 & 0.89 \\
\hline Venom, $\mathrm{Ca}^{2+}$, Factor Va, $200 \mu \mathrm{M} \mathrm{PL}$ & 2.35 & 0.80 \\
\hline Venom, $\mathrm{Ca}^{2+}$, Factor $\mathrm{Va}, 300 \mu \mathrm{M} \mathrm{PL}$ & 2.39 & 0.81 \\
\hline
\end{tabular}

Venom, EDTA

Venom, $\mathrm{Ca}^{2+}$

Venom, $\mathrm{Ca}^{2+}, 10 \mu \mathrm{M} \mathrm{PL}$

Venom, Ca2+, $100 \mu \mathrm{MPL}$

Venom, $\mathrm{Ca}^{2+}, 200 \mu \mathrm{MPL}$

Venom, $\mathrm{Ca}^{2+}$, Factor $\mathrm{Va}$

Venom, $\mathrm{Ca}^{2+}$, Factor $\mathrm{Va}, 10 \mu \mathrm{M} \mathrm{PL}$

Venom, Ca2+, Factor Va, $100 \mu \mathrm{M} P L$

Venom, $\mathrm{Ca}^{2+}$, Factor Va, $200 \mu \mathrm{M} \mathrm{PL}$

Venom, $\mathrm{Ca}^{2+}$, Factor $\mathrm{Va}, 300 \mu \mathrm{M} \mathrm{PL}$
Relative

rate

$1.05 \mu \mathrm{M}$ prothrombin in $475 \mu \mathrm{l}$ of $50 \mathrm{mM}$ Tris- $\mathrm{HCl}(\mathrm{pH} 7.9), 175 \mathrm{mM} \mathrm{NaCl}$ containing 0.5 $\mathrm{mg} / \mathrm{ml}$ human serum albumin was incubated for $5 \mathrm{~min}$ at $37^{\circ} \mathrm{C}$. When indicated in the table, $0.26 \mathrm{mM}$ EDTA or $2.1 \mathrm{mM} \mathrm{CaCl} 2,5.3 \mathrm{nM}$ factor $\mathrm{Va}$ and/or various amounts of phospholipid (PL) vesicles (25 mol\% phosphatidylserine/75 mol\% phosphatidylcholine) were included in the preincubation mixture. Prothrombin activation was started with the addition of $25 \mu \mathrm{l}(0.21 \mathrm{ng})$ purified prothrombin activator diluted in the same buffer without $\mathrm{CaCl}_{2}$. Prothrombin activation was determined by measuring the generation of Procedures. 
Venom-catalyzed prothrombin activation was somewhat stimulated by $\mathrm{Ca} 2+$, but was not affected by the presence of bovine factor Va. Phospholipids plus $\mathrm{Ca}^{2}+$ even caused some decrease in the rate of prothrombin activation: $\mathrm{A}$ possible explanation for the inhibitory effect of phospholipids might be that prothrombin bound to the phospholipid surface is less readily activated by the venom activator. The purified activator was also tested for its ability to hydrolyze a number of commercially available chromogenic substrates. S2222, S2337, S2238, S2302, S2366, Chromozym TH and the Pentapharm Xa substrate in concentrations of $0.5 \mathrm{mM}$ were incubated with $1.64 \mu \mathrm{g} / \mathrm{ml}$ venom activator in $50 \mathrm{mM}$ Tris- $\mathrm{HCl}(\mathrm{pH} 7.9), 175 \mathrm{mM} \mathrm{NaCl}$ and $0.5 \mathrm{mg} / \mathrm{ml}$ human serum albumin. No $p$-nitroaniline formation was detectable, indicating that the venom activator did not hydrolyze any of these chromogenic substrates, and, therefore, did not possess significant amidolytic activity.

\section{Identification of activation products formed during prothrombin activa- tion}

Since more than one peptide bond is available for proteolytic cleavage in prothrombin, several reaction products can be formed during prothrombin activation. Figure 6 shows a schematic diagram of prothrombin with its proteolytic cleavage sites. Peptide-bond cleavage by prothrombin activators generally occurs at position Arg274-Thr275 (site 2) and at position Arg323lle324 (site 3). These cleavages result in the formation of prethrombin 2 plus fragment 1.2 (cleavage at site 2), meizothrombin (cleavage at site 3 ), or thrombin plus fragment 1.2 (cleavage at sites 2 and 3). Cleavage at site 3 results in the exposure of the active-site serine and conversion of prothrombin into a catalytically active product (i.e., thrombin or meizothrombin). Peptide bond 1 (Arg156-Ser157) is generally not cleaved by prothrombin activators, but is susceptible to proteolytic cleavage by thrombin, meizothrombin and other thrombin-like enzymes. In that case, fragment 1 and prethrombin 1 (cleavage at site 1) or fragment 1 and meizothrombin des fragment 1 (cleavage at site 1 and 3) are formed.

The fluorescent chloromethyl ketone, dansyl-Glu-Gly-Arg- $\mathrm{CH}_{2} \mathrm{Cl}$, can be used to visualize thrombin ( $\mathrm{Mr} 36,000)$, meizothrombin ( $\mathrm{Mr} \mathrm{72,000)}$ and meizothrombin des fragment $1(\mathrm{Mr}$ 48,000) after SDS-gel electrophoresis. At high concentrations, this inhibitor alkylates the histidine of the catalytic triad of thrombin and meizothrombin, and, due to its fluorescent properties, the proteins that incorporate this inhibitor can be detected on gels after electrophoresis. It is also possible to distinguish thrombin and meizothrombin on a functional basis. Thrombin and meizothrombin have the same 
amidolytic activity towards commercially available chromogenic substrates, but differ in their reactivity towards macromolecular substrates such as fibrinogen or the antithrombin III - heparin complex [19]. Experimental conditions can be chosen such that thrombin is readily inhibited by antithrombin III plus heparin, whereas meizothrombin (or meizothrombin des fragment 1) is not [19]. Determination of the amidolytic activity of reaction aliquots treated with antithrombin III plus heparin allows calculation of the amount of meizothrombin present (thrombin is inhibited), while the amidolytic activity of nontreated aliquots is determined by the sum of thrombin plus meizothrombin (cf. Ref. 19 and Experimental Procedures).

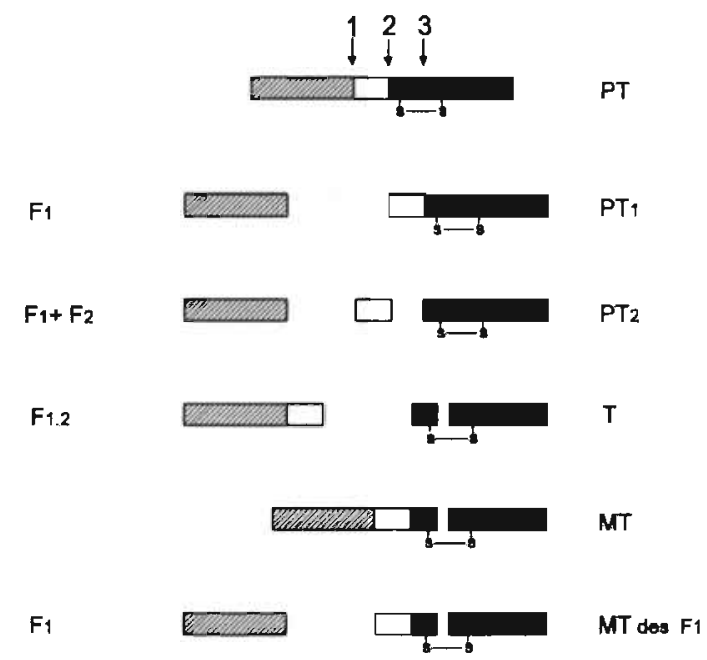

Figure 6. Schematic diagram of prothrombin and possible prothrombin activation products. Peptide bonds susceptible to proteolytic cleavage are indicated. Site 1 (Arg156-Ser157) is cleaved by thrombin-like enzymes, and sites 2 (Arg274-Thr275) and 3 (Arg323-lle 324 ) are susceptible to proteolysis by prothrombin activators. The reaction products that can be formed during prothrombin activation are also indicated in the figure. PT1, prethrombin 1; F1, fragment 1; T, thrombin; PT2, prethrombin 2; F1.2, fragment 1.2; MT, meizothrombin; MT des F1, meizothrombin des fragment 1 ; $F 2$, fragment 2.

In a typical experiment designed to quantitate thrombin and/or meizothrombin formation during venom-catalyzed prothrombin activation, aliquots from the prothrombin activation mixture were tested for their amidolytic activity towards $\mathrm{S} 2238$ in the absence and presence of antithrombin III plus heparin (Figure 7A). At the same time, samples from the reaction mixture were taken to follow the peptide bond cleavage pattern by 
polyacrylamide gel electrophoresis in the presence of SDS. Prior to electrophoresis, these samples were treated with dansyl-Glu-Gly-Arg- $\mathrm{CH}_{2} \mathrm{Cl}$ in order to fluorescently label reaction products which have exposed their active site. The reversible thrombin inhibitor, 12581, was included in the prothrombin activation mixture to slow down autocatalytic removal of fragment 1 from prothrombin and meizothrombin.

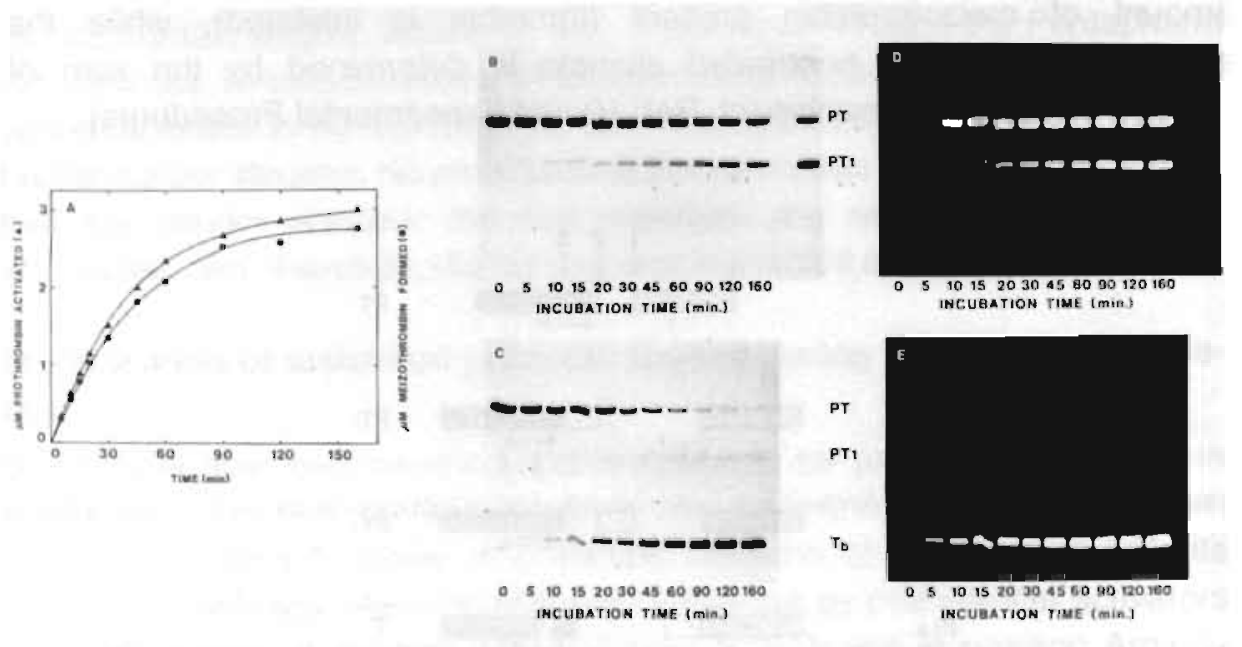

Figure 7. Gel electrophoretic analysis of the time-course of prothrombin activation by the purified venom activator. $3 \mu \mathrm{M}$ prothrombin was activated at $37^{\circ} \mathrm{C}$ in a reaction mixture containing $50 \mathrm{mM}$ Tris- $\mathrm{HCl}(\mathrm{pH} 7.9), 175 \mathrm{mM} \mathrm{NaCl}, 20 \mu \mathrm{M}$ of the reversible thrombin inhibitor $12581,5 \mathrm{mM} \mathrm{CaCl} 2$ and $18.8 \mathrm{ng} / \mathrm{ml}$ purified activator. At the time intervals indicaled, samples were withdrawn for determination of amidolytic activities (panel A) and for SDS-gelelectrophoresis (panel B-E). Panel A: amidolytic activities were determined in appropriately diluted samples using S2238 as described under Materials and Methods. From the amidolytic activities determined in the absence and presence of antithrombin III plus heparin, the amounts of total prothrombin activated $(\mathbf{\Lambda})$ and meizothrombin formed $(\bullet)$ were calculated. See text for further explanation. Panel B-E. Samples $(150 \mu \mathrm{l})$ withdrawn for gel electrophoresis were immediately added to $20 \mu \mathrm{l}$ of $2 \mathrm{mM}$ dansyl-Glu-Gly-Arg- $\mathrm{CH}_{2} \mathrm{Cl}$ in $10 \mathrm{mM} \mathrm{HCl}$ and $5 \mu \mathrm{l}$ of $350 \mathrm{mM}$ EDTA. After $45 \mathrm{~min}$ incubation at $37^{\circ} \mathrm{C}$, a $75 \mu \mathrm{l}$ aliquot was added to $25 \mu$ of gel buffer containing $250 \mathrm{mM}$ Tris- $\mathrm{HCl}(\mathrm{pH} 7.9), 5 \%$ SDS, and 50\% ( $/ \mathrm{v})$ glycerol (gel B and D) and another $75 \mu \mathrm{l}$ aliquot was added to $25 \mu \mathrm{l}$ of the same buffer containing $5 \%(\mathrm{v} / \mathrm{v}) 2$-mercaptoethanol (gel $\mathrm{C}$ and $\mathrm{E}$ ). Prior to electrophoresis, the samples were kept for $1 \mathrm{~h}$ at $37^{\circ} \mathrm{C}$. After electrophoresis, the gels were photographed while illuminated with long-wave ultraviolet light using a yellow filter and Polaroid type 55 film (D and $E$ ) and subsequently stained with Coomassie blue (gel $\mathrm{B}$ and $\mathrm{C}$ ). The lane at the far right of gel $\mathrm{B}$ contains a reference mixture of prothrombin and prethrombin 1.

PT, prothrombin; PT1, prethrombin $1 ; T_{b}, B$ chain of thrombin. 
In Figure 7A, it is shown that the amidolytic activity generated during prothrombin activation by the purified activator from Bothrops neuwiedi was almost completely resistent to antithrombin III plus heparin. This indicates that there was no detectable thrombin formation and that meizothrombin is the major reaction product formed during venom-catalyzed prothrombin activation. The small difference between amidolytic activities determined in the absence and presence of antithrombin III plus heparin is likely due to some inhibition of meizothrombin by AT III plus heparin that occurs under the assay conditions [19]. The generation of meizothrombin (or meizothrombin des fragment 1) as reaction product was confirmed by SDS gel electrophoresis. On non-reduced Coomassie-blue-stained gels of the prothrombin activation mixture, no thrombin was detectable. The only visible proteins were those comigrating with prothrombin and prethrombin 1 . Upon reduction, there was a considerable decrease in staining intensity of the band comigrating with prothrombin, complete disappearance of the band comigrating with prethrombin 1 , and the appearance of a band comigrating with the $B$ chain of thrombin. SDS gels of reaction aliquots that were treated with dansyl-Glu-Gly-Arg- $\mathrm{CH}_{2} \mathrm{Cl}$ showed incorporation of the fluorescent inhibitor (i.e., active-site exposure) in products comigrating with prothrombin and prethrombin 1 on non-reduced gels and with the thrombin $B$ chain on reduced gels. Such gel data are indicative for the presence of meizothrombin and meizothrombin des fragment 1 . Therefore, the gel-electrophoretic data confirmed meizothrombin and meizothrombin des fragment 1 occurring as the only reaction products during venom-catalyzed prothrombin activation. The venom activator does apparently not produce thrombin, and therefore lacks the ability to cleave the Arg274-Thr275 bond in prothrombin. The presence of meizothrombin des fragment 1 presumably results from autocatalytic cleavage of the Arg 156 -Ser 157 bond releasing the fragment 1 region of meizothrombin.

\section{Kinetic parameters of prothrombin activation by the purified activator from Bothrops neuwiedi}

To quantitate the catalytic efficiency of prothrombin activation by the venom activator, we determined the kinetic parameters $\left(K_{m}\right.$ and $\left.V_{\text {max }}\right)$ of venomcatalyzed prothrombin activation. Since the rates of prothrombin activation by the venom activator varied at different calcium concentrations, we first determined the calcium-dependence of the reaction by measuring prothrombin activation at different $\mathrm{CaCl}_{2}$ concentrations at a constant amount of purified snake venom activator and prothrombin. Activation of 
prothrombin was followed by measuring the generation of amidolytic activity towards the chromogenic substrate S2238. The venom activator from Bothrops neuwiedi did not have an absolute requirement for added calcium ions (Figure 8). In the absence of calcium prothrombin, activation occurred at $63 \%$ of the rate observed at optimal calcium concentration $(2 \mathrm{mM})$. Significant inhibition was observed at higher calcium concentrations. Lineweaver-Burk plots of venom-catalyzed prothrombin activation were determined at 2 and $25 \mathrm{mM} \mathrm{CaCl}$ (Figure 9). At $2 \mathrm{mM} \mathrm{CaCl}_{2}$, a $\mathrm{Km}$ of $38 \mu \mathrm{M}$ and a $V_{\max }$ of $120 \mu \mathrm{mol}$ of prothrombin activated per min per $\mathrm{mg}$ venom were determined from the Lineweaver-Burk plot. Assuming a molecular weight of 60,000 , this corresponds to a turnover number ( $k_{\text {cat }}$ ) of $120 \mathrm{~s}^{-1}$ (i.e., mol prothrombin activated per s per mol of venom activator). In the presence of $25 \mathrm{mM} \mathrm{CaCl}_{2}$, there was an increase in the $\mathrm{K}_{\mathrm{m}}(103 \mu \mathrm{M})$, while the $V_{\max }$ was hardly affected $(133 \mu \mathrm{mol}$ of prothrombin activated per min per $\mathrm{mg}$ venom).

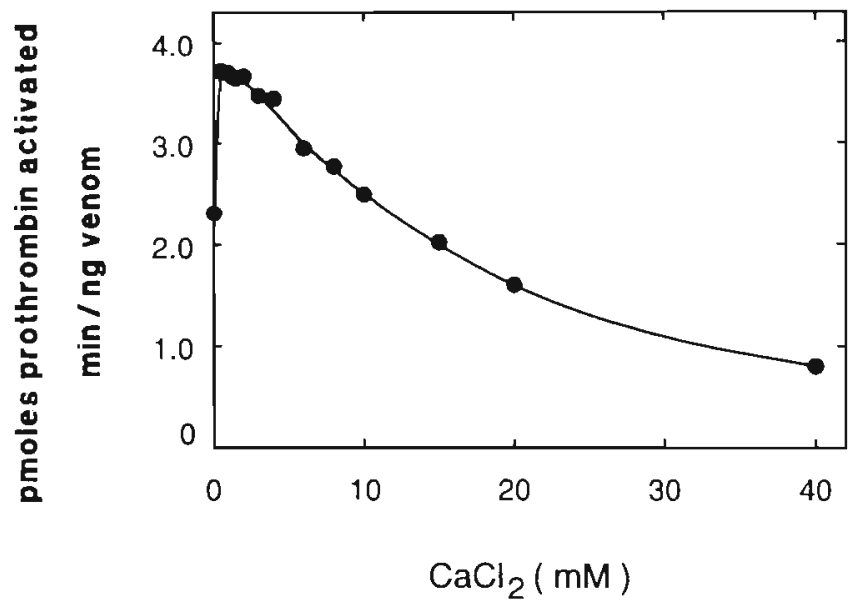

Figure 8. Calcium dependence of prothrombin activiation by the purified venom activator. $1 \mu \mathrm{M}$ prothrombin was incubated at $37^{\circ} \mathrm{C}$ in a buffer containing $50 \mathrm{mM}$ Tris$\mathrm{HCl}(\mathrm{pH} 7.9), 175 \mathrm{mM} \mathrm{NaCl}, 0.5 \mathrm{mg} / \mathrm{ml}$ human serum albumin with varying amounts of $\mathrm{CaCl}_{2}$. Activation was started by addition of purified venom activator $(0.41 \mathrm{ng} / \mathrm{ml})$ in the same buffer. Prothrombin activation was determined by measuring the arnidolytic activity generated after 2 and 4 min of incubation. Prothrombin activation without $\mathrm{CaCl}_{2}$ was measured in the presence of $0.75 \mathrm{mM}$ EDTA and was determined after 1 and $2 \mathrm{~min}$ reaction time. Rates of prothrombin activation were calculated as described in Experimental Procedures. 


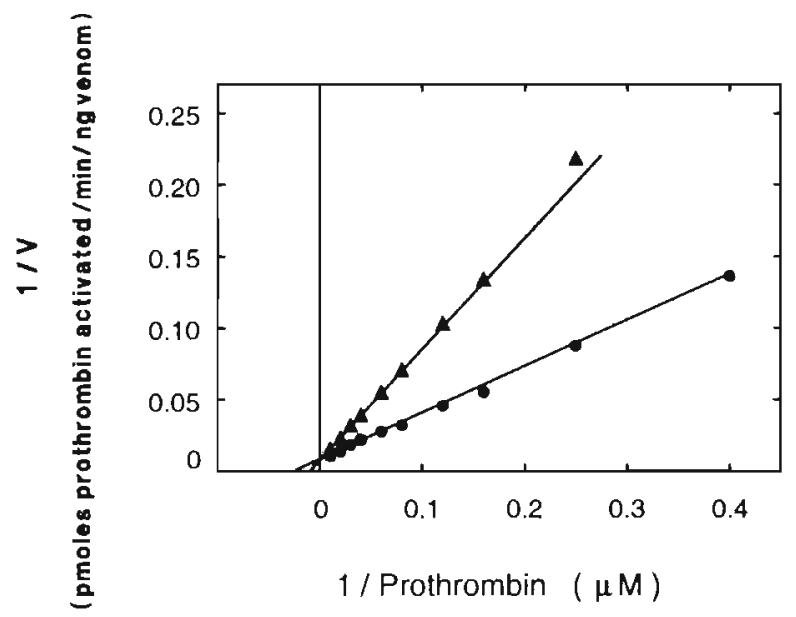

Figure 9. Lineweaver-Burk plots of prothrombin activation by the purified venom activator from Bothrops neuwiedi. Prothrombin activation at varying concentrations of prothrombin was determined at $37^{\circ} \mathrm{C}$ in $0.25 \mathrm{ml}$ of a reaction mixture containing $50 \mathrm{mM}$ Tris- $\mathrm{HCl}(\mathrm{pH} 7.9), 175 \mathrm{mM} \mathrm{NaCl}, 0.5 \mathrm{mg} / \mathrm{ml}$ human serum albumin $0.16 \mathrm{ng} / \mathrm{ml}$ purified venom activator and $2 \mathrm{mM} \mathrm{CaCl}_{2}$ (๑) or $25 \mathrm{mM} \mathrm{CaCl}_{2}$ (A). Prothrombin activation was started by addition of purified venom activator. After 2 and $4 \mathrm{~min}$, samples were taken and the amounts of prothrombin activated were determined by measuring the amidolytic activity generated. Rates of prothrombin activation were calculated as described in Experimental Procedures. The Lineweaver-Burk plots were drawn after statistical analysis of the data according to Eisenthal and Cornish-Bowden [23].

The decrease in the rate of venom-catalyzed prothrombin activation at higher $\mathrm{CaCl}_{2}$ concentrations is, therefore, likely due to the fact that the affinity of the venom activator for prothrombin decreases at increasing $\mathrm{CaCl}_{2}$ concentrations.

\section{The effect of proteinase inhibitors on the prothrombin-converting acti- vity of the purified venom activator from Bothrops neuwiedi}

Table 3 summarizes the effects of a large number of proteinase inhibitors on the catalytic activity of the purified prothrombin activator from the venom of Bothops neuwiedi. The prothrombin-converting activity of the venom activator was not affected by incubation of the activator with high concentrations of soy-bean trypsin inhibitor, PMSF, dansyl-Glu-Gly-Arg- $\mathrm{CH}_{2} \mathrm{Cl}$, Pro-Phe-Arg$\mathrm{CH}_{2} \mathrm{Cl}$, iodoacetamide or $\mathrm{N}$-ethylmaleimide. Venom-catalyzed prothrombin activation was also not inhibited by benzamidine at concentrations up to $10 \mathrm{mM}$. The sulfhydryl reagent, 2-mercaptoethanol, had a minor effect on the catalytic activity of the venom activator. At high concentrations of mercaptoethanol ( more than $10 \mathrm{mM}$ ) significant inhibition occurred. Metal- 
Table 3. Effect of various inhibitors on prothrombin activation by the purified venom activator

Inhibitor

Relative

rate (\%)

None

100

$\operatorname{EDTA}(0.1 \mathrm{mM})$

EDTA $(0.2 \mathrm{mM})$

EGTA $(0.1 \mathrm{mM})$

EGTA (0.5 mM)

85

o-Phenanthroline $(0.1 \mathrm{mM})$

50

o-Phenanthroline $(0.25 \mathrm{mM})$

o-Phenanthroline $(0.5 \mathrm{mM})$

Benzamidine (10 mM)

102

PMSF (10 mM)

Dansyl-Glu-Gly-Arg- $\mathrm{CH}_{2} \mathrm{Cl}(2.5 \mu \mathrm{M})$

92

Pro-Phe-Arg- $\mathrm{CH}_{2} \mathrm{Cl}(6 \mu \mathrm{M})$

94

Soy-bean trypsin inhibitor $(0.5 \mathrm{mg} / \mathrm{ml})$

100

2-Mercaptoethanol (1 mM)

88

2-Mercaptoethanol (2 $\mathrm{mM}$ )

2-Mercaptoethanol (10 $\mathrm{mM}$ )

68

2-Mercaptoethanol (25 mM)

96

$\mathrm{N}$-Ethylmaleimide (10 mM)

94

lodoacetamide (10 $\mathrm{mM}$ )

The purified prothrombin activator from the venom of Bothrops neuwiedi $(205 \mathrm{ng} / \mathrm{ml}$ ) was preincubated at $37^{\circ} \mathrm{C}$ in a total volume of $200 \mu$ containing $50 \mathrm{mM} \mathrm{Tris}-\mathrm{HCl}(\mathrm{pH} 7.9)$, $175 \mathrm{mM} \mathrm{NaCl}, 0.5 \mathrm{mg} / \mathrm{ml}$ human serum albumin, and amounts of inhibitor indicated in the table. After $10 \mathrm{~min}, 10 \mu \mathrm{l}$ of this mixture was transferred to $240 \mu \mathrm{l}$ of a prothrombin activation mixture $\left(37^{\circ} \mathrm{C}\right)$ containing $50 \mathrm{mM}$ Tris- $\mathrm{HCl}(\mathrm{pH} 7.9), 175 \mathrm{mM} \mathrm{NaCl}, 0.5 \mathrm{mg} / \mathrm{ml}$ human serum albumin, $0.5 \mu \mathrm{M}$ prothrombin, and $2 \mathrm{mM} \mathrm{CaCl} 2$. To determine the effects of the chelating agents, $0.25 \mathrm{mM}$ EDTA instead of $2 \mathrm{mM} \mathrm{CaCl} 2$ was present in the prothrombin activation mixture. The reason for this is that the prothrombin-converting activity of the chelator-treated venom activator restored during a prothrombin-activation measurement when calcium is present. Prothrombin activation was determined by measuring the amidolytic activity generated after 0.5, 1 and 2 min. With Pro-Phe-Arg$\mathrm{CH}_{2} \mathrm{Cl}$ (an irreversible inhibitor of thrombin), the rate of prothrombin activation was corrected for a minor inhibitory effect of Pro-Phe-Arg- $\mathrm{CH}_{2} \mathrm{Cl}$ on the meizothrombin that is formed as product of prothrombin activation. In the case of inhibition by benzamidine, the inhibitor was present in the prothrombin activation mixture. $100 \%$ velocity was determined by adding buffer instead of inhibitor to the venom activator in the preincubation mixture. Rates of prothrombin activation were determined as described in the Experimental Procedures. 
chelating agents readily inhibited the prothrombin-converting activity of the venom activator. Incubation of venom activator with low concentrations of EDTA caused a rapid loss of the ability of the venom protein to activate prothrombin. EGTA and o-phenanthroline were somewhat less effective than EDTA, although prolonged incubation with these chelating agents also resulted in complete inactivation of the venom activator (data not shown).

The prothrombin-converting activity of chelator-treated venom activator could be restored by the addition of excess $\mathrm{CaCl}_{2}$. A chelator-treated venom activator preparation (preincubated $20 \mathrm{~min}$ with $0.1 \mathrm{mM}$ EDTA) with no detectable prothrombin-converting activity regained $40 \%$ of its native activity after $20 \mathrm{~min}$ incubation in the presence of $2 \mathrm{mM} \mathrm{CaCl} 2$. Other divalent cations were not $\mathrm{Hg}^{2}+, \mathrm{Mg}^{2}+, \mathrm{Cd}^{2}+\mathrm{Ni}^{2}+\mathrm{Mn}^{2}+\mathrm{Cu}^{2}+$ and $\left.\mathrm{Co}^{2}+\right)$ or less $\left(\mathrm{Zn}^{2+}, \mathrm{Ba}^{2+}\right.$ and $\left.\mathrm{Sr}^{2+}\right)$ effective in restoring the activity of the EDTA-treated venom activator. After prolonged incubation of the venom activator with high concentrations of EDTA, the prothrombin-converting activity could not be restored anymore with divalent cations. This indicates that the reaction sequence of chelator-induced inactivation of the venom activator is best described by

chelator

$\mathrm{E}-\mathrm{Me} \rightarrow \mathrm{E} \rightarrow \mathrm{E}^{*}$

in which $E$ - $M e$ is active prothrombin activator, $E$ is non-active venom activator whose prothrombin converting activity can be restored by divalent cations and $\mathrm{E}^{*}$ is inactive activator whose activity cannot be restored by divalent cations.

\section{Discussion}

In this paper, we have described the purification and the structural and functional characterization of a prothrombin activator from the venom of Bothrops neuwiedi. The venom activator from Bothrops neuwiedi is a singlechain protein with an apparent molecular weight of 60,000 . It readily activates prothrombin in a reaction that is not affected by the presence of phospholipids and factor $\mathrm{Va}$, the non-enzymatic cofactors of the prothrombinase complex. Gel electrophoretic analysis of venom-catalyzed prothrombin activation shows that the venom activator can only cleave the Arg323-Ile324 bond of bovine prothrombin, since meizothrombin (and 
meizothrombin des fragment 1) are the only products visible on a gel. The presence of meizothrombin des fragment 1 likely resulted from autocatalytic cleavage of the Arg156-Ser157 bond in meizothrombin producing fragment 1 and meizothrombin des fragment 1.

The catalytic efficiency of prothrombin activation by the venom activator is rather high. From the kinetic parameters, a kcat / $\mathrm{K}_{\mathrm{m}}$ of $3.2 .106 \mathrm{M}^{-1} . \mathrm{s}^{-1}$ can be calculated. Especially the $k_{c a t}$ of venom-catalyzed prothrombin activation is high. The calculated value of $120 \mathrm{ss}^{-1}$ even exceeds the $\mathrm{k}_{\mathrm{c}}$ value reported for prothrombin activation by the complete prothrombinase complex (factor $\mathrm{Xa}$, factor $\mathrm{Va}, \mathrm{Ca}^{2+}+$, phospholipid) which is $35 \mathrm{~s}^{-1}$ [10] or the $\mathrm{k}_{\mathrm{cat}}$ of prothrombin activation by the venom activator from Echis carinatus which is reported to be $5 \mathrm{~s}^{-1}$ [24].

The venom activator is neither inhibited by the serine proteinase inhibitors benzamidine, soybean trypsin inhibitor, PMSF and the chloromethyl ketones, Dansyl-Glu-Gly-Arg- $\mathrm{CH}_{2} \mathrm{Cl}$ and Pro-Phe-Arg- $\mathrm{CH}_{2} \mathrm{Cl}$, nor by thiol proteinase inhibitors such as $\mathrm{N}$-ethylmaleimide and iodoacetamide. However, the Bothrops activator rapidly loses its ability to activate prothrombin when it is incubated with metal-chelating agents such as EDTA, EGTA and o-phenanthroline. These results indicate that the venom prothrombin activator from Bothrops neuwiedi likely belongs to the metalloproteinases. Prothrombinconverting activity of chelator-treated enzyme can be regained upon incubation in the presence of excess $\mathrm{CaCl}_{2}$.

The structural and functional properties of this venom activator considerably differ from those of factor $\mathrm{Xa}$ and from the factor $\mathrm{Xa-like}$ prothrombin activators present in the venoms of Natechis scutatus [25] and Oxyuranus scutellatus [26]. However, the Bothrops activator strongly resembles the prothrombin activators present in the venoms of Echis carinatus $[24,27]$ and Dispholidus typus $[28,29]$. These venom activators are also single-chains proteins with apparent molecular weights of about $\mathrm{Mr}$ 60,000 [24-29] that convert prothrombin into meizothrombin [24] in a reaction that is not affected by phospholipids and factor Va. Morita et al. [24] reported that the venom activator from Echis carinatus was also strongly inhibited by chelating agents. In their case, inhibition could not be reversed with excess calcium ions, which means that there are some minor differences between the Echis and Bothrops prothrombin activators. 


\section{References}

1. Pirkle H. and Markland Jr, F.S. (1988) Hemostasis and animal venoms, New York, Basel: Marcel Dekker, Inc.

2. Rosing J., Zwaal R.F.A. and Tans G. (1988) Hemostasis and animal venoms (Pirkle, H. and Markland, F.S., eds.), pp 1-25, New York, Basel: Marcel Dekker, Inc.

3. Nahas L., Kamigutti A.S. and Barros M.A.P. (1979) Thrombin-like and factor Xactivator components of Bothrops snake venoms, Thromb. Haemost. 41, 314-328

4. Stocker K. and Egberg N. (1973) Reptilase as a defibrinogenating agent, Thromb. Diath. Haemorrh. 1, 361-370

5. Niewiarowski S., Kirby E.P. and Stocker K. (1977) Thrombocytin, a novel platelet activating enzyme from Bothrops atrox venom, Thromb. Res. 10, 863-869

6. Hofmann $H$. and Bon C. (1987) Blood coagulation induced by the venom of Bothrops atrox. 2. Identification, purification and properties of two factor $X$ activators, Biochemistry 26, 780-787

7. Hofmann $H$. and Bon C. (1987) Blood coagulation induced by the venom of Bothrops atrox. 1. Identification, purification and properties of a prothrombin activator, Biochemistry 26, 772-780

8. Porath J., Carlsson J., Olsson I. and Belfrage G. (1975) Metal chelate affinity chromatography, a new approach to protein fractionation, Nature 258, 598-599

9. Owen W.G., Esmon C.T. and Jackson C.M. (1974) The conversion of prothrombin to thrombin. I. Characterization of reaction products formed during the activation of bovine prothrombin, J. Biol. Chem. 249, 594-605

10. Rosing J., Tans G., Govers-Riemslag J.W.P., Zwaal R.F.A. and Hemker H.C. (1980) The role of phospholipids and factor $\mathrm{Va}$ in the prothrombinase complex, $J$. Biol. Chem. 255, 274-283

11. Fujikawa K., Legaz M.E. and Davie E.W. (1972) Bovine factor X(1) and X(2) (Stuart factor) isolation and characterization, Biochemistry 11, 4882-4891

12. Fujikawa K., Legaz M.E. and Davie E.W. (1972) Bovine factor $X(1)$ (Stuart factor) mechanism of activation by a protein from Russel's viper venom, Biochemistry 11 , 4892-4899

13. Thaler E. and Schmer G. (1975) A simple two-step isolation procedure for human and bovine antithrombin II/III (heparin cofactor): a comparison of two methods, $\mathrm{Br}$. J. Haematol. 31, 233-243

14. Lindhout T., Govers-Riemslag J.W.P., van de Waart P., Hemker H.C. and Rosing J. (1982) Factor Va-factor Xa interaction. Effects of phospholipid vesicles of varying composition, Biochemistry 21 5494-5502

15. Chase T. Jr., and Shaw E. (1969) Comparison of the esterase activities of trypsin plasmin and thrombin on guanidinobenzoate esters - titration of the enzymes, Biochemistry 8, 2212-2224

16. Sedmak J.J. and Grossberg S.E. (1977) A rapid, sensitive and versatile assay for protein using Coomassie brilliant blue G250, Analyt. Biochem. 79, 544-552

17. Comfurius P. and Zwaal R.F.A. (1977) The enzymatic synthesis of phosphatidylserine and purification by $\mathrm{CM}$-cellulose column chromatography, Biochim. Biophys. Acta 488, 36-42

18. Böttcher C.J.F., van Gent C.M. and Pries C. (1961) A rapid and sensitive sub-micro phosphorus determination, Anal. Chim. Acta 24, 203-207 
19. Rosing J., Zwaal R.F.A. and Tans G. (1986) Formation of meizothrombin as an intermediate in factor Xa-catalyzed prothrombin activation, J. Biol. Chem. 261, 4224-4228

20. Laemmli U.K. (1970) Cleavage of structural protein during the assembly of the head bacteriophage T4, Nature 227, 680-685

21. Granelli-Pipemo A. and Reich G. (1978) A study of proteases and proteaseinhibitor complexes in biological fluids, J. Exp. Med. 148, 223-234

22. Wagner O.F., Bergman I. and Binder B.R. (1985) Chromogenic substrate autography: A method for the detection, characterization, and quantitative measurement of serine proteases after sodium dodecyl sulfate-polyacrylamide gel electrophoresis or isoelectric focusing in polyacrylamide gels, Anal. Biochem. 151, 7-12

23. Eisenthal R. and Comish-Bowden A. (1974) The direct linear plot. A new graphical procedure for estimating enzyme kinetic parameters, Biochem. J. 139, 715-720

24. Morita T. and Iwanaga S. (1978) Purification and properties of prothrombin activator from the venom of Echis carinatus, J. Biochem. 83, 559-570

25. Tans G., Govers-Riemslag J.W.P., van Rijn J.L.M.L. and Rosing J. (1985) Purification and properties of a prothrombin activator from the venom of Notechis scutatus scutatus, J. Biol. Chem. 260, 9366-9372

26. Speijer H., Govers-Riemslag J.W.P., Zwaal R.F.A. and Rosing J. (1986) Prothrombin activation by an activator from the venom of Oxyuranus scutellatus (Taipan snake), J. Biol. chem. 261, 13258-13267

27. Rhee M.J., Morris S. and Kosow D.P. (1982) Role of meizothrombin and meizothrombin (des F1) in the conversion of prothrombin to thrombin by the Echis carinatus venom coagulant, Biochemistry 21, 3437-3443

28. Mackay N., Ferguson J.C., Ashe J., Bagshawe A., Forrester A. and McNicol G.P. (1969) Venom of boomslang (Dispholidus typus) in vivo and in vitro studies, Thromb. Diath. Haemorm. 21, 234-244

29. Guillin M.C., Bezeaud A. and Menache D. (1978) The mechanism of activation of human prothrombin by an activator isolated from Dipholidus typus venom, Biochim. Biophys. Acta 537, 160-168 


\section{Chapter 4}

\section{Purification and Properties of a Prothrombin Activator from the Venom of an Australian Elapid Snake, Notechis scutatus scutatus}




\section{Summary}

The prothrombin activator present in the venom of the mainland tiger snake (Notechis scutatus scutatus) was purified to homogeneity by gel chromatography on Sephadex G-200 followed by ion-exchange chromatography on SP-Sephadex. The venom activator has an apparent molecular weight of 54,000 . It consists of a heavy chain $(\mathrm{Mr} 32,000)$ and a light chain ( $\mathrm{Mr} 23,000$ ) held together by one or more disulfide bridges. The active site is located at the heavy chain region of the molecule. The venom activator contains 8 -carboxyglutamic acid residues/molecule. Gel electrophoretic analysis of prothrombin activation indicates that the venom activator is capable of cleaving both the Arg274-Thr275 and Arg323-Ile324 bonds of bovine prothrombin. The order of bond cleavage appears to be random since prethrombin 2 and meizothrombin occur as intermediates during prothrombin activation. Prothrombin activation by the venom activator alone is very slow. This is explained by the unfavorable kinetic parameters for the reaction $\left(K_{m}\right.$ for prothrombin $=105 \mu \mathrm{M}, V_{\max }=0.0025 \mathrm{nmol}$ of prothrombin activated per min/ $\mu \mathrm{g}$ of venom activator). Phospholipids plus $\mathrm{Ca}^{2+}$ and Factor $\mathrm{Va}$ greatly stimulate venom-catalyzed prothrombin activation. In the presence of $50 \mu \mathrm{M}$ phospholipid vesicles composed of 20 mol \% phosphatidylserine and $80 \mathrm{~mol} \%$ phosphatidylcholine, the $\mathrm{K}_{\mathrm{m}}$ drops to $0.2 \mu \mathrm{M}$, whereas there is hardly any effect on the $V_{\max }$. Factor $V a$ causes a 3,500-fold increase of the $V_{\max }(8.35 \mathrm{nmol}$ of prothrombin activated per $\mathrm{min} / \mu \mathrm{g}$ of venom activator) and a 10-fold decrease of the $\mathrm{K}_{\mathrm{m}}(9.5 \mu \mathrm{M})$. The most favorable kinetic parameters are observed in the presence of both $50 \mu \mathrm{M}$ phospholipid and Factor $\mathrm{Va}\left(\mathrm{K}_{\mathrm{m}}=0.16 \mu \mathrm{M}, \mathrm{V}_{\max }=27.9 \mathrm{nmol}\right.$ of prothrombin activated per $\mathrm{min} / \mu \mathrm{g}$ of venom activator). These changes of the kinetic parameters explain the stimulatory effects of Factor $\mathrm{Va}$ and phospholipid on venom-catalyzed prothrombin activation. The venom activator slowly converts the Factor $\mathrm{Xa}$ specific chromogenic substrates $\mathrm{CH}_{3} \mathrm{SO}_{2}$-D-leucyl-glycyl-L-arginine- $p$-nitroanilide and $\mathrm{N}$-benzoyl-L-isoleucyl -L-glutamyl-(piperidyl)-glycyl-L-arginyl-p-nitroanilide hydrochloride. Factor $V$ a causes a 7 -fold stimulation of chromogenic substrate conversion by the venom activator. This stimulation appears to be the result of the formation of a tight 1:1 complex between the venom activator and Factor $\mathrm{Va}$. 


\section{Introduction}

One of the central reactions in blood coagulation is the activation of the zymogen prothrombin into the active serine protease thrombin. Under physiological conditions prothrombin activation is catalyzed by activated Factor $\mathrm{X}(\mathrm{Xa})$. In order to achieve sufficiently high rates of prothrombin activation in vivo, the so-called accessory components $\mathrm{Ca}^{2+}$, phospholipid, and the protein cofactor Factor $V a$ have to be present. In recent years much has been learned about the function of these accessory components in prothrombin activation. Phospholipids stimulate prothrombin activation by lowering the $\mathrm{K}_{\mathrm{m}}$ for prothrombin to levels below the plasma concentration [1]. The role of Factor $V a$ appears to be 3-fold: (a) Factor $V a$ enhances the $k_{\text {cat }}$ of prothrombin activation about 1000-fold [1,2], (b) it promotes the binding of Factor $\mathrm{Xa}$, to phospholipids [2,3], and (c) it causes a decrease in the $\mathrm{K}_{\mathrm{m}}$ for prothrombin, which is most apparent when phospholipids are used that have a low affinity for prothrombin $[4,5]$. The precise mechanisms by which these changes in kinetic parameters are brought about remain, however, to be established.

Many snake venoms have been described that contain strong procoagulants. In those cases where the proteases responsible for the procoagulant activity are purified, they can be very useful tools in studies on the mechanism of individual coagulation reactions. It has been reported [6] that the venom of the mainland tiger snake (Notechis scutatus scutatus) contains a strong procoagulant, the action of which can be attributed to prothrombin activation. Since the venom activity on prothrombin is greatly stimulated by the presence of phospholipid and Factor $V a$ this activator can be very useful in the further elucidation of the mechanism of action of accessory components in prothrombin activation.

In this chapter we report the purification and characterization of the prothrombin activator present in the venom of Notechis scutatus scutatus. The enzymatic properties of the venom activator were studied by determining the effects of phospholipids and Factor $\mathrm{Va}$ on the kinetic parameters and on the peptide bond cleavage pattern of venom-catalyzed prothrombin activation.

\section{Experimental procedures}

- Reagents. Lyophilized crude venoms from Notechis scutatus scutatus, Russel's viper as well as benzamidine-HCl, diisopropyl fluorophosphate (DFP), ovalbumin, human serum albumin (fatty acid free), bovine serum albumin (grade $V$ ), soybean 
trypsin inhibitor and 1,2-dioleoyl-sn-glycero-3-phosphocholine (PC) were obtained from Sigma. S2238, S2337 and 12581 were purchased from AB Kabi Diagnostica and $p$-NPGB was from Nutritional Biochemicals. CBS 31.39 was obtained from Diagnostica Stago, Paris, France. Dansyl-GGACK was from Calbiochem-Behring. DEAE-Sephadex A-50, QAE Sephadex A-50, SP-Sephadex C-50, Sephadex G100, G-200 and CNBr activated Sepharose-4B were purchased from Pharmacia. Soybean trypsin inhibitor, bovine Factor $X$ and antibodies against bovine Factor $X$ were coupled to $\mathrm{CNBr}$-activated Sepharose $4 \mathrm{~B}$ according to the manufacturers instructions. All reagents used were of the highest grade commercially available.

Proteins. Bovine prothrombin was purified according the method of Owen et al. [7], thrombin was purified as described earlier [1] and bovine Factor $X$ was purified as described by Fujikawa et al. [8]. Factor $X a$ was prepared from Factor $X$ that was activated with RW-X [9]. Factor $V$ and Factor $V a$ were obtained as described by Lindhout et al. [3]. The protein preparations were stored at $-80^{\circ} \mathrm{C}$ in $50 \mathrm{mM}$ Tris- $\mathrm{HCl}, 175 \mathrm{mM} \mathrm{NaCl}, 0.5 \mathrm{mg} / \mathrm{ml}$ human serum albumin (pH 7.9) Factor $V a$ was stored in the same buffer containing $5 \mathrm{mM} \mathrm{CaCl}$.

Rabbit antibodies against bovine factor $\mathrm{X}$ were immunopurified on Factor $\mathrm{X}$ Sepharose and dialysed against $50 \mathrm{mM}$ Tris $(\mathrm{pH} 7.9)$ and $175 \mathrm{mM} \mathrm{NaCl}$.

- Protein concentrations. The molar concentration of thrombin was determined by active site titration with p-NPGB according to Chase and Shaw [10]. Prothrombin concentrations were determined by the same method after complete activation with Echis carinatus venom. Factor Xa concentrations were determined by active site titration [11]. The concentration of Factor $\mathrm{Va}$ was determined by kinetic analysis [3]. The concentration of purified activator from Notechis scutatus scutatus was calculated from a protein determination according to Lowry et al. [12] using bovine serum albumin as a standard and assuming a molecular weight of 54,000 for the venom activator (see results).

- Phospholipid and phospholipid vescles preparations. Single bilayer phospholipid vesicles were prepared by sonication of mixtures of $20 \mathrm{~mole} \% \mathrm{1,2}$ dioleoyl-sn-glycero-3-phosphoserine (PS) and $80 \mathrm{~mole} \%$ 1,2-dioleoyl-sn-glycero3-phosphocholine (PC) as described before [1]. Phospholipid concentrations were determined by phosphate analysis [13].

- Assay system for measurements of prothrombin activation. Unless otherwise indicated prothrombin activation by Notechis scutatus scutatus was followed by measuring the generation of amidolytic activity towards the chromogenic substrate S2238. Appropriate dilutions of the venom activator were preincubated for $5 \mathrm{~min}$ in a buffer containing $50 \mathrm{mM}$ Tris- $\mathrm{HCl}(\mathrm{pH} 7.9), 175 \mathrm{mM}$ $\mathrm{NaCl}$ and $0.5 \mathrm{mg} / \mathrm{ml}$ human serum albumin at $37^{\circ} \mathrm{C}$. When Factor $\mathrm{Va}$, phospholipid vesicles (20\%PS/ $80 \% \mathrm{PC}$ ) or $\mathrm{CaCl}_{2}$ were present these were included in the preincubation mixture. Activation was started with the addition of prothrombin (prewarmed at $37^{\circ} \mathrm{C}$ ) in the same buffer. After different time intervals samples were withdrawn and transferred to disposable cuvettes $(1 \mathrm{~cm}$ pathlength) containing the thrombin specific substrate S2238. The final volume in the cuvettes was $1 \mathrm{ml}$ of $50 \mathrm{mM}$ Tris ( $\mathrm{pH}$ 7.9), $175 \mathrm{mM} \mathrm{NaCl}, 20 \mathrm{mM}$ EDTA, $0.5 \mathrm{mg} / \mathrm{ml}$ ovalbu$\mathrm{min}$ and $235 \mu \mathrm{M} \mathrm{S} 2238$. Further prothrombln activation in the cuvette is prevented by dilution and by the presence of EDTA. The amidolytic activity in the samples 
was determined by measuring the absorbance change on a SLM-Aminco DW2-C spectrophotometer set in the dual wavelength mode at $405-500 \mathrm{~nm}$. From a calibration curve made with known amounts of active site-titrated thrombin the amounts of activated prothrombin in the reaction mixture could be determined and from these the rates of prothrombin activation were calculated. Further experimental details are given in the legends to the figures.

- Procoagulant assay for thrombin formation. In some experiments the amount of thrombin formed during prothrombin activation was also determined in a clotting assay. Thrombin containing samples $(50 \mu \mathrm{l})$ from prothrombin activation mixtures were transferred to glass tubes containing $300 \mu \mathrm{l}$ fibrinogen $(3 \mathrm{mg} / \mathrm{ml}$ in $50 \mathrm{mM}$ Tris, $175 \mathrm{mM} \mathrm{NaCl}, \mathrm{pH} 7.9)$ and $50 \mu \mathrm{l} \mathrm{CaCl} 2(80 \mathrm{mM})$. The clotting time was measured and from a reference curve made with known amounts of active site-titrated thrombin the molar thrombin concentration present in the reaction mixture was calculated.

\section{Results and Discussion}

\section{Purification and characterization of the prothrombin activator from Notechis scutatus scutatus}

The prothrombin activator from Notechis scutatus scutatus was purified from the crude venom by gel filtration on Sephadex G-200 (Figure 1) followed by SP-Sephadex ion-exchange chromatography. The fractions from the G-200 column containing the prothrombin activator were pooled and after dialysis applied to a SP-sephadex column $(2.2 \times 30 \mathrm{~cm})$ in $25 \mathrm{mM}$ Mes $(\mathrm{pH} 6.5)$, $10 \mathrm{mM}$ benzamidine at a flow rate of $15 \mathrm{ml} / \mathrm{hr}$ at $4^{\circ} \mathrm{C}$. The activator adhered to the resin and was eluted with a linear gradient of $(2 \times 250 \mathrm{ml})$ with starting

Table 1. Purification of the prothrombin activator of Notechis scutatus scutatus venom

$\begin{array}{cc}\begin{array}{c}\text { Total protein } \\ (\mathrm{mg})\end{array} & \begin{array}{c}\text { Specific Activity } \\ (\text { nmoles prothrombin } \\ \text { activated } / \mathrm{min} / \mu \mathrm{g} \text { venom) }\end{array}\end{array}$

Recovery

$(\%)$

activated $/ \mathrm{min} / \mu \mathrm{g}$ venom)

Crude venom

Sephadex G-200

100

7

1.2
1.5

12.9

26.0
100

60

20

Total protein was determined according to Lowry et al. [12] using bovine serum albumin as a standard. Prothrombin activation was determined as described in the legend to Figure 1. 


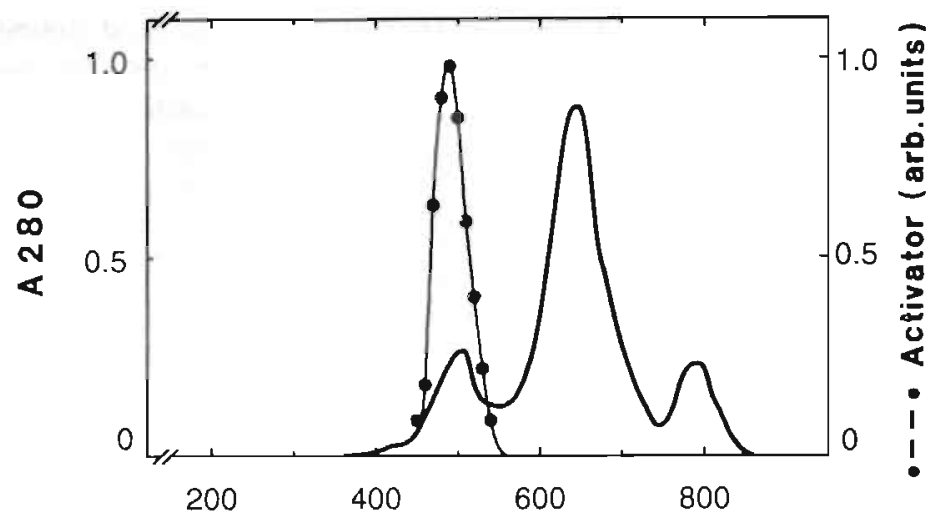

Elution volume $(\mathrm{ml})$

Figure 1. Sephadex G-200 elution profile of Notechis scutatus scutatus venom. Crude venom (100 mg) was dissolved in $4 \mathrm{ml} 50 \mathrm{mM}$ Tris (pH 7.6), $500 \mathrm{mM} \mathrm{NaCl}$ and 10 $\mathrm{mM}$ benzamidine and applied to a Sephadex G-200 column $(3.3 \times 90 \mathrm{~cm})$ equilibrated with the same buffer at a flow rate of $15 \mathrm{ml} / \mathrm{hr}$ at $4^{\circ} \mathrm{C}$. Protein elution was determined by monitoring the column at $280 \mathrm{~nm}$. The eluted fractions were tested for their ability to activate prothrombin (e) at $37^{\circ} \mathrm{C}$ in an activation mixture containing $50 \mathrm{mM}$ Tris ( $\mathrm{pH} 7.9$ ), $175 \mathrm{mM} \mathrm{NaCl}, 5 \mathrm{mM} \mathrm{CaCl} 2,0.5 \mathrm{mg} / \mathrm{ml} \mathrm{HSA}, 0.4 \mu \mathrm{M}$ prothrombin, $5 \mathrm{nM}$ Factor $\mathrm{Va}, 50 \mu \mathrm{M}$ phospholipids (20\% PS $/ 80 \% \mathrm{PC}$ ) and appropriate dilutions of column fractions. The activation of prothrombin in these reaction mixtures was followed by measuring the generation of amidolytic activity as described in the experimental procedures. The prothrombin-converting activity was expressed relative to the peak fraction which was taken as $100 \%$.

buffer in the front chamber and the same buffer containing $250 \mathrm{mM} \mathrm{NaCl}$ in the distal chamber. The activator eluted in a single peak at about $140 \mathrm{mM}$ $\mathrm{NaCl}$. Benzamidine was present in the puritication to avoid the appearance of degradation products in the final material. The overall purification was about 17 -fold with a $20 \%$ yield (Table 1). From the gain in specific activity it can be calculated that the activator comprises about $6 \%$ of the crude venom.

Figure 2 shows that the protein obtained was homogeneous as judged by sodium dodecyl sulfate-gel electrophoresis. The nonreduced material showed a single band at approximately $\mathrm{Mr} 54,000$. This molecular weight was confirmed by gel permeation chromatography on Sephadex G-200. Upon reduction a heavy and a light chain of about $\mathrm{Mr} 32,000$ and $\mathrm{Mr} 23,000$ were seen, and we conclude that the purified protein consists of two polypeptide chains held together by one or more disulfide bonds. The purified activator could be completely inhibited with dansyl-GGACK, a chloromethyl ketone inhibitor that specifically alkylates the histidine of the 
catalytic triad of Factor Xa-like enzymes [15]. Gels of the chloromethyl ketone-inhibited venom activator showed that the fluorescent label comigrated with the heavy chain of the protease, demonstrating that the active site is located on the heavy chain region of the molecule.

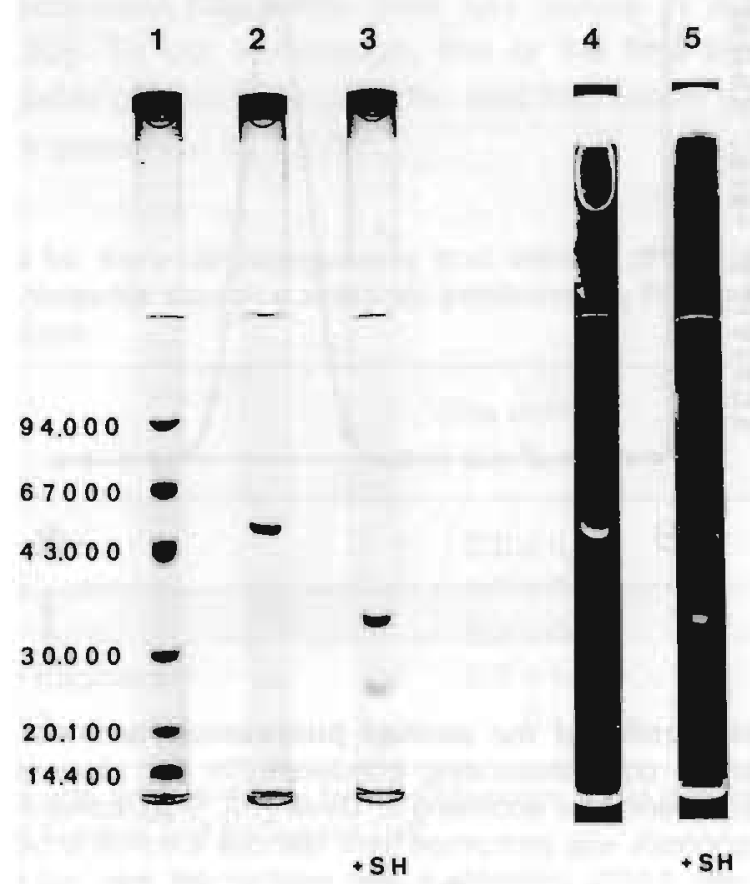

Figure 2. Polyacrylamide gel electrophoresis of purified and active site-labeled prothrombin activator from the venom of Notechis scutatus scutatus. Active sitelabeled activator was obtained by incubation of $1 \mathrm{ml}$ of activator $(50 \mu \mathrm{g})$ with $10 \mu \mathrm{M}$ dansyl-GGACK at $37^{\circ} \mathrm{C}$ for $10 \mathrm{~min}$. Excess inhibitor was removed by extensive dialysis. Gel electrophoresis of $8 \mu \mathrm{g}$ of activator (lanes 2 and 3 ) and active site-labeled activator (lanes 4 and 5) was carried out on $10 \%$ gels in the presence of sodium dodecyl sulfate according to Laemmli [14].

$5 \% \beta$-mercaptoethanol was present in reduced samples $(+\mathrm{SH})$. The gels conlaining activator were stained with Coomassie Brilliant Blue R-250, and the gels containing the active site-labeled activator were photographed under UV light using a yellow filter (cutoff $40 \mathrm{~nm}$ ). Lane 1 shows a gel containing molecular weight markers.

Discontinuous gel electrophoresis under nondenaturing conditions showed multiple bands migrating close together toward the anode (Figure 3). From a similar gel, slices were made from which the prothrombin activator could be eluted with a recovery of approximately $70 \%$. The elution pattern (Figure 3) shows that the venom activator co-migrated with the bands of the stained 
gel. Therefore, the prothrombin activator and the protein visible on the stained gels are one and the same.

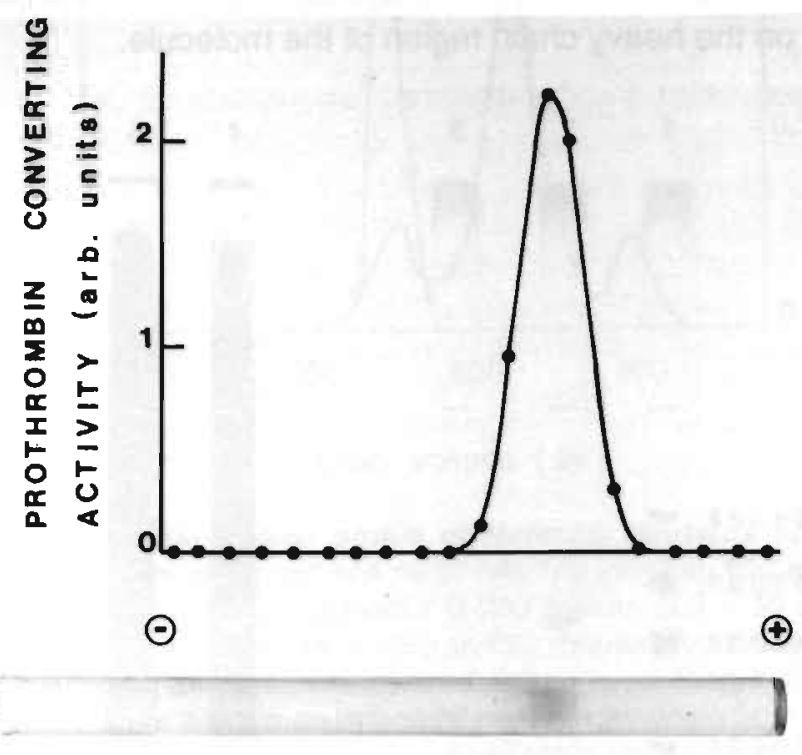

Figure 3. Gel elution profile of the purified prothrombin activator. Discontinuous gelelectrophoresis under non-denaturating conditions (in the absence of SDS) was performed on $7 \%$ acrylamide gels according to Davis [16]. $9 \mu \mathrm{g}$ activator was applied to the gels and electrophoresis was performed from cathode towards anode. One gel was stained for protein with $0.05 \%$ amidoblack and another gel was cut in $5 \mathrm{~mm}$ slices. Protein was eluted from the slices by incubation with $0.5 \mathrm{ml} 50 \mathrm{mM}$ Tris $(\mathrm{pH} 7.9), 175 \mathrm{mM}$ $\mathrm{NaCl}, 5 \mathrm{mM} \mathrm{CaCl} 2$ and $0.5 \mathrm{mg} / \mathrm{ml}$ human serum albumin and shaking for $48 \mathrm{hr}$ at $4^{\circ} \mathrm{C}$. The eluate was then diluted 1000 -fold and $10 \mu \mathrm{l}$ was added to $190 \mu \mathrm{l}$ of the same buffer containing $0.4 \mu \mathrm{M}$ prothrombin, $5 \mathrm{nM}$ Factor $\mathrm{Va}$ and $50 \mu \mathrm{M}$ phospholipids $(20 \% \mathrm{PS} / 80 \%$ $\mathrm{PC}$ ) at $37^{\circ} \mathrm{C}$. The rate of prothrombin activation in the reaction mixtures (expressed in arbitrary units) was calculated from the generation of amidolytic activity as described in the experimental procedures.

Since prothrombin activation by the venom of Notechis scutatus scutatus is stimulated by phospholipids, we investigated whether the purified venom activator contains $\gamma$-carboxyglutamic acid (Gla) residues. Gla residues are carboxylated glutamic acid residues present in the peptide chains of vitamin K-dependent coagulation factors (e.g prothrombin and Factor $\mathrm{X}$ ) which are responsible for $\mathrm{Ca}^{2+-d e p e n d e n t ~ b i n d i n g ~ o f ~ t h e s e ~ p r o t e i n s ~ t o ~ n e g a t i v e l y ~}$ charged phospholipid surfaces. In Table 2 it is shown that the purified activator from Notechis scutatus scutatus contained approximately 8 Gla residues/molecule of protein. These Gla residues were not detectable in an 
acid hydrolysate of the activator. This actually identifies the peak in the chromatogram of a basic hydrolysate as Gla, since upon acid hydrolysis Gla is decarboxylated and converted into glutamic acid [17]. The validity of the Gla determination is shown by the fact that prothrombin, Factor $X$, and prothrombin activation fragments gave Gla values in agreement with the literature $[19,20]$. To our knowledge, this is the first report that a snake species is capable of modifying glutamic acid into Gla in a blood coagulation factor activator present in its venom.

Table 2. Values for the $\gamma$-carboxyglutamic acid content of the purified prothrombin activator from Notechis scutatus scutatus, prothrombin, Factor $\mathrm{X}$, and prothrombin activation products

\begin{tabular}{lcc}
\hline Protein & $\begin{array}{c}\text { Gla content } \\
\%\end{array}$ & $\begin{array}{c}\text { Gla/protein } \\
\text { mol/mol }\end{array}$ \\
\hline Venom activator & $2.0 \pm 0.5$ & $8 \pm 2$ \\
Prothrombin & $1.7 \pm 0.4$ & $10 \pm 2$ \\
Factor X & $2.4 \pm 0.5$ & $11 \pm 3$ \\
Prothrombin fragment 1 & $5.3 \pm 1.4$ & $8 \pm 2$ \\
Prethrombin 1 & 0 & 0
\end{tabular}

The Gla content was determined by high performance liquid chromatography according to the method of Kuwada and Katayama [18].

The effect of various inhibitors on the activation of prothrombin by Notechis scutatus scutatus and by Factor $\mathrm{Xa}$ is compared in Table 3 . The venom activator likely belongs to the class of serine proteases since it is inhibited by diisopropyl fluorophosphate. The reversible competitive inhibitor benzamidine caused similar inhibition of both the venom and Factor $\mathrm{Xa}$. The venom activator could be completely inhibited with the active site-directed chloromethyl ketone dansyl-GGACK although the rate of inhibition was about 10-fold less than that for Factor Xa. Soybean trypsin inhibitor was 400fold more effective in inhibiting bovine Factor Xa than the Notechis scutatus scutatus activator. Immunopurified rabbit anti-bovine Factor $\mathrm{X}$ antibodies completely blocked prothrombin activation by Factor Xa but had no effect on the activation by the Notechis scutatus scutatus activator. Moreover, passage of our prothrombin and purified venom activator preparations over anti-bovine Factor $X$ coupled to Sepharose did not affect the rates of venomcatalyzed prothrombin activation. Therefore, it can be concluded that the activation of prothrombin by Notechis scutatus scutatus venom must be 
completely attributed to the activator, and we rule out the possibility that prothrombin activation in our experiments may be catalyzed by Factor $\mathrm{Xa}$ formed from trace amounts of Factor $X$ that might be present in our prothrombin preparations.

Table 3. Effect of various inhibitors on prothrombin activation by Factor $\mathrm{Xa}$ and the venom activator from Notechis scutatus scutatus

\begin{tabular}{|c|c|c|c|}
\hline \multirow[t]{2}{*}{ Inhibitor } & & \multicolumn{2}{|c|}{ Relative Rate (\%) } \\
\hline & & Factor $\mathrm{Xa}$ & Venom \\
\hline none & & 100 & 100 \\
\hline Benzamidine & $(2 \mathrm{mM})$ & 49.9 & 33.5 \\
\hline Dansyl-GGACK & $\left(0.1 \mu \mathrm{M} ; 10 \mathrm{~min}, 0^{\circ} \mathrm{C}\right)$ & 3.7 & 21.5 \\
\hline DFP & $(50 \mathrm{mM} ; 60 \mathrm{~min})$ & 68.3 & 73.5 \\
\hline STI & $(80 \mathrm{ng} / \mathrm{ml} ; 10 \mathrm{~min})$ & 46.7 & 98.2 \\
\hline STI & $(80 \mu \mathrm{g} / \mathrm{ml} ; 10 \mathrm{~min})$ & 0.3 & 32.3 \\
\hline Anti-bovine Factor $X$ & $(10 \mu \mathrm{g} / \mathrm{ml} ; 5 \mathrm{~min})$ & 5.9 & 100 \\
\hline
\end{tabular}

Factor $\mathrm{Xa}(3.5 \mathrm{ng} / \mathrm{ml})$ or the purified activator from the venom of Notechis scutatus scutatus $(12.5 \mathrm{ng} / \mathrm{ml})$ were preincubated at $37^{\circ} \mathrm{C}$ in a total volume of $100 \mu \mathrm{l}$ containing $200 \mathrm{mM}$ Tris (pH 7.9), $175 \mathrm{mM} \mathrm{NaCl}, 0.5 \mathrm{mg} / \mathrm{ml} \mathrm{HSA}$ and amounts of inhibitor as indicated. With the Dansyl-GGACK the preincubation was carried out on ice. After the time intervals indicated the remaining enzyme activity was determined by transferring 10 $\mu \mathrm{l}$ of this mixture to $490 \mu \mathrm{l}$ of a prothrombin activation mixture $\left(37^{\circ} \mathrm{C}\right)$ containing $50 \mathrm{mM}$ Tris ( $\mathrm{pH} 7.9$ ), $175 \mathrm{mM} \mathrm{NaCl}, 0.5 \mathrm{mg} / \mathrm{ml} \mathrm{HSA}, 5 \mathrm{mM} \mathrm{CaCl} 2,0.4 \mu \mathrm{M}$ prothrombin, $5 \mathrm{nM}$ Factor $\mathrm{Va}$ and $50 \mu \mathrm{M}$ phospholipid. To determine the effect of the reversible inhibitor benzamidine $10 \mu \mathrm{l}$ Factor $\mathrm{Xa}(3.5 \mathrm{ng} / \mathrm{ml})$ or venom $(12.5 \mathrm{ng} / \mathrm{ml})$ were added directly to a prothrombin activation mixture containing $2 \mathrm{mM}$ benzamidine. The rate of prothrombin activation was calculated from the generation of amidolytic activity as described in the experimental procedures.

\section{Venom-catalyzed prothrombin activation}

To facilitate interpretation and discussion of the data on prothrombin activation, a schematic diagram of the prothrombin molecule and its activation is given in Figure 4. Two cleavages are necessary to convert prothrombin into thrombin and these are at Arg274-Thr275 (site 1) and at Arg323-lle324 (site 2). Both sites are available for proteolytic cleavage and, depending upon the order of bond cleavage, two possible pathways of activation exist. Thus, prothrombin activation by the venom of Echis carinatus leads to meizothrombin formation (pathway A, Ref. [21] ). Factor 


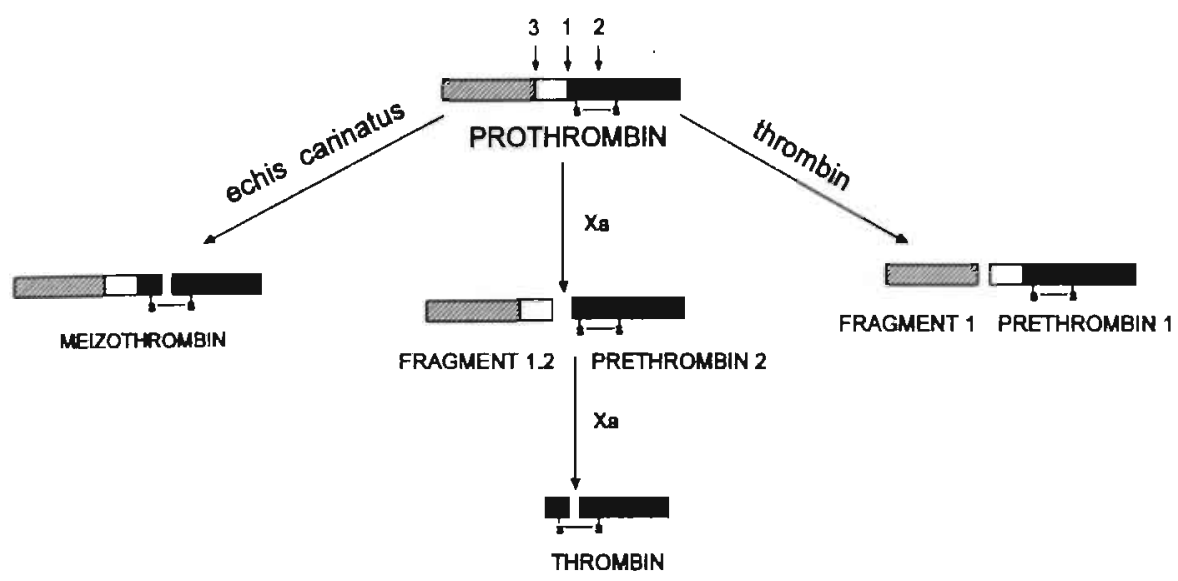

(A)

(B)

(C)

Figure 4. Peptide bonds in bovine prothrombin susceptible to proteolytic cleavage.

Xa-dependent prothrombin activation presumably occurs via pathway B, since only prethrombin 2 has been observed as intermediate [7]. Cleavage at site 2 results in the exposure of the active site since both meizothrombin and thrombin have proteolytic activity, whereas prethrombin 2 does not. Thrombin and meizothrombin have the same activity toward the chromogenic substrate $\$ 2238$ but meizothrombin has a much lower activity toward fibrinogen than thrombin [22]. Thus, one can discriminate between the formation of thrombin and meizothrombin by comparing the generation of amidolytic and clotting activity.

Figure $5 \mathrm{~A}$ shows that, upon activation of prothrombin with the purified venom activator, amidolytic activity was generated much faster than clotting activity. This indicates that during the activation process meizothrombin is formed in excess of thrombin. Meizothrombin is also the main product in the presence of phospholipid, $\mathrm{Ca}^{2+}$, and Factor Va since under these conditions as well a considerable difference between the generation of amidolytic and clotting activity was observed (Figure 5B).

The formation of meizothrombin during prothrombin cleavage by the venom activator was confirmed in experiments in which we followed the peptide bond cleavage pattern during prothrombin activation by sodium dodecyl sulfate-gel electrophoresis. 

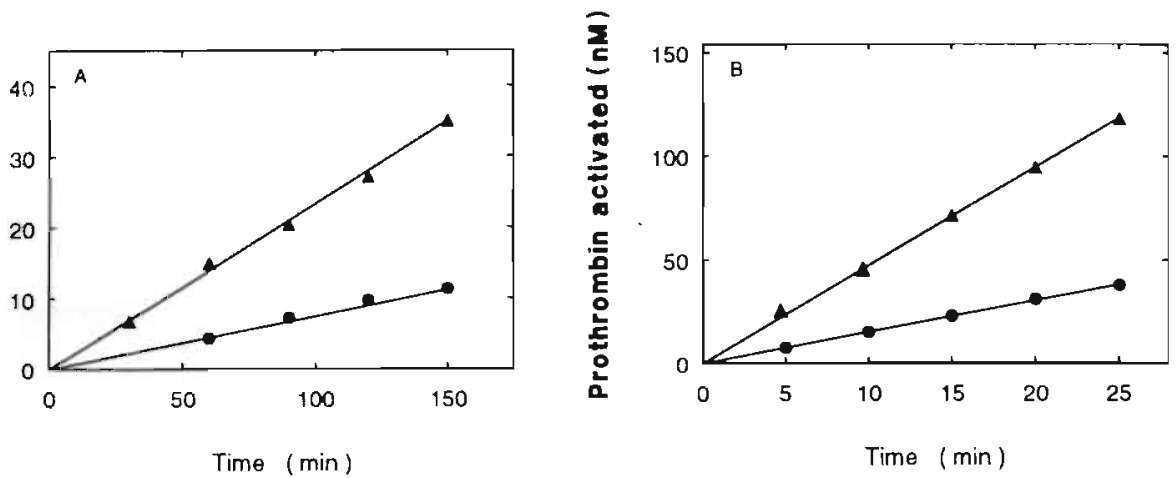

Figure 5. Generation of amidiolytic and clotting activity during prothrombin activation by the purified activatior from the venom of Notechis scutatus scutatus. Prothrombin was activated by the puritied Activator from Notechis scutatus scutatus in a buffer containing $50 \mathrm{mM}$ Tris $(\mathrm{pH} 7.9), 175 \mathrm{mM} \mathrm{NaCl}$ and $5 \mathrm{mM} \mathrm{CaCl} 2$ either in the absence (A) or presence (B) of phospholipid and Factor $\mathrm{Va}$. The amidolytic (A) and clolting activity (O) were measured as described in the experimental procedures.

A: $20 \mu \mathrm{M}$ prothrombin, $1.22 \mu \mathrm{g} / \mathrm{ml}$ purified venom activator.

B: $1 \mu \mathrm{M}$ prothrombin, $0.27 \mathrm{ng} / \mathrm{ml}$ purified venom activator, $50 \mu \mathrm{M}$ phospholipid (20\% PS/80\% PC) and $5 \mathrm{nM}$ factor $\mathrm{Va}$.

Figure 6 shows the time course of prothrombin cleavage by purified venom in the presence of phospholipid, $\mathrm{Ca}^{2+}$, and Factor $\mathrm{Va}$. The activation products generated during the time course of prothrombin conversion by the venom activator are indicated in the figure. ${ }^{1}$

On the nonreduced gel, thrombin and minor amounts of prethrombin 2 are seen (the dark stained activation band is mainly thrombin, since fragment 1.2 stains rather poorly). This indicates that like Factor $\mathrm{Xa}$, the venom activator can cleave both the peptide bonds at site 1 and site 2 in the prothrombin molecule (cf. Figure 4). However, there is an important difference between prothrombin activation by Factor $\mathrm{Xa}$ and the purified venom activator. During prothrombin activation by Factor $\mathrm{Xa}$ there is no

\footnotetext{
1 A complicating factor in the analysis of gel cleavage patterns of prothrombin activation is that the product of the reaction (thrombin) can cleave prothrombin at a third site (site 3 in Figure 4), giving rise 10 fragment 1 and prethrombin 1 [23]. Therefore, the reversible thrombin inhibitor 12581 was present in the activation mixture to avoid appearance of fragment 1 and prethrombin 1 by feedback proteolysis of thrombin on prothrombin or its activation products. The presence of this inhibitor only slightly inhibited prothrombin activation by the purified venom activator.
} 
detectable meizothrombin formation, whereas careful comparison of the nonreduced and reduced gels obtained during venom-catalyzed prothrombin activation indicates that substantial amounts of meizothrombin are formed. Meizothrombin (ct. Figure 4) co-migrates with prothrombin on nonreduced gels, whereas on reduced gels it produces two protein bands (prothrombin fragment 1.2 covalently linked to the A chain of thrombin and the B chain of thrombin). The considerable decrease of intensity of the prothrombin band observed upon reduction and the concomitant increase of the $B$ chain band of thrombin is indicative of meizothrombin formation in this experiment.

A

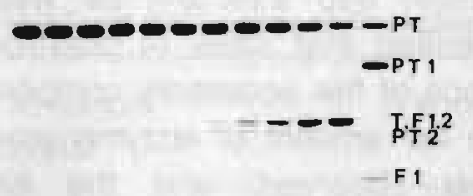

0 5102030456090120165210

INCUBATION TIME (min)
B

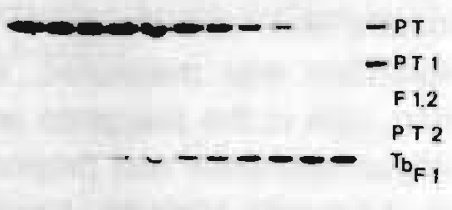

$0 \quad 5102030456090120165210$

INCUBATION TIME (min)

Figure 6. Gel electrophoretic analysis of prothrombin cleavage by the purified venom activator in the presence of phospholipids and Factor Va. Purified venom activator was incubated at $37^{\circ} \mathrm{C}$ with Factor $\mathrm{Va}$ and phospholipids (20\% PS/80\% PC) in a buffer containing $50 \mathrm{mM}$ Tris (pH 7.9), $175 \mathrm{mM} \mathrm{NaCl}, 5 \mathrm{mM} \mathrm{CaCl}$, and $200 \mu \mathrm{M}$ I 2581 . After $5 \mathrm{~min}$, the reaction was started with the addition of prothrombin prewarmed at $37^{\circ} \mathrm{C}$ in the same buffer. The final concentrations reached were: $8.5 \mathrm{ng} / \mathrm{ml}$ activator, $5 \mathrm{nM}$ Factor $\mathrm{Va}, 50 \mu \mathrm{M}$ phospholipid, $3 \mu \mathrm{M}$ prothrombin, and $5 \mathrm{mM} \mathrm{CaCl} 2$. At the time intervals indicated, $50 \mu \mathrm{l}$ samples were withdrawn for gel electrophoresis in the presence of sodium-dodecyl sulfate on 10\% slab gels according to Laemmli [14]. After gel electrophoresis, the gels were stained for protein with Coomassie Brilliant Blue R-250. The lanes at the far right contain a reference mixture of purified prothrombin $(3 \mu \mathrm{g})$, prethrombin $1(4 \mu \mathrm{g})$, and fragment $1(2 \mu \mathrm{g})$. The identification of the band pattern is shown. PT, prothrombin; PT1, prethrombin $1 ; \mathrm{F} 1.2$, fragment 1.2; T, thrombin; PT2, prethrombin 2; $\mathrm{T}_{\mathrm{b}}, \mathrm{B}$ chain of thrombin; $\mathrm{F} 1$, fragment 1 . A, nonreduced samples; $\mathrm{B}$, samples reduced with $5 \% \beta$-mercaptoethanol.

The purified venom activator was also capable of cleaving prothrombin in the absence of accessory components. In this case as well, meizothrombin, thrombin, and prethrombin 2 were observed during prothrombin activation. 
Under these conditions, however, prethrombin 2 is formed in large excess of thrombin and meizothrombin (gels not shown).

\section{Kinetic parameters of prothrombin activation by the purified activator}

The relative rate of prothrombin activation by the Notechis scutatus scutatus activator is stimulated enormously by the presence of phospholipids plus $\mathrm{Ca}_{2}+$ and Factor $\mathrm{Va}$ (Table 4). To gain more insight in the mechanism by which these rate enhancements are brought about, we determined the effect of accessory components on the kinetic parameters of venom-catalyzed prothrombin activation at optimal amounts of $\mathrm{CaCl}_{2}$ and Factor Va. Prothrombin activation was followed by generation of amidolytic activity versus the chromogenic substrate S2238. That means that in these experiments the conversion of prothrombin into thrombin as well as meizothrombin was measured. It was verified that rates of prothrombin activation both in the presence and absence of the accessory components were linear with time and proportional to the amount of enzyme present. Overall Michaelis-Menten kinetics were observed, and the kinetic parameters $\left(\mathrm{K}_{\mathrm{m}}\right.$ for prothrombin and $\left.\mathrm{V}_{\max }\right)$ were obtained from LineweaverBurk plots.

Table 4. Effect of phospholipid, $\mathrm{Ca}^{2+}$, and Factor $\mathrm{Va}$ on the rate of prothrombin activation by the activator from the venom of Notechis scutatus scutatus

\begin{tabular}{lcc}
\hline Activator & $\begin{array}{c}\mathrm{v} \\
\text { pmol prothrombin } \\
\text { activated } / \mathrm{min} / \mu \mathrm{g} \text { venom }\end{array}$ & $\begin{array}{c}\text { Relative } \\
\text { rate }\end{array}$ \\
\hline Venom & 0.0089 & 1 \\
Venom, Ca2+ & 0.0134 & 1.5 \\
Venom, Ca2+, PL & 8.72 & $9.8 \times 10^{2}$ \\
Venom, Ca2+, Va & 1268 & $1.4 \times 10^{5}$ \\
Venom, Ca2+, PL, Va & 26376 & $3.0 \times 10^{6}$ \\
\hline
\end{tabular}

Prothrombin activation was determined as follows. Purified activator in appropriate dilutions was incubated at $37^{\circ} \mathrm{C}$ in $300 \mu$ l of $50 \mathrm{mM}$ Tris $(\mathrm{pH} 7.9), 175 \mathrm{mM} \mathrm{NaCl}$, which when indicated in the table also contained $6.7 \mathrm{mM} \mathrm{CaCl}_{2}$ and/or $6.7 \mathrm{nM}$ Factor $\mathrm{Va}$ and/or $67 \mu \mathrm{M}$ phospholipid (PL) (20\% PS/80\% PC). After 5 min, the reaction was started with the addition of $100 \mu \mathrm{l}$ of prothrombin $\left(4 \mu \mathrm{M}\right.$, prewarmed at $\left.37^{\circ} \mathrm{C}\right)$. Final concentrations reached in the reaction mixture were $1 \mu \mathrm{M}$ prothrombin and when present, $5 \mathrm{mM} \mathrm{CaCl} 2$ and/or $5 \mathrm{nM}$ Factor $\mathrm{Va}$ and/or $50 \mu \mathrm{M}$ phospholipid. The experiment in which prothrombin was activated by the venom activator alone was carried out in the presence of $5 \mathrm{mM}$ EDTA. The rate of prothrombin activation was calculated from the generation of amidolytic activity as described under "Experimental Procedures." 
The kinetic parameters for prothrombin activation by the purified activator in the absence and presence of accessory components are summarized in Table 5. In the absence of components, the purified activator was a poor enzyme, as judged by the very high $\mathrm{Km}$ for prothrombin $(105 \mu \mathrm{M})$ and a low $V_{\max }$. The presence of $50 \mu \mathrm{M}$ phospholipid caused a 500 -fold decrease of the $K_{m}(0.2 \mu M)$, whereas $V_{\max }$ was hardly affected. Factor $V a$ increased the $V_{\max }$ approximately 3500 -fold and caused a 10-fold decrease in the $\mathrm{K}_{\mathrm{m}}$. In the presence of both factor $\mathrm{Va}$ and phospholipid, the kinetic parameters were the most favorable $\left(\mathrm{K}_{\mathrm{m}}=0.16 \mu \mathrm{M}\right.$, and $\mathrm{V}_{\max } 27.9 \mathrm{nmol}$ of prothrombin activated per $\mathrm{min} / \mu \mathrm{g}$ of venom activator).

Table 5. Kinetic parameters of prothrombin activation by the purified prothrombin activator from the venom of Notechis scutatus scutatus

\begin{tabular}{|c|c|c|c|}
\hline $\begin{array}{l}\text { Prothrombin } \\
\text { activator }\end{array}$ & $\begin{array}{c}\text { [Venom] } \\
\mathrm{nM}\end{array}$ & $\begin{array}{l}\mathrm{K}_{\mathrm{m}} \\
\mu \mathrm{M}\end{array}$ & $\begin{array}{l}V_{\max } \\
\text { nmol prothrombin } \\
\text { activated } / \min / \mu \mathrm{g}\end{array}$ \\
\hline Venom, $\mathrm{Ca}^{2+}$ & 27.2 & 105 & 0.0025 \\
\hline Venom, $\mathrm{Ca}^{2}+, \mathrm{PL}$ & 6.8 & 0.20 & 0.0056 \\
\hline Venom, $\mathrm{Ca}^{2}+, \mathrm{Va}$ & 0.0068 & 9.5 & 8.35 \\
\hline Venom, $\mathrm{Ca}^{2+}, \mathrm{PL}, \mathrm{Va}$ & 0.0027 & 0.16 & 27.9 \\
\hline
\end{tabular}

The kinetic parameters of prothrombin activation were determined as follows. Purified venom activator in appropriate dilutions, either in the absence or presence of Factor $\mathrm{Va}$ and/or phospholipid (PL) vesicles (20\% PS/80\% PC), was preincubated at $37^{\circ} \mathrm{C}$ in $300 \mu \mathrm{l}$ of buffer containing $50 \mathrm{mM}$ Tris (pH 7.9), $175 \mathrm{mM} \mathrm{NaCl}, 5 \mathrm{mM} \mathrm{CaCl} 2$, and $0.5 \mathrm{mg} / \mathrm{ml}$ human serum albumin. After $5 \mathrm{~min}$, prothrombin activation was started with the addition of $100 \mu \mathrm{l}$ of the same buffer (prewarmed at $37^{\circ} \mathrm{C}$ ) containing varying amounts of prothrombin. The final concentrations reached were: venom activator as indicated in the table, $5 \mathrm{mM} \mathrm{CaCl}_{2}$, varying amounts of prothrombin and when present, $5 \mathrm{nM}$ Factor $\mathrm{Va}$ and/or $50 \mu \mathrm{M}$ phospholipid. The rates of prothrombin activation were calculated from the generation of amidolytic activity as described under "Experimental Procedures." The kinetic parameters $K_{m}$ and $V_{\max }$ were obtained from Lineweaver-Burk plots after statistical analysis as described by Eisenthal and Comish-Bowden [24].

The effects of Factor $\mathrm{Va}$ and phospholipids on the kinetic parameters of venom-catalyzed prothrombin activation are similar to the effects of these accessory components on prothrombin activation by Factor $\mathrm{Xa}$ [1]. Factor $\mathrm{Xa}$ in the presence of Factor $\mathrm{Va}$ and phospholipid can catalyze the activation of approximately 3,000 prothrombin molecules/min [1,2,5]. For prothrombin activation by the purified venom activator in the presence of phospholipid 
and saturating amounts of Factor $V_{a}$, the $V_{\max }=27.9 \mathrm{nmol}$ of prothrombin activated per $\mathrm{min} / \mu \mathrm{g}$ of venom activator. Assuming a molecular weight of 54,000 for the venom activator, this would correspond to a turnover number of 1,500 molecules of prothrombin activated per $\mathrm{min} / \mathrm{mol}$ of venom activator, which is close to that observed for the Factor Xa-Factor Va complex. As for Factor Xa-dependent prothrombin activation, the kinetic parameters for prothrombin activation by the venom activator vary when the amount of phospholipid in the activation mixture is changed (Table 6).

Table 6. Effect of phospholipid on the kinetic parameters of venom-catalyzed prothrombin activation

\begin{tabular}{ccc}
\hline $\begin{array}{c}\text { Phospholipid } \\
(\mu \mathrm{M})\end{array}$ & $\begin{array}{c}K_{\mathrm{m}} \\
(\mu \mathrm{M})\end{array}$ & $\begin{array}{c}V_{\text {max }} \\
\text { (nmoles prothrombin } \\
\text { activated } / \mathrm{min} / \mu \mathrm{g} \text { venom) }\end{array}$ \\
\hline 20 & 0.109 & 0.0036 \\
30 & 0.161 & 0.0048 \\
50 & 0.205 & 0.0056 \\
100 & 0.443 & 0.0084 \\
200 & 1.06 & 0.0127
\end{tabular}

The kinetic parameters of prothrombin activation were measured at different concentrations of phospholipid (20\% PS/80\% PC) in the absence of Factor Va as described in the legend to table 4.

A 10-fold increase of the phospholipid concentration causes a 10-fold increase of the $\mathrm{K}_{\mathrm{m}}$ and a 3.5 -fold increase of the $V_{\text {max. }}$. These large changes brought about by the accessory components explain the effect of these components on the relative rate of the reaction (Table 4). These changes in the kinetic parameters can be satisfactorily explained by a model in which phospholipid-bound prothrombin is activated by a phospholipidbound activator. In such a model [5]. the effective prothrombin concentration available for interaction with the venom activator will be decreased at increasing phospholipid concentrations due to prothrombin binding to the excess of phospholipid surface present. Therefore, at higher phospholipid concentrations more prothrombin will be required to saturate the phospholipid-bound venom activator, which results in an increase of the observed $\mathrm{K}_{\mathrm{m}}$. The increase of $\mathrm{V}_{\max }$ at higher phospholipid concentrations is explained by the fact that more activator participates in prothrombin 
activation under these conditions, since more activator is bound to the phospholipid surface.

\section{Chromogenic substrate conversion by the purified venom activator}

The purified venom activator was also able to cleave a number of commercially available chromogenic substrates that were designed for Factor Xa. Maximal activity was observed against the chromogenic substrate CBS 31.39. However, bovine Factor Xa was approximately 120fold more active. Interestingly, the rate of chromogenic substrate conversion by the venom activator was stimulated significantly in the presence of Factor Va. In agreement with the literature we did not find a stimulatory effect of Factor Va on the cleavage of chromogenic substrates by Factor Xa.

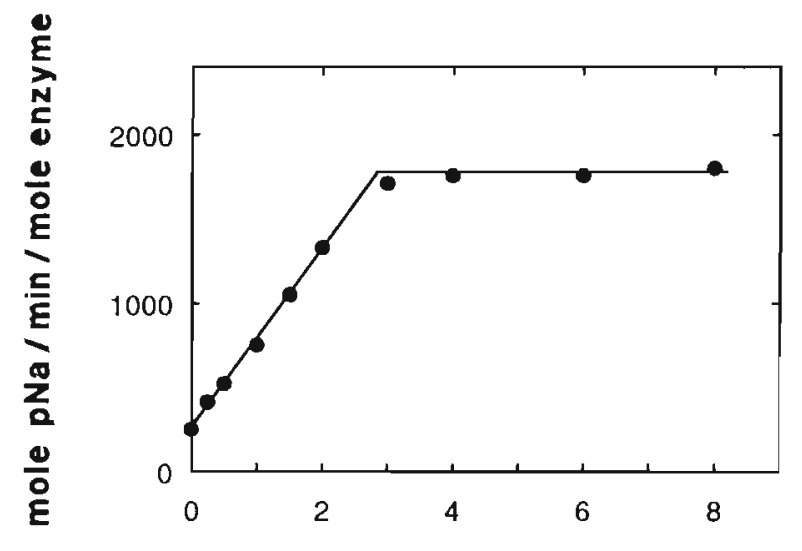

Factor $V_{a}(n M)$

Figure 7. Effect of Factor Va on the amidolytic activity of Notechis scutatus scutatus venom. The effect of bovine Factor $\mathrm{Va}$ on the rate of cleavage of the chromogenic substrate CBS 31.39 was determined at $37^{\circ} \mathrm{C}$ in plastic disposable cuvettes (1 $\mathrm{cm}$ pathlength) on a SLM- Aminco DW2-C spectrophotometer set In the dual wavelength mode at $405-500 \mathrm{~nm}$. Venom activator and Factor Va were incubated at $37^{\circ} \mathrm{C}$ in $950 \mu \mathrm{l} 50 \mathrm{mM}$ Tris ( $\mathrm{pH} 7.9$ ), $175 \mathrm{mM} \mathrm{NaCl}, 5 \mathrm{mM} \mathrm{CaCl} 2$ and $0.5 \mathrm{mg} / \mathrm{ml} \mathrm{HSA}$. After $5 \mathrm{~min}$ $50 \mu \mathrm{I}$ CBS 31.39 was added and the absorbance change was recorded. The rate of $p$ nitroanilide formation was calculated using a molar exctinction coefficient of 8,600 for $p$ nitroanilide The final concentrations in the cuvette were: $2.7 \mathrm{nM}$ venom activator, Factor $\mathrm{Va}$ as indicated in the figure and $435 \mu \mathrm{M}$ CBS 31.39.

Figure 7 shows that the rate of $p$-nitroanilide formation by the purified venom activator $(2.7 \mathrm{nM})$ increased linearly with increasing amounts of Factor $\mathrm{Va}$ until at $3 \mathrm{nM}$ Factor $\mathrm{Va}$ a plateau was reached. This indicates that a 1:1 
stoichiometric complex is formed between Factor $\mathrm{Va}$ and the purified activator and that the affinity of venom activator for Factor $V a$ is high. The maximum stimulation that we observed with Factor Va was about 7-fold. Therefore, even in the presence of Factor $\mathrm{Va}$, the rate of chromogenic substrate conversion by the venom activator was still 17 -fold lower than that observed for Factor Xa

\section{Comparison of the prothrombin activator from the venom of Notechis scutatus scutatus with venom prothrombin activators from other snakes belonging to the Australian Elapidae?}

The catalytic activity of prothrombin activators from venoms of the Australian Elapidae is greatly enhanced by the presence of accessory components (phospholipids and/or factor $\mathrm{Va}$ ) of the prothrombinase complex. These venom prothrombin activators can be subdivided into two groups: (1) the Notechis-like prothrombin activators from the venoms of Notechis scutatus, Notechis ater niger, Notechis ater humphreysi,Tropidechis carinatus, Pseudechis porphyriacus and Hoplocephalus stephensii, which are greatly stimulated by phospholipid, calcium ions as well as factor $\mathrm{Va}$ [25-27], and (2) the Oxyuranus-like prothrombin activators from the venoms of Oxyuranus scutelatus, Oxyuranus microlepidotus and Pseudonaja textilis which are greatly enhanced by the presence of phospholipids and calcium ions alone and are not further stimulated by factor $\mathrm{Va}$ [28-33]. The structural properties of the venom activators of these two groups are considerably different. The Notechis-like prothrombin activators strongly resemble factor $X \mathrm{X}$. The data presented in this chapter show that the purified activator from Notechis scutatus scutatus is a glycoprotein with an apparent molecular weight of $54,000$ that consists of a heavy chain ( $\mathrm{Mr} 32,000)$ and a light chain ( $\mathrm{Mr}$ 23,000 ) linked to each other via a disulfide bridge. The active site is located on the heavy chain, as in factor $\mathrm{Xa}$. The Oxyuranus-like prothrombin activators are not stimulated by factor $\mathrm{Va}$ and this appears to be due to their remarkable structure. The purified activator from Oxyuranus scutellatus scutellatus is a large protein with a molecular weight of 300,000 , which is composed of a factor Va-like cofactor unit (two subunits of $\mathrm{Mr} 110,000$ and Mr 80,000) non covalently associated with a factor Xa-like enzyme unit (two

2 Data are taken from: Speijer H., Govers-Riemslag J.W.P., Zwaal R.F.A. and Rosing J. (1986) J. Biol. Chem. 261, 13258-13267 
disulfide linked polypeptide chains of $\mathrm{Mr} 30,000)$ [31,32]. All prothrombin activators from the Australian Elapidae are greatly stimulated by the presence of phospholipids. The purified prothrombin activator from Notechis scutatus scutatus and from Oxyuranus scutellatus scutellatus both contain $\gamma$ carboxyglutamic acid or Gla-residues and it is likely that these Gla residues are involved in the binding of these proteins to the membrane surface.

Since the purified prothrombin activator from Notechis scutatus scutatus resembles Factor $\mathrm{Xa}$ with respect to a number of essential catalytic properties (interactions with phospholipids, Factor Va and prothrombin), it would be interesting to compare the amino acid sequence of the venom activator with that of Factor $\mathrm{Xa}$ in order to define from sequence homologies the peptide regions in these protein molecules that are involved in the above-mentioned interactions.

\section{References}

1. Rosing J., Tans G., Govers-Riemslag J.W.P., Zwaal R.F.A. and Hemker H.C. (1980) The role of phospholipids and factor $\mathrm{Va}$ in the prothrombinase complex, J. Biol. Chem. 255, 274-283

2. Nesheim M.E., Taswell J.B. and Mann K.G. (1979) The contribution of bovine factor $V$ and factor $V a$ to the activity of prothrombinase, J. Biol. Chem. 254, 1095210962

3. Lindhout T., Govers-Riemslag J.W.P., van de Waart P., Hemker H.C. and Rosing J. (1982) Factor Va-factor Xa interaction. Effects of phospholipid vesicles of varying composition, Biochemistry 21 5494-5502

4. Pusey M.L. and Nelsestuen G.L. (1983) The physical significance of $\mathrm{Km}$ in the prothrombinase reaction, Biochem. Biophys. Res. Commun. 114, 526-532

5. van Rijn J.L.M.L., Govers-Riemslag J.W.P., Zwaal R.F.A. and Rosing J. (1984) Kinetic studies of prothrombin activation: Effect of factor $\mathrm{Va}$ and phospholipids on the formation of the enzyme substrate complex, Biochemistry 23, 4557-4564

6. Jobin F. and Esnouf M.P. (1966) Coagulant activity of Tiger snake (Notechis scutatus scutatus) venom, Nature 211, 874-875

7. Owen W.G., Esmon C.T. and Jackson C.M. (1974) The conversion of prothrombin to thrombin. I. Characterization of reaction products formed during the activation of bovine prothrombin, J. Biol. Chem. 249, 594-605

8. Fujikawa K., Legaz M.E. and Davie E.W. (1972) Bovine factor $X(1)$ and $X(2)$ (Stuart factor) isolation and characterization, Biochemistry 11, 4882-4891

9. Fujikawa K., Legaz M.E. and Davie E.W. (1972) Bovine factor X(1) (Stuart factor) mechanism of activation by a protein from Russel's viper venom, Biochemistry 11 . 4892-4899

10. Chase T. Jr., and Shaw E. (1969) Comparison of the esterase activities of trypsin plasmin and thrombin on guanidinobenzoate esters - titration of the enzymes, Biochemistry 8, 2212-2224 
11. Smith R.L. (1973) Titration of activated bovine factor X, J. Biol. Chem. 248, 24182423

12. Lowry O.H., Rosebrough N.J., Farr A.L. and Randall R.J. (1951) Protein measurement with the folin phenol reagent, J. Biol. Chem. 193, 265-275

13. Böttcher C.J.F., van Gent C.M. and Pries C. (1961) A rapid and sensitive sub-micro phosphorus determination, Anal. Chim. Acta 24, 203-207

14. Laemmli U.K. (1970) Cleavage of structural protein during the assembly of the head bacteriophage T4, Nature 227,680-685

15. Kettner C.A. and Shaw E.N. (1981) Inactivation of trypsin-like enzymes with peptides of arginine chloromethyl ketone, Methods Enzymol. 80, 826-842

16. Davis B.J. (1964) Disc electrophoresis II. Method and application to human serum proteins, Ann. N. Y. Acad. Sci. 121, 404-427

17. Kuwada M. and Katayama K. (1981) A high-performance liquid chromatographic method for the simultaneous determination of gamma-carboxyglutamic acid and glutamic acid in proteins, bone, and urine, Anal Biochem. 117, 259-265

18. Kuwada M. and Katayama K. (1983) An improved method for the determination of $\gamma$-carboxyglutamic acid in proteins, bone and urine, Anal. Biochem. 131, 173-179

19. Magnusson S., Sottrup-Jensen L., Petersen T.E., Morris H.R. and Dell A. (1974) Primary structure of the vitamin K-dependent part of prothrombin, FEBS Letters 44, 189-193

20. Bucher D., Nebelin E., Thomson J. and Stenflo, J. (1976) Identification of $\gamma$ carboxyglutamic acid residues in bovine factor $\mathrm{IX}$ and $\mathrm{X}$ and in a new vitamin $\mathrm{K}$ dependent protein, FEBS Letters 68, 293-296

21. Morita T., Iwanaga S. and Suzuki T. (1976) The mechanism of activation of bovine prothrombin by an activator isolated from Echis carinatus venom and characterization of the new active intermediates, J. Biochem. 79, 1089-1108

22. Kornalik F. and Blombäck B. (1975) Prothrombin activation induced by Ecarin. A prothrombin converting enzyme from Echis carinatus venom, Thromb. Res. 6, 5363

23. Seegers W.H., Marciniak E., Kipfer R.K. and Yasunaga K. (1967) Isolation and some properties of prethrombin and autoprothrombin III, Arch. Biochem. Biophys. 121, 372-383

24. Eisenthal R. and Cornish-Bowden A. (1974) The direct linear plot. A new graphical procedure for estimating enzyme kinetic parameters, Biochem. J. 139, 715-720

25. Chester A. and Crawford G.P.M. (1982) In vitro coagulant properties of venoms from australian snakes, Toxicon 20, 501-504

26. Tans G., Govers-Riemslag J.W.P., van Rijn J.L.M.L. and Rosing J. (1985) Purification and properties of a prothrombin activator from the venom of Notechis scutatus scutatus, J. Biol. Chem. 260, 9366-9372

27. Williams $V$. and White J. (1989) Purification and properties of a procoagulant from peninsula tiger snake (Notechis ater niger) venom, Toxicon 27, 773-779

28. Marshall L.R. and Herrmann R.P. (1983) Coagulant and anticoagulant actions of australian snake venoms, Thromb. Haemostas. 50, 707-711

29. Pirkle H., Mclntosh M., Theodor J.and Vemon S. (1972) Activation of prothrombin with Taipan snake venom, Thromb. Res. 1, 559-568

30. Walker F.J., Owen W.G. and Esmon C.T. (1980) Characterization of the prothrombin activator from the venom of Oxyuranus scutellatus scutellatus (Taipan venom), Biochemistry 19, 1020-1023 
31. Speijer H., Govers-Riemslag J.W.P., Zwaal R.F.A. and Rosing J. (1986) Prothrombin activation by an activator from the venom of Oxyuranus scutellatus (Taipan snake), J. Biol. chem. 261, 13258-13267

32. Govers-Riemslag J.W.P., Speijer H., Zwaal R.F.A. and Rosing J. (1988) Purification and characterization of the prothrombin activator from Oxyuranus scutellatus (Taipan snake) Hemostasis and animal venoms (Pirkle, $\mathrm{H}$. and Markland, F.S., eds.), pp 41-53, New York, Basel: Marcel Dekker, Inc.

33. Masci P.P., Whitaker A.N. and DeJersey J. (1988) Purification and characterization of a prothrombin activator from the venom of the Australian brown snake, Pseudonaja textilts textilis, Biochem. Int. 17, 825-835 


\section{Chapter 5}

\section{Membranes and Blood Coagulation}




\section{Introduction}

In vivo blood coagulation is mediated by highly specific proteolytic enzyme complexes assembled on the surface of cellular membranes [1-4]. These socalled procoagulant membrane surfaces can be provided by artificial phospholipid vesicles [5-9], activated platelets [10-13], leukocytes, lymphocytes, monocytes [14,15], endothelial cells [16,17] and cancer cells [see ref 13 and references there in]. Assembly of the proteolytic enzyme complexes on cellular or sub-cellular membranes is required for optimal generation of thrombin. Studies with artificial membranes have been mainly focused on the prothrombinase complex [7,18-20] and, to a lesser extent, on the tissue factor - factor VIIa $[21,22]$ and factor VIIIa - factor IXa tenase complexes $[8,9]$. It is generally accepted that the membranes in these coagulation factor activating complexes act as a catalytic surface onto which the proteins of the complexes bind [4]. These surface interactions lead to increased rates of coagulation factor activation by raising the local enzyme and substrate levels and promoting the interactions and reactions between the participating proteins.

\section{Chemical stuctures of phospholipid molecules}

Every living cell is surrounded by a plasma membrane, which separates the cell constituents from the external environment. The basic structure of a biological membrane is a bilayer of phospholipid molecules. With the exception of sphingomyelin, phospholipid molecules consist of a glycerol backbone usually esterified to two fatty acyl side chains and a polar headgroup, which in most cases is a small organic molecule that is linked via a phosphate group to the glycerol backbone. This general structure of a phospholipid molecule is shown in Figure1.

Phospholipid molecules have dual solubility properties, since they consist of a hydrophylic part (the polar headgroup) and a hydrophobic part (the fatty acyl side chains). Such molecules with dual-solubility properties are termed amphipathic or amphiphilic. When phospholipid molecules, with two fatty acyl side chains, are suspended in water they assemble into multilamellar liposomes or hexagonal or micellar structures. When multilamellar liposomes are subjected to sonication they transform into so-called small unilamellar vesicles that consist of a single bilayer of phospholipid molecules. The phospholipid molecules in small unilamellar vesicles orient 
in such a way that the polar headgroups face the surrounding aqueous medium on either side of the membrane, and the nonpolar fatty acyl side chains associate end to end in the nonpolar membrane interior.

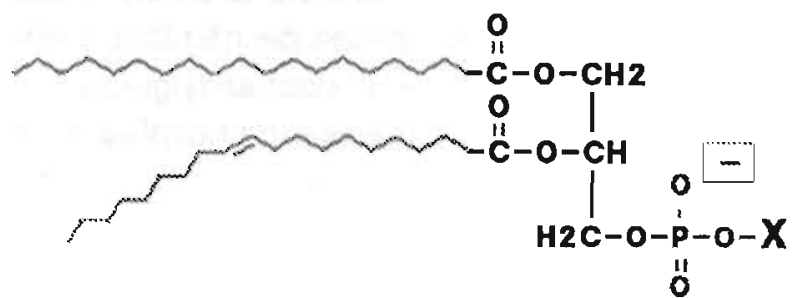

(a)

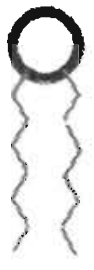

(b)

Figure 1. Schematic illustration of a phospholipid molecule. (a). A phospholipid molecule usually consists of a glycerol backbone, two fatty acyl side chains (indicated in this figure with zigzag lines) and a polar headgroup. The polar headgroup consists of a negatively charged phosphate group that may be esterified with an organic component $X$. (b). This diagram is widely used to depict a phospholipid molecule. The circle represents the polar headgroup of the molecule and the zigzag lines indicate the fatty acyl side chains.

The organisation of lipids in a bilayer structure was proposed in the late 1960s and refined in 1972 by Singer and Nicolson in their fluid mosaic membrane model [ref 23]. This bilayer structure fulfils the dual solubility property of membrane phospholipids.

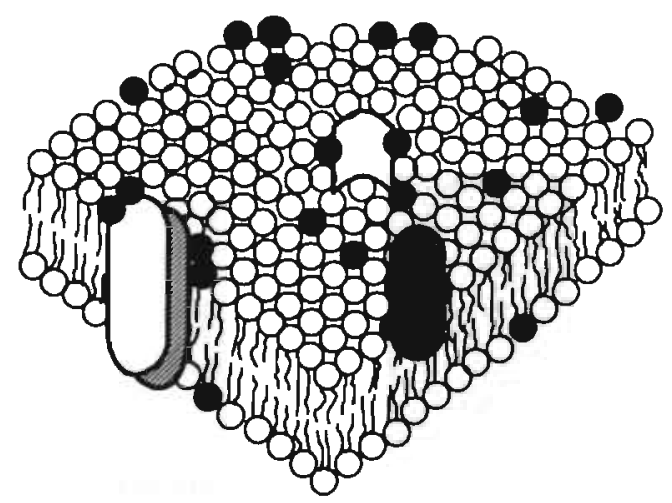

Figure 2. Arrangement of phospholipid molecules in a bilayer structure. The open and closed circles represent the different polar headgroups facing the surrounding aqueous medium. The fatty acyl side chains, which are illustrated by wavy lines, form the nonpolar inner core of the membrane. This figure also includes membrane proteins. 
The chemical and physical properties of phospholipid membranes, which appear to be very important for their role in blood coagulation can be altered by variation of polar headgroups and by the chemical structure of the fatty acyl side chains of the phospholipid molecules. The fatty acyl side chains can differ in hydrocarbon chain length and may have different degrees of unsaturation (Table 1). The polar headgroup can be negatively charged at physiological $\mathrm{pH}$ like in phosphatidylserine, phosphatidylglycerol or phosphatidic acid, or may have a net neutral charge like in phosphatidylcholine or phosphatidylethanolamine (Fig. 3).

Table 1. Fatty acyl side chains of phospholipids that are used in experiments presented in this thesis

\begin{tabular}{ccl}
$\begin{array}{c}\text { Number of } \\
\text { Carbon atoms }\end{array}$ & $\begin{array}{c}\text { Number of } \\
\text { double bonds }\end{array}$ & Name \\
\hline 14 & 0 & Myristoyl \\
16 & 0 & Palmitoyl \\
16 & 1 & Palmitoleoyl \\
18 & 0 & Stearoyl \\
18 & 1 & Oleoyl \\
18 & 2 & Linoleoyl \\
18 & 3 & Linolenoyl \\
\hline
\end{tabular}

Fatty acyl side chains in biological systems usually contain an even number of carbon atoms and the double bond of most unsaturated fatty acyl side chains has the cis configuration
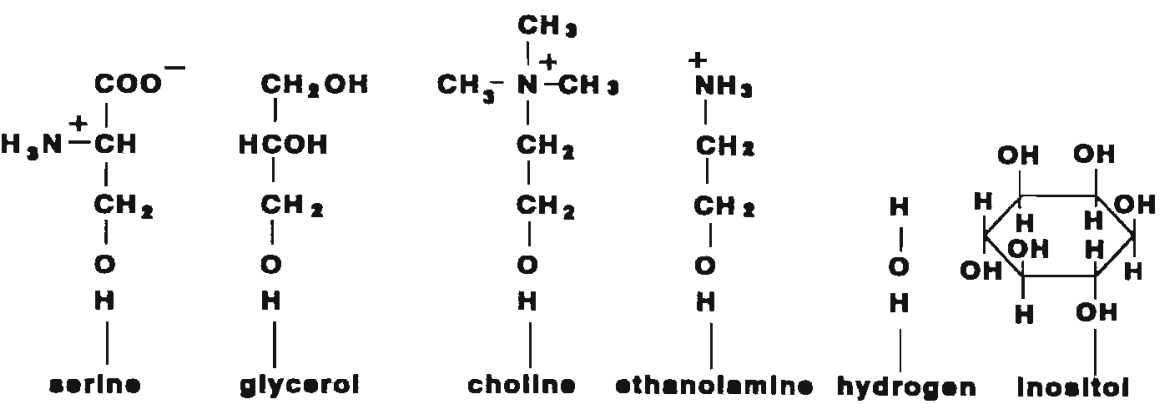

Figure 3. Chemical stuctures of the most common headgroups $X$ found in phospholipid membranes related to blood coagulation. The site at which the molecule is esterified with the phosphate group is indicated by the dashed line. 


\section{Physical characteristics of phospholipid membranes}

Studies of artificial phospholipid bilayers have provided a great deal of information about the physical properties of biological membranes. The fatty acyl side chains of the phospholipid molecules determine a number of important physical properties of phospholipid membranes. In bilayers the fatty acyl side chains may arrange in an ordered rigid state or in a disordered fluid state. The arrangement of the bilayer, which appears to be dependent on the chemical structures of the fatty acyl side chains, determines the membrane fluidity. This physical condition of the membrane depends on the temperature and is described by the phase transition temperature $\left(T_{m}\right)$. Below the transition temperature, membranes are in the gel or solid phase and when the temperature is raised above $T_{m}$ membranes are in the liquid crystalline or fluid phase. The actual temperatures at which phase transitions in biological membranes occur depend on the length and on the degree of unsaturation of the fatty acyl side chains of the lipid molecules that constitute the membrane. A high concentration of unsaturated fatty acids generally results in bilayers with a low phase transition temperature, whereas membranes which contain a high concentration of saturated fatty acyl side chains usually have higher transition temperatures.

Another important feature, determined by the fatty acyl side chains, is the packing density of the phospholipid molecules in the membrane. Condensed packing of phospholipid molecules occurs when saturated fatty acyl side chains are present. However, when the membrane phospholipids contain unsaturated fatty acyl side chains the hydrocarbon chains are bended at the positions of the cis double bonds, which increases the distance between the phospholipid molecules and results in a more loosely packed membrane.

Both the fluidity of the membrane and the packing density of the phospholipid molecules in the membrane may be an important parameter for its procoagulant activity. The influence of variation of the fatty acyl side chains of phospholipid molecules on the prothrombin-converting activity of membranes is reported in Chapter 8 of this thesis. 


\section{Platelet procoagulant activity}

Blood platelets (thrombocytes) are surrounded by an outer membrane, which is composed of lipids and proteins. The most important function of the platelet plasma membrane is to provide a permeability barrier between the cell constituents and the external environment. The phospolipids in the platelet membrane appear to be asymmetrically distributed, which means that the inner and outer surfaces of the membrane bilayer contain different proportions of various (phospho)lipids [24]. The outer leaflet of the plasma membrane of non-activated platelets is primarily composed of the neutral choline-containing lipids phosphatidylcholine (PC) and sphingomyelin, whereas phosphatidylinositol (PI) and the aminophospholipids, phosphatidylserine (PS) and phosphatidylethanolamine (PE) are predominantly confined to the inner bilayer half of the membrane. This lipid composition in the plasma membrane is such that the unactivated platelet is hardly able to stimulate coagulation reactions. Lipid asymmetry is considered to be maintained by restrictions on spontaneous transbilayer movement (flip-flop) of phospholipids from one side of the membrane to the other. However, when platelets become activated with collagen and thrombin the asymmetric distribution of lipids is lost by a rapid transbilayer movement, of among others, the negatively charged phosphatidylserine from the inner to the outer leaflet of the plasma membrane, a process that results in the formation of a procoagulant membrane surface $[11,12,25]$.

Furthermore it is important to mention that platelet activation is accompanied by the formation and detachment of small membrane vesicles from the platelet cell surface, a process which is called shedding [26]. These microparticles have also lost their membrane lipid asymmetry and usually some $25-30 \%$ of the total platelet procoagulant activity is associated with these microvesicles [27-29].

In addition, it has been proposed that the procoagulant platelet membrane surface also contains specific protein receptors, which participate in the assembly of the coagulation factor activating complex on the platelet membrane.

That the process of flip-flop does not occur spontanously, but is induced by proteins which activate platelets (thrombin and collagen) and are generated or exposed at the site of vascular injury, limits the exposure of a procoagulant surface and haemostatic plug formation to a localized region where platelet aggregation occurs. 


\section{Kinetic aspects. The role of phospholipids in prothrombin acti- vation}

Procoagulant membranes function by providing a surface onto which the factor $\mathrm{Xa}$ - factor $\mathrm{Va}$ complex and the substrate prothrombin will bind. Through binding the local concentration of the different protein components is increased, which promotes their interactions and results in an increased velocity of prothrombin activation. The actual rate of prothombin activation by the prothrombinase complex is determined by (a) the $\mathrm{K}_{\mathrm{m}}$ for prothrombin, the affinity of the substrate for its enzyme, (b) the $V_{\max }$ of prothrombin activation, the maximal velocity of the reaction obtained under optimal reaction conditions, when the enzyme is saturated with the substrate, and (c) the $K_{d}$ or dissociation constant for the factor $\mathrm{Xa}-\mathrm{Va}$ complex on the membrane surface.

Phospholipids affect the $\mathrm{K}_{\mathrm{m}}$ for prothrombin. Prothrombin activation in free solution is characterized by a high $\mathrm{K}_{\mathrm{m}}(9 \mu \mathrm{M})$, which means that a very low reaction rate is obtained under physiological conditions. In the presence of membranes which contain anionic phospholipids, the $\mathrm{Km}$ for prothrombin drops to values $(-0.15 \mu \mathrm{M})$ below the plasma concentration of prothrombin and as a result the reaction rates increase and the activation of prothrombin occurs optimal with respect to the substrate concentration $[7,19,20,30]$.

The cofactor factor $\mathrm{Va}$ promotes the binding of factor $\mathrm{Xa}$ to the membrane surface [31] and the binding of factor $X a$ to factor $V a$ results in a 3,000-fold increase of the $V_{\max }[7,19,32,33]$. The kinetic properties of the prothrombinase complex also apply to the other coagulation factor activating complexes.

It seems necessary that procoagulant membrane surfaces have to contain anionic phospholipids. Not only the surface charge of the membrane appears to be important, but also the chemical structure of the polar headgroups of the phospholipid molecules which constitute the membrane. This is concluded from the fact that vesicles which contain the anionic phospholipid phosphatidylserine show the highest prothrombinase activity, and are the least susceptible to surface charge [34]. The influence of the chemical structure of the polar headgroup of anionic lipids on the prothrombin-converting activity of membranes is reported in chapter 6 of this thesis. 


\section{Protein-phospholipid interactions. A model for membrane-bound prothrombin activation}

The interaction of coagulation proteins with membrane phospholipids appears to be essential for blood coagulation. Specific interactions between these proteins and the membranes are dependent on critical features of both the membrane and the protein. Artificial bilayers are more frequently used in experiments than natural membranes because they can be assembled from well-defined lipid mixtures.

The amino-terminal region of the vitamin K-dependent coagulation factors contains the so-called $\gamma$-carboxyglutamic acids (Gla's), which interact with the anionic phospholipids in the presence of calcium ions [18]. Prothrombin binds to membranes composed of a mixture of phosphatidylserine and phosphatidylcholine in an ionic strength independent manner [35] in contrast to membranes containing other anionic phospholipids. A binding which is insensitive to ionic strength variation indicates that the contribution of electrostatic interactions is not important and this fact supports a chelation model [36]. The chelation model proposed for the binding of vitamin $\mathrm{K}$ dependent proteins to phosphatidylserine-containing membranes is with respect to its basic structure similar with the Calcium-EDTA complex and contains 6 coordinate bonds. Two protein Gla residues and a hypothetical ligand $X$ supplied by the protein have been proposed to form a chelatecomplex with a calcium ion and with the phosphate, amino and carboxyl groups of phosphatidylserine.

Membranes which contain negatively charged phospholipids are the most effective procoagulant surfaces. Recently, it has been reported, however, that membranes that are solely composed of the neutral phospholipid, phosphatidylcholine, can under certain experimental conditions also stimulate the activation of vitamin K-dependent coagulation factors $[21,22,37]$. It has been suggested that only the activities of complexes with integral membrane cofactor proteins can be increased by membranes that are solely composed of the neutral phospholipid, phosphatidylcholine [4]. However, phosphatidylcholine membranes can also promote prothrombin activation [38]. Phosphatidylcholines (sometimes called lecithins) are zwitterionic phospholipids and membranes composed of phosphatidylcholine are therefore also charged and contain equal amounts of negative and positive charges, which results in a net neutral membrane. In chapter 7 the role of membranes, solely composed of phosphatidylcholine, in prothrombin activation is described. 


\section{References}

1. Zwaal R.F.A. and Hemker H.C. (1982) Blood cell membranes and haemostasis, Haemostasis 11, 12-39

2. Mann K.G. (1987) The assembly of blood clotting complexes on membranes, TIBS $12,229-233$

3. Nemerson Y. (1988) Tissue factor and hemostasis, Blood 71, 1-8

4. Mann K.G., Nesheim M.E., Church W.R., Haley P. and Krishnaswamy S. (1990) Review article: surface-dependent reactions of the vitamin K-dependent enzyme complexes, Blood 76, 1-16

5. Nelsestuen G. L. (1978) Interactions of vitamin K-dependent proteins with calcium ions and phospholipid membranes, Fed.Proc. 37, 2621-2625

6. Jackson C.M. and Nemerson Y. (1980) Blood coagulation, Ann. Rev. Biochem. 49, 765-811

7. Rosing J., Tans G., Govers-Riemslag J.W.P., Zwaal R.F.A. and Hemker H.C. (1980) The role of phospholipids and factor Va in the prothrombinase complex, $J$. Biol. Chem. 255, 274-283

8. van Dieijen G., Tans G., Rosing J. and Hemker H.C. (1981) The role of phospholipid and factor VIlla in the activation of bovine factor $X_{1} J$. Biol. Chem. 256, 3433-3442

9. van Dieijen G., van Rijn J.L.M.L., Govers-Riemslag J.W.P., Hemker H.C. and Rosing J. (1985) Assembly of the intrinsic factor $X$ activating complex-Interactions between factor IXa, factor VIIla and phospholipid, Thromb. Haemostas. 53, 396400

10. Kane W.H., Lindhout M.J., Jackson C.M. and Majerus P.W. (1980) Factor Vadependent binding of factor Xa to human platelets, J. Biol. Chem. 255, 1170-1174

11. Bevers E.M., Comfurius P., van Rijn J.L.M.L., Hemker H.C. and Zwaal R.F.A. (1982) Generation of prothrombin-converting activity and the exposure of phosphatidylserine at the outer surface of platelets, Eur. J. Biochem. 122, 429-436

12. Rosing J., van Rijn J.L.M.L., Bevers E.M., van Dieijen G., Comfurius P. and Zwaal R.F.A. (1985) The role of activated human platelets in prothrombin and factor $X$ activation, Blood $65,319-332$

13. Schroit A.J. and Zwaal R.F.A. (1991) Transbilayer movement of phospholipids in red cell and platelet membranes, Biochim. Biophys. Acta 1071, 313-329

14. Tracy P.B., Eide L.S. and Mann K.G. (1985) Human prothrombinase complex assembly and function on isolated peripheral blood cell populations, J. Biol. Chem. 260, 2119-2124

15. Altieri D.C. (1993) Coagulation assembly on leukocytes in transmembrane signaling and cell adhesion, Blood 81, 569-579

16. Rogers G.M. and Schuman M.A. (1983) Prothrombin is activated on vascular endothelial cells by factor $\mathrm{Xa}$ and calcium, Proc. Natl. Acad. Sci. 80, 7001-7005

17. Hamilton K.K., Hattori R., Esmon C.T. and Sims P.J. (1990) Complement proteins C5b-9 induce vesiculation of the endothelial plasma membrane and expose catalytic surface for assembly of the prothrombinase enzyme complex, J. Biol. Chem. 265, 3809-3814

18. Suttie J.W. and Jackson C.M. (1977) Prothrombin structure, activation and biosynthesis, Physiol. Rev. 57, 1-70. 
19. van Rijn J.L.M.L., Govers-Riemslag J.W.P., Zwaal R.F.A. and Rosing J. (1984) Kinetic studies of prothrombin activation: Effect of factor $\mathrm{Va}$ and phospholipids on the formation of the enzyme substrate complex, Biochemistry 23, 4557-4564

20. Krishnaswamy S., Jones K.C. and Mann K.G. (1988) Prothrombinase complex assembly. Kinetic mechanism of enzyme assembly on phospholipid vesicles, $J$. Biol. Chem. 263, 3823-3834

21. Forman S.D. and Nemerson Y. (1986) Membrane-dependent coagulation reaction is independent of the concentration of phospholipid-bound substrate: fluid phase factor $X$ regulates the extrinsic system, Proc. Natl. Acad. Sci. 83, 4675-4679

22. Krishnaswamy S., Field K.A., Edgington T.S., Morrissey J.H. and Mann K.G. (1992) Role of the membrane surface in the activation of human coagulation factor $X, J$. Biol. Chem. 267, 26110-26120

23. Singer S.J. and Nicolson G.L. (1972) The fluid mosaic model of the structure of cell membranes, Science 175, 720-731

24. Chap H.J., Zwaal R.F.A. and van Deenen L.L. (1977) Action of highly purified phospholipases on bloodplatelets. Evidence for an asymmetric distribution of phospholipids in the surface membrane, Biochim. Biophys. Acta 467, 146-164

25. Bevers E.M., Comfurius P. and Zwaal R.F.A. (1983) Changes in membrane phospholipid distribution during platelet activation, Biochim. Biophys. Acta 736, 57 66

26. Sandberg H., Andersson L. and Höglund S. (1982) Isolation and characterization of lipidprotein particles containing platelet factor 3 released from human platelets, Biochem J. 203, 303-311

27. Sims P.J., Wiedmer T., Esmon C.T., Weiss H.J. and Shattil S.J. (1989) Assembly of the platelet prothrombinase complex is linked to vesiculation of the platelet plasma membrane, J. Biol. Chem. 264, 17049-17057

28. Tans G., Rosing J., Thomassen M.C.L.G.D., Heeb M.J., Zwaal R.F.A. and Griffin J.H. (1991) Comparison of anticoagulant and procoagulant activities of stimulated platelets and platelet-derived microparticles, Blood 77, 2641-2648

29. Zwaal R.F.A., Comfurius P. and Bevers, E.M. (1992) Platelet procoagulant activity and microvesicle formation. Its putative role in hemostasis and thrombosis, Biochim. Biophys. Acta 1180, 1-8

30. Pusey M.L. and Nelsestuen G.L. (1983) The physical significance of $\mathrm{Km}$ in the prothrombinase reaction, Biochem. Biophys. Res. Commun. 114, 526-532

31. Lindhout T., Govers-Riemslag J.W.P., van de Waart P., Hemker H.C. and Rosing J. (1982) Factor Va-factor Xa interaction. Effects of phospholipid vesicles of varying composition, Biochemistry 21 5494-5502

32. Mann K.G., Jenny R.J. and Krishnaswamy S. (1988) Cofactor proteins in the assembly and expression of blood clotting enzyme complexes, Ann. Rev. Biochem. 57, 915-956

33. Pusey M.L., Mayer L.D., Jason Wei G., Bloomfield V.A. and Nelsestuen G.L. (1982) Kinetic and hydronamic analysis of blood clotting factor $V$-membrane binding, Biochemistry 21, 5262-5269

34. Rosing J., Speijer H. and Zwaal R.F.A. (1988) Prothrombin activation on phos pholipid membranes with positive electrostatic potential, Biochemistry 27, 8-11

35. Resnick R. M. and Nelsestuen G. L. (1980) Prothrombin-membrane interaction. Effects of ionic strength, $\mathrm{pH}$ and temperature, Biochemistry 19,3028-3033 
36. Speijer H. (1987) Studies on the chemical nature of procoagulant sites on phospholipid vesicles and platelets membranes, Thesis University of Limburg.

37. Galvin J.B., Kurosawa S., Moore K., Esmon C.T. and Esmon N.L. (1987) Reconstitution of rabbit thrombomodulin into phospholipid vesicles, J. Biol. Chem: 262, 2199-2205

38. Gerads I., Govers-Riemslag J.W.P., Tans G., Zwaal R.F.A. and Rosing J. (1990) Prothrombin activation on membranes with anionic lipids containing phosphate, sulfate, and/or carboxyl groups, Biochemistry 29, 7967-7974 


\section{Chapter 6}

The Prothrombin-Converting Activity of Membranes with Varying Polar Headgroups 


\section{Summary}

Factor Xa-catalyzed prothrombin activation is strongly stimulated by the presence of negatively charged membranes plus calcium ions. Here we report experiments in which we determined the prothrombin-converting activity of phosphatidylcholine (PC) membranes that contain varying amounts of different anionic lipids viz. phosphatidylserine (PS), phosphatidic acid (PA), phosphatidylmethanol (MePA), phosphatidylglycerol (PG), phosphatidylethanol-amine (PE), phosphatidyl- $\beta$-lactate (PLac), sulfatides (SF), sodium dodecyl sulfate (SDS) and oleic acid. All anionic lipids tested were able to accelerate factor Xa-catalyzed prothrombin activation, both in the absence and presence of the protein cofactor $\mathrm{Va}$. This shows that the prothrombin-converting activity of negatively charged membranes is not strictly dependent on the presence of a phosphate group but that lipids which contain a carboxyl or sulfate moiety are also able to promote the formation of a functionally active prothrombinase complex. In the absence of factor $\mathrm{Va}$, the prothrombin-converting activity of membranes with MePA, PG, PE, PLac, SF or SDS was strongly inhibited at high ionic strength, while the activity of PS and PA-containing membranes was hardly affected by ionic strength variation. This suggests that in the case of the ionic strength sensitive lipids electrostatic forces play an important role in the formation of the membrane-bound prothrombinase complex. For PS and to a lesser extent for PA we propose that the formation of a coordinated complex (chelate complex) with $\mathrm{Ca}^{2}+$ as central ion and ligands provided by the $\gamma$ carboxyglutamic acid residues of prothrombin and factor $\mathrm{Xa}$ and the polar head group of phospholipids is the major driving force in protein-membrane association. Our data indicate that the anionic lipids used in this study can be useful tools for further investigation of the molecular interactions that play a role in the assembly of a membrane-bound prothrombinase complex. Membranes that were solely composed of PC can also considerably enhance prothrombin activation however only in the presence of factor $\mathrm{Va}$ and when the measurements are performed at low ionic strength.

\section{Introduction}

The activation of prothrombin by the serine protease factor $\mathrm{Xa}$ is greatly accelerated by the presence of negatively charged membranes plus calcium ions and by the protein cofactor $\mathrm{Va}$ (for reviews see refs [1-3]). Negatively 
charged lipids are thought to promote prothrombin activation by simultaneous binding of the protein components of the prothrombinase complex, a phenomenon that facilitates factor $\mathrm{Xa}$ - factor $\mathrm{Va}$ complex formation [4,5] and that causes an increased affinity (decreased $\mathrm{K}_{\mathrm{m}}$ ) for the substrate prothrombin [6]. Factor $\mathrm{Va}$ stimulates prothrombin activation by enhancing the enzymatic activity ( $k_{\text {cat }}$ ) of factor $X a[4,6]$ and by providing additional interactions with factor $\mathrm{Xa}[4,5]$ and prothrombin $[7,8]$ that further support the assembly of the prothrombinase-prothrombin complex.

Several laboratories have investigated the binding of the individual proteins to various phospholipid preparations. Factor Va-membrane interaction has been shown to require negatively charged phospholipids [9] and it has been suggested that the association of factor Va with membranes involves both non-ionic $[9,10]$ and ionic forces $[10,11]$. In contrast to factor $\mathrm{Va}$ binding, the association of the substrate (prothrombin) and the enzyme (factor $\mathrm{Xa}$ ) with negatively charged membrane surfaces requires $\mathrm{Ca}^{2}+$ ions. Since both prothrombin and factor Xa contain $\gamma$-carboxyglutamic acid (Gla) residues that bind $\mathrm{Ca}_{2}+$ ions [12-15] and since membranes with anionic phospholipids also have a high affinity for $\mathrm{Ca}^{2}+$ ions [16-18] the formation of prothrombin- and factor Xa-membrane complexes is apparently mediated by calcium bridges between the proteins and anionic phospholipids.

The chemical and physical nature of the calcium-dependent binding of Gla-containing proteins to negatively charged membranes is, however, not yet fully understood. Both electrostatic attraction [19] and coordination binding $[3,20]$ have been suggested to be the driving force in proteinmembrane association. Electrostatic attraction may occur between the Glacontaining protein domain, which becomes positively charged after calcium binding, and the negatively charged membrane surface. Coordination binding may result from the formation of chelate complexes of calcium ions with ligands provided by the Gla-residues of the proteins and by the polar head groups of anionic membrane lipids. It is possible, however, that both electrostatic attraction and chelate formation are involved in membrane binding of Gla-containing proteins and that the extent to which these forces contribute to binding is dependent on the kind of anionic lipid present in the membrane. Rosing et al. [21] suggested that coordination complex formation is the major driving force for the binding of vitamin K-dependent proteins to PS-containing membranes, while electrostatic attraction may significantly contribute to protein binding to membranes which contain other anionic phospholipids (e.g. PG [19]. Limited information is, however, available on 
protein binding characteristics and prothrombin-converting activities of membranes that contain anionic lipids other than PS or PG.

In the present study we have investigated the prothrombin-converting activities of negatively charged membranes that contain a wide variety of different anionic lipids. In addition to anionic phospholipids, we have also examined lipids that do not contain a phosphate group and which derive their negative charge from a carboxyl (fatty acid) or a sulfate group (sulfatide, SDS). This investigation has been carried out in order to obtain more information on the chemical requirements of the polar head groups of anionic lipids that are able to participate in the assembly of the prothrombinase complex and to get more insight into the physical nature of $\mathrm{Ca}^{2}$--dependent interactions between vitamin $\mathrm{K}$-dependent proteins and negatively charged membranes.

\section{Experimental procedures}

- Materials. S2238 was purchased from AB Kabi Diagnostica, Stockholm, Sweden. Dioleoyl-sn-glycero-3-phosphocholine, dioleoyl-sn-glycero-3-phosphomethanol and oleic acid were obtained from Sigma, St. Louis, Mo, USA. Sulfatides were purchased from Supelco Inc., Bellefonte, $\mathrm{Pa}$, USA. Sodium dodecyl sulfate was obtained from Bio-Rad Laboratories, Richmond, $\mathrm{Ca}$, USA. Column materials for protein purification (DEAE-Sephadex A-50, QAE-Sephadex A-50, SPSephadex C-50. Sephadex G-100, Sephadex G-200 and Sepharyl S-300) were obtained from Pharmacia, Uppsala, Sweden. Silica gel 60 plates for thin- layer chromatography of phospholipids were from Merck, Darmstadt, Germany.

- Proteins. Bovine prothrombin was purified as described by Owen et al. [22]. Bovine factor $X$ was purified as described by Fujikawa et al. [23]. Bovine factor $X a$ was prepared from factor $X$ after activation with RVV-X [24]. RVV-X was purified from the crude venom of Russell's viper by the method of Schiffman et al. [25]. Bovine factor Va was obtained according to the procedure of [5]. Prothrombin and factor Xa were stored at $-80^{\circ} \mathrm{C}$ in $50 \mathrm{mM}$ Tris- $\mathrm{HCl}(\mathrm{pH} \mathrm{7.9)}$ and $175 \mathrm{mM} \mathrm{NaCl}$. Factor $V a$ was stored at $-80^{\circ} \mathrm{C}$ in the same buffer with $5 \mathrm{mM} \mathrm{CaCl}_{2}$.

- Protein concentrations. The molar concentration of factor Xa was determined by active site titration with p-NPGB [26]. Prothrombin concentrations were determined with p-NPGB (ct. thrombin active site titration, [27] ) after complete activation of prothrombin with the venom activator from Echis carinatus. Factor Va concentrations were determined by kinetic analysis [5].

- Phospholipid and phospholipid preparations. 1,2-Dioleoyl-sn-glycero-3phosphoserine (PS), 1,2-dioleol-sn-glycero-3-phosphoglycerol (PG), 1,2-dioleoylsn-glycero-3-phosphate (PA), 1,2-dioleoyl-sn-glycero-3-phospho- $\beta$-lactate (PLac) and 1,2-dioleoyl-sn-phospho- ethanolamine (PE) were prepared from 1,2dioleoyl-sn-glycero-3-phosphocholine (PC) by enzymatic synthesis [28]. Single 
bilayer lipid vesicles were prepared as follows: lipid preparations, usually dissolved in $\mathrm{CHCl}_{3} / \mathrm{CH}_{3} \mathrm{OH}(1 / 1, v / v)$, were dried under a stream of $\mathrm{N}_{2}$ and the

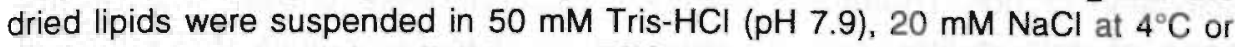
$65^{\circ} \mathrm{C}$ (when oleic acid, sulfatides or SDS were part of the lipid mixture) and vigorously vortexed for $1 \mathrm{~min}$. The lipid suspensions were subsequently sonicated for $10 \mathrm{~min}$. at $4^{\circ} \mathrm{C}$ or $65^{\circ} \mathrm{C}$ using a MSE Mark II 150-W ultrasonic desintegrator set at $8 \mu \mathrm{m}$ peak to peak amplitude. Phospholipid concentrations were determined by phosphate analysis according to the method of Böttcher et al. [29]. Extraction of total lipid from aqueous vesicle suspensions was carried out as described by Reed et al. [30]. TLC analysis of lipids was performed at room temperature on $20 \times 20 \mathrm{~cm}$ plates coated with $0.5-\mathrm{mm}$ silica gel 60 . Chloroform $/ \mathrm{metha}$ nol/ammonia/water $(95 / 50 / 5.5 / 5.5, v / v)$ was used as eluent and the lipids on the TLC plate were subsequently visualised with iodine vapor.

- Assay system for measuring rates of prothrombin activation. Phospholipids, factor $\mathrm{Xa}$ and, if present, factor Va were incubated for $5 \mathrm{~min}$. at $37^{\circ} \mathrm{C}$ in 50 $\mathrm{mM}$ Tris- $\mathrm{HCl}$ buffer ( $\mathrm{pH} \mathrm{7.9)}$ containing $5 \mathrm{mM} \mathrm{CaCl}, 0.5 \mathrm{mg} / \mathrm{ml}$ ovalbumin and concentrations $\mathrm{NaCl}$ as indicated in the legends to the tables and figures. Prothrombin activation was started by the addition of prothrombin that was preincubated at $37^{\circ} \mathrm{C}$ in the same buffer. After different time intervals aliquots from the reaction mixture were transferred to plastic disposable cuvettes containing $235 \mu \mathrm{M}$ of the thrombin specific chromogenic substrate S2238 in 50 $\mathrm{mM}$ Tris- $\mathrm{HCl}(\mathrm{pH} 7.9), 175 \mathrm{mM} \mathrm{NaCl}, 20 \mathrm{mM}$ EDTA and $0.5 \mathrm{mg} / \mathrm{ml}$ ovalbumin. The amount of thrombin present in the reaction mixtures was calculated from the absorbance change ( $\triangle \mathrm{A} 405-500 / \mathrm{min})$ measured on a dual-wavelength spectrophotometer, using a calibration curve of chromogenic substrate conversion by known amounts of active site-titrated thrombin. Rates of prothrombin activation were usually expressed as moles of prothrombin activated per minute per mole of factor $X a$ present in the reaction mixture.

\section{Results}

\section{Effect of different anionic lipids on the prothrombin-converting activity of PC membranes}

Quantitative comparison of the ability of various anionic lipids to stimulate prothrombin activation is a rather complex pursuit. The prothrombinase activity measured in the presence of phospholipid vesicles is greatly affected by the reaction conditions and depends among others on the prothrombin-, phospholipid- and $\mathrm{Ca}_{2}+$ concentrations, the absence or presence of factor $\mathrm{Va}$, the mole fraction anionic lipid in the procoagulant membrane and on the $\mathrm{pH}$, temperature and ionic strength of the reaction medium. Reaction conditions that are optimal for one kind of anionic lipid are not necessarily optimal for other lipids. However, the major objective of the introductory 
experiment is to test whether an anionic lipid is able to promote prothrombin activation or not. Therefore, reaction conditions were chosen that on the basis of data in literature [8] were expected to favor lipid stimulation of prothrombinase i.e. $0.5 \mu \mathrm{M}$ prothrombin, $100 \mu \mathrm{M}$ lipid vesicles containing 80 mole \% of the neutral phospholipid PC and 20 mole\% anionic lipid, $\mathrm{pH} 7.9$, $37^{\circ} \mathrm{C}$ and low ionic strength. In this experiment, which was carried out both in the absence and presence of factor $\mathrm{Va}$, the following anionic lipids were tested: a) phospholipids that contain a negatively charged phosphate moiety (PA), esterified with groups without (MePA, PG) or with additional charges (PS, PLac, PE1), b) oleic acid, that contains a negatively charged carboxyl group and $c$ ) sulfolipids (SF, SDS) that contain a sulfate moiety with a net negative charge.

Table 1. Prothrombin activation on membranes containing 20 mole $\%$ of different anionic lipids

Lipid composition

rate of prothrombin acivation $(\mathrm{mol} / \mathrm{min} / \mathrm{mol} \mathrm{Xa})$

- factor Va factor Va

$\begin{array}{lrr}\text { PS/PC } & 0.43 & 1720 \\ \text { Plac/PC } & 0.38 & 2470 \\ \text { PA/PC } & 0.34 & 2530 \\ \text { MePA/PC } & 0.15 & 2580 \\ \text { PG/PC } & 0.081 & 2460 \\ \text { PE/PC } & 0.040 & 2260 \\ \text { SF/PC } & 0.052 & 2180 \\ \text { SDS/PC } & 0.071 & 2120 \\ \text { PC } & 0.023 & 420 \\ \text { No Lipid } & 0.010 & 11\end{array}$

Prothrombin $(0.5 \mu \mathrm{M})$ was activated in a reaction mixture containing $50 \mathrm{mM}$ Tris- $\mathrm{HCl}(\mathrm{pH} 7.9), 20 \mathrm{mM} \mathrm{NaCl}, 5 \mathrm{mM} \mathrm{CaCl} 2,0.5 \mathrm{mg} / \mathrm{ml}$ ovalbumin, $100 \mu \mathrm{M}$ phospholipid, $3 \mathrm{nM}$ factor $\mathrm{Xa}$ or $5 \mathrm{pM}$ factor $\mathrm{Xa}$ plus $5 \mathrm{nM}$ factor $\mathrm{Va}$. Lipid vesicles contained 80 mole\% PC and 20 mole\% anionic lipid.

IIt should be emphasized that PE-containing membranes will be considerably less negatively charged than membranes with the other anionic lipids. PE contains a negative charge on the phosphate group and a positive charge on the ethanolamine group $\left(\mathrm{O}-\mathrm{PO}_{3}{ }^{-}-\left(\mathrm{CH}_{2}\right)_{2}-\mathrm{NH}_{3}{ }^{+}\right)$: Since the amino group of $\mathrm{PE}$ will have a pK $\sim 9$ it can be calculated that at $\mathrm{pH} 7.9$, at which prothrombinase activities are measured, some $5 \%$ of the PE molecules will be negatively charged. 
In the presence of factor $\mathrm{Va}$, all membranes containing anionic lipids were able to accelerate factor Xa-catalyzed prothrombin activation (Table 1).

Compared to the rate of the reaction in free solution the anionic lipidcontaining membranes caused a more than 150-fold stimulation of prothrombin activation. Membranes that were only composed of the neutral phospholipid PC and that did not contain added anionic lipid showed a 40fold increase of prothrombin activation.

In the absence of factor $\mathrm{Va}, \mathrm{PC}$ membranes hardly affected prothrombin activation, while membranes with sulfolipids caused only a 6-fold stimulation and membranes with oleic acid exhibited a 12-fold increase of the reaction rate. The rate enhancements observed with anionic phospholipids were strongly dependent on the polar head group of the phospholipid molecule. Only 4-fold stimulation of prothrombinase was observed for membranes with $P E$, while membranes containing PG or MePA caused some 10 -fold rate enhancement. Maximal stimulation ( $30-40$ fold) of prothrombinase was obtained with membranes that contain PS, PLac or PA.

To put the data presented in table 1 in a proper perspective, it should be emphasized that the experimental conditions might not be optimal for all anionic lipids and that the relation to one another might be different at other reaction conditions. It is also important to mention that this experiment has been carried out at a rather low ionic strength $(1=0.07)$ which especially favors the prothrombin-converting activity of some of the lipids (see below). However, irrespective of the reaction conditions, the data presented in Table 1 allow the conclusion that the prothrombinase activity on negatively charged membranes is not strictly dependent on the presence of a phosphate group (phospholipid), but that anionic lipids with sulfate- or carboxyl groups can also promote prothrombin activation.

\section{Prothrombin-converting activity of membranes with various anionic lipids as a function of the total lipid concentration}

It is now well established that membrane stimulation of prothrombinase requires association of all reactants (prothrombin, factor $\mathrm{Xa}$ and factor $\mathrm{Va}$ ) with the procoagulant membrane. Titration curves of prothrombinase activity as a function of the lipid concentration may, however, show an optimum in the sense that low lipid concentrations proportionally stimulate prothrombin activation until an optimal lipid concentration is reached after which a further increase of the amount of lipid may even cause inhibition of prothrombin activation. Such inhibition can be explained by substrate depletion caused by binding of substrate to non-productive binding sites on the membrane 
(free-substrate model $[8,31]$ or by dilution of reactants on an excess of lipid surface (bound-substrate model [8] The actual shape of the titration curves will be determined by the binding parameters (i.e. number of binding sites and dissociation constants) that describe the interaction between the coagulation factors and the procoagulant membranes.

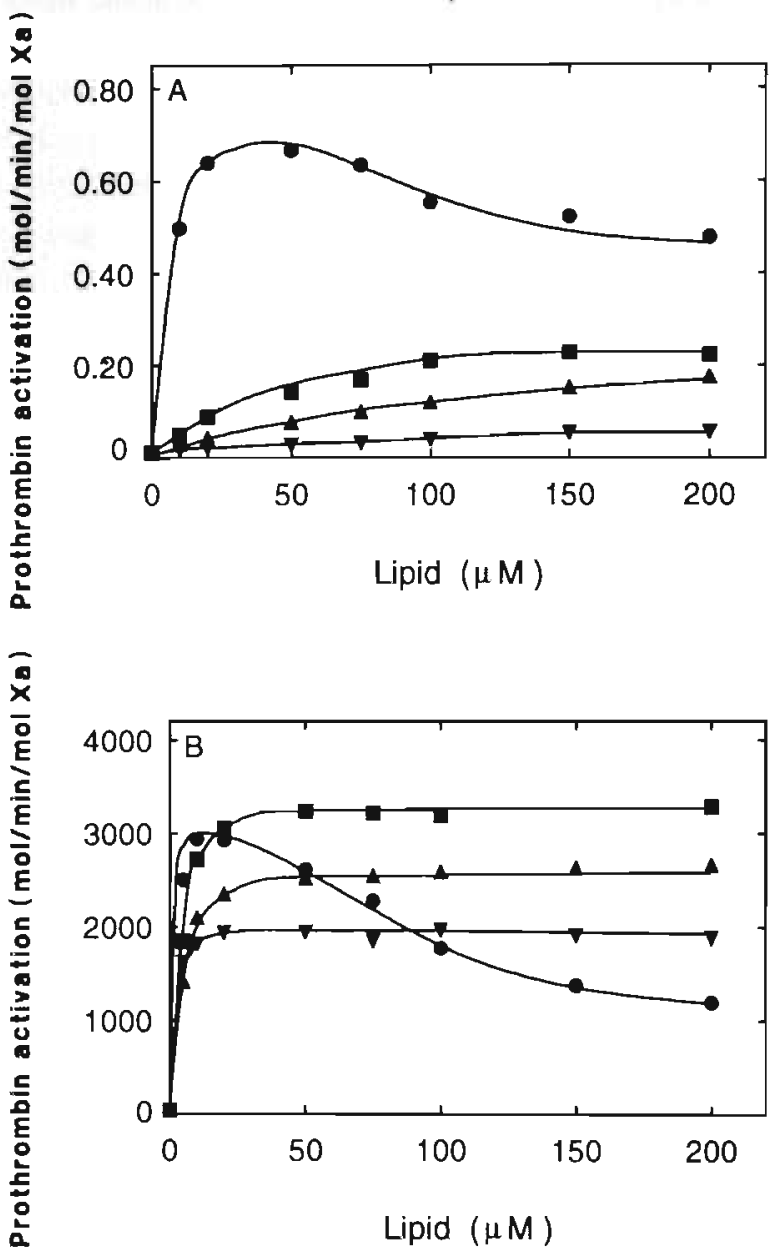

Figure 1. Prothrombin activation on membranes containing different anionic lipids as function of the lipid concentration. Prothrombin $(0.5 \mu \mathrm{M})$ was activated in a reaction mixture containing $50 \mathrm{mM}$ Tris- $\mathrm{HCl}(\mathrm{pH} 7.9), 20 \mathrm{mM} \mathrm{NaCl}, 5 \mathrm{mM} \mathrm{CaCl}, 0.5 \mathrm{mg} / \mathrm{ml}$ ovalbumin, $(0-200 \mu \mathrm{M}$ lipid vesicles ( 80 mole\% PC/20 mole\% anionic lipid) and $3 \mathrm{nM}$ factor Xa (A) or $3 \mathrm{pM}$ factor $X$ a plus $5 \mathrm{nM}$ factor $\mathrm{Va}(\mathrm{B})$. The anionic lipids used were: $\mathrm{PS}$ $(\boldsymbol{)}), \operatorname{MePA}(\boldsymbol{\square})$, oleic acid $(\boldsymbol{\Delta})$, and SF $(\boldsymbol{\nabla})$. 
The effect of variation of the total lipid concentration on prothrombin activation was studied both in the absence (Figure 1A) and presence of factor Va (Figure 1B) for membranes that contain either 20 mole $\%$ PS, MePA, oleic acid or SF as anionic lipid. These lipids were taken as typical examples of those tested in the experiment presented in Table 1. In the absence of factor $V a$ rather large amounts of lipid were required to obtain significant stimulation of the prothrombinase complex. Optimal rates of prothrombin activation were obtained at $50 \mu \mathrm{M}$ PS/PC and at about $150 \mu \mathrm{M}$ phospholipid for PC vesicles with MePA, oleic acid or SF.

When factor $\mathrm{Va}$ is part of the prothrombinase complex, much less lipid was needed to obtain optimal rates of prothrombin activation. For all anionic lipids tested, saturation of prothrombinase activity was obtained at 10-20 $\mu \mathrm{M}$ lipid. The shift in lipid requirement is apparently caused by factor $\mathrm{Va}$ and is presumably the result of the ability of factor Va to promote the binding of factor $\mathrm{Xa}[4,5]$ and prothrombin $[8,32]$ to procoagulant membranes. Inhibition of prothrombinase activity at high lipid concentrations was only observed with PS. It is not surprising that this occurs with this anionic lipid since it is to be expected that PS has the highest affinity for coagulation factors $[6,33]$.

\section{Prothrombin converting activity on membranes containing different mole fractions of various anionic lipids}

The ability of negatively charged membranes to enhance prothrombin activation appears to be dependent on the amount of anionic lipid present in the membrane [8]. At low mole fractions of anionic lipid the prothrombinconverting activity of a membrane increases with the mole fraction anionic lipid. At high mole fractions of anionic lipid, saturation can be obtained while in some cases (PS-containing membranes in the presence of factor $\mathrm{Va}$ [8] excess anionic lipid may even inhibit the prothrombin-converting activity of a membrane.

In the present investigation we have determined the effect of variation of the mole fraction of four typical anionic lipids (PS, MePA, SF and oleic acid) on membrane stimulation of prothrombinase. In the absence of factor $\mathrm{Va}$ there appear to be large differences between the various anionic lipids (Figure 2A). With PS half maximal stimulation of prothrombinase was obtained between 5 and 10 mole\% anionic lipid. In case of MePA, SF and oleic acid the membranes required much larger amounts of anionic lipid in order to stimulate prothrombin activation. Surprisingly, high mole fractions MePA produced membranes that exhibited a higher prothrombin-converting activity than membranes that contained the same amount of PS. 


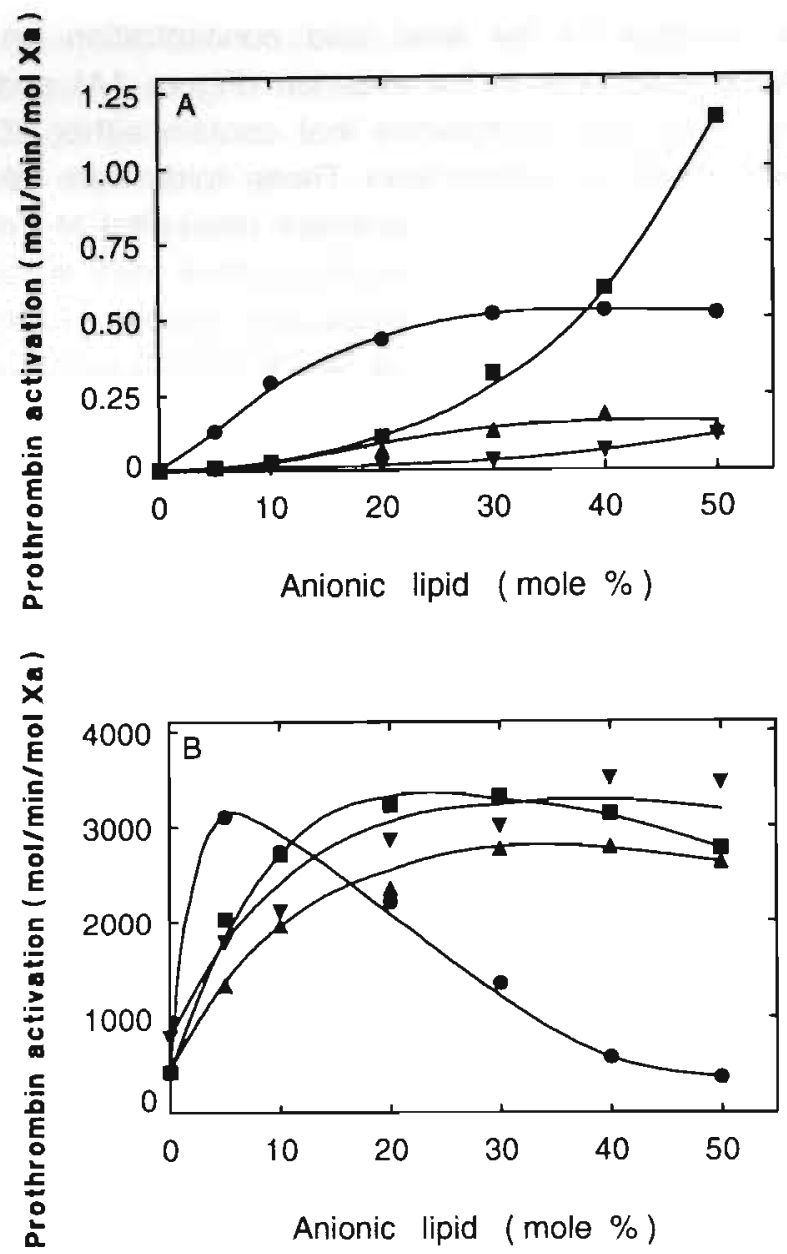

Figure 2. Prothrombin activation on membranes containing different anionic lipids as function of the mole percentage anionic lipid. Prothrombin $(0.5 \mu \mathrm{M})$ was activated in a reaction mixture containing $50 \mathrm{mM}$ Tris- $\mathrm{HCl}(\mathrm{pH} 7.9), 20 \mathrm{mM} \mathrm{NaCl}, 5 \mathrm{mM} \mathrm{CaCl} 2,0.5$ $\mathrm{mg} / \mathrm{ml}$ ovalbumin, $100 \mu \mathrm{M}$ PC vesicles with varying mole\% anionic lipid and $4 \mathrm{nM}$ factor $\mathrm{Xa}(\mathrm{A})$ or $3 \mathrm{pM}$ factor $\mathrm{Xa}$ plus $5 \mathrm{nM}$ factor $\mathrm{Va}(\mathrm{B})$. The anionic lipids used here: PS (O), $\operatorname{MePA}(\mathbf{\square})$, oleic acid $(\boldsymbol{\Delta})$, and $\operatorname{SF}(\boldsymbol{\nabla})$.

When factor $\mathrm{Va}$ is part of the prothrombinase complex, PS-containing membranes were already optimally active at 5 mole\% PS (Figure 2B). Introduction of more PS resulted in inhibition of prothrombin-converting activity. With the other anionic lipids (MePA, SF and oleic acid) saturation curves were obtained which showed half maximal stimulation of 
prothrombinase at about 5 mole $\%$ anionic lipid and negligible inhibition at high mole fractions anionic lipid.

\section{The effect of variation of the salt concentration (ionic strength) on the prothrombin-converting activity of membranes with different anionic lipids}

It has been suggested that ionic interactions between positively charged protein domains and negatively charged lipids as well as specific $\mathrm{Ca}^{2+-}$ dependent chelate complex formation between $\gamma$-carboxyglutamic acid residues and negatively charged lipids may be responsible for the association of vitamin K-dependent coagulation factors with procoagulant membranes [21]. Information about the contribution of ionic interaction to protein-membrane binding can be obtained by variation of the ionic strength of the reaction medium. Increases in ionic strength will cause increased screening of the electrostatic potential of the interacting components, which will result in decreased protein-membrane association [19].

The effect of variation of the ionic strength on factor Xa-catalyzed prothrombin activation on membranes with different anionic lipids is shown in Figures $3 \mathrm{~A}$ and $3 \mathrm{~B}$. The prothrombin-converting activity of membranes with PS and PA was hardly affected by increasing the ionic strength of the reaction medium. Membranes with oleic acid exhibited intermediate sensitivity while the prothrombin-converting activity of membranes with MePA, PG, PE, PLac, SDS and SF was strongly inhibited at increasing ionic strength. These results indicate that there may be rather large differences between the contributions of ionic interaction and chelate complex formation to the binding of vitamin K-dependent coagulation factors to membranes with various anionic lipids.

When factor $\mathrm{Va}$ was part of the prothrombinase complex, variation of the ionic strength had much less effect on the prothrombin-converting activity of the various membranes. As a typical example this is shown in Figure $3 \mathrm{C}$ for membranes that contain 20 mole $\%$ SDS. The presence of membrane-bound factor $V a$ apparently compensates for the electrostatic screening effects, presumably by enabling additional interactions with prothrombin $[8,32]$ and factor $\mathrm{Xa}[4,5]$.

\section{Prothrombin activation on membranes composed of PC}

The data presented in Table 1 and Figure $2 \mathrm{~B}$ indicate that membranes that did not contain added anionic lipid and that were only composed of dioleoyl 

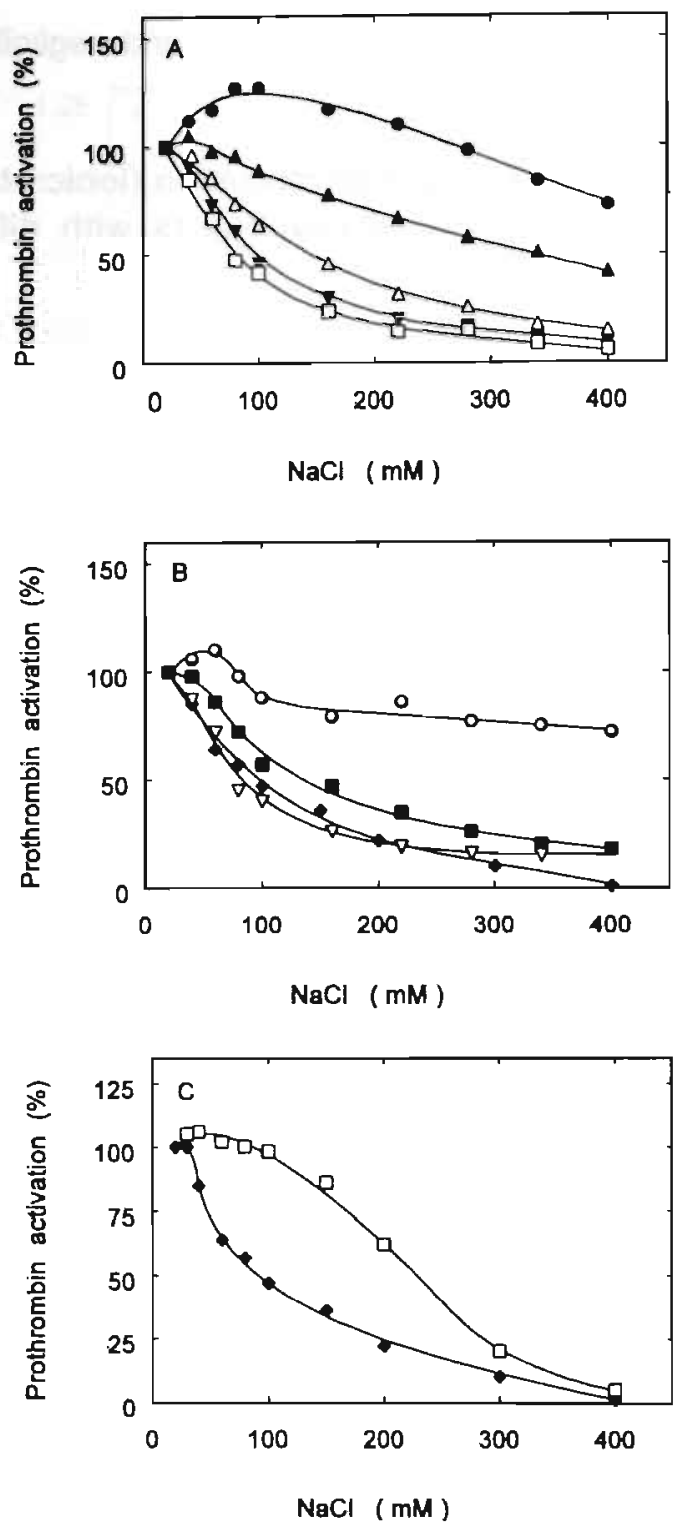

Figure 3. The effect of ionic strength variation on the prothrombin-converting activity of membranes containing different anionic lipids. Prothrombin $(0.5 \mu \mathrm{M})$ was activated in a reaction mixture containing $50 \mathrm{mM}$ Tris- $\mathrm{HCl}(\mathrm{pH} 7.9), 20-400 \mathrm{mM} \mathrm{NaCl}, 5$ $\mathrm{mM} \mathrm{CaCl}_{2}, 0.5 \mathrm{mg} / \mathrm{ml}$ ovalbumin, $100 \mu \mathrm{M}$ lipid vesicles ( $80 \mathrm{~mole} \% \mathrm{PC} / 20 \mathrm{~mole} \%$ anionic lipid) and $3 \mathrm{nM}$ factor $\mathrm{Xa}(\mathrm{A}-\mathrm{C})$ or $5 \mathrm{pM}$ factor $\mathrm{Xa}$ plus $5 \mathrm{nM}$ factor $\mathrm{Va}(\mathrm{C})$. (A) PS (O), PLac $(\Delta)$, oleic acid $(\Delta), P G(\nabla)$ and PE $(\square)$. (B) PA $(O)$, MePA $(\square)$, SF $(\nabla)$ and SDS $(\downarrow)$. (C) SDS with $3 \mathrm{nM}$ factor $\mathrm{Xa}(\diamond)$, SDS with $5 \mathrm{pM}$ factor Xa plus $5 \mathrm{nM}$ factor $\mathrm{Va}(\square)$. 


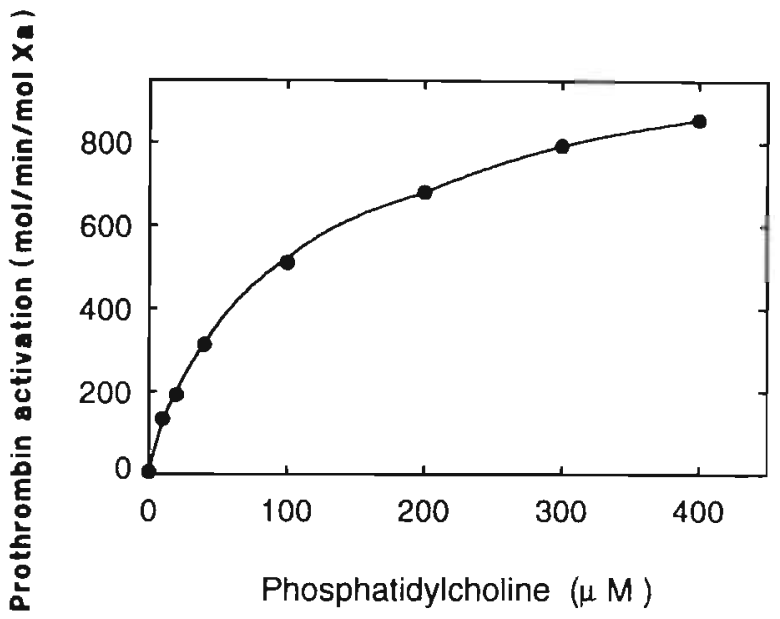

Figure 4. Prothrombin activation on PC membranes as a function of the lipid concentration. Prothrombin $(0.5 \mu \mathrm{M})$ was activated in a reaction mixture containing 50 $\mathrm{mM}$ Tris- $\mathrm{HCl}$ (pH 7.9), $20 \mathrm{mM} \mathrm{NaCl}, 5 \mathrm{mM} \mathrm{CaCl}_{2}, 0.5 \mathrm{mg} / \mathrm{ml}$ ovalbumin, $5 \mathrm{pM}$ factor $\mathrm{Xa}_{2} 5$ $\mathrm{nM}$ factor $\mathrm{Va}$, and varying concentrations $\mathrm{PC}$ vesicles.

PC were able to cause significant stimulation of prothrombin activation, provided that the reaction is carried out at low ionic strength and in the presence of factor $\mathrm{Va}$. Prothrombinase activity as a function of the concentration of dioleoyl PC vesicles is shown in Figure 4.

Maximal rates of prothrombin activation $1900 \mathrm{~mol}$ prothrombin activated $/ \mathrm{min} / \mathrm{molXa}$ ) were obtained at PC concentrations $>400 \mu \mathrm{M}$ and half maximal rates of activation were observed at about $100 \mu \mathrm{M}$ PC. The prothrombin-converting activity of PC membranes may either be due to the presence of trace amounts of anionic lipids contaminating PC preparations or to the phosphocholine moiety of $\mathrm{PC}$, which despite its net neutral charge, may participate in the formation of a functionally active prothrombinase complex.

TLC analysis of the dioleoyl PC preparations used in these experiments and of the vesicles obtained after sonication of this $\mathrm{PC}$ in aqueous solution indicated the presence of trace amounts (less than 1.5\%) of contaminating lipids (Figure 5). Spot 1 on the TLC plate was identified as lyso PC and spot 2 and 3 were as yet unidentified lipids. However, incorporation of lyso PC or of the lipids present in spot 2 and 3 (obtained after extraction from the TLC plate) at amounts $5 \times$ of that present in the original PC preparation did not further enhance the prothrombin-converting activity of PC vesicles which 


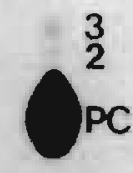

1

A

B

Figure 5. Thin layer chromatographic analysis of dioleoyl-PC. Lane A: $500 \mu \mathrm{g}$ dioleoyl-PC. Lane B: $10 \mu \mathrm{g}$ of lyso-PC plus $5 \mu \mathrm{g}$ of oleic acid. Spot 4 is lyso-PC and spot 5 is oleic acid. TLC analysis was performed as described in the experimental procedures.

indicates that these contaminations were not responsible for the observed prothrombinase activity. Since the occurrence of lyso PC may go together with the presence the corresponding fatty acid and since fatty acids promote the prothrombin-converting activity of membranes (Table 1, Figures 1 and 2) we decided to determine whether fatty acids are present in our dioleyl PC.

Visual inspection of the PC on the TLC platelet (lane A, Figure 5) and comparison with the fatty acid spot of a reference sample (spot 5 , lane $B$ ) indicates that there is no fatty acid detectable in our PC preparation. The virtual absence of fatty acid was confirmed by gaschromatographic analysis which showed that dioleoyl PC contained less than $0.2 \%$ fatty acid. From these data we conclude that it is unlikely that fatty acid or one of the other contaminations (spot 1,2 or 3 ) present in dioleoyl PC is responsible for the prothrombin-converting activity of PC membranes.

These results indicate that the phosphocholine moiety of PC can indeed promote the assembly of a functionally active prothrombinase complex. 


\section{Discussion}

Previous studies on the role of negatively charged membranes in the assembly of the prothrombinase complex have been carried out with mixtures of neutral and anionic phospholipids. In this paper we show that the presence of phosphate groups is no prerequisite for membranes to promote prothrombinase complex formation. Incorporation of lipids with a carboxyl(oleic acid) or a sulfate group (SF, SDS) produced membranes which considerably accelerated factor Xa-catalyzed prothrombin activation. The prothrombin-converting activities of membranes with oleic acid, SF or SDS were compared with the activities of membranes that derived their negative charge from the presence of anionic phospholipids (PS, PA, MePA, P-Lac, $P E^{1}$ or $\left.P G\right)$.

In the absence of factor $\mathrm{Va}$ there were rather large differences between the prothrombin-converting activities of different anionic lipids (Table 1). Prothrombin activation rates obtained with the different lipids were strongly dependent on the reaction conditions (total lipid concentration, mole \% anionic lipid and ionic strength of the reaction medium). The ability of the different anionic lipids to enhance prothrombin activation by factor $\mathrm{Xa}$ decreased in the order PS-PLac-PA-MePA-oleic acid-PG-SDS-SF-PE. The prothrombin-converting activities of membranes containing MePA, PG, PE, PLac, SDS and SF were considerably decreased when the ionic strength of the reaction medium was raised (Figure 3). Prothrombin activation on membranes with PS or PA was, however, hardly affected by ionic strength variation. The ionic strength effects suggest that for the first group of lipids electrostatic interactions between prothrombin, factor $\mathrm{Xa}$ and the membrane significantly contribute to the assembly of a catalytically active prothrombinase complex [19]. The observations with PS- and PA-containing membranes suggest that with these anionic lipids electrostatic interactions are less important and that coordination binding (chelate complex formation) between $\mathrm{Ca}_{2}+$-ions and ligands provided by the Gla-residues of the proteins and the polar head groups of membrane phospholipids is the major driving force in protein-membrane association $[20,21]$. Ligands that may participate in the formation of such a coordination complex are the phosphate-, carboxyl- and/or the amino groups of the phospholipids [16] and the carboxyl groups of the Gla-residues. Furthermore it is possible that the coordination sphere of the $\mathrm{Ca}^{2}+$ ions may be completed by water or by ligands provided by other amino acids present in the binding domains of prothrombin and factor Xa. Taken together these data show that the different anionic lipids 
used in this study can be useful tools in further studies on the importance of different molecular interactions for the assembly of the prothrombinase complex on procoagulant membranes.

When factor $\mathrm{Va}$ was part of the prothrombin activating complex the differences between the various anionic lipids were much less pronounced. In the presence of factor $\mathrm{Va}$ all anionic lipids exhibited excellent prothrombin-converting activities (Table 1) and optimal rates of prothrombin activation were already obtained at low total lipid concentrations (Figure 1) and at rather low mole percentages anionic lipid (Figure 2). lonic strength variation also had much less effect on the ability of membranes to enhance prothrombin activation by the factor $\mathrm{Xa}-\mathrm{Va}$ complex. These observations presumably reflect additional effects of factor $\mathrm{Va}$ on the assembly of the prothrombinase complex on membranes with a low affinity for coagulation factors [8], a phenomenon that is most likely explained by the fact that factor $\mathrm{Va}$ can promote membrane binding of factor $\mathrm{Xa}[4,5]$ and prothrombin [32].

In this study we also observed that membranes composed of only PC were not inert in prothrombin activation. At low ionic strength and in the presence of factor $\mathrm{Va}, \mathrm{PC}$ membranes exhibited considerable prothrombinconverting activity. Although activity of $\mathrm{PC}$ membranes in extrinsic factor $\mathrm{X}$ activation has been published [34], this is to the best of our knowledge the first report on PC activity in prothrombin activation.

A more detailed investigation on the prothrombin-converting activity of PC membranes is presented in chapter 7 of this thesis.

\section{References}

1. Jackson C.M. and Nemerson Y. (1980) Blood coagulation, Ann. Rev. Biochem. 49, 765-811

2. Tans G. and Rosing J. (1987) in New Comprehensive Biochemistry. Blood Coagulation (Hemker H.C., and Zwaal R.F.A., eds.) pp 59-85, Elsevier, Amsterdam, The Netherlands

3. Rosing J. and Tans G. (1989) in Coagulation and Lipids (Zwaal R.F.A., ed.) pp 159-187, CRC Press, Boca Raton, FL.

4. Nesheim M.E., Taswell J.B. and Mann K.G. (1979) The contribution of bovine factor $V$ and factor $V a$ to the activity of prothrombinase, J. Biol. Chem. 254, 1095210962

5. Lindhout T., Govers-Riemslag J.W.P., van de Waart P., Hemker H.C. and Rosing J. (1982) Factor Va-factor Xa interaction. Effects of phospholipid vesicles of varying composition, Biochemistry 21 5494-5502 
6. Rosing J., Tans G., Govers-Riemslag J.W.P., Zwaal R.F.A. and Hemker H.C. (1980) The role of phospholipids and factor $\mathrm{Va}$ in the prothrombinase complex, $\mathrm{J}$. Biol. Chem. 255, 274-283

7. Pusey M.L. and Nelsestuen G.L. (1983) The physical significance of $\mathrm{Km}$ in the prothrombinase reaction, Biochem. Biophys. Res. Commun. 114, 526-532

8. van Rijn J.L.M.L., Govers-Riemslag J.W.P., Zwaal R.F.A. and Rosing J. (1984) Kinetic studies of prothrombin activation: Effect of factor $\mathrm{Va}$ and phospholipids on the formation of the enzyme substrate complex, Biochemistry 23, 4557-4564

9. Bloom J.W., Nesheim M.E., and Mann K.G. (1979) Phospholipid-binding properties of bovine factor Va, Biochemistry 18, 4419-4425

10. Pusey M.L., Mayer L.D., Jason Wei G., Bloomfield V.A. and Nelsestuen G.L. (1982) Kinetic and hydronamic analysis of blood clotting factor V-membrane binding, Biochemistry 21, 5262-5269

11. van de Waart P., Bruls H., Hemker H.C. and Lindhout T. (1983) Interaction of bovine blood clotting factor $\mathrm{Va}$ and its subunits with phospholipid vesicles, Biochemistry 22, 2427-2432

12. Nelsestuen G.L. (1976) Role of gamma-carboxyglutamic acid. An unusual protein transition required for the calcium-dependent binding of prothrombin to phospholipid, J. Biol. Chem. 251, 5648-5656

13. Prendergast F.G. and Mann K.G. (1977) Differentiation of metal ion-induced transitions of prothrombin fragment 1, J. Biol. Chem. 251, 840-850

14. Furie B.C., Mann K.G. and Furie B. (1976) Substitution of lanthanide ions for calcium ions in the activation of bovine prothrombin by activated factor $X$. High affinity metal binding sites of prothrombin and the derivatives of prothrombin activation, J. Biol..Chem. 251, $3235-3241$

15. Deerfield D.W., Berkowitz P., Olson D.L., Wells S., Hoke R.A., Koehler K.A., Pedersen L. G. and Hiskey R. G. (1986) The effect of divalent metal ions on the electrophoretic mobility of bovine prothrombin and prothrombin fragment $1, \mathrm{~J}$. Biol. Chem. 261, 4833-4839

16. Hendrickson H.S. and Fullington J. G. (1965) Stabilities of metal complexes of phospholipids: $\mathrm{Ca}(\mathrm{II}), \mathrm{Mg}(\mathrm{II})$, and $\mathrm{Ni}(\mathrm{II})$ complexes of phosphatidylserine and triphosphoinositide, Biochemistry 4, 1599-1605

17. Abramson M.B., Katzman R., Gregor H. and Curci R. (1966) The reaction of cations with aqueous dispersions of phosphatidic acid. Determination of stability constant, Biochemistry 5, 2207-2213

18. Hauser H., Darke A. and Phillips M. C. (1976) Ion binding to phospholipids, Eur. J. Bioch. 62, 335-344

19. Dombrose F.A., Gitel S.N., Zawalich K. and Jackson C.M. (1979) The association of bovine prothrombin fragment 1 with phospholipid. Quantitative characterization of the $\mathrm{Ca} 2+$ ion mediated binding of prothrombin fragment 1 to phospholipid vesicles and a molecular model for its association with phospholipids, J. Biol. Chem. 254, 5027-5040

20. Resnick R. M. and Nelsestuen G. L. (1980) Prothrombin-membrane interaction. Effects of ionic strength, $\mathrm{pH}$ and temperature, Biochemistry 19, 3028-3033

21. Rosing J., Speijer H. and Zwaal R.F.A. (1988) Prothrombin activation on phospholipid membranes with positive electrostatic potential, Biochemistry 27, 811 
22. Owen W.G., Esmon C.T. and Jackson C.M. (1974) The conversion of prothrombin to thrombin. I. Characterization of reaction products formed during the activation of bovine prothrombin, J. Biol. Chem. 249, 594-605

23. Fujikawa K., Legaz M.E. and Davie E.W. (1972) Bovine factor $X(1)$ and $X(2)$ (Stuart factor) isolation and characterization, Biochemistry 11, 4882-4891

24. Fujikawa K., Legaz M.E. and Davie E.W. (1972) Bovine factor X(1) (Stuart factor) mechanism of activation by a protein from Russel's viper venom, Biochemistry 11 , 4892-4899

25. Schiffman S., Theodor J. and Rapaport S.J. (1969) Separation from Russel's viper venom of one fraction reacting with factor $X$ and another reacting with factor $V$, Biochemistry 8, 1397-1405

26. Smith R.L. (1973) Titration of activated bovine factor X, J. Biol. Chem. 248, 24182423

27. Chase T. Jr., and Shaw E. (1969) Comparison of the esterase activities of trypsin plasmin and thrombin on guanidinobenzoate esters - titration of the enzymes, Biochemistry 8, 2212-2224

28. Comfurius P. and Zwaal R.F.A. (1977) The enzymatic synthesis of phosphatidylserine and purification by $\mathrm{CM}$-cellulose column chromatography, Biochim. Biophys. Acta 488, 36-42

29. Böttcher C.J.F., van Gent C.M. and Pries C. (1961) A rapid and sensitive sub-micro phosphorus determination, Anal. Chim. Acta 24, 203-207

30. Reed C. F., Swisher S. N., Marinetti G.V. and Eden E. G. (1960) Studies of the lipids of the erythrocyte. 1. Quantitative analysis of the lipids of normal human red blood cells, J. Lab. Clin. Med. 56, 281-286

31. Nelsestuen G. L. (1978) Interactions of vitamin K-dependent proteins with calcium ions and phospholipid membranes, Fed.Proc. 37, 2621-2625

32. van de Waan P., Hemker H. C. and Lindhout T. (1984) Interaction of prothrombin with Factor Va-phospholipid complexes, Biochemistry 23, 2838-2842

33. Nelsestuen G.L. and Broderius M. (1977) Interactions of prothrombin and bloodclotting factor $X$ with membranes of varying composition, Biochemistry $16,4172-$ 4177

34. Forman S.D. and Nemerson Y. (1986) Membrane-dependent coagulation reaction is independent of the concentration of phospholipid-bound substrate: fluid phase factor $\mathrm{X}$ regulates the extrinsic system, Proc. Natl. Acad. Sci. 83, 4675-4679 
Chapter 7

\section{Prothrombin Activation on Dioleoylphosphatidylcholine Membranes}




\section{Summary}

Factor Xa-catalyzed prothrombin activation is greatly accelerated by negatively charged phospholipids plus calcium ions. In 1990, we reported that neutral phosphatidylcholine membranes also stimulated prothrombin activation [1]. In the present study, we have performed a detailed analysis of the prothrombin-converting activity of phosphatidylcholine membranes. Stimulation of prothrombin activation by phosphatidylcholine vesicles was particularly observed: (1) with phosphatidylcholines that contained unsaturated hydrocarbon side chains, (2) in the presence of factor $\mathrm{Va}$, (3) at low ionic strength and (4) when $\mathrm{Ca}^{2+-i o n s}$ were present in the reaction medium. It is unlikely that the prothrombinase activity of phosphatidylcholine preparations was due to contaminating anionic phospholipids. This is concluded from the fact that thin layer chromatographic analysis showed that dioleoylphosphatidylcholine (DOPC) contained less than 0.1 mole \% anionic phospholipid, and that incorporation of such amounts of anionic lipids in DOPC membranes hardly increased their prothrombin-converting activity. At low ionic strength and in the presence of factor $\mathrm{Va}$ and calcium ions DOPC membranes accelerated prothrombin activation about 100-fold.

At ionic strength (I) 0.06 , prothrombin activation on $100 \mu \mathrm{M}$ DOPC was characterized by a $K_{m}$ for prothrombin of $2 \mu \mathrm{M}$, a $V_{\max }$ of $3020 \mathrm{Ila} / \mathrm{min} / \mathrm{Xa}$ and a $K_{d}$ for factor $\mathrm{XaVa}$ complex formation at the membrane surface of 7.5 $\mathrm{nM}$. Prothrombin activation on DOPC membranes was drastically reduced when the ionic strength was increased. The inhibition at high ionic strength could be explained by an effect on the $K_{d}$ for XaVa complex formation which increased from $7.5 \mathrm{nM}$ at $\mathrm{I}=0.06$ to $100 \mathrm{nM}$ at $\mathrm{I}=0.22$.

Prothrombin-converting activity of PC membranes was only observed on membranes which are composed of PC that contains unsaturated hydrocarbon side chains. Membranes prepared from phosphocholinecontaining lipids with saturated hydrocarbon side chains such as dimyristoyl$P C$, dipalmitoyl-PC, distearoyl-PC and dioctadecylglycerophosphocholine hardly accelerated prothrombin activation. These results indicate that the phosphocholine moiety of PC can promote the assembly of a functionally active prothrombinase complex provided that the nonpolar core of the membrane contains unsaturated hydrocarbon chains.

Prothrombin activation on DOPC required $\mathrm{Ca}_{2} 2+$-ions and was dependent on the presence of Gla domains in prothrombin and factor $\mathrm{Xa}$. This indicates that similar interactions may account for the assembly of prothrombinase 
complexes on phosphatidylcholine and on anionic lipid-containing membranes.

\section{Introduction}

The enzyme complexes that convert the zymogens of vitamin K-dependent coagulation factors into the corresponding serine proteases show a striking resemblance with respect to composition, cofactor requirement and mechanism of action [2,3]. Each complex consists of a vitamin K-dependent serine protease that is associated with a non-enzymatic protein cofactor on a suitable membrane surface. The same membrane surface also supports the binding of the zymogen substrate which becomes activated after proteolytic cleavage of one or more specific peptide bonds by the serine proteasecofactor complex.

Most of our knowledge on the structural and functional properties of the vitamin K-dependent enzyme complexes originate from studies of prothrombin activation. This reaction is catalyzed by the so-called prothrombinase complex that consists of the serine protease, factor $\mathrm{Xa}$, the protein cofactor, factor $\mathrm{Va}, \mathrm{Ca} 2+$-ions and a phospholipid membrane. Membrane surfaces that contain negatively charged phospholipids exhibit the highest activity in prothrombin activation. The presence of negatively charged phospholipids appears to be important for optimal binding of prothrombin, factor $\mathrm{Xa}$ as well as factor $\mathrm{Va}$ (for a review see ref. [4]).

Both prothrombin and factor $\mathrm{Xa}$ are vitamin $\mathrm{K}$-dependent proteins which contain $\gamma$-carboxyglutamic acid residues $[5,6]$ that are involved in the $\mathrm{Ca}^{2+-}$ dependent binding of these proteins to the polar head groups of negatively charged phospholipid molecules that form part of the membrane $[7,8]$. The formation of the factor Va-membrane complex also requires negatively charged phospholipids [9] and has been reported to involve both hydrophobic $[9,10]$ and electrostatic interactions $[11,12]$.

A wide variety of negatively charged (phospho)lipids support the binding of the prothrombinase proteins to the membrane [13] and accelerate prothrombin activation [1]. It appears, however, that not every negatively charged phospholipid serves equally well in the assembly and in the expression of the catalytic activity of the prothrombinase complex. Van Rijn et al. [14] demonstrated that phosphatidylserine (PS)-containing membranes are much more effective in stimulating prothrombin activation than are membranes containing phosphatidic acid (PA) or phosphatidylglycerol (PG). 
The remarkable procoagulant properties of PS have been suggested to be due to specific interactions between the polar head group of PS and the coagulation factors participating in prothrombin activation $[15,16]$.

Although it is generally accepted that procoagulant membranes derive their functional activity from the presence of negatively charged phospholipids there are several reports in literature which demonstrate that there is not an absolute requirement for negatively charged lipids. The activations of factor $X$ by the tissue factor-factor VIla complex $[17,18]$, protein $C$ by the thrombin-thrombomodulin complex [19] and prothrombin by the factor XaVa complex [1] are also enhanced by membranes that are solely composed of phosphatidylcholine (PC).

Proper evaluation of the procoagulant activity of pure PC membranes and comparison with negatively charged membranes is hampered by the fact that the activities of PC in coagulation factor activation [1,17-19] were studied with limited variation of the reaction conditions. In the present investigation we have, therefore, compared the prothrombin-converting activities of PC and PS/PC membranes under a wide variety of experimental conditions in order to evaluate the specific contributions of neutral and negatively charged phospholipids to the assembly and to the catalytic activity of the prothrombinase complex. It is the first time that the kinetic constants for DOPC membranes are reported.

\section{Experimental procedures}

- Materials. S2238 was purchased from AB Kabi Diagnostica, Stockholm, Sweden. $p$ NPGB was from Nutritional Biochemicals. Dioleoyl-sn-glycero-3phosphocholine ( $\mathrm{diC}_{18: 1} \mathrm{PC}$ ), dioleoyl-sn-glycero-3-phosphoserine ( $\mathrm{diC}_{18: 1} \mathrm{PS}$ ), dioleoyl-sn-glycero-3-phosphate ( $\left.\mathrm{diC}_{18: 1} \mathrm{PA}\right)$ and dioleoyl-sn-glycero-3phosphoglycerol (diC 18:1PG) were obtained from Avanti Polar Lipids Inc., Alabaster, Alabama (USA). Dimyristoyl-sn-glycero-3-phosphocholine (diC ${ }_{14: 0} \mathrm{PC}$ ), dipalmitoyl-sn-glycero-3-phosphocholine ( $\mathrm{diC}_{16: 0} \mathrm{PC}$ ) and distearoyl-sn-glycero-3phosphocholine (diC $18: 0 \mathrm{PC}$ ) were supplied by Calbiochem, La Jolla, Ca, USA. Dilinoleoyl-sn-glycero-3-phosphocholine $\left(\mathrm{diC}_{18: 2} \mathrm{PC}\right)$, dilinolenoyl-sn-glycero-3phosphocholine ( $\mathrm{diC}_{18: 3} \mathrm{PC}$ ) and 1-stearyl-2-oleoyl-sn-glycero-3-phosphocholine $\left(\mathrm{C}_{18: 0} \mathrm{PC} / \mathrm{C}_{18: 1} \mathrm{PC}\right)$ were purchased from Applied Science Laboratories, Penn, PA, USA.Dioctadecyl-rac-glycero-3-phosphocholine (diC 18 :0-ether PC) was obtained from Novabiochem, Läufelfingen, Switzerland and sphingomyelin was obtained from Koch-Light, England. Ovalbumin (grade V), chymotrypsin, Russell's viper venom, Echis carinatus venom and benzamidine- $\mathrm{HCl}$ were obtained from Sigma, St. Louis. Column materials for protein purification (DEAE-Sephadex A-50, QAE-Sephadex A-50, SP-Sephadex C-50, Sephadex G-100, Sephadex G-200, 
and Sephacryl S-300) were purchased from Pharmacia, Uppsala, Sweden. Silica gel 60 plates for thin-layer chromatography of phospholipids were from Merck, Darmstadt, Germany.

- Proteins. Bovine prothrombin and prethrombin 1 were purified according to Owen et al. [20]. Bovine factor $X$ was purified as described by Fujikawa et al. [21]. Bovine factor $X$ a was prepared from factor $X$ after activation with RVV-X [22]. Gladomainless factor $X a$ was prepared as described by Morita and Jackson [23]. RVV-X was purified from the crude venom of Russell's viper [24]. Bovine factor Va was obtained according to the procedure of Lindhout et al. [25]. Prothrombin and factor Xa were stored at $-80^{\circ} \mathrm{C}$ in $50 \mathrm{mM}$ Tris- $\mathrm{HCl}(\mathrm{pH} \mathrm{7.9)}$ and $175 \mathrm{mM} \mathrm{NaCl}$. Factor Va was stored at $-80^{\circ} \mathrm{C}$ in the same buffer with $5 \mathrm{mM} \mathrm{CaCl}$.

- Protein concentrations. Prothrombin and prethrombin 1 concentrations were determined with p-NPGB (cf. thrombin active site titration [26] ), after complete activation of prothrombin with the activator from Echis carinatus venom. The molar concentrations of factor $\mathrm{Xa}$ and Gla-domainless factor $\mathrm{Xa}$ were determined by active site titration with p-NPGB [27]. Factor Va concentrations were determined by kinetic analysis [25].

- Phospholipids and phospholipid vesicle preparations. Single bilayer lipid vesicles were prepared as follows: lipid preparations, dissolved in chloroform/methanol $(1 / 1, v / v)$, were dried under a stream of $N_{2}$. The dried lipids were suspended in $50 \mathrm{mM}$ Tris- $\mathrm{HCl}(\mathrm{pH} 7.9)$ and $20 \mathrm{mM} \mathrm{NaCl}$ at room temperature or $65^{\circ} \mathrm{C}$ (in the case of $\mathrm{PC}$ which contained saturated hydrocarbon side chains) by vigorously vortexing for $1 \mathrm{~min}$. The phospholipid suspensions were subsequently sonicated for $10 \mathrm{~min}$ at $4^{\circ} \mathrm{C}$ or $65^{\circ} \mathrm{C}$ with a MSE Mark $\| 150-\mathrm{W}$ ultrasonic disintegrator set at $8 \mu \mathrm{M}$ peak to peak amplitude. Phospholipid concentrations were determined by phosphate analysis according to the method of Böttcher et al. [28].

- Assay system for measuring rates of prothrombin activation. Phospholipids, factor $\mathrm{Xa}$, and factor $\mathrm{Va}$ were incubated for $5 \mathrm{~min}$ at $37^{\circ} \mathrm{C}$ in $50 \mathrm{mM}$ Tris$\mathrm{HCl}$ buffer $(\mathrm{pH} 7.52)$ containing, $0.5 \mathrm{mg} / \mathrm{ml}$ ovalbumin and concentrations of $\mathrm{CaCl}_{2}$ and $\mathrm{NaCl}$ as indicated in the legends to the tables and figures. Prothrombin activation was started by the addition of prothrombin that was prewarmed at $37^{\circ} \mathrm{C}$ in the same buffer with $5 \mathrm{mM} \mathrm{CaCl}_{2}$. After appropiate time intervals aliquots from the reaction mixture were taken and added to disposable cuvettes containing 235 $\mu \mathrm{M}$ of the thrombin-specific chromogenic substrate $\mathrm{S} 2238$ in $50 \mathrm{mM}$ Tris- $\mathrm{HCl}$ $(\mathrm{pH} 7.9), 175 \mathrm{mM} \mathrm{NaCl}, 20 \mathrm{mM}$ EDTA, and $0.5 \mathrm{mg} / \mathrm{ml}$ ovalbumin. The amount of prothrombin activated was calculated from the absorbance change ( $\triangle \mathrm{A} \quad 405-500$ /min) measured on a dual-wavelength spectrophotometer, using a calibration curve of chromogenic substrate conversion by known concentrations of activesite-titrated thrombin. Rates of prothrombin activation were calculated from the amounts of prothrombin that were activated in the aliquots taken from the reaction mixture after different time intervals. Kinetic parameters for prothrombin activation $\left(\mathrm{K}_{\mathrm{m}}, \mathrm{KdXaVa}_{\mathrm{a}}\right.$ and $\left.\mathrm{V}_{\max }\right)$ were obtained by fitting the data of experiments in which the rate of prothrombin activation was measured as function of the prothrombin or factor Va concentration to the Michaelis-Menten equation using the Enzfitter computer program. 
- TLC analysis of phosphatidylcholine. Two-dimensional TLC analysis of phospholipids was performed at room temperature on $20 \times 20 \mathrm{~cm}$ plates coated with $0.5 \mathrm{~mm}$ silicagel 60 . The phospholipids were dissolved in chloroform/methanol $(1 / 1, v / v)$ and applied to the thin layer plate. Chloroform/methanol/ammonia $(25 \%) /$ water $(95: 50: 5.5: 5.5, \mathrm{v} / \mathrm{v})$ was used as eluent in the first dimension and chloroform/methanol/acetic-acid/water $(90: 40: 12: 2, v / v)$ was the eluent in the second dimension. After chromatography the silica gel plates were thoroughly dried and the phospholipids were visualized with iodine vapor. The amount of phospholipid present in each spot was determined by removing the silica from the plate, hydrolyzing the silica-bound phospholipid by destruction with $70 \% \mathrm{HClO}_{4}$ at $190^{\circ} \mathrm{C}$ and quantitating the liberated phosphate with the method of Böttcher et al. [28].

\section{Results}

\section{Prothrombin activition on neutral and negatively charged membranes}

The prothrombin-converting activities of neutral (DOPC) and negatively charged (DOPS/DOPC) membranes were compared in an experiment in which phospholipid-dependent prothrombin activation was examined both in the absence and presence of factor $\mathrm{Va}$ at low and high ionic strength (Table 1).

Table 1. The effect of DOPC and DOPS/DOPC on rates of prothrombin activation

rate of prothrombin activation ${ }^{a}$

phospholipid $\quad \frac{\text { without factor Va }}{20 \mathrm{mM} \mathrm{NaCl} 175 \mathrm{mM} \mathrm{NaCl}} \quad \frac{\text { with factor Va }}{20 \mathrm{mM} \mathrm{NaCl} 175 \mathrm{mM} \mathrm{NaCl}}$

\begin{tabular}{lrrrr}
\hline no phospholipid & 0.021 & 0.018 & 13 & 4 \\
DOPC (100) & 0.031 & 0.022 & 1181 & 87 \\
DOPS/DOPC (20/80) 1.35 & 1.31 & 3317 & 3048
\end{tabular}

$2 \mu \mathrm{M}$ Prothrombin was activated in a reaction mixture containing $50 \mathrm{mM}$ Tris- $\mathrm{HCl}$ $(\mathrm{pH} 7.5), 20 \mathrm{mM} \mathrm{NaCl}$ or $175 \mathrm{mM} \mathrm{NaCl}, 5 \mathrm{mM} \mathrm{CaCl} 2,0.5 \mathrm{mg} / \mathrm{ml}$ ovalbumin, $100 \mu \mathrm{M}$ phospholipic vesicles, and $4 \mathrm{nM}$ factor $\mathrm{Xa}$ without factor $\mathrm{Va}$ or $5 \mathrm{pM}$ factor Xa plus $5 \mathrm{nM}$ factor Va.

amoles prothrombin activated per minute per mole factor $X a$ present in the reaction mixture.

The stimulatory effect of phospholipids on prothrombin activation by factor $\mathrm{Xa}$ alone (i.e. without factor $\mathrm{Va}$ ) appeared to be strictly dependent on the 
presence of negatively charged phospholipids. This can be concluded from the fact that similar rates of prothrombin activation were observed in free solution and in the presence of DOPC membranes, whereas negatively charged membranes that contained 20 mole \% DOPS in DOPC caused a 70-fold acceleration of factor Xa-catalyzed prothrombin activation. When factor Va was part of the prothrombinase complex, DOPC membranes were also able to accelerate prothrombin activation. Prothrombin-converting activity of DOPC membranes was especially observed at low ionic strength, conditions at which the activity of DOPC membranes was $35 \%$ of that of the DOPS/DOPC membranes.

The data presented in Table 1 indicate that membranes solely composed of dioleoyl-PC are able to stimulate the activation of prothrombin. We decided to investigate whether the fatty acyl side chain composition of PC may be important in the formation of a functionally active prothrombinase complex. To this end we have compared the prothrombin-converting activity of a variety of phosphatidylcholines with fatty acyl chains of different length and degree of unsaturation, and of phosphocholine-containing lipids in which unsaturated hydrocarbon side chains are attached to a sphingosine

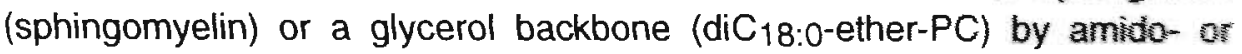
ether linkages, respectively.

In Table 2 we have summarized the prothrombin-converting activities of the different phosphocholine-containing lipids. All lipid vesicles composed of PC with unsaturated fatty acyl chains were able to cause considerable stimulation of prothrombin activation, in the presence of factor Va. Vesicles prepared from PC with one saturated and one unsaturated side chain (1stearyl-2-oleoyl-PC) or from egg PC, which is a mixture of PC molecules with side chains of different length and degree of unsaturation, were less active, but were still able to enhance prothrombin activation. Phosphocholine-containing lipids with saturated hydrocarbon side chains (diC 14:0 PC, diC 16:0 PC, diC 18:0 PC, sphingomyelin and diC $_{18: 0 \text {-ether-PC) }}$ hardly stimulated prothrombin activation. It could be argued that the lack of prothrombin-converting activity of the latter group of membranes is due to the fact that these membranes may be in the so-called gel phase. However, under the experimental conditions membranes composed of $\mathrm{diC}_{14: 0} \mathrm{PC}$ were in the liquid-crystalline state since the transition temperature of this PC is $23^{\circ} \mathrm{C}$ [29] and the prothrombin-converting activity of these membranes was determined at $37^{\circ} \mathrm{C}$. Assaying prothrombin activation at $50^{\circ} \mathrm{C}$, which is also above the transition temperature of $\mathrm{diC}_{16: 0} \mathrm{PC}\left(\mathrm{T}_{\mathrm{m}}=41.5^{\circ} \mathrm{C}[30]\right)$ did not enhance the prothrombin-converting activity of membranes composed of 
PC with saturated hydrocarbon side chains (data not shown). These results indicate that the phosphocholine moiety of PC can indeed promote the assembly of a functionally active prothrombinase complex provided that the PC molecules contain unsaturated hydrocarbon side chains.

Table 2. Prothrombin activation on vesicles composed of different cholinecontaining phospholipids

\begin{tabular}{|c|c|}
\hline phospholipid & $\begin{array}{c}\text { rate of prothrombin } \\
\text { activation } \\
(\mathrm{mol} / \mathrm{min} / \mathrm{mol} \mathrm{Xa})\end{array}$ \\
\hline no phospholipid & 10 \\
\hline dioleoyl-PC ( $\left.\mathrm{diC}_{18: 1} \mathrm{PC}\right)$ & 410 \\
\hline dilinoleoyl-PC (diC $18: 2 \mathrm{PC}$ ) & 730 \\
\hline dilinolenoyl-PC (diC $18: 3 \mathrm{PC}$ ) & 738 \\
\hline 1-stearyl-2-oleoyl PC $\left(\mathrm{C}_{18: 0}-\mathrm{C}_{18: 1} \mathrm{PC}\right)$ & 162 \\
\hline egg PC & 95 \\
\hline dimyristoyl-PC (diC $14: 0 P C)$ & 13 \\
\hline dipalmitoyl PC (diC $16: 0$ PC) & 41 \\
\hline distearoyl-PC (diC18:0 PC) & 23 \\
\hline diC $_{18: 0}$-ether PC & 28 \\
\hline sphingomyelin & 26 \\
\hline
\end{tabular}

Prothrombin $(0.5 \mu \mathrm{M})$ was activated in a reaction mixture containing $50 \mathrm{mM}$ Tris- $\mathrm{HCl}$ (pH 7.9), $20 \mathrm{mM} \mathrm{NaCl}, 5 \mathrm{mM} \mathrm{CaCl} 2,0.5 \mathrm{mg}$ ovalbumin, $100 \mu \mathrm{M}$ phospholipid, $5 \mathrm{pM}$ factor $\mathrm{Xa}$, and $5 \mathrm{nM}$ factor $\mathrm{Va}$.

The data presented in this section show that neutral membranes, that are solely composed of phosphatidylcholine, effectively promote the assembly of a functionally active prothrombinase complex when: (a) phosphatidylcholine contains unsaturated hydrocarbon side chains, (b) factor $\mathrm{Va}$ is part of the prothrombinase complex and (c) prothrombin is activated at low ionic strength.

Since prothrombin-converting activity of DOPC membranes was only observed in the presence of factor $\mathrm{Va}$ all data discussed in the remainder of this paper pertain to experiments performed in the presence of factor $\mathrm{Va}$.

\section{TLC of DOPC preparations with prothrombin-converting activity}

To rule out the possibility that the acceleration of prothrombin activition by DOPC was due to the presence of trace amounts of contaminating anionic 


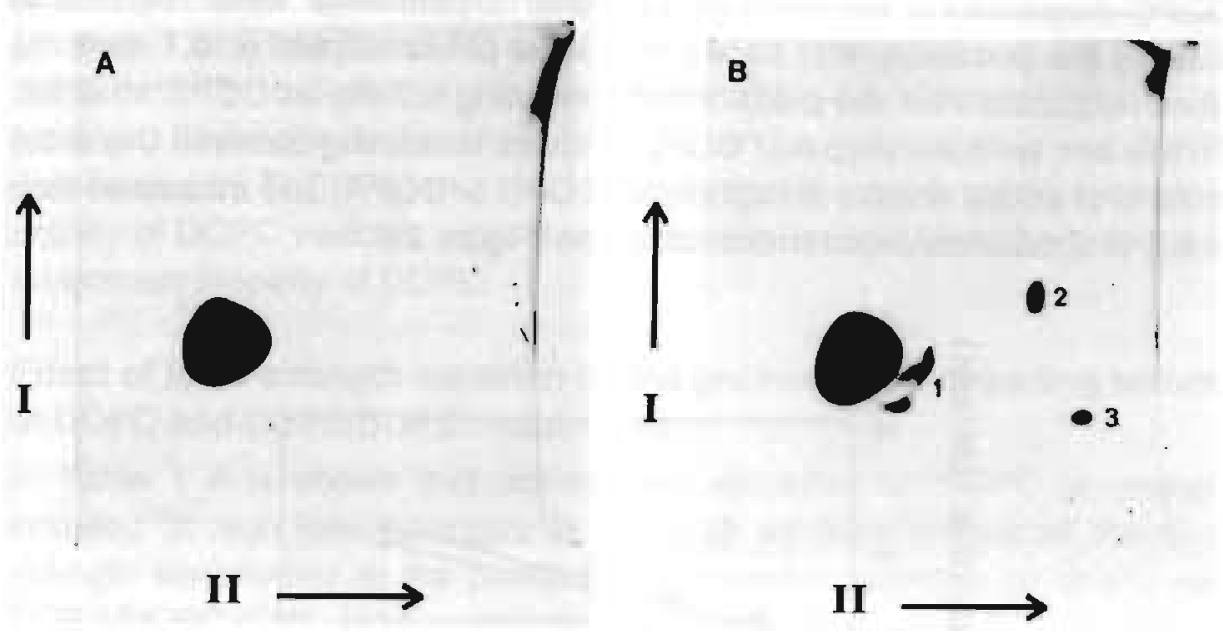

Figure 1. Two-dimensional TLC analysis of DOPC. Solvent I: chloroform/methanol/ ammonia $(25 \%) /$ water $(95: 50: 5.5: 5.5, \mathrm{v} / \mathrm{v})$. Solvent II: chloroform/methanol/acelic acid/water $(90: 40: 12: 2$, v/v). (A): $10 \mathrm{mg}$ of DOPC. (B): $10 \mathrm{mg}$ of DOPC plus $0.1 \mathrm{~mole} \%$ DOPS, plus 0.1 mole\% DOPA, and 0.1 mole\% DOPG. Spot 1 is DOPS, spot 2 is DOPG, and spot 3 is DOPA. TLC analysis was performed as described under Experimental Procedures.

phospholipids we have analyzed the purity of our DOPC preparation with two-dimensional TLC (Figure 1A). In order to test the sensitivity of the TLC method for the detection of traces of phospholipids we have also chromatographed a DOPC sample to which we added 0.1 mole \% DOPS, 0.1 mole \% DOPG and 0.1 mole \% DOPA (Figure 1B).

Comparison of the two chromatograms shows that the DOPC preparation used in the prothrombinase experiments contained less than 0.1 mole $\%$ anionic phospholipid, if at all.

We also ruled out the possibility that sonication of DOPC in aqueous environment resulted in lipid hydrolysis which could introduce prothrombinconverting activity in the resulting vesicles preparation. Prolonged sonication (up to 2 hours) of the DOPC vesicles did neither increase the prothrombinconverting activity of the vesicles nor did it change the TLC pattern of DOPC extracted from the sonicated vesicle preparation (data not shown). 


\section{Prothrombin activation on DOPC membranes containing trace amounts of anionic phospholipids}

Although we were not able to detect anionic phospholipids in procoagulant DOPC preparations we felt that additional experiments were required to exclude the possibility that traces of anionic phospholipids $(<0.1$ mole \%) were responsible for the prothrombin-converting activity of DOPC vesicles. To this end we have prepared DOPC vesicles containing between 0 and 0.5 mole $\%$ of added anionic phospholipid (DOPS or DOPA) and measured their ability to accelerate prothrombin activation (Figure 2).

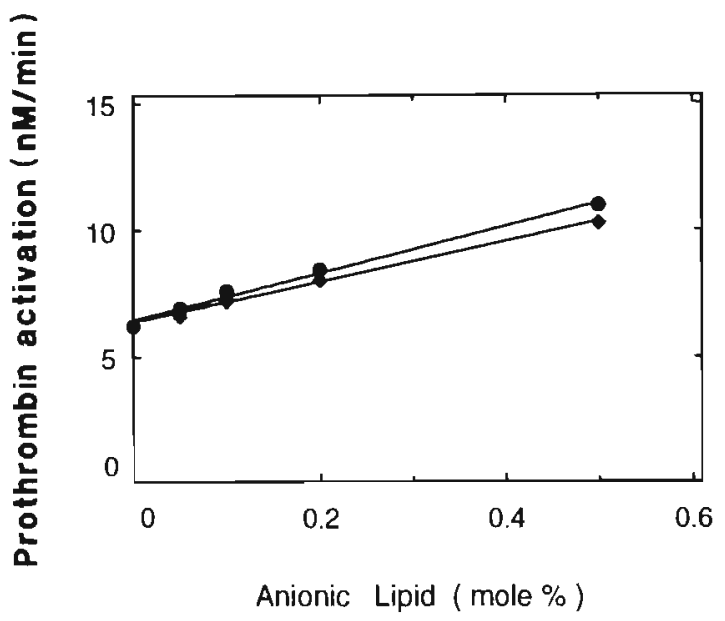

Figure 2. Effect of low mole percentages anionic lipids on the prothrombinconverting activity of DOPC membranes. Prothrombin $(2 \mu \mathrm{M})$ was activated in a reaction mixture containing $50 \mathrm{mM}$ Tris- $\mathrm{HCl}(\mathrm{pH} 7.5), 20 \mathrm{mM} \mathrm{NaCl}, 5 \mathrm{mM} \mathrm{CaCl}, 0.5$ $\mathrm{mg} / \mathrm{ml}$ ovalbumin, $5 \mathrm{pM}$ factor $\mathrm{Xa}, 5 \mathrm{nM}$ factor $\mathrm{Va}$ and $100 \mu \mathrm{M}$ DOPC vesicles with varying mole percentages anionic lipid. The anionic lipids used were DOPS (๑) and DOPA $(\$)$. Rates of prothrombin activation were determined as described under Experimental Procedures.

These low concentrations of anionic phospholipids caused a small but statistically significant stimulation of prothrombin activation which appeared to be linearly dependent on the added mole percentage of anionic phospholipid.

The equations that describe these linear relationships are

$v=9.23 \times$ mole PSadded $+v^{\prime}$ (eq.1)

$v=7.94 \times$ mole PAadded $+v^{\prime}$ (eq. 2)

in which $v$ is the observed rate of prothrombin activation and $v^{\prime}$ is the rate of prothrombin activation determined on pure $P C$ vesicles $(6.41 \mathrm{nM} / \mathrm{min})$. It can 
be argued that this activity of the $P C$ vesicles $\left(v^{\prime}\right)$ is actually due to an unknown trace amount of PS or PA and that the actual rate of prothrombin activation on pure $P C$ vesicles should equal the rate of prothrombin activation in free solution $(0.07 \mathrm{nM} / \mathrm{min})$. In that case it can be calculated from eq. 1 or 2 that "pure" PC should contain 0.7 mole \% PS or 0.8 mole \% $\mathrm{PA}$ in order to explain the observed prothrombin-converting activity of $\mathrm{PC}$ vesicles. Since this is far above any PS or PA detectable in our DOPC preparation by TLC (Figure 1) we conclude that the prothrombin-converting activity of DOPC vesicles is not due to traces of anionic phospholipids but is an intrinsic property of DOPC.

\section{Effect of ionic strength variation on the prothrombin-converting activity of DOPC and DOPS/DOPC membranes}

In Table 1 it is shown that prothrombin activation on DOPC is strongly inhibited at high ionic strength. In Figure 3 we have compared the ionic strength sensitivities of the prothrombin-converting activities of DOPC and DOPS/DOPC (5/95, M/M) membranes.

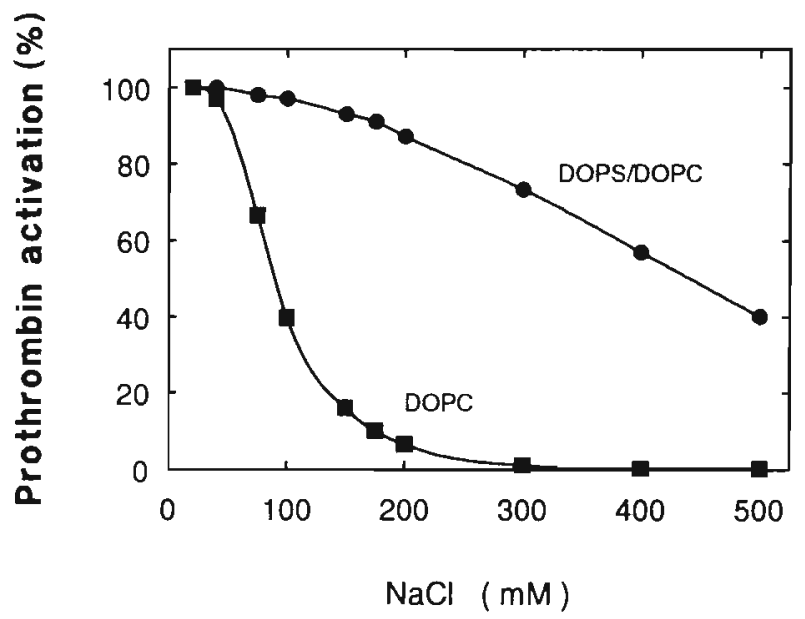

Figure 3. Effect of ionic strength variation on the prothrombin-converting activity of DOPC or DOPS/DOPC (5/95) membranes. Prothrombin $(2 \mu \mathrm{M})$ was activated in a reaction mixture containing $50 \mathrm{mM}$ Tris $-\mathrm{HCl}(\mathrm{pH} 7.5), 20-500 \mathrm{mM} \mathrm{NaCl}, 5 \mathrm{mM} \mathrm{CaCl} 2,0.5$ $\mathrm{mg} / \mathrm{ml}$ ovalbumin, $5 \mathrm{pM}$ factor $\mathrm{Xa}, 5 \mathrm{nM}$ factor $\mathrm{Va}$ and $100 \mu \mathrm{M}$ DOPC (a) or $100 \mu \mathrm{M}$ DOPS/DOPC, 5/95, M/M (๑). Rates of prothrombin activation were determined as described under Experimental Procedures. Rates of prothrombin activation at $20 \mathrm{mM}$ $\mathrm{NaCl}$ were $6.4 \mathrm{nM} / \mathrm{min}$ (DOPC) or $17.4 \mathrm{nM} / \mathrm{min}$ (DOPS/DOPC). 
Prothrombin activation on DOPC vesicles appeared to be already inhibited at rather low $\mathrm{NaCl}$ concentrations $(50 \%$ inhibition at $90 \mathrm{mM} \mathrm{NaCl})$ whereas the activity of DOPS/DOPC vesicles was much more resistent to variation of the $\mathrm{NaCl}$ concentration $(50 \%$ inhibition at $450 \mathrm{mM} \mathrm{NaCl})$. It is important to note that at physiological ionic strength, which corresponds to $[\mathrm{NaCl}]=150$ $\mathrm{mM}$, the prothrombin-converting activity of DOPC was already inhibited for more than $90 \%$ and that in absolute terms the activity of the DOPC vesicles was only $6 \%$ of that of the DOPS/DOPC vesicles (15.8 vs. $1.0 \mathrm{nM}$ prothrombin activated/min).

\section{Calcium and Gla requirements of prothrombin activation on DOPC and DOPS/DOPC membranes}

Stimulation of prothrombin activation by negatively charged membranes is strictly dependent on the presence of calcium ions. It is generally accepted that the calcium ions are required for bridging the Gla-domains of the vitamin $\mathrm{K}$-dependent proteins to the polar head groups of anionic membrane phospholipids (see ref. [3], for a review)

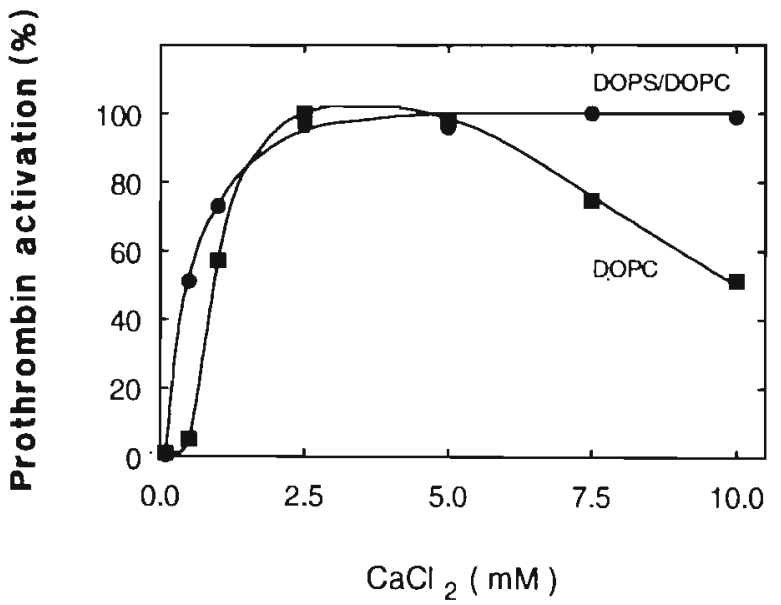

Figure 4. $\mathrm{Ca}^{2+-d e p e n d e n c e ~ o f ~ p r o t h r o m b i n ~ a c t i v a t i o n ~ o n ~ D O P C ~ o r ~ D O P S / D O P C ~}$ $(5 / 95)$ membranes. Prothrombin $(2 \mu \mathrm{M})$ was activated in a reaction mixture containing 50 $\mathrm{mM}$ Tris-HCl $(\mathrm{pH} 7.5), 20-50 \mathrm{mM} \mathrm{NaCl}, 0-10 \mathrm{mM} \mathrm{CaCl}_{2}, 0.5 \mathrm{mg} / \mathrm{ml}$ ovalbumin, $5 \mathrm{pM}$ factor $\mathrm{Xa}, 5 \mathrm{nM}$ factor $\mathrm{Va}$ and $100 \mu \mathrm{M}$ DOPC (ם) or $100 \mu \mathrm{M}$ DOPS/DOPC, 5/95, M/M ()). The ionic strength of the reaction mixtures with varying $\mathrm{CaCl}_{2}$ concentrations was adjusted with appropriate amounts of $\mathrm{NaCl}$. Rates of prothrombin activation were determined as descibed under Experimental Procedures. 
Prothrombin activation on DOPC membranes also required the presence of calcium ions, but showed a calcium dependence that is somewhat different from that observed for DOPS/DOPC membranes (Figure 4).

Whereas low $\mathrm{Ca}^{2+}+$-concentrations $(<0.5 \mathrm{mM})$ already caused considerable stimulation of prothrombin activation on DOPS/DOPC vesicles, the prothombin-converting activity of DOPC vesicles was hardly stimulated and required much higher $\mathrm{CaCl}_{2}$ concentrations. Another difference was the gradual inhibition of prothrombin activation on DOPC membranes at $\left[\mathrm{Ca}^{2}+\right]$ $>5 \mathrm{mM}$.

Ca2t-ions may enhance the prothrombin-converting activity of DOPC membranes by at least 3 different mechanisms: (1) by promoting the binding of prothrombin and/or factor $\mathrm{Xa}$ to the membrane surface in a manner similar to that suggested for negatively charged membranes, (2) by mediating factor $\mathrm{Xa}-\mathrm{Va}$ complex formation, and (3) by increasing the catalytic activity of the prothrombinase complex. With respect to the second possibility it is important to note that it has been reported that $\mathrm{Ca}^{2}+$-ions are required for factor $\mathrm{Xa}$ - Va complex formation in free solution [31]. If $\mathrm{Ca}^{2+-i o n s}$ are required for the binding of factor $\mathrm{Xa}$ and/or prothrombin to the DOPC membrane surface (possibility 1 ) it is to be expected that stimulation of prothrombin activation by DOPC would also be dependent on the presence of Gla-domains in prothrombin and factor $\mathrm{Xa}$. Indeed it was observed that

Table 3. Effect of DOPC membranes on rates of prothrombin activation. Determined with Gla-Containing and Gla-Domainless Proteins

rate of prothrombin activationa

prothrombin activating complex

prothrombin prethrombin 1

1) factor $\mathrm{Xa}$, factor $\mathrm{Va}, \mathrm{Ca} 2+$

13.4

26.3

2) factor $\mathrm{Xa}$, factor $\mathrm{Va}, \mathrm{DOPC}, \mathrm{Ca} 2+$

1107.0

71.3

3) factor $\mathrm{Xa}(-\mathrm{GD})$, factor $\mathrm{Va}, \mathrm{Ca} 2+$

2.3

2.6

4) factor $\mathrm{Xa}(-\mathrm{GD})$, factor $\mathrm{Va}, \mathrm{DOPC}, \mathrm{Ca}^{2+}$

4.6

3.0

$2 \mu \mathrm{M}$ Prothrombin or $2 \mu \mathrm{M}$ prethrombin 1 was activated in a reaction mixture containing $50 \mathrm{mM}$ Tris- $\mathrm{HCl}$ (pH 7.5), $20 \mathrm{mM} \mathrm{NaCl}, 5 \mathrm{mM} \mathrm{CaCl} 2,0.5 \mathrm{mg} / \mathrm{ml}$ ovalbumin, by (1) $0.2 \mathrm{nM}$ factor $X a$ plus $5 \mathrm{nM}$ factor $V a$ or (2) $5 \mathrm{pM}$ factor $X a$ plus $5 \mathrm{nM}$ factor $V a$ and $100 \mu \mathrm{M}$ DOPC vesicles or (3) $0.2 \mathrm{nM}$ factor $\mathrm{Xa}(-\mathrm{GD}$ ) plus $5 \mathrm{nM}$ factor $V a$ or (4) $0.2 \mathrm{nM}$ factor $\mathrm{Xa}$ (-GD) plus $5 \mathrm{nM}$ factor $\mathrm{Va}$ and $100 \mu \mathrm{M}$ DOPC vesicles. Rates of prothrombin activation were determined as described under the Experimental Procedures.

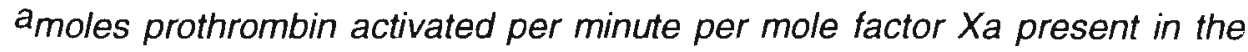
reaction mixture. 
DOPC hardly stimulated activation rates of Gla-domainless proteins (Table 3).

Neither the activation of prethrombin 1 by factor $\mathrm{Xa}$ nor the activation of prothrombin by Gla-domainless factor Xa (factor Xa-GD, [23] ) was stimulated by DOPC vesicles. These requirements for $\mathrm{Ca} 2+$-ions and $\mathrm{Gla}$ domains suggest that $\mathrm{Ca}^{2+-d e p e n d e n t ~ i n t e r a c t i o n s ~ b e t w e e n ~ t h e ~ G l a-~}$ domains of prothrombin and factor $\mathrm{Xa}$ and the DOPC surface are essential for the expression of the prothrombin-converting activity of DOPC vesicles.

\section{Comparison of kinetic parameters for prothrombin activation on DOPC and DOPS/DOPC membranes}

Negatively charged membranes accelerate prothrombin activation by decreasing the $\mathrm{K}_{\mathrm{m}}$ for prothrombin [32] and by promoting factor $\mathrm{XaVa}$ complex formation at the membrane surface [25,33]. This effect of phospholipids is illustrated by literature data summarized in Table 4.

Table 4. Effect of phospholipids on the kinetic parameters of prothrombin activation

\begin{tabular}{lcccc}
\hline Salt concentration & $\begin{array}{c}\mathrm{K}_{\mathrm{d}} \\
(\mathrm{nM})\end{array}$ & $\begin{array}{c}\mathrm{K}_{\mathrm{m}} \\
(\mu \mathrm{M})\end{array}$ & $\begin{array}{c}\mathrm{V}_{\max } \\
(\mathrm{nM} / \mathrm{min} / \\
\mathrm{nMXa})\end{array}$ \\
\hline Without phospholipid & $175 \mathrm{mM} \mathrm{NaCl}$ & $800-1300^{a, b}$ & $9.0 a$ & $1860 a$ \\
DOPS/DOPC (5/95) & $175 \mathrm{mM} \mathrm{NaCl}$ & 0.28 & 0.15 & 3830 \\
DOPC & $20 \mathrm{mM} \mathrm{NaCl}$ & 7.5 & 1.9 & 3020 \\
DOPC & $175 \mathrm{mM} \mathrm{NaCl}$ & 100 & 2.3 & $3522 \mathrm{c}$ \\
\hline
\end{tabular}

Prothrombin was activated in a reaction mixture containing $50 \mathrm{mM} \mathrm{Tris-HCl}(\mathrm{pH} \mathrm{7.5)}$, $\mathrm{NaCl}$ concentrations indicated in the table, $5 \mathrm{mM} \mathrm{CaCl} 2,0.5 \mathrm{mg} / \mathrm{ml}$ ovalbumin, $3 \mathrm{pM}$ factor $\mathrm{Xa}, 100 \mu \mathrm{M}$ DOPC vesicles, and $100 \mathrm{nM}$ factor $\mathrm{Va}\left(\mathrm{K}_{\mathrm{m}}\right.$ and $\mathrm{V}_{\max }$ determination) or varying concentrations factor $\mathrm{Va}$ (factor $\mathrm{Va}$ titration). The factor $\mathrm{Va}$ titration (Kd determination) was performed at $2 \mu \mathrm{M}$ prothrombin (see also Figure 5). Rates of prothrombin activation were determined as described under Experimental Procedures. The kinetic parameters were obtained by fitting double reciprocal plots of rates of prothrombin activation versus the factor $V_{a}$ concentration (Kd) or the prothrombin concentration ( $\mathrm{Km}$ and $V_{\max }$ ) to the Michaelis-Menten equation using the Enzfitter computer program

a $22^{\circ} \mathrm{C}$, Boskovic et al.[34]

b $20^{\circ} \mathrm{C}$, Pryzdial and Mann [31]

$c$ calculated for $[\mathrm{FVa}] \rightarrow \infty$, i.e. $2 x$ observed $V_{\max }$ since $[\mathrm{FVa}]=100 \mathrm{nM}=K_{d}$ 
Prothrombin activation by the factor XaVa complex in free solution is slow since it is characterized by a rather high $K_{m}$ for prothrombin $(9 \mu \mathrm{M}$, [34] and by rather unfavorable parameters for factor $\mathrm{XaVa}$ complex formation $\left(\mathrm{K}_{d}=\right.$ 800-1300 nM, [31,34]. The major effects of negatively charged phospholipids are on the $K_{m}$ for prothrombin, which in the presence of $100 \mu$ $M$ DOPS/DOPC $(5 / 95, M / M)$ vesicles drops to $0.15 \mu \mathrm{M}$, and on the $K_{d}$ for dissociation of the membrane bound factor $\mathrm{XaVa}$ complex which is $0.28 \mathrm{x}$ $10^{-3} \mu \mathrm{M}$ being 3000 -fold lower than in free solution.
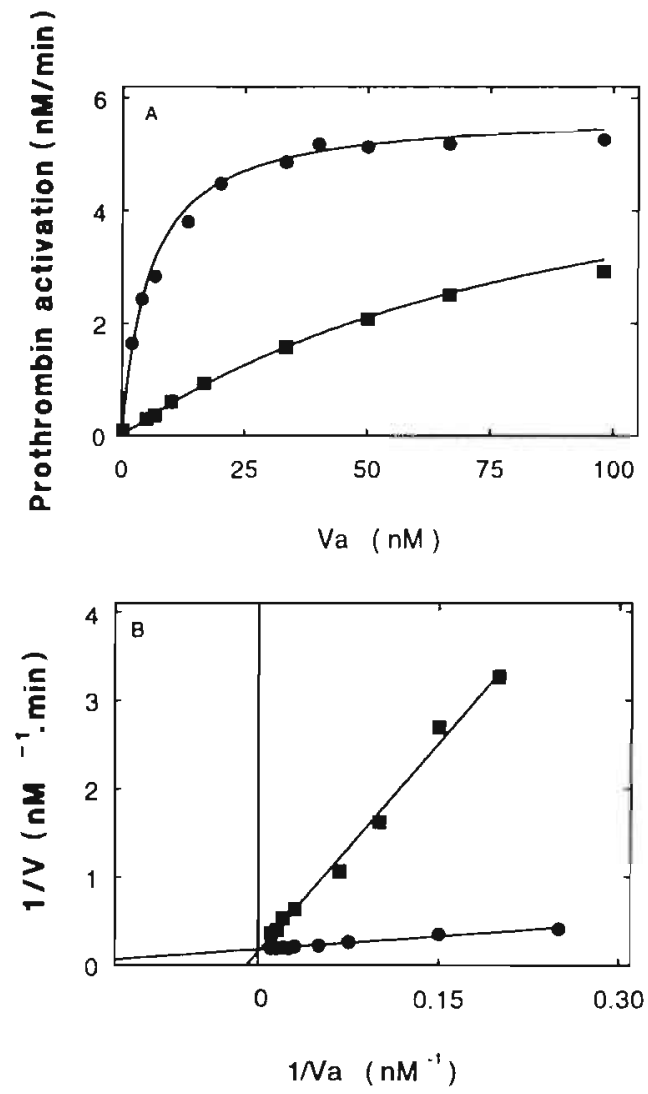

Figure 5. Influence of the ionic strength on the factor $\mathrm{Va}$ dependence of prothrombin activation on DOPC membranes. A) Prothrombin $(2 \mu \mathrm{M})$ was activated in a reaction mixture containing $50 \mathrm{mM} \mathrm{Tris}-\mathrm{HCl}(\mathrm{pH} 7.5), 40 \mathrm{mM} \mathrm{NaCl}(0)$ or $175 \mathrm{mM} \mathrm{NaCl}$ (ద), $5 \mathrm{mM} \mathrm{CaCl} 2,0.5 \mathrm{mg} / \mathrm{ml}$ ovalbumin, $3 \mathrm{pM}$ factor $\mathrm{Xa}$ and $100 \mu \mathrm{M}$ DOPC vesicles and varying concentrations factor $V a$. Rates of prothrombin activation were determined as described under Experimental Procedures. B) Double reciprocal plots of the same data. 
Table 4 also includes the results of a kinetic analysis of prothrombin activation on DOPC membranes. At $20 \mathrm{mM} \mathrm{NaCl}$ the $\mathrm{K}_{d}$ for dissociation of the membrane-bound factor $\mathrm{Xa}-\mathrm{Va}$ complex is $7.5 \times 10^{-3} \mu \mathrm{M}$ and the $\mathrm{K}_{\mathrm{m}}$ for prothrombin is $1.9 \mu \mathrm{M}$. These parameters (especially the $\mathrm{K}_{\mathrm{d}}$ ) are considerably below those observed in free solution which provides an adequate explanation for the stimulatory effect of DOPC membranes on prothrombin activation.

At high ionic strength there was a more than 10-fold increase of the $K_{d}$ for factor XaVa complex formation (Figures $5 \mathrm{~A}$ and $5 \mathrm{~B}$ ) which explains the decreased prothrombin-converting activity of DOPC membranes at high salt concentrations. The $V_{\max }$ values for prothrombin activation in free solution and in the presence of DOPC and DOPS/DOPC membranes are of the same order of magnitude.

These data indicate that both DOPC and DOPS membranes accelerate prothrombin activation by promoting the formation of the factor $\mathrm{XaVa}$ complex and the interaction of this complex with its substrate prothrombin. The similarity of the observed $V_{\text {max }}$ shows that membranes have a minimal effect on the intrinsic catalytic activity of the factor XaVa complex.

\section{Discussion}

Although it has been thought for a long time that membrane-dependent activation of vitamin K-dependent coagulation factors has an absolute requirement for negatively charged phospholipids, there are now several papers in literature in which it is shown that membranes solely composed of phosphatidylcholine can also be functional in coagulation factor activation. Factor $X$ activation by the tissue factor-VIla complex $[17,18]$, protein $C$ activation by thrombin plus thrombomodulin [19] and prothrombin activation by the factor XaVa complex [1] have been reported to be more or less stimulated by phosphatidylcholine. However, not much research has been directed to the nature of the stimulation of coagulation factor activation by neutral phosphatidylcholine membranes. In the present study we have investigated the effect of phosphatidylcholine on prothrombin activation under a wide variety of reaction conditions in order to further increase our understanding of the mechanism by which prothrombinase can be stimulated by this phospholipid.

It is shown that PC-dependent prothrombin activation is distinctively observed: (a) in the presence of the protein cofactor, factor $\mathrm{Va}$, (b) on 
phosphatidylcholines that contain unsaturated hydrocarbon side chains, (c) at low ionic strength, (d) in the presence of $\mathrm{Ca}^{2+-i o n s}$ and (e) with coagulation factors (i.e. prothrombin and factor $\mathrm{Xa}$ ) that contain a native Gladomain. When one or more of these conditions is not fulfilled the prothrombin converting activity of phosphatidylcholine is greatly reduced or even absent.

Since the $\mathrm{Ca}^{2}+$ and $\mathrm{Gla}$ requirement for $\mathrm{PC}$-dependent prothrombin activation is also characteristic for stimulation of prothrombin activation by negatively charged membranes $[3,4]$ we felt that we should rule out a scenario in which the stimulation of prothrombin activation by $P C$ is actually caused by traces of anionic lipids present in our PC preparation. In a previous publication we have shown that $\mathrm{PC}$ vesicles prepared by sonication contain less than $0.2 \%$ fatty acid [1]. In the present paper we show that we can also not detect any appreciable amounts of PS, PA or PG in the DOPC preparation used in our prothrombinase experiments. TLC analysis of the DOPC reveals that it contains less than $0.1 \%$ of these anionic phospholipids. Kinetic analysis shows that even if such amounts of negatively charged lipids were present in our PC preparation it could not account for the observed rates of prothrombin activation on DOPC. Thus, we conclude that the stimulation of prothrombin activation by membranes that are solely composed of DOPC is due to an intrinsic property of the phosphatidylcholine moiety.

The above mentioned requirements for DOPC-dependent prothrombin activation shows many similarities with the requirements for prothrombin activation on membranes that contain low amounts of negatively charged phospholipids with low binding affinities for vitamin K-dependent coagulation factors (e.g. PG). Prothrombin activation on membranes containing less than 10 mole \% PG is only observed in the presence of factor $\mathrm{Va}$ [14] and is strongly inhibited at increasing ionic strength [1]. On the basis of these similarities we propose that the assembly of the prothrombinase complex on $\mathrm{PC}$ membranes is the result of weak ionic and hydrophobic interactions. The importance of weak ionic interactions is concluded from the fact that prothrombin activation on DOPC membranes is strongly inhibited at increasing ionic strength.

The involvement of additional hydrophobic interactions is indicated by the the fact that prothrombin activation is only observed on PC membranes that are composed of PC with unsaturated hydrocarbon side chains, a property that is well-known to facilitate hydrophobic interaction between proteins and membranes. The experiment, in which we determined the prothrombin- 
converting activity of different phosphocholine-containing lipids, indicated that only PC molecules with unsaturated hydrocarbon side chains produce membranes that are able to promote prothrombin activation.

The presence of unsaturated hydrocarbon chains with cis double bonds may affect the packing density of the PC molecules in the membrane. It is to be expected that the phospholipid molecules in membranes composed of PC with unsaturated side chains will be more loosely packed than phospholipid molecules in membranes composed of PC with saturated side chains [35] and that coagulation factors that become embedded in the membrane (i.e. factor $\mathrm{Va}$ ) may better bind to loosely packed membranes. Such a phenomenon may explain why prothrombin activation on PC membranes requires $\mathrm{PC}$ with unsaturated hydrocarbon chains.

The fact that factor $\mathrm{Va}$ is required for the assembly and the expression of the functional activity of the prothrombinase complex on PC membranes indicates that coordinate binding of factor $\mathrm{Xa}$ and/or prothrombin with factor $\mathrm{Va}[3,14]$ or even conformational cage formation [36] is required to compensate for the weak binding affinities of the individual coagulation factors.

The observed $\mathrm{Ca}_{2}+$ and $\mathrm{Gla}$ requirements suggest that the binding of both prothrombin and factor $\mathrm{X}$ a to DOPC is supported by the formation of $\mathrm{Ca}^{2+-}$ bridges between the Gla-domains of these proteins and the phosphocholine moiety of the DOPC membrane. Although interactions between $\mathrm{Ca}^{2}+$-ions and phospholipids are often implicated to be reserved for anionic phospholipids it is important to note that it has been reported that $\mathrm{Ca}^{2+-i o n s}$ also bind to pure phosphatidylcholine bilayers in aqueous environment [37]. Thus it is plausible that DOPC-bound $\mathrm{Ca}^{2+-i o n s}$ form the locus to which the Gla-domains of prothrombin and factor Xa bind.

A comparison between the efficiencies by which phosphatidylcholine and negatively charged membranes stimulate prothrombin activation can be made on basis of the kinetic data presented in Table 4. Prothrombin activation in free solution is characterized by rather unfavorable kinetic parameters, i.e. a high $K_{m}$ for prothrombin of $9 \mu \mathrm{M}$ [34] and a high $K_{d}$ for dissociation of the factor Xa-Va complex of $800-1300 \mathrm{nM}$ [31,34]. The stimulatory effect of DOPC membranes appears to be due to effects on the $\mathrm{K}_{\mathrm{m}}$ for prothrombin, which drops to $1.9 \mu \mathrm{M}$, and on the $\mathrm{K}_{d}$ for dissociation of the factor XaVa complex which becomes $7.5 \mathrm{nM}$. DOPS/DOPC $(5 / 95, \mathrm{M} / \mathrm{M})$ membranes exhibit even more favorable kinetic parameters i.e. a $\mathrm{K}_{\mathrm{m}}$ for prothrombin of $0.15 \mu \mathrm{M}$ and a Kd for factor $\mathrm{Xa}-\mathrm{Va}$ complex dissociation of $0.28 \mathrm{nM}$. These data implicate that at low ionic strength and high factor $\mathrm{Va}$ 
( $\geq 15 \mathrm{nM}$ ) and prothrombin ( $\geq 5 \mu \mathrm{M})$, DOPC and DOPS/DOPC membranes exhibit equal prothrombin converting activities. At lower coagulation factor concentrations and at increasing ionic strength DOPC gradually loses its ability to stimulate prothrombin activation while the prothrombin-converting activity of DOPS/DOPC membranes is hardly affected. The loss of the prothrombin-converting activity of DOPC membranes at high ionic strength is not caused by an effect on the $\mathrm{K}_{\mathrm{m}}$ for prothrombin, but appears to be due to an effect on de $K_{d}$ for dissociation of the factor XaVa complex which increases from $7.5 \mathrm{nM}$ at $\mathrm{I}=0.06$ to $100 \mathrm{nM}$ at $\mathrm{I}=0.22$. From these values for the kinetic parameters it is obvious that at high ionic strength the prothrombin-converting activity of DOPC membranes will be negligible to that of membranes composed of DOPS/DOPC for a wide range of coagulation factor concentrations.

The major function of phospholipids in prothrombin activation is to provide a membrane surface that promotes both the assembly of the factor XaVa complex and the interaction of this complex with its substrate prothrombin [3]. There are some reports in the literature in which it is suggested that anionic membrane phospholipids also alter the catalytic activity of the membrane-bound prothrombinase complex, and that different anionic phospholipids may even do this to a different extent [38]. However, such a lipid effect seems to be of limited importance if one considers the observations of Boskovic et al. [34] who reported at saturating factor $\mathrm{Va}$ concentration the same kcat values for prothrombin activation in the absence and presence of phospholipids. Our data also indicate that anionic lipids per se have a negligible effect on the intrinsic catalytic activity of the prothrombinase complex since the same $k_{c a t}$ values were obtained for prothrombin activation on DOPC and DOPS/DOPC membranes.

\section{References}

1. Gerads I., Govers-Riemslag J.W.P., Tans G., Zwaal R.F.A. and Rosing J. (1990) Prothrombin activation on membranes with anionic lipids containing phosphate, sulfate, and/or carboxyl groups, Biochemistry 29, 7967-7974

2. Tans G. and Rosing J. (1987) in New Comprehensive Biochemistry. Blood Coagulation (Hemker H.C., and Zwaal R.F.A., eds.) pp 59-85, Elsevier, Amsterdam, The Netherlands

3. Mann K.G., Nesheim M.E., Church W.P., Haley P. and Krishnaswamy S. (1990) Review article: surface-dependent reactions of the vitamin K-dependent enzyme complexes, Blood 76, 1-16 
4. Rosing J. and Tans G. (1989) in Coagulation and Lipids (Zwaal R.F.A., ed.) pp 159-187, CAC Press, Boca Raton, FL.

5. Nelsestuen G. L., Zytkovicz T.H. and Howard J.B. (1974) The mode of action of vitamin $\mathrm{K}$. Identification of gamma-carboxyglutamic acid as a component of prothrombin, J. Biol. Chem. 249, 6347-6350

6. Stenflo J. Femlund P., Egan W., and Roepstorff P. (1974) Vitamin K dependent modifications of glutamic acid residues in prothrombin, Proc. Nat. Acad. Sci. 71, 2730-2733

7. Nelsestuen G.L. (1976) Role of gamma-carboxyglutamic acid. An unusual protein transition required for the calcium-dependent binding of prothrombin to phospholipid, J. Biol. Chem. 251, 5648-5656

8. Furie B.C. Mann K.G., and Furie B. (1976) Substitution of lanthanide ions for calcium ions in the activation of bovine prothrombin by activated factor $X$. High affinity metal binding sites of prothrombin and the derivatives of prothrombin activation, J. Biol. Chem. 251, $3235-3241$

9. Bloom J.W., Nesheim M.E. and Mann K.G. (1979) Phospholipid-binding properties of bovine factor $\mathrm{Va}$, Biochemistry 18, 4419-4425

10. Krishnaswamy S. and Mann K.G. (1988) The binding of factor Va to phospholipid vesicles, J. Biol. Chem. 263, 5714-5723

11. Pusey M.L., Mayer L.D., Jason Wei G., Bloomfield V.A. and Nelsestuen G.L. (1982) Kinetic and hydronamic analysis of blood clotting factor V-membrane binding, Biochemistry 21, 5262-5269

12. van de Waart P., Bruls H., Hemker H.C. and Lindhout T. (1983) Interaction of bovine blood clotting factor $\mathrm{Va}$ and its subunits with phospholipid vesicles, Biochemistry 22, 2427-2432

13. Nelsestuen G.L. and Broderius M. (1977) Interactions of prothrombin and bloodclotting factor $X$ with membranes of varying composition, Biochemistry 16,4172 4177

14. van Rijn J.L.M.L., Govers-Riemslag J.W.P., Zwaal R.F.A. and Rosing J. (1984) Kinetic studies of prothrombin activation: Effect of factor $\mathrm{Va}$ and phospholipids on the formation of the enzyme substrate complex, Biochemistry 23, 4557-4564

15. Rosing J., Speijer H. and Zwaal R.F.A. (1988) Prothrombin activation on phospholipid membranes with positive electrostatic potential, Biochemistry 27, 811

16. Wu J.R. and Lentz B.R. (1991) Fourier transform infrared spectroscopic study of $\mathrm{Ca} 2+$ and membrane-induced secondary structural changes in bovine prothrombin and prothrombin fragment 1, Biophys. J. 60, 70-80

17. Forman S.D. and Nemerson Y. (1986) Membrane-dependent coagulation reaction is independent of the concentration of phospholipid-bound substrate: fluid phase factor $X$ regulates the extrinsic system, Proc. Natl. Acad. Sci. 83, 4675-4679

18. Krishnaswamy S., Field K.A., Edgington T.S., Morrissey J.H. and Mann K.G. (1992) Role of the membrane surface in the activation of human coagulation factor $X, J$. Biol. Chem. 267, 26110-26120

19. Galvin J.B., Kurosawa S., Moore K., Esmon C.T. and Esmon N.L. (1987) Reconstitution of rabbit thrombomodulin into phospholipid vesicles, J. Biol. Chem. 262, 2199-2205

20. Owen W.G., Esmon C.T. and Jackson C.M. (1974) The conversion of prothrombin to thrombin. I. Characterization of reaction products formed during the activation of bovine prothrombin, J. Biol. Chem. 249, 594-605 
21. Fujikawa K., Legaz M.E. and Davie E.W. (1972) Bovine factor $X(1)$ and $X(2)$ (Stuart factor) isolation and characterization, Biochemistry 11, 4882-4891

22. Fujikawa K., Legaz M.E. and Davie E.W. (1972) Bovine factor X(1) (Stuait factor) mechanism of activation by a protein from Russel's viper venom, Biochemistry 11 . 4892-4899

23. Morita T. and Jackson C.M. (1986) Preparation and properties of derluatives df bovine factor $X$ and factor $X a$ from which the gamma-carboxyglutamic acid containing domain has been removed, J. Biol. Chem. 261,4015-4023

24. Schiffman S., Theodor J. and Rapaport S.J. (1969) Separation from Russelfs viper venom of one fraction reacting with factor $X$ and another reacting with facter $v$, Biochemistry 8, 1397-1405

25. Lindhout T., Govers-Riemslag J.W.P., van de Waart P., Hemker H.C. and Rosing J. (1982) Factor Va-factor Xa interaction. Effects of phospholipid vesicles af varying composition, Biochemistry 21 5494-5502

26. Chase T. Jr., and Shaw E. (1969) Comparison of the esterase activities of trypsin plasmin and thrombin on guanidinobenzoate esters - titration of the enzymes, Biochemistry B, 2212-2224

27. Smith R.L. (1973) Titration of activated bovine factor X, J. Biol. Chem. 248, 24,8 2423

28. Böttcher C.J.F., van Gent C.M. and Pries C. (1961) A rapid and sensitive sub-mict: phosphorus delermination, Anal. Chim. Acta 24, 203-207

29. Tans G., van Zutpen H., Comfurius P., Hemker H.C. and Zwaal R.F.A. (1979) Lipid phase transitions and procoagulant activity, Eur. J. Biochem. 95, 449-457

30. Ladbrooke B.D. and Chapman D. (1969) Thermal analysis of lipids proteins and biological membranes, a review and summary of some recent studies, Chem. Phys. Lipids 3, 304-367

31. Pryzdial E.L.G., and Mann K.G. (1991) The association of coagulation factor Xa and factor Va, J. Biol. Chem. 266 8969-8977

32. Rosing J., Tans G., Govers-Riemslag J.W.P., Zwaal R.F.A. and Hemker H.C. (1980) The role of phospholipids and faclor $\mathrm{Va}$ in the prothrombinase complex, J. Biol. Chem. 255, 274-283

33. Nesheim M.E., Taswell J.B. and Mann K.G. (1979) The contribution of bovine factor $V$ and factor $V a$ to the activity of prothrombinase, J. Biol. Chem. 254, 1095210962

34. Boskovic D.S., Giles A.R. and Nesheim M.E. (1990) Studies of the role of Va in the factor Xa-catalyzed activation of prothrombin, fragment 1.2-prethrombin-2, and dansyl-L-glutamyl-glycyl-L-arginine-meizothrombin in the absence of phospholipid, J. Biol. Chem. 265, 10497-10505

35. Demel R.A., Geurts van Kessel W.S.M. and van Deenen, L.L.M. (1972) The Properties of polyunsaturated lecithins in monolayers and liposomes and the interactions of these lecithins with cholesterol, Biochim. Biophys. Acta 266, 26-40

36. Nemerson Y. and Gentry R. (1986) An ordered addition, essential activation model of the tissue factor pathway of coagulation: evidence for a confomational cage. Biochemistry 25, 4020-4033

37. Lis L.J., Lis W.T., Parsegian V.A. and Rand R.P. (1981) Adsorption of divalent cations to a variety of phosphatidylcholine bilayers, Biochemistry 20, 1771-1777 
38. Pei G., Powers D.D. and Lentz B.R. (1993) Specific contribution of different phospholipid surfaces to the activation of prothrombin by the fully assembled prothrombinase, J. Biol. Chem. 268, 3226-3233 
Chapter 8

\section{Effect of Membrane Fluidity and Fatty Acid Composition on the Prothrombin-Converting Activity of Phospholipid Vesicles}




\section{Summary}

Vesicles composed of phospholipids with different fatty acyl side chains have been utilized to examine the importance of the nonpolar membrane region for the prothrombin-converting activity of procoagulant phospholipid vesicles. Membranes composed of phosphatidylserine (PS) and phosphatidylcholine (PC) with unsaturated fatty acyl side chains were more active in prothrombin activation than membranes composed of phospholipids with saturated fatty acyl chains. This phenomenon was observed above the phase transition temperature i.e. on membranes in the liquid-crystalline state. The prothrombin-converting activity of saturated phospholipids approached the activity of unsaturated phospholipids at high factor $V a$ concentrations, which is indicative for a less favorable equilibrium constant for prothrombinase assembly on membrane surfaces composed of saturated phospholipids. The difference between saturated and unsaturated phospholipids was annulled on membranes with high mole percentages PS. This may result from a compensating contribution of electrostatic forces to the binding equilibria involved in prothrombinase assembly. Additional effects on the prothrombin-converting activity were observed when membranes containing saturated phospholipids were studied below their phase transition temperature. In agreement with Higgins et al. [1] we found that the time required for the assembly of prothrombinase from membranebound factor $\mathrm{Xa}$ and $\mathrm{Va}$ is considerably prolonged on solid membranes. However, we also observed an effect of membrane fluidity on the steadystate rate of prothrombin activation. Kinetic experiments at saturating factor $V a$ concentrations showed that the transition from the liquid-crystalline to the gel state caused a more than 9 -fold decrease of the $k_{c a t}$ of prothrombin activation without affecting the $\mathrm{K}_{\mathrm{m}}$ for prothrombin. This effect of membrane fluidity on the catalytic activity of prothrombinase was accompanied by a shift in the peptide bond cleavage pattern during prothrombin activation. Meizothrombin and thrombin were the only detectable prothrombin activation products on fluid membranes. A considerable reduction of meizothrombin formation and additional prethrombin 2 generation were observed on membranes in the gel phase. It is hypothesized that effects of membrane fluidity on the proper juxtaposition of enzyme (factor $\mathrm{Xa}-\mathrm{Va}$ ) and substrate (prothrombin) on the membrane may explain both the decreased $k_{c a t}$ values and the shift in the peptide bond cleavage pattern observed for prothrombin activation on solid membranes. 


\section{Introduction}

The blood coagulation factor prothrombin is enzymaticaly converted into thrombin by the so-called prothrombinase complex. Prothrombinase is a multicomponent complex composed of the serine protease factor $\mathrm{Xa}$ that is tightly associated with the protein cofactor $V a$ on phospholipid membranes in the presence of calcium ions (for a review see ref. [2]). It is well established that optimal prothrombinase activity requires coordinate binding of prothrombin, factor $\mathrm{Xa}$ and factor $\mathrm{Va}$ to the membrane surface.

The prothrombin-converting activity of procoagulant membranes is greatly influenced by the chemical and physical properties of the membrane phospholipids. The presence of anionic phospholipids is a prerequisite to bind the participating proteins and to facilitate the reactions leading to thrombin formation. Substantial knowledge is available on the effects of anionic phospholipids on the protein-membrane interactions essential for prothrombinase complex formation (for a review see ref. [3]). Prothrombin and factor $\mathrm{Xa}$ are vitamin K-dependent proteins containing $\gamma$ carboxyglutamic acid residues [4-6] that are involved in the $\mathrm{Ca}^{2+-d e p e n d e n t}$ binding of these proteins to the polar head groups of anionic membrane phospholipids [7-9]. Equilibrium binding parameters have been reported for the association of prothrombin and factor $\mathrm{Xa}$ with small unilamellar phospholipid vesicles [10] and planar phospholipid layers [11-13]. The interaction between factor $\mathrm{Va}$ and membranes also requires anionic phospholipids [14] but is independent of the presence of added $\mathrm{Ca}^{2+-i o n s . ~}$ The formation of the factor Va-phospholipid complex may involve both hydrophobic $[14,15]$ and electrostatic interactions [16-19].

The effects of phospholipid concentration and composition on the catalytic activity of the prothrombinase complex have been studied in detail for membranes containing different anionic phospholipids [20-22]. It was shown that membranes that contain the aminophospholipid PS as anionic phospholipid exhibit the highest prothrombin-converting activity $[22,23]$. The ability of membranes to accelerate prothrombin activation is, however, not strictly dependent on the presence of amino and phosphate groups. This can be concluded from the fact that negatively charged lipids that only contain a phosphate (PA), sulfate (sulfatides or dodecylsulfuric acid) or carboxyl group (oleic acid) also promote factor Xa-catalyzed prothrombin activation [21].

The prothrombin-converting activity of membranes is not only dependent on the chemical nature of the polar headgroup but is also affected by the 
chemical and physical properties of the nonpolar membrane region. Sterzing and Barton [24] have shown that the procoagulant activity of membranes composed of egg-yolk PC and bovine brain PS was greatly reduced upon hydrogenation and they concluded that the liquid-crystalline phase is essential for the expression of procoagulant activity. This was confirmed by subsequent studies with vesicles composed of synthetic phospholipids in which it was shown that the phase transition from the gel state to the liquidcrystalline state is accompanied by a sharp increase of the clot-promoting activity of the vesicles [25]. In a more recent study Higgins et al. [1] investigated the effect of membrane fluidity on the catalytic properties of the prothrombinase complex. They observed a considerable lag in the time required for the assembly of the prothrombinase complex on membrane surfaces in the gel'state and concluded that lipid fluidity affects the rate of assembly of the factor Xa-Va complex at the membrane surface.

Recently we observed that membranes solely composed of PC also promote prothrombin activation provided that the PC molecules contain unsaturated fatty acyl side chains and the reaction is studied at low ionic strength [21]. The differences between the prothrombin-converting activities of PC membranes with saturated and unsaturated side chains were not due to fluidity differences since vesicles composed of DMPC or DPPC were also not active above the phase transition temperature.

On the basis of these results we decided to perform a detailed study on the effects of fatty acyl side chain composition of membrane phospholipids on the prothrombin-converting activities of negatively charged phospholipid vesicles. The assembly of the prothrombinase complex and the expression of its catalytic activity were investigated on membranes composed of unsaturated or saturated phospholipids both below and above the phase transition temperature of the vesicles.

\section{Experimental procedures}

- Materials. S2238 and 12581 were purchased from AB Kabi Diagnostica, Stockholm. Sweden. p-NPGB was from Nutritional Biochemicals. Dimyristoyl-snglycero-3-phosphoserine ( $\mathrm{diC}_{14: 0 \mathrm{PS}}$, dioleoyl-sn-glycero-3-phosphoserine ( diC $_{18: 1} \mathrm{PS}$ ), dilauroyl-sn-glycero-3-phosphocholine ( $\mathrm{diC}_{12: 0} \mathrm{PC}$ ), dimyristoyl-snglycero-3-phosphocholine ( $\mathrm{diC}_{14: 0} \mathrm{PC}$ ), dipalmitoyl-sn-glycero-3-phosphocholine ( $\mathrm{diC}_{16: 0} \mathrm{PC}$ ), dipalmitoleoyl-sn-glycero-3-phosphocholine ( $\mathrm{diC}_{16: 1} \mathrm{PC}$ ), dioleoylsn-glycero-3-phosphocholine ( $\mathrm{diC}_{18: 1 \mathrm{PC})}$ and dierucoyl-sn-glycero-3-phosphocholine (diC22:1 PC) were obtained from Avanti Polar Lipids Inc., Alabaster, Alabama (USA). Dilauroyl-sn-glycero-3-phosphoserine ( $\mathrm{diC}_{12: 0} \mathrm{PS}$ ), dipalmitoyl- 
sn-glycero-3-phosphoserine ( $\mathrm{diC}_{16: 0 \mathrm{PS}}$ ), dipalmitoleoyl-sn-glycero-3-phosphoserine ( $\mathrm{diC}_{16: 1} \mathrm{PS}$ ) and dierucoyl-sn-glycero-3-phosphoserine $\left(\mathrm{diC}_{22: 1} \mathrm{PS}\right)$ were a kind gift of Dr. P. Comfurius, Rijksuniversiteit Limburg. Maastricht, The Netherlands. Benzamidine- $\mathrm{HCl}$, ovalbumin (grade V), Russell's viper venom and Echis carinatus venom were obtained from Sigma, St. Louis. Column materials for protein purification (DEAE-Sephadex A-50, QAE-Sephadex A-50, SP-Sephadex C-50, Sephadex G-100, Sephadex G-200, and Sephacryl S-300) were obtained from Pharmacia, Uppsala, Sweden. Silica gel 60 plates for thin-layer chromatography of phospholipids were from Merck, Darmstadt, Germany. Crude porcine intestinal mucosal heparin (USP activity 175 units/mg) was purchased from Organon, The Netherlands.

- Proteins. Bovine prothrombin and prethrombin 1 were purified according to Owen et al. [26]. Bovine factor $X$ was purified as described by Fujikawa et al. [27]. Bovine factor Xa was prepared from factor $X$ after activation with RVV-X [28]. RVV-X was purified from the crude venom of Russell's viper by the method of Schiffman et al. [29]. Bovine factor Va was obtained according to the procedure of Lindhout et al. [30]. Bovine AT-III was purified according to Thaler and Schmer [31]. Prothrombin, factor $\mathrm{Xa}$ and AT-III were stored at $-80^{\circ} \mathrm{C}$ in $50 \mathrm{mM}$ Tris- $\mathrm{HCl}$ $(\mathrm{pH} 7.9)$ and $175 \mathrm{mM} \mathrm{NaCl}$. Factor $\mathrm{Va}$ was stored at $-80^{\circ} \mathrm{C}$ in the same buffer with $5 \mathrm{mM} \mathrm{CaCl}_{2}$.

- Protein Concentrations. The molar concentration of factor Xa was determined by active site titration with $p$-NPGB [32]. Prothrombin concentrations were determined with p-NPGB (cf. thrombin active site titration, [33] ) after complete activation of prothrombin with the venom activator from Echis carinatus. Factor $\mathrm{Va}$ concentrations were determined by kinetic analysis [30].

- Phospholipids and phospholipid vesicle preparations. TLC analysis of the phospholipid preparations was performed at room temperature on $20 \times 20 \mathrm{~cm}$ plates coated with $0.5 \mathrm{~mm}$ silica gel 60 . Chloroform/methanol/ammonia/water $(95 / 50 / 5.5 / 5.5 \mathrm{v} / \mathrm{v})$ was used as a eluent and the purity of the different preparations was checked after visualization of the phospholipids on the TLC plate with iodine vapor. Single bilayer phospholipid vesicles were prepared as follows: phospholipid preparations, usually dissolved in $\mathrm{CHCl}_{3} / \mathrm{CH}_{3} \mathrm{OH}(1 / 1 \mathrm{v} / \mathrm{v})$, were dried under a stream of $\mathrm{N}_{2}$. The dried lipids were suspended in $50 \mathrm{mM}$ Tris$\mathrm{HCl}\left(\mathrm{pH} \mathrm{7.9)}\right.$ and $175 \mathrm{mM} \mathrm{NaCl}$ at $65^{\circ} \mathrm{C}$ and vigorously vortexed for $1 \mathrm{~min}$. The phospholipid suspensions were subsequently sonicated for $10 \mathrm{~min}$ at $65^{\circ} \mathrm{C}$ with a MSE Mark II 150-W ultrasonic disintegrator set at $8 \mu \mathrm{M}$ peak to peak amplitude. Phospholipid concentrations were determined by phosphate analysis [34].

- Assay system for measuring rates of prothrombin activation. Phospholipids, factor $\mathrm{Xa}$, and, factor $\mathrm{Va}$ were incubated for $5 \mathrm{~min}$ at the reaction temperature in $50 \mathrm{mM}$ Tris- $\mathrm{HCl}$ buffer $\left(\mathrm{pH}\right.$ 7.52) containing $5 \mathrm{mM} \mathrm{CaCl}_{2}, 0.5$ $\mathrm{mg} / \mathrm{ml}$ ovalbumin. Prothrombin activation was started by the addition of prothrombin preincubated at the same temperature in the same buffer. After different time intervals aliquots from the reaction mixture were transferred to disposable cuvettes containing $235 \mu \mathrm{M}$ of the thrombin-specific chromogenic substrate $\mathrm{S} 2238$ in $50 \mathrm{mM}$ Tris- $\mathrm{HCl}(\mathrm{pH} 7.9), 175 \mathrm{mM} \mathrm{NaCl}, 20 \mathrm{mM}$ EDTA, and $0.5 \mathrm{mg} / \mathrm{ml}$ ovalbumin. The amount of prothrombin activated was calculated from 
the absorbance change ( $\triangle \mathrm{A} 405-500 / \mathrm{min}$ ) measured on a dual-wavelength spectrophotometer, using a calibration curve of chromogenic substrate conversion by known amounts of active-site-titrated thrombin. In order to specifically determine meizothrombin, the amidolytic activity was also measured with $4 \mathrm{nM}$ AT-III and $10 \mu \mathrm{g} / \mathrm{ml}$ heparin in the cuvette [35]. In that case, samples from the prothrombin activation mixture were incubated for $1 \mathrm{~min}$ in the cuvette with AT-III and heparin to inhibit thrombin prior to the addition of S2238.

- Gel electrophoretic analysis of prothrombin activation. Polyacrylamide gel electrophoresis of prothrombin activation was carried out in the presence of SDS on $10 \%$ polyacrylamide slabgels $(6 \%$ stacking gel [36]) in a miniprotean II cell from Bio-Rad. Aliquots $(25 \mu \mathrm{l})$ from the reaction mixtures were added to $10 \mu \mathrm{l}$ of gel buffer containing $250 \mathrm{mM}$ Tris- $\mathrm{HCl}(\mathrm{pH} 6.9), 5 \%$ SDS, $50 \%(\mathrm{v} / \mathrm{v})$ glycerol, and $5 \%(\mathrm{v} / \mathrm{v}) \beta$-mercaptoethanol. Prior to electrophoresis, the samples were kept for $20 \mathrm{~min}$ at $37^{\circ} \mathrm{C}$. After electrophoresis the gels were stained with Coomassie Brilliant Blue R-250.

\section{Results}

\section{Physical properties of the phospholipid vesicles used in this study}

Variation of the hydrocarbon chain length and the introduction of cis double bonds in the acyl side chains of membrane phospholipids greatly affects the physical properties of small unilamellar vesicle membranes [37]. In Table 1

Table 1. Phase transition temperatures for phosphatidylserines and phosphatidylcholines used in this study

\begin{tabular}{lclc}
\hline phospholipid & $T_{m}\left({ }^{\circ} \mathrm{C}\right)$ & phospholipid & $\mathrm{T}_{\mathrm{m}}\left({ }^{\circ} \mathrm{C}\right)$ \\
\hline $\mathrm{DiC}_{12: 0} \mathrm{PS}$ & $d$ & $\mathrm{DiC}_{12: 0} \mathrm{PC}$ & $0^{b, c}$ \\
$\mathrm{DiC}_{14: 0} \mathrm{PS}$ & $35^{a}$ & $\mathrm{DiC}_{14: 0} \mathrm{PC}$ & $23^{b, c}$ \\
$\mathrm{DiC}_{16: 0} \mathrm{PS}$ & $57^{d}$ & $\mathrm{DiC}_{16: 1} \mathrm{PC}$ & $-36^{c}$ \\
$\mathrm{DiC}_{18: 1} \mathrm{PS}$ & $-15.5^{a}$ & $\mathrm{DiC}_{18: 1} \mathrm{PC}$ & $-16^{a}$ \\
$\mathrm{DiC}_{22: 1} \mathrm{PS}$ & $d$ & $\mathrm{DiC}_{22: 1} \mathrm{PC}$ & $d$ \\
\hline
\end{tabular}

a Tans et al. [25]

b Ladbrooke and Chapman [38]

c van Dijck et al. [39]

${ }^{d}$ No literature data were found for the phase transition temperatures of these phospholipids. From comparison of PS and PC and the relation between $T m$ and fatty acyl side chain length it is likely that the phase transition temperatures of these phospholipids will be below $20^{\circ} \mathrm{C}$. 
we have summarized the transition temperatures for the gel $\rightarrow$ liquidcrystalline-phase transition of the phospholipids used in this study. Phospholipids which contain fatty acyl side chains with a cis double bond ( $\mathrm{diC}_{16: 1}, \mathrm{diC}_{18: 1}$, and $\mathrm{diC}_{22: 1}$ variants of both $\mathrm{PS}$ and $\mathrm{PC}$ ) have low phase transition temperatures. This means that the prothrombin-converting activities of vesicles composed of these phospholipids can only be studied in the liquid-crystalline state. DMPS, DMPC and DPPC have phase transition temperatures of $35^{\circ} \mathrm{C}, 23^{\circ} \mathrm{C}$ and $41^{\circ} \mathrm{C}$, respectively, and phospholipid vesicles composed of mixtures of DMPS with DMPC or DPPC will, therefore, have phase transition temperatures below $41^{\circ} \mathrm{C}$. This means that the prothrombin-converting activities of vesicles prepared from DMPS/DMPC or DMPS/DPPC mixtures can be studied both below and above their respective phase transition temperatures, which allows determination of the effect of the gel $\rightarrow$ liquid $\rightarrow$ crystalline transition on prothrombin activation. Vesicles composed of the other phospholipids summarized in Table 1 have a phase transition outside the physiological temperature range and reliable data on these vesicles can be only obtained in either the liquid-crystalline or gel state.

It is unlikely that the different vesicle preparations will have identical physical properties above their respective phase transition temperatures. It has been reported that the introduction of a cis double bond in the hydrocarbon chain of a phospholipid molecule not only decreases the transition temperature but also increases the area per phospholipid molecule in a phospholipid monolayer at an air-water interface $[38,40]$. Such a phenomenon will likely affect the lipid packing in a vesicle membrane and it is to be expected that the phospholipid molecules in for instance, DMPS/DMPC or DPPS/DMPC vesicles will be more densily packed than in DOPS/DOPC vesicles, even if these membranes are above their phase transition temperature.

\section{Effect of membrane fluidity on the time course of prothrombin activa- tion}

In 1985, Higgins et al. [1] reported that membranes in the gel phase exhibited a considerable lag in thrombin formation, when prothrombin activation was started with factor Xa or factor Va. They concluded that factor $\mathrm{Xa}$ and factor $\mathrm{Va}$ separately bind to the membrane and have to diffuse across the membrane surface in order to assemble into a catalytically active prothrombinase complex. This diffusion was proposed to be considerably slowed down on solid membranes which might explain the occurrence of a 
lag phase when prothrombin activation on such membranes was started with factor $\mathrm{Xa}$ or with factor $\mathrm{Va}$.

We also observed that time courses of prothrombin activation were strongly dependent on the fluidity of the phospholipid vesicles and on the order of addition of the prothrombinase proteins. Time courses of prothrombin activation were analyzed at $45^{\circ} \mathrm{C}$ and $15^{\circ} \mathrm{C}$ on vesicles composed of DOPS/DOPC or DMPS/DMPC.
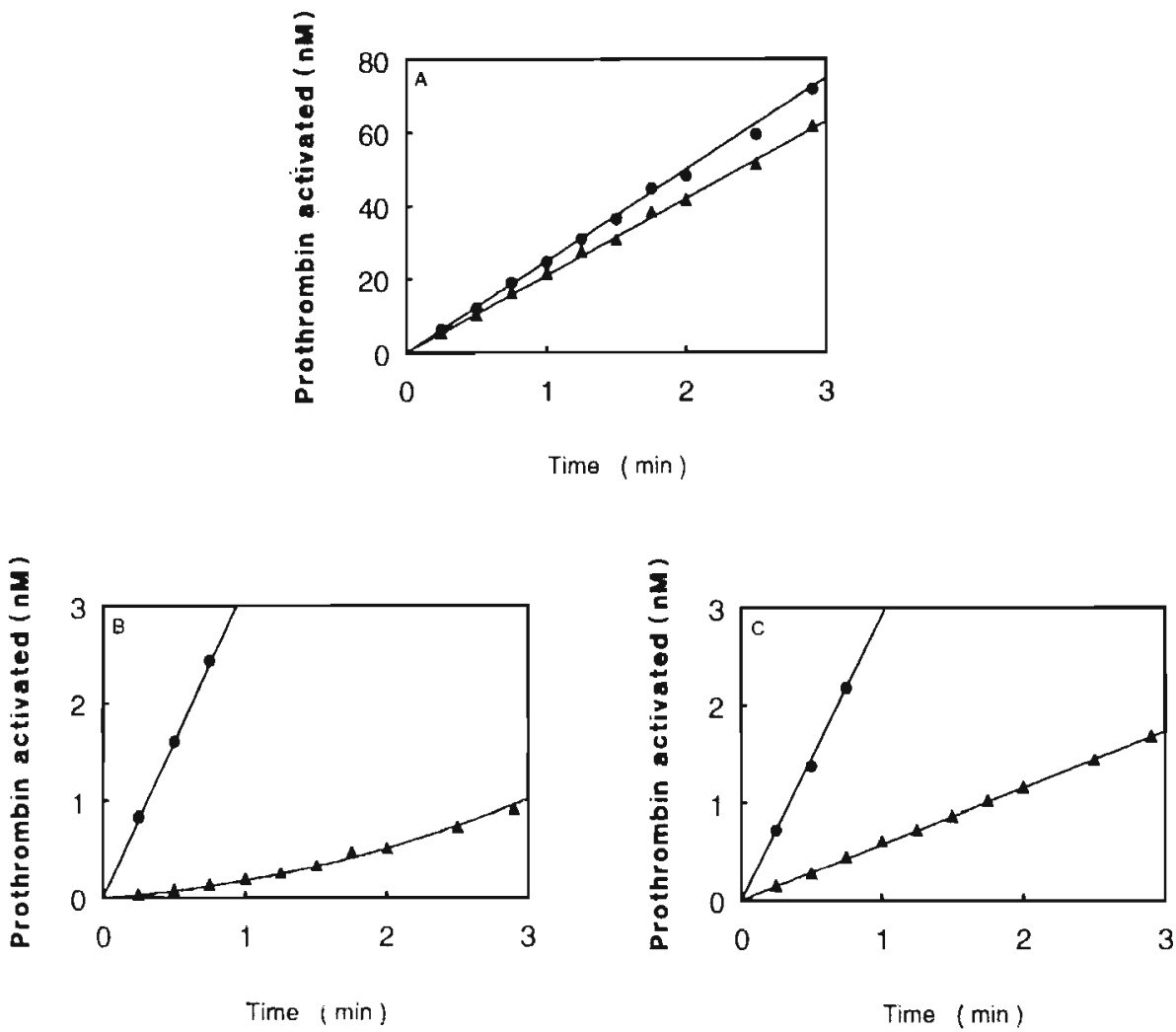

Figure 1. Time courses of prothrombin activation at different temperatures on vesicles composed of saturated and nonsaturated phospholipids. Prothrombin $(1 \mu \mathrm{M})$ was activated in a reaction mixture containing $50 \mathrm{mM}$ Tris- $\mathrm{HCl}(\mathrm{pH} 7.5), 175 \mathrm{mM}$ $\mathrm{NaCl}, 2.5 \mathrm{mM} \mathrm{CaCl} 2,0.5 \mathrm{mg} / \mathrm{ml}$ ovalbumin, $10 \mathrm{pM}$ factor $\mathrm{Xa}, 5 \mathrm{nM}$ factor $\mathrm{Va}$ and $10 \mu \mathrm{M}$ DMPS/DMPC [20/80, MM (A) ] or DOPS/DOPC [20/80, M/M (•)] vesicles. Prothrombin activation was started by simultaneous addition of factor $\mathrm{Xa}$ and factor $\mathrm{Va}$ at $45^{\circ} \mathrm{C}(\mathrm{A})$ or $15^{\circ} \mathrm{C}(\mathrm{B})$, or with prothrombin at $15^{\circ} \mathrm{C}(\mathrm{C})$. The amounts of prothrombin activated were calculated from the generation of amidolytic activity towards the chromogenic substrate \$2238 as described under Experimental Procedures. 
When prothrombin activation was started with factor $\mathrm{Xa}$ or $\mathrm{Va}$ at $45^{\circ} \mathrm{C}$, where both vesicles were in the liquid-crystalline phase, there was no lag in thrombin generation and the prothrombin-converting activities of both vesicles were the same (Figure 1A). However, as shown in Figure 1B, there was a rather large difference between these vesicles at $15^{\circ} \mathrm{C}$. On DOPS/DOPC vesicles, which were still in the liquid-crystalline phase at this temperature, thrombin generation was linear in time and was slowed down approximately 6-fold. On the DMPS/DMPC vesicles, which were in the gel phase at $15^{\circ} \mathrm{C}$, prothrombin activation showed a lag phase of more than 1 min. This lag phase was only observed when prothrombin activation was started with factor $\mathrm{Xa}$ or with factor $\mathrm{Va}$ and was absent when the reaction was started with prothrombin (Figure 1C). Under these conditions, time courses of prothrombin activation were not affected by prolonged incubation of factor $\mathrm{Xa}$ and factor $\mathrm{Va}$ with the phospholipid vesicles and did not deviate from linearity when the reaction times were extended up to 30 min (data not shown). This demonstrates that the time courses shown in Figure $1 \mathrm{C}$ represent steady-state rates of prothombin activation. In contrast to Higgins et al. [1] we observed that mernbrane fluidity affected the steady-state rate of prothrombin activation. On membranes in the gel phase the steady-state rate of prothrombin activation was about 7-fold slower than on membranes in the liquid-crystalline state (Figure $1 \mathrm{C}$ ).

\section{Effect of membrane fluidity on steady-state rates of prothrombin acti- vation}

The effect of membrane fluidity on steady-state prothrombin activation was further investigated by measuring the temperature dependency of the rate of prothrombin activation on phospholipid vesicles with different phase transition temperatures (Figure 2). To enable a proper determination of the steady-state rate, prothrombin activation was started by the addition of prothrombin to reaction mixtures in which factor $\mathrm{Xa}$ and $\mathrm{Va}$ had been preincubated with phospholipid vesicles.

In this experiment, in which the reaction temperature was varied between $45^{\circ} \mathrm{C}$ and $0^{\circ} \mathrm{C}$, steady-state rates of prothrombin activation were determined on DOPS/DOPC, DMPS/DMPC and DMPS/DPPC vesicles which have phase transition temperatures at about $-16^{\circ} \mathrm{C}, 25^{\circ} \mathrm{C}$ and $40^{\circ} \mathrm{C}$, respectively (Table 1). There appeared to be a good correlation between the fluidity and the prothrombin-converting activity of these membranes. At $45^{\circ} \mathrm{C}$, all membranes were in the liquid-crystalline state and were equally active in prothrombin activation. The Arrhenius plot of the rate of prothrombin 
activation on DOPS/DOPC vesicles, which were in the liquid-crystalline state over the whole temperature range, showed no discontinuity and gradually decreased with a temperature coefficient $\left(Q_{10}\right)$ of about 1.6 (Figure 2).

Marked discontinuities were observed in the Arrhenius plots of the prothrombin-converting activities of DMPS/DMPC and DMPS/DPPC vesicles. Rates of prothrombin activation on DMPS/DMPC and DMPS/DPPC vesicles showed an additional decrease with temperature beginning at $25^{\circ} \mathrm{C}$ and $40^{\circ} \mathrm{C}$, respectively. This discontinuity of the rate profile occurred in a temperature range in which these vesicles are expected to undergo phase transition from the liquid-crystalline to the gel state.

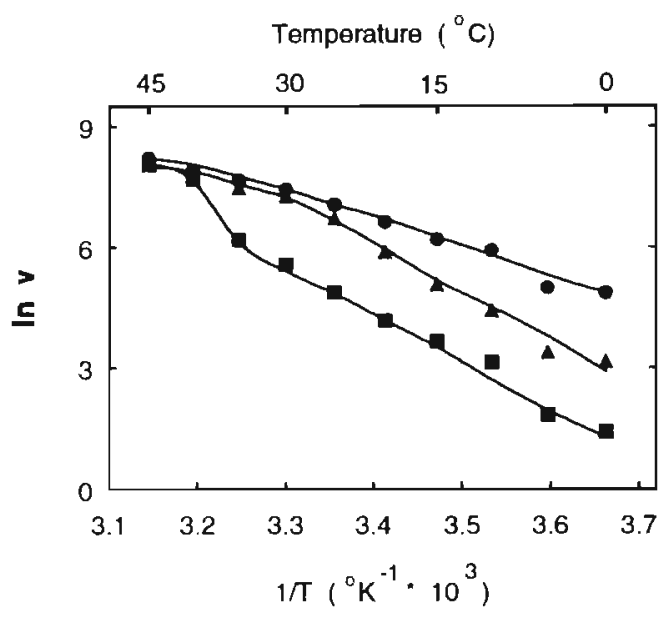

Figure 2. The effect of temperature on the steady-state rates of prothrombin activation on membranes composed of phospholipids with different phase transition temperatures. $10 \mathrm{pM}$ factor $\mathrm{Xa}$ and $5 \mathrm{nM}$ factor $\mathrm{Va}$ were incubated for $5 \mathrm{~min}$ at varying temperatures in a reaction buffer containing $50 \mathrm{mM} \mathrm{Tris}-\mathrm{HCl}(\mathrm{pH} 7.5$ at the indicated lemperature), $175 \mathrm{mM} \mathrm{NaCl}, 5 \mathrm{mM} \mathrm{CaCl} 2,0.5 \mathrm{mg} / \mathrm{ml}$ ovalbumin and $100 \mu \mathrm{M}$ phospholipid (PS/PC, 20/80, M/M). The phospholipid vesicles were prepared from DOPS/DOPC (ब), DMPS/DMPC (A) or DMPS/DPPC (ם) mixtures. Prothrombin activation was started by the addition of prothrombin to a final concentration of $1 \mu \mathrm{M}$. Rates of prothrombin activation were determined as described under the Experimental Procedures.

These data show that membrane fluidity not only affects the time required for prothrombinase assembly but also affects the catalytic properties of the prothrombin-converting complex. 


\section{Effect of membrane fluidity on the kinetic parameters of prothrombin activation}

In the previous paragraph we have shown that steady-state rates of prothrombin activation were considerably decreased when the membrane did undergo a phase transition from the liquid-crystalline to the gel phase. Since the experiments presented in the previous paragraphs were performed at single factor $V a(5 \mathrm{nM})$ and prothrombin $(1 \mu \mathrm{M})$ concentrations, the effect of membrane fiuidity on the steady-state rate of prothrombin activation can be (a) on the equilibrium constant for factor Xa-Va complex formation at the membrane surface, (b) on the $K_{m}$ for prothrombin or (c) on the $V_{\max }$ of prothrombin activation.

To distinguish between these possibilities, we have performed a kinetic analysis of prothrombin activation on DOPS/DOPC and on DMPS/DPPC vesicles at $45^{\circ} \mathrm{C}$ and $15^{\circ} \mathrm{C}$ i.e., above and below the phase transition temperature of the latter vesicles. In this experiment, DOPS/DOPC vesicles were compared with vesicles composed of a mixture of DMPS and DPPC, which in contrast to DMPS/DMPC mixtures showed essentially complete miscibility in both the gel and in the liquid-crystalline state [25]. Information on the equilibrium constant for the formation of the membrane-bound factor $\mathrm{Xa}-\mathrm{Va}$ complex was obtained by measuring the factor Va dependency of the rate of prothrombin activation at limited factor $\mathrm{Xa}$ concentration [30]. The concentrations of factor $\mathrm{Va}$ required for $50 \%$ saturation of prothrombin activation $\left(\mathrm{K}_{1 / 2} \mathrm{Va}\right)$ are summarized in Table 2. For vesicles containing 20 mole \% PS the formation of the membrane-bound factor $\mathrm{Xa}-\mathrm{Va}$ complex appeared to be hardly influenced by membrane fluidity, and the $\mathrm{K}_{1 / 2 \mathrm{Va}}$ values were considerably below the factor $V a$ concentration of $5 \mathrm{nM}$ present in the experiments shown in Figures 1 and 2. This indicates that the low steady-state rates of prothrombin activation observed on membranes in the gel phase were not due to an effect of membrane fluidity on the equilibrium constant for factor $\mathrm{Xa}-\mathrm{Va}$ complex formation at the membrane surface.

In Table 2, we have also summarized the effect of temperature and membrane fluidity on the kinetic parameters $\left(\mathrm{K}_{\mathrm{m}}\right.$ and $\left.\mathrm{V}_{\text {max }}\right)$ of prothrombin activation. The $\mathrm{K}_{\mathrm{m}}$ for prothrombin appeared to be neither influenced by the temperature nor by the fluidity of the phospholipid vesicles. $\mathrm{K}_{m}$ values between 0.15 and $0.3 \mu \mathrm{M}$ were determined at $15^{\circ} \mathrm{C}$ and $45^{\circ} \mathrm{C}$ on DOPS/DOPC and DMPS/DPPS vesicles.

Variation of temperature had a considerable effect on the $V_{\max }$ values (Table 2). Lowering the temperature from $45^{\circ} \mathrm{C}$ to $15^{\circ} \mathrm{C}$ caused a 6 -fold decrease of the $V_{\max }$ of prothrombin activation on the DOPS/DOPC 
vesicles. However, temperature had a much more pronounced effect on the $V_{\max }$ determined on DMPS/DPPC vesicles. Whereas at $45^{\circ} \mathrm{C}$ the same $V_{\max }$ values were obtained on DMPS/DPPC and DOPS/DOPC vesicles, the $V_{\max }$ determined at $15^{\circ} \mathrm{C}$ on the DMPS/DPPC vesicles, which are in the gel phase, was 9-fold lower then the $V_{\max }$ determined on the DOPS/DOPC vesicles, which are in the liquid-crystalline phase at this temperature.

Table 2. Effect of membrane fluidity on the kinetic parameters of prothrombin activation on DOPS/DOPC and DMPS/DPPC vesicles

\begin{tabular}{|c|c|c|c|c|c|c|}
\hline \multirow[b]{2}{*}{ reaction temp $\left({ }^{\circ} \mathrm{C}\right)$} & \multicolumn{3}{|c|}{ DOPS/DOPC } & \multicolumn{3}{|c|}{ DMPS/DPPC } \\
\hline & $\begin{array}{c}\mathrm{K}_{1 / 2 \mathrm{Va}} \\
(\mathrm{nM})\end{array}$ & $\begin{array}{c}\mathrm{K}_{\mathrm{m}} \\
(\mu \mathrm{M})\end{array}$ & $V_{\max ^{a}}$ & $\begin{array}{c}\mathrm{K}_{1 / 2 \mathrm{Va}} \\
(\mathrm{nM})\end{array}$ & $\begin{array}{c}\mathrm{K}_{\mathrm{m}} \\
(\mu \mathrm{M})\end{array}$ & $V_{\max }{ }^{a}$ \\
\hline 45 & 0.12 & 0.30 & 13.5 & 0.29 & 0.22 & 11.9 \\
\hline 15 & 0.14 & 0.30 & 2.5 & 0.13 & 0.16 & 0.27 \\
\hline
\end{tabular}

Prothrombin was activated in a reaction mixture containing $50 \mathrm{mM}$ Tris- $\mathrm{HCl}(\mathrm{pH} 7.5)$, $175 \mathrm{mM} \mathrm{NaCl}, 5 \mathrm{mM} \mathrm{CaCl}_{2}, 0.5 \mathrm{mg} / \mathrm{ml}$ ovalbumin, $3 \mathrm{pM}$ factor $\mathrm{Xa}, 100 \mu \mathrm{M}$ phospholipid vesicles (DOPS/DOPC or DMPS/DPPC: 20/80, MM) and $5 \mathrm{nM}$ factor $\mathrm{Va}$ (in $\mathrm{K}_{\mathrm{m}}$ and $V_{\max }$ determination) or varying concentrations factor $\mathrm{Va}$ (in factor $\mathrm{Va}$ titration). The factor $\mathrm{Va}$ titration $\left(\mathrm{K}_{1 / 2 \mathrm{Va}}\right.$ determination) was performed at $1 \mu \mathrm{M}$ prothrombin. Rates of prothrombin activation were determined as described under Experimental Procedures. The kinetic parameters were obtained from double reciprocal plots of rates of prothrombin activation versus the factor $\mathrm{Va}$ concentration $\left(\mathrm{K}_{1 / 2} \mathrm{Va}\right)$ or the prothrombin concentration ( $\mathrm{K}_{\mathrm{m}}$ and $\mathrm{V}_{\max }$ ) after statistical analysis according to Eisenthal and Comish-Bowden [41].

a nanomolar prothrombin activated per minute.

These results demonstrate that membrane fluidity affects the prothrombinconverting activity by decreasing the catalytic activity of the prothrombinase complex as represented by the decrease of the $V_{\max }$ at the transition from the liquid-crystalline to the gel phase.

\section{Effect of lipid-phase transition on the catalytic properties of the pro- thrombinase complex}

To obtain further information on the effect of membrane fluidity on the catalytic activity of the prothrombinase complex, we have performed experiments with prethrombin 1 as substrate for prothrombinase. Prethrombin 1 is a prothrombin derivative that lacks the fragment 1 domain 
responsible for prothrombin binding to procoagulant membranes $[7,42]$. Comparison of the activity of the membrane-bound prothrombinase complex with prothrombin and prethrombin 1 as substrate may discriminate between effects of membrane fluidity on steps involved in the interaction of prothrombin with the membrane (association, dissociation and proper juxtaposition of enzyme and substrate) and direct effects on the catalytic site activity (conformation of the active site) of the membrane-bound factor Xa$\mathrm{Va}$ complex. The results presented in Table 3 demonstrate that membrane fluidity does not affect the prothrombinase activity on prethrombin 1 .

Table 3. Effect of membrane fluidity on rates of prothrombin and prethrombin 1 activation

\begin{tabular}{|c|c|c|c|c|}
\hline \multirow[b]{3}{*}{ substrate } & \multicolumn{4}{|c|}{$\begin{array}{l}\text { rate of prothrombin/prethrombin } 1 \\
\text { activation }{ }^{a} \text { at }\end{array}$} \\
\hline & \multicolumn{2}{|c|}{$45^{\circ} \mathrm{C}$} & \multicolumn{2}{|c|}{$15^{\circ} \mathrm{C}$} \\
\hline & $\begin{array}{l}\text { DOPSI } \\
\text { DOPC }\end{array}$ & $\begin{array}{l}\text { DMPS/ } \\
\text { DPPC }\end{array}$ & $\begin{array}{l}\text { DOPS/ } \\
\text { DOPC }\end{array}$ & $\begin{array}{l}\text { DMPS/ } \\
\text { DPPC }\end{array}$ \\
\hline prethrombin 1 & 50 & 62 & 236 & 218 \\
\hline prothrombin & 3527 & 3324 & 654 & 73 \\
\hline
\end{tabular}

$1 \mu \mathrm{M}$ prothrombin or prethrombin 1 was activated in a reaction mixture containing $50 \mathrm{mM}$ Tris- $\mathrm{HCl}(\mathrm{pH} 7.5), 175 \mathrm{mM} \mathrm{NaCl}, 5 \mathrm{mM} \mathrm{CaCl} 2,0.5 \mathrm{mg} / \mathrm{ml}$ ovalbumin, $100 \mu \mathrm{M}$ PS/PC (20/80, M/M) vesicles, different factor $X a$ concentrations (2 pM $-100 \mathrm{pM})$ and $5 \mathrm{nM}$ Factor Va. The phospholipid vesicles were composed of PS and PC with fatty acyl side chains indicated in the Table. The factor $X a$ concentrations were adapted to the rates of prothrombin or prethrombin 1 activation determined under the various reaction conditions.

a Nanomolar prothrombin or prethrombin 1 activated per minute per nanomolar faclor Xa present in the reaction mixture.

Rates of prethrombin 1 activation on DOPS/DOPC and DMPS/DPPC vesicles were the same both above $\left(45^{\circ} \mathrm{C}\right)$ and below $\left(15^{\circ} \mathrm{C}\right)$ the phase transition temperature of the DMPS/DPPC vesicles. In this table, we have included rates of prothrombin activation determined on the same vesicles in order to reconfirm the reduced prothrombin-converting activity of phospholipid vesicles in the gel phase (DMPS/DPPC vesicles at $15^{\circ} \mathrm{C}$ ). From the fact that rates of prethrombin 1 activation were not affected by membrane fluidity, we conclude that the phase transition from the liquid- 
crystalline to the gel phase does not affect the intrinsic catalytic activity of the membrane-bound factor Xa-Va complex.

One peculiarity observed in the experiment presented in Table 3 needs further attention and that is the effect of temperature on prethrombin 1 activation. To our surprise the rate of prethrombin 1 activation was increased 4-fold when the reaction temperature was lowered from $45^{\circ} \mathrm{C}$ to $15^{\circ} \mathrm{C}$. For this phenomenon we have as yet no good explanation.

\section{Gel electrophoretic analysis of prothrombin activation}

Three different reaction products can be formed during factor Xa-catalyzed prothrombin activation i.e. the inactive reaction intermediate prethrombin 2 and the enzymatically active products meizothrombin and thrombin. When prothrombin is activated by factor $\mathrm{Xa}$ in the absence of factor $\mathrm{Va}$ prethrombin 2 is the major initial reaction product and relatively small amounts of thrombin and meizothrombin are formed $[20,35]$. When factor $\mathrm{Va}$ is part of the prothrombinase complex there is no detectable formation of prethrombin 2 and in the initial phase of prothrombin activation meizothrombin and thrombin are the only reaction products formed $[20,35,43]$.

To test whether the effect of membrane fluidity on the $V_{\max }$ of prothrombin activation might be explained by an effect on the product generation pattern, we have followed time courses of prothrombin activation by gelelectrophoretic analysis and with amidolytic assays that allow separate quantitation of thrombin and meizothrombin [35]. This experiment was performed in the presence of the reversible thrombin inhibitor 12581 in order to prevent autocatalytic degradation of prothrombin and its activation products by thrombin.

In Figure $3 A$ it is shown that in the presence of fluid vesicles (DOPS/DOPC at $15^{\circ} \mathrm{C}$ ) meizothrombin was the main reaction product in the early phase of prothrombin activation.

After approximately $15 \mathrm{~min}$, meizothrombin began to disappear, while thrombin formation continued. The amidolytic data were confirmed by gelelectrophoretic analysis (Figure 3B). The transient band on the gels at the migrating distance of fragment 1.2-A is indicative for the formation of meizothrombin as temporary reaction intermediate [43]. The only other products observed on the gel were fragment 1.2 and the B-chain of thrombin. This cleavage pattern confirms earlier observations on product generation during prothrombin activation by the factor $\mathrm{Xa}-\mathrm{Va}$ complex on DOPS/DOPC vesicles at $37^{\circ} \mathrm{C}$. 
An important shift in the peptide bond cleavage pattern occurred when prothrombin was activated on phospholipid vesicles in the gel phase.
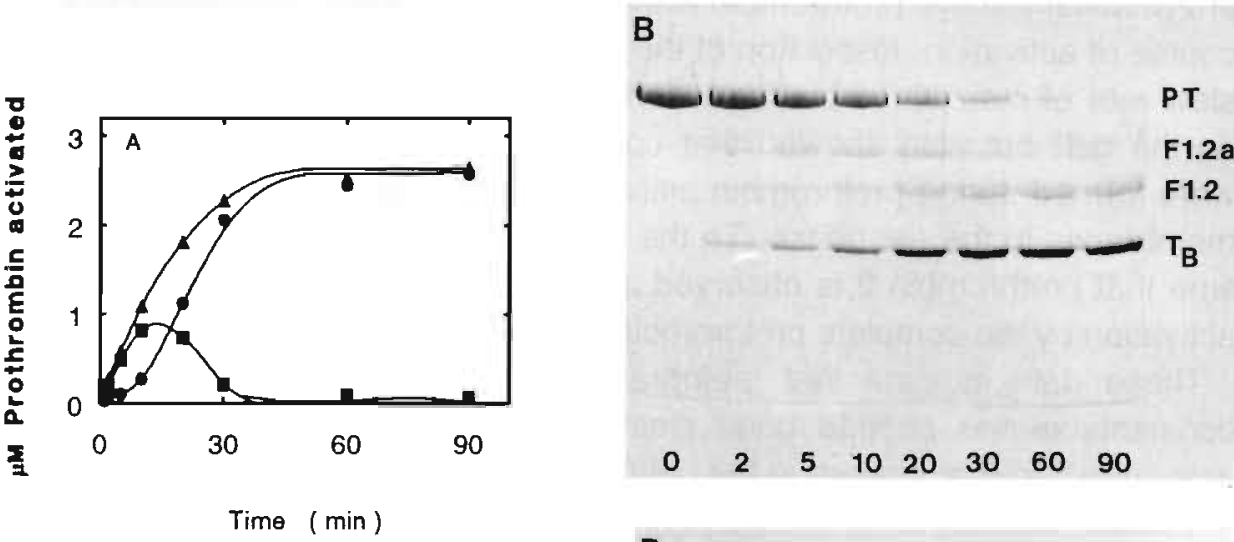

D
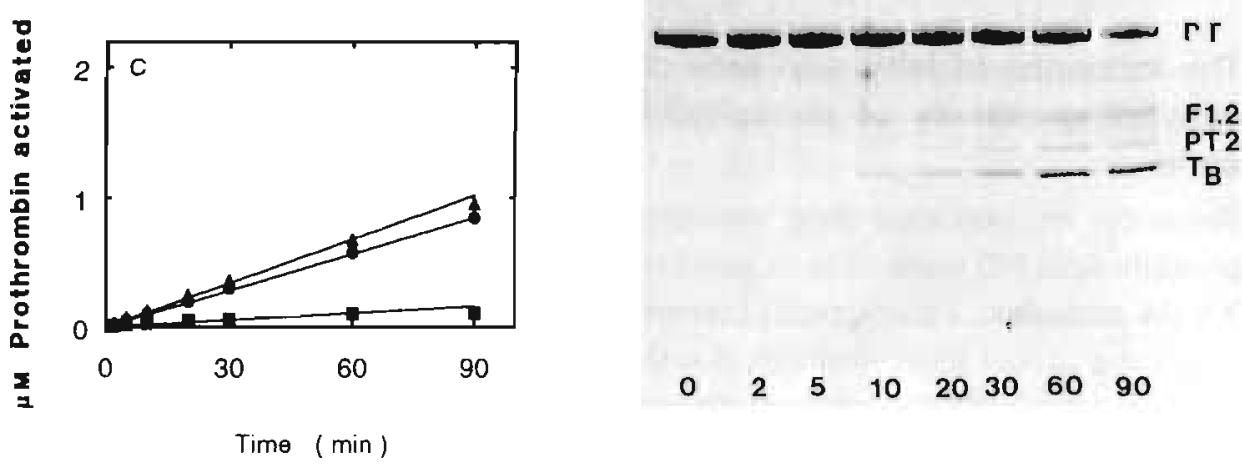

Figure 3. Effect of membrane fluidity on time courses of product generation during prothrombin activation. Prothrombin $(3 \mu \mathrm{M})$ was activated at $15^{\circ} \mathrm{C}$ in a reaction mixture containing $50 \mathrm{mM}$ Tris- $\mathrm{HCl}(\mathrm{pH} 7.5), 175 \mathrm{mM} \mathrm{NaCl}, 5 \mathrm{mM} \mathrm{CaCl} 2,1 \mathrm{nM}$ factor $\mathrm{Xa}, 10 \mathrm{nM}$ factor $\mathrm{Va}, 20 \mu \mathrm{M} 12581$ and $100 \mu \mathrm{M}$ phospholipid vesicles composed of 20 mole $\%$ DOPS and 80 mole $\%$ DOPC (A, B) or 20 mole\% DMPS and 80 mole\% DPPC (C, D). At the time intervals indicated, samples were withdrawn for the determination of total prothrombin activated (A) and meizothrombin ( $\boldsymbol{C}$ ) and thrombin (O) formed (A, C) and for gelelectrophoretic analysis (B, D). Quantitation of thrombin and meizothrombin and gelelectrophoretic analysis were performed as described under Experimental Procedures. PT, prothrombin; F1.2A, fragment $1.2+A$ chain thrombin; F1.2, fragment 1.2; PT2, prethrombin 2; $T_{B}, B$-chain of thrombin.

Whereas the product generation patterns during prothrombin activation on DOPS/DOPC and DMPS/DPPC vesicles at $45^{\circ} \mathrm{C}$ were the same and identical to those observed on DOPS/DOPC vesicles at $15^{\circ} \mathrm{C}$ (data not 
shown) there was hardly any meizothrombin formation during prothrombin activation on DMPS/DPPC vesicles in the gel phase i.e. at $15^{\circ} \mathrm{C}$ (Figure $3 \mathrm{C}$ ). Minor amounts of meizothrombin were formed, and thrombin was the major enzymatically active prothrombin activation product during the complete time course of activation. Inspection of the gel (Figure 3D) not only confirmed the slow rate of meizothrombin formation (there was no fragment 1.2-A visible on the gel) but also showed that considerable amounts of prethrombin 2 were formed during prothrombin activation by the factor $\mathrm{Xa}-\mathrm{Va}$ complex on membranes in the gel phase. To the best of our knowledge, this is the first time that prethrombin 2 is observed as reaction product during prothrombin activation by the complete prothrombinase complex.

These data indicate that membrane fluidity affects the individual rate constants of the peptide bond cleavages that occur during prothrombin activation. On membranes in the gel phase, there is reduced meizothrombin formation and generation of prethrombin 2 as prothrombin activation intermediate becomes possible.

\section{The influence of fatty acyl side chain saturation on the prothrombin- converting activity of phospholipid vesicles in the liquid-crystalline state}

Recently we reported that membranes solely composed of the neutral phospholipid PC were able to accelerate prothrombin activation by the factor $\mathrm{Xa}-\mathrm{Va}$ complex. Prothrombin-converting activity on $\mathrm{PC}$ vesicles was only observed at low ionic strength $(I<0.05)$, high factor Va concentrations and when the membranes were composed of PC that contained fatty acyl side chains with one or more unsaturated bonds [21].

To test whether this effect of fatty acyl side chain saturation is also observed on negatively charged membranes, we have compared the prothrombin-converting activities of a number of different membranes composed of either saturated or unsaturated phospholipids (Table 4). To avoid effects of membrane fluidity on the prothrombinase activity the reaction temperature $\left(45^{\circ} \mathrm{C}\right)$ was above the phase transition temperature of the various vesicles studied in this experiment.

Prothrombin activation was performed at physiological ionic strength $(I=0.2)$ on membranes containing 5 mole $\%$ PS. The factor $\mathrm{Va}$ concentration present in the activation mixture was $0.5 \mathrm{nM}$ in order to ensure $\sim 80 \%$ incorporation of factor $\mathrm{Xa}$ into the membrane-bound factor $\mathrm{Xa}-\mathrm{Va}$ complex in the case of DOPS/DOPC $(5 / 95, \mathrm{~mol} / \mathrm{mol})$ vesicles. In Table 4 , it 
Table 4. Effect of fatty acyl side chain saturation on the prothrombin-converting activities of fluid phospholipid vesicles

phospholipid

rate of prothrombin activationa

$\begin{array}{lr}\mathrm{diC}_{12: 0} \mathrm{PS} / \mathrm{DiC}_{12: 0} \mathrm{PC} & 143 \\ \mathrm{diC}_{14: 0} \mathrm{PS} / \mathrm{DiC}_{14: 0} \mathrm{PC} & 24 \\ \mathrm{diC}_{16: 0} \mathrm{PS} / \mathrm{DiC}_{16: 0} \mathrm{PC} & 43 \\ \mathrm{diC}_{16: 1} \mathrm{PS} / \mathrm{DiC}_{16: 1} \mathrm{PC} & 2551 \\ \mathrm{diC}_{18: 1} \mathrm{PS} / \mathrm{DiC}_{18: 1} \mathrm{PC} & 3304 \\ \mathrm{diC}_{22: 1} \mathrm{PS} / \mathrm{DiC}_{22: 1} \mathrm{PC} & 3823\end{array}$

$1 \mu \mathrm{M}$ prothrombin was activated activated in a reaction mixture containing $50 \mathrm{mM}$ Tris$\mathrm{HCl}(\mathrm{pH} 7.5), 175 \mathrm{mM} \mathrm{NaCl}, 5 \mathrm{mM} \mathrm{CaCl} 2,0.5 \mathrm{mg} / \mathrm{ml}$ ovalbumin, $100 \mu \mathrm{M}$ phospholipid vesicles, $0.5 \mathrm{nM}$ factor $\mathrm{Va}$ and $40 \mathrm{pM}$ factor Xa (experiment saturated phospholipids) or $2 \mathrm{pM}$ factor $\mathrm{Xa}$ (experiment unsaturated phospholipids). The phospholipid vesicles were composed of 5 mole \% PS and 95 mole \% PC with fatty acyl side chains indicated in the Table. The trivial names of the phospholipids used in this experiment are given in the Materials section of the Experimental Procedures.

a Nanomolar prothrombin activated per minute per nanomolar factor Xa present in the reaction mixture.

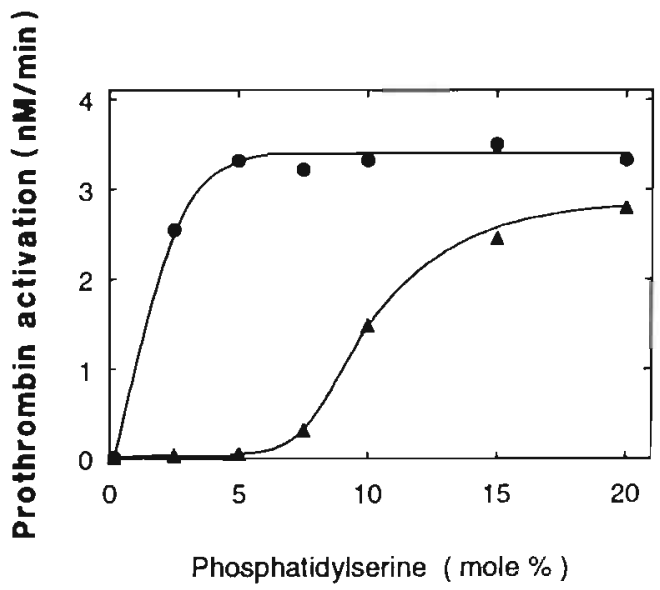

Figure 4. Prothrombin activation on membranes composed of saturated and unsaturated phospholipids as a function of the PS content. Prothrombin $(1 \mu \mathrm{M})$ was activated at $45^{\circ} \mathrm{C}$ in a reaction mixture containing $50 \mathrm{mM}$ Tris- $\mathrm{HCl}(\mathrm{pH} 7.5), 175 \mathrm{mM}$ $\mathrm{NaCl}, 5 \mathrm{mM} \mathrm{CaCl} 2,0.5 \mathrm{mg} / \mathrm{ml}$ ovalbumin, $100 \mu \mathrm{M}$ phospholipid vesicles, $1 \mathrm{pM}$ Xa and 0.5 $\mathrm{nM}$ factor $\mathrm{Va}$. The phospholipid vesicles were prepared from DOPS/DOPC (0) or DMPS/DPPC (A) mixtures containing mole percentages DOPS or DMPS indicated in the figure. Rates of prothrombin activation (nanomolar per minule) were determined as described under Experimental Procedures. 
is shown that PS-containing vesicles composed of unsaturated phospholipids exhibit a considerable higher prothrombin-converting activity than vesicles composed of saturated phospholipids. Thus it appears that fatty acyl side chain saturation is also an important parameter for the prothrombin-converting activity of membranes above the phase transition temperature.

In Figure 4 it is shown that this effect is especially observed on membranes with low amounts of negatively charged phospholipid (PS).

On vesicles composed of dioleoylphospholipids optimal rates of prothrombin activation were already obtained between 2.5 and 5 mole \% DOPS. Substantially higher mole percentages PS were required on membranes containing saturated phospholipids i.e. vesicles composed of DMPS and DPPC. On these membranes a plateau value for the prothrombin-converting activity was obtained at 20 mole \% DMPS.

Kinetic analysis of prothrombin activation at different factor $\mathrm{Va}$ concentrations provided an explanation for the different PS requirements of prothrombin activation on membranes composed of saturated and nonsaturated phospholipids (Table 5).

Table 5. Assembly and catalytic activity of prothrombinase on membranes with unsaturated and saturated phospholipids

\begin{tabular}{|c|c|c|c|c|}
\hline \multirow[b]{2}{*}{$\begin{array}{l}\text { mol \% PS } \\
\text { in vesicle }\end{array}$} & \multicolumn{2}{|c|}{ DOPS/DOPC } & \multicolumn{2}{|c|}{ DMPS/DPPC } \\
\hline & $\begin{array}{c}\mathrm{K}_{1 / 2 \mathrm{Va}} \\
(\mathrm{nM})\end{array}$ & $V_{o p t}{ }^{a}$ & $\begin{array}{c}\mathrm{K}_{1 / 2 \mathrm{Va}} \\
(\mathrm{nM})\end{array}$ & $\mathrm{V}_{\mathrm{opt}}{ }^{\mathrm{a}}$ \\
\hline 20 & 0.12 & 4.31 & 0.29 & 4.23 \\
\hline 15 & 0.09 & 4.14 & 0.39 & 4.27 \\
\hline 10 & 0.13 & 4.15 & 1.20 & 3.48 \\
\hline 7.5 & 0.12 & 3.95 & 5.33 & 3.64 \\
\hline 5 & 0.12 & 3.89 & 19.45 & 3.19 \\
\hline
\end{tabular}

Prothrombin $(1 \mu \mathrm{M})$ was activated at $45^{\circ} \mathrm{C}$ in a reaction mixture containing $50 \mathrm{mM}$ Tris$\mathrm{HCl}(\mathrm{pH} 7.5), 175 \mathrm{mM} \mathrm{NaCl}, 5 \mathrm{mM} \mathrm{CaCl}, 0.5 \mathrm{mg} / \mathrm{ml}$ ovalbumin, $100 \mu \mathrm{M}$ phospholipid vesicles, $1 \mathrm{pM} \mathrm{Xa}$ and varying concentrations of factor $\mathrm{Va}$. The phospholipid vesicles were composed of DOPS/DOPC or DMPS/DPPC mixtures with mole percentages DOPS or DMPS indicated in the table. Rates of prothrombin activation were determined as described under Experimental Procedures. $K_{1 / 2}$ and $V_{\text {opt }}$ were obtained from double reciprocal plots of rates of prothrombin activation versus the factor $V a$ concentration after statistical analysis according to Eisenthal and Comish-Bowden [41].

a Nanomolar prothrombin activated per minute. 
On vesicles containing dioleoylphospholipids, half maximal rates of prothrombin activation were obtained at factor Va concentrations $\left(K_{1 / 2}\right)$ of about $0.1 \mathrm{nM}$, independent of the mole percentage DOPS in the membrane. Much higher concentrations factor $\mathrm{Va}$ were required for halfmaximal stimulation of prothrombin activation on DMPS/DPPC vesicles and the $K_{1 / 2}$ appeared to be a function of the mole percentage DMPS. At high mole percentages $P S$ the $K_{1 / 2}$ values on DMPS/DPPC and DOPS/DOPC vesicles were of the same order of magnitude whereas reduction of the PS content caused a considerable increase of the $\mathrm{K}_{1 / 2} \mathrm{Va}$ observed on DMPS/DPPC

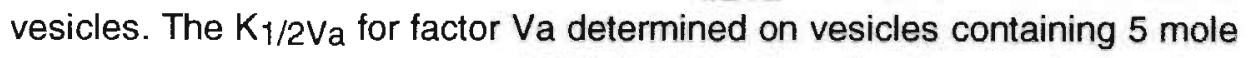
$\%$ DMPS in DPPC was about 150 -fold higher than the $\mathrm{K}_{1 / 2 \mathrm{Va}}$ observed on vesicles composed of 5 mole \% DOPS in DOPC.

The rates of prothrombin activation $\left(V_{\mathrm{Opt}}\right)$ calculated for saturating factor $\mathrm{Va}$ concentrations were independent of the phospholipid composition of the membrane. This means that on membranes with a low surface charge fatty acyl side chain saturation of phospholipids has a considerable influence on the formation of the membrane-bound factor $\mathrm{Xa}$ - Va complex (see also discussion).

\section{Discussion}

The prothrombin-converting activity of procoagulant membranes appears to be critically affected by the kind of (phospho)lipids that constitute the membrane. The importance of the polar head group of the phospholipid molecules was recognized long ago [44] and was afterwards related to the ability of membranes to bind the proteins (substrate, enzyme and protein cofactor) of the different coagulation factor-activating complexes. However, the membrane interior or hydrophobic core of the membrane also appeared to be an important parameter for the procoagulant activity of a membrane. Hydrogenation of fatty acyl side chains of phospholipids greatly reduced their procoagulant activity $[24,25]$. This effect appeared to be related to the phase transition of the membranes and it was established that membranes in the liquid-crystalline state exhibit a higher procoagulant activity than membranes in the gel state. In a later study with purified proteins Higgins et al. [1] demonstrated that the decreased prothrombin-converting activity of membranes in the gel state was at least partially due to a prolongation of the time required for the assembly of the prothrombinase complex. 
Our studies confirm these observations [1] on the occurrence of lag phases in thrombin generation when prothrombin activation is started with factor $\mathrm{Xa}$ or factor Va on phospholipid membranes in the gel state. Such a pre-steadystate interval indicates that membrane fluidity affects the time required for the assembly of the membrane-bound factor Xa-Va complex. On membranes below the phase transition temperature complex formation is apparently slowed down due to retarded lateral diffusion of factor $\mathrm{Xa}$ and factor $\mathrm{Va}$, a process that appears to be an essential step in factor $\mathrm{Xa}-\mathrm{Va}$ complex formation [45].

In contrast to Higgins et al. [1] we observed that membrane fluidity also affected the steady-state rate of prothrombin activation. Membranes in the gel state exhibited steady-state rates of prothrombin activation that were considerably below those observed on liquid-crystalline membranes (Figure $1 \mathrm{C})$. This effect of membrane fluidity on the expression of the catalytic activity of the prothrombinase complex appeared to be related to the phase transition of the membrane phospholipids. Above their phase transition temperatures the prothrombin-converting activities of DOPS/DOPC, DMPS/DMPC and DMPS/DPPC vesicles were the same. When the reaction temperatures were lowered from 45 to $0^{\circ} \mathrm{C}$ steady-state rates of prothrombin activation on DOPS/DOPC vesicles gradually decreased with a $Q_{10}$ of 1.6. Arrhenius plots of steady-state rates of prothrombin activation on DMPS/DPPC and DMPS/DMPC vesicles showed clear discontinuities beginning at $40^{\circ} \mathrm{C}$ and $25^{\circ} \mathrm{C}$, respectively, which is close to their respective phase transition temperatures. Below the phase transition temperature, the steady-state rates of prothrombin activation on the DMPS/DPPC and DMPS/DMPC vesicles were considerably lower than those determined on the fluid DOPS/DOPC vesicles.

Kinetic analysis showed that the $\mathrm{K}_{\mathrm{m}}$ for prothrombin and the $\mathrm{K}_{1 / 2 \mathrm{Va}}$ for $\mathrm{Xa}-\mathrm{Va}$ complex formation were hardly affected by the phase transition of membrane phospholipids (Table 2). The reduced steady-state rates of prothrombin activation appeared to be due to an effect of membrane fluidity on the $V_{\max }$ of prothrombin activation. Since the kinetic parameters were determined at a factor $V a$ concentration $>K_{1 / 2} V_{a}$ for $X a-V a$ complex formation it can be assumed that all factor Xa present was complexed with factor $\mathrm{Va}$ and participated in prothrombin activation. This allows the calculation of $k_{\text {cat }}$ values from the experimentally determined $V_{\text {max }}$. From the kinetic data obtained on DOPS/DOPC and DMPS/DPPC vesicles at $15^{\circ} \mathrm{C}$ it can be calculated that the $k_{c a t}$ for prothrombin activation drops from 
$14 \mathrm{~s}^{-1}$ on membranes in the liquid-crystalline state to $1.5 \mathrm{~s}^{-1}$ on membranes in the gel state.

Experiments with prethrombin 1 showed that the phase transition did not affect prothrombinase-catalyzed activation of this substrate. This indicates that the phase-dependent decrease of the $\mathrm{k}_{\mathrm{c}}$ at of prothrombin activation is not due to an effect of membrane fluidity on the intrinsic catalytic activity of the prothrombinase complex. However, prethrombin 1 is a prothrombin derivative that does not bind to phospholipid and that will react with the prothrombinase complex directly from solution. In this respect it differs from prothrombin which, due to its phospholipid binding properties, may also have an interaction with the membrane surface that contributes to prothrombinprothrombinase complex formation. On the basis of these observations we propose that membrane fluidity affects the phospholipid-dependent interaction between prothrombin and the factor Xa-Va complex (see below).

The effect of membrane fluidity on the activity of the prothrombinase complex may be related to the observed shift in the product generation pattern during prothrombin activation on membranes in the gel phase. Prothrombin conversion into thrombin requires the cleavage of two peptide bonds and dependent on the order of cleavage meizothrombin or prethrombin 2 may occur as reaction products. Analysis of product generation during prothrombin activation by the complete prothrombinase complex (factor $\mathrm{Xa}$, factor $\mathrm{Va}, \mathrm{Ca}_{2}+$ and phospholipid) on fluid membranes showed that thrombin and meizothrombin were the only detectable reaction products which confirms earlier observations [35,46]. However, on membranes in the gel phase there is a considerable reduction of meizothrombin formation and prethrombin 2 occurs as reaction product (Figure 3), indicating that membrane fluidity has an effect on the peptide bond cleavage and product generation patterns during prothrombin activation.

These data suggest, but do not prove, that membrane fluidity affects the pathway of prothrombin activation in such a way that thrombin formation on fluid membranes occurs via meizothrombin and on liquid-crystalline membranes via prethrombin 2 as reaction intermediate. It should be emphasized, however, that definite conclusions with respect to enzymebound reaction intermediates cannot be drawn from steady-state kinetic studies like those reported in the present paper [47]. This would require a combination of a more detailed steady-state and pre-steady-state approach.

The effects of membrane fluidity on the catalytic activity of prothrombinase and on the product generation pattern may have a common cause. It is likely 
that one of the functions of membranes in prothrombin activation is to properly juxtapose the enzyme (factor $\mathrm{XaVa}$ ) and substrate (prothrombin) for efficient catalysis [48]. It is tempting to speculate that membrane fluidity may affect the juxtaposition of the proteins of the prothrombinase complex in such a way that there is a less favorable orientation for catalysis on membranes in the gel phase. The changes in the product generation pattern may also result from a different positioning of the active site of the prothrombinase complex relative to the peptide bonds that have to be cleaved in prothrombin.

We have also determined the effect of fatty acyl side chain saturation in fluid membranes by comparing the prothrombin-converting activities of vesicles composed of saturated or unsaturated phospholipids above the phase transition temperature. The prothrombin-converting activity of liquidcrystalline membranes containing 20 mole\% PS was hardly affected by the saturation of the fatty acyl side chains of the phospholipids. However, greatly reduced rates of prothrombin activation were observed on membranes that contained a low mole percentage PS and that were composed of phospholipids with saturated fatty acyl side chains (Table 4, Figure 4). The low prothrombin-converting activities of such membranes appeared to be due to a much higher factor $\mathrm{Va}$ requirement for full incorporation of factor $\mathrm{Xa}$ in the ternary Xa.Va.PS/PC complex (Table 5). This indicates that on membranes with a low surface charge (i.e. low mole percentage of PS) the equilibrium constants for factor $\mathrm{Xa}-\mathrm{Va}$ complex formation are less favorable for membranes containing saturated phospholipids. Formation of a membrane-bound factor Xa-Va complex involves three distinct steps: (1) binding of factor $\mathrm{Xa}$ and (2) factor $\mathrm{Va}$ to distinct membrane sites and (3) diffusion of membrane-bound factor $\mathrm{Xa}$ and $\mathrm{Va}$ and subsequent prothrombinase formation [45]. At present we do not know which of these steps is actually affected by fatty acyl side chain saturation of membrane phospholipids. The fact that diminished factor Xa-Va complex formation is only observed on saturated membranes with a low surface charge points, however, in the direction of factor $\mathrm{Va}$. Binding of factor $\mathrm{Va}$ may involve electrostatic $[16,17,19]$ and hydrophobic interactions $[14,15]$ and penetration of factor $\mathrm{Va}$ into nonpolar membrane regions $[49,50]$. Membrane penetration and hydrophobic interactions may be prevented on membranes composed of phospholipids with saturated fatty side chains in which the phospholipid molecules are more densily packed than in membranes composed of phospholipids with fatty acyl side chains that contain one or more cis double bonds $[38,40]$. This may result in a decreased affinity of factor $\mathrm{Va}$ for 
membranes composed of saturated phospholipids. The fact that the decreased affinity for factor Va was much less pronounced on membranes with higher mole percentages PS (Table 5) may result from an increased contribution of electrostatic interactions to the overall binding equilibrium. This hypothesis can be tested by measuring the effect of fatty acyl side chain saturation on the individual steps required for prothrombinase assembly (protein-membrane association and dissociation steps and prothrombinase formation from membrane-bound constituents).

\section{References}

1. Higgins D.L., Callahan P.J., Prendergast F.G., Nesheim M.E. and Mann K.G. (1985) Lipid mobility in the assembly and expression of the activity of the prothrombinase complex, J. Biol. Chem. 260, 3604-3612

2. Mann K.G., Nesheim M.E., Church W.R., Haley P. and Krishnaswamy S. (1990) Review article: surface-dependent reactions of the vitamin K-dependent enzyme complexes, Blood 76, 1-16

3. Rosing J. and Tans G. (1989) in Coagulation and Lipids (Zwaal R.F.A., ed.) pp 159-187, CRC Press, Boca Raton, FL.

4. Stenflo J., Fernlund P., Egan W., and Roepstorff P. (1974) Vitamin K dependent modifications of glutamic acid residues in prothrombin, Proc. Nat. Acad. Sci. 71, 2730-2733

5. Nelsestuen G. L., Zytkovicz T.H. and Howard J.B. (1974) The mode of action of vitamin $\mathrm{K}$. Identification of gamma-carboxyglutamic acid as a component of prothrombin, J. Biol. Chem. 249, 6347-6350

6. Howard J.B. and Nelsestuen G.L. (1975) Isolation and characterization of vitamin K-dependent region of bovine blood clotting Factor X, Proc. Natl. Acad. Sci. 72, 1281-1285

7. Nelsestuen G.L. (1976) Role of gamma-carboxyglutamic acid. An unusual protein transition required for the calcium-dependent binding of prothrombin to phospholipid, J. Biol. Chem. 251, 5648-5656

8. Furie B.C., Mann K.G. and Furie B. (1976) Substitution of lanthanide ions for calcium ions in the activation of bovine prothrombin by activated factor $X$. High affinity metal binding sites of prothrombin and the derivatives of prothrombin activation, J. Biol..Chem. 251, $3235-3241$

9. Prendergast F.G. and Mann K.G. (1977) Differentiation of metal ion-induced transitions of prothrombin fragment 1, J. Biol. Chem. 251, 840-850

10. Nelsestuen G.L. and Broderius M. (1977) Interactions of prothrombin and bloodclotting factor $X$ with membranes of varying composition, Biochemistry 16, 4172 4177

11. Lecompte M.F., Miller I.R., Elion J. and Benarous R. (1980) Interaction of prothrombin and its fragments with monolayers containing phosphatidylserine. I. Binding of prothrombin and its fragment 1 to phosphatidylserine-containing monolayers, Biochemistry 19, 3434-3439 
12. Mayer L.D., Nelsestuen G.L. and Brockman H.L. (1983) Prothrombin association with phospholipid monolayers, Biochemistry 22, 316-321

13. Kop J.M.M., Cuypers P.A., Lindhout T., Hemker H.C. and Hermens W.Th. (1984) The adsorption of prothrombin to phospholipid monolayers quantitated by ellipsometry, J. Biol. Chem. 259, 13993-13998

14. Bloom J.W., Nesheim M.E. and Mann K.G. (1979) Phospholipid-binding properties of bovine factor $\mathrm{Va}$, Biochemistry 18, 4419-4425

15. Krishnaswamy S. and Mann K.G. (1988) The binding of factor Va to phospholipid vesicles, J. Biol. Chem. 263, 5714-5723

16. Pusey M.L., Mayer L.D., Jason Wei G., Bloomfield V.A. and Nelsestuen G.L. (1982) Kinetic and hydronamic analysis of blood clotting factor V-membrane binding, Biochemistry 21, 5262-5269

17. van de Waart P., Bruls H., Hemker H.C. and Lindhout T. (1983) Interaction of bovine blood clotting factor $\mathrm{Va}$ and its subunits with phospholipid vesicles, Biochemistry 22, 2427-2432

18. Mayer L.D., Pusey M.L., Griep M.G. and Nelsestuen G.L. (1983) Association of blood coagulation factors $V$ and $X$ with phospholipid monolayers, Biochemistry 22, 6226-6232

19. Pusey M.L. and Nelsestuen G.L. (1984) Membrane binding properties of blood coagulation factor $V$ and derived peptides, Biochemistry 23, 6202-6210

20. Rosing J., Tans G., Govers-Riemslag J.W.P., Zwaal R.F.A. and Hemker H.C. (1980) The role of phospholipids and factor Va in the prothrombinase complex, $J$. Biol. Chem. 255, 274-283

21. Gerads I., Govers-Riemslag J.W.P., Tans G., Zwaal R.F.A. and Rosing J. (1990) Prothrombin activation on membranes with anionic lipids containing phosphate, sulfale, and/or carboxyl groups, Biochemistry 29, 7967-7974

22. van Rijn J.L.M.L., Govers-Riemslag J.W.P., Zwaal R.F.A. and Rosing J. (1984) Kinetic studies of prothrombin activation: Effect of factor $V a$ and phospholipids on the formation of the enzyme substrate complex, Biochemistry 23, 4557-4564

23. Rosing J., Tans G., Speijer H. and Zwaal R.F.A. (1988) Calcium-independent activation of prothrombin on membranes with positively charged lipids, Biochemistry 27, 9048-9055

24. Sterzing P.A. and Barton P.G. (1973) The influence of cholesterol on the activity of phospholipid in blood coagulation: requirement for a lipid crystalline lipid phase, Chem.Phys.Lipids 10, 137-148

25. Tans G., van Zutpen H., Comfurius P., Hemker H.C. and Zwaal R.F.A. (1979) Lipid phase transitions and procoagulant activity, Eur. J. Biochem. 95, 449-457

26. Owen W.G., Esmon C.T. and Jackson C.M. (1974) The conversion of prothrombin to thrombin. I. Characterization of reaction products formed during the activation of bovine prothrombin, J. Biol. Chem. 249, 594-605

27. Fujikawa K., Legaz M.E. and Davie E.W. (1972) Bovine factor X(1) and X(2) (Stuart factor) isolation and characterization, Biochemistry 11, 4882-4891

28. Fujikawa K., Legaz M.E. and Davie E.W. (1972) Bovine faclor X(1) (Stuart factor) mechanism of activation by a protein from Russel's viper venom, Biochemistry 11, $4892-4899$

29. Schiffman S., Theodor J. and Rapaport S.J. (1969) Separation from Russel's viper venom of one fraction reacting with factor $X$ and another reacting with factor $V$, Biochemistry 8, 1397-1405 
30. Lindhout T., Govers-Riemslag J.W.P., van de Waant P., Hemker H.C. and Rosing J. (1982) Factor Va-factor Xa interaction. Effects of phospholipid vesicles of varying composition, Biochemistry 21 5494-5502

31. Thaler E. and Schmer G. (1975) A simple two-step isolation procedure for human and bovine antithrombin II/III (heparin cofactor): a comparison of two methods, $\mathrm{Br}$. J. Haematol. 31, 233-243

32. Smith R.L. (1973) Titration of activated bovine factor $X$, J. Biol. Chem. 248, 2418 2423

33. Chase T. Jr., and Shaw E. (1969) Comparison of the esterase activities of trypsin plasmin and thrombin on guanidinobenzoate esters - titration of the enzymes, Biochemistry 8, 2212-2224

34. Böttcher C.J.F., van Gent C.M. and Pries C. (1961) A rapid and sensitive sub-micro phosphorus determination, Anal. Chim. Acta 24, 203-207

35. Rosing J., Zwaal R.F.A. and Tans G. (1986) Formation of meizothrombin as an intermediate in factor Xa-catalyzed prothrombin activation, J. Biol. Chem. 261, 4224-4228

36. Laemmli U.K. (1970) Cleavage of structural protein during the assembly of the head bacteriophage T4, Nature 227,680-685

37. Huang C. (1991) in Phospholipid-Binding Antibodies (Harris, E.N., Exner, T., Hughes, G.R.V. and Asherson, R.A., Ed.) pp 3-30, CRC Press, Boca Raton, FL.

38. Ladbrooke B.D. and Chapman D. (1969) Thermal analysis of lipids proteins and biological membranes, a review and summary of some recent studies, Chem. Phys. Lipids 3, 304-367

39. van Dijck P.W.M., de Kruijff B., van Deenen L.L.M., de Gier J. and Demel R.A. (1976) The preference of cholesterol for phosphatidylcholine in mixed phosphatidylcholine-phosphatidylethanolamine bilayers, Biochim. Biophys. Acta 455, 576-587

40. Demel R.A., Geurts van Kessel W.S.M. and van Deenen, L.L.M. (1972) The Properties of polyunsaturated lecithins in monolayers and liposomes and the interactions of these lecithins with cholesterol, Biochim. Biophys. Acta 266, 26-40

41. Eisenthal R. and Comish-Bowden A. (1974) The direct linear plot. A new graphical procedure for estimating enzyme kinetic parameters, Biochem. J. 139, 715-720

42. Stenn K.S. and Blout E.R. (1972) Mechanism of bovine prothrombin activation by an insoluble preparation of bovine factor Xa (thrombokinase), Biochemistry 11 , 4502-4515

43. Krishnaswamy S., Mann K.G. and Nesheim M.E. (1986) The prothrombinasecatalyzed activation of prothrombin proceeds through the intermediate meizothrombin in an ordered, sequential reaction, J. Biol. Chem. 261, 8977-8984

44. Troup S.B. and Reed C.F. (1958) Platelet thromboplastic factor. Its chemical nature, in vitro activity and the identification of similar thromboplastic substances in red blood cells, J. Clin. Invest. 37, 937-944

45. Krishnaswamy S., Jones K.C. and Mann K.G. (1988) Prothrombinase complex assembly. Kinetic mechanism of enzyme assembly on phospholipid vesicles, $J$. Biol. Chem. 263, 3823-3834

46. Krishnaswamy S., Church W.R., Nesheim M.E. and Mann K.G. (1987) Activation of human prothrombin by human prothrombinase. Influence of factor $\mathrm{Va}$ on the reaction mechanism, J. Biol. Chem. 262, 3291-3299 
47. Rosing J. and Tans G. (1988) Meizothrombin, a major product of factor Xacatalyzed prothrombin activation, Thromb. Haemostas. 60, 355-360

48. Husten E.J., Esmon C.T. and Johnson A.E. (1987) The active site of blood coagulation factor $\mathrm{Xa}$. Its distance from the phospholipid surface and its conformational sensitivity to components of the prothrombinase complex, J. Biol. Chem. 262, 12953-12961

49. Lecompte M.F., Krishnaswamy S., Mann K.G., Nesheim M.E. and Gitler C. (1987) Membrane penetration of bovine factor $V$ and $V a$ detected by labeling with 5iodonaphthalene-1-azide, J. Biol. Chem. 262, 1935-1937

50. Krieg U.C., Isaacs B.S., Yemul S.S., Esmon C.T., Bayley H. and Johnson A.E. (1987) Interaction of blood coagulation factor $\mathrm{Va}$ with phospholipid vesicles examined by using lipophilic photoreagents, Biochemistry 26, 103-109 


\section{Chapter 9}

\section{Summary and Concluding Remarks}


The conversion of prothrombin into thrombin is the pivotal reaction in blood coagulation. This reaction is catalyzed by the prothrombinase complex, that comprises the enzyme factor $\mathrm{Xa}$, the protein cofactor $\mathrm{Va}$, a procoagulant phospholipid surface and calcium ions. The proteins, prothrombin, factor $\mathrm{Xa}$ and factor $\mathrm{Va}$ bind with high affinity to procoagulant membranes. This binding increases the local concentration of the proteins on the membrane surface, which promotes the formation of the enzyme-cofactor-substrate complex and results in an increased rate of prothrombin activation.

Both the proteins and the procoagulant membrane have to meet specific requirements in order to enable the protein-membrane interactions responsible for the assembly of a functionally active prothrombinase complex. This thesis concems a study of the importance of proteinmembrane interactions for both the assembly and the activity of the prothrombinase complex. In the first part of this thesis the question is approached through the protein components of this complex and the second part of the thesis is focused on the significance of the physical- and chemical properties of the membrane surfaces for their activity in prothrombin activation.

In chapter 3 the structural and functional characterization of a prothrombin activator purified from the venom of the snake species Bothrops neuwiedi is described. This venom enzyme appears to be an effective prothrombin activator, which only cleaves the Arg323-Ilez24 peptide bond in the prothrombin molecule thus converting it into meizothrombin. The activity of the venom prothrombin activator is not influenced by the presence of the accessory components of the prothrombinase complex, phospholipids and factor $\mathrm{Va}$. The prothrombin activator is single chain protein with an apparent molecular weight of 60,000 . It is a metalloproteinase and, therefore, belongs to a different class of proteolytic enzymes than the physiological prothrombin activator factor $\mathrm{Xa}$, which is a serine protease. The venom activator from Bothrops neuwiedi appears to be structurally and functionally similar, however, to the prothrombin activators present in the venoms of Echis caninatus and Dispholidus typus.

Chapter 4 concerns the purification and characterization of the prothrombin activator from the venom of Notechis scutatus. This enzyme strongly resembles factor $\mathrm{Xa}$. This venom prothrombin activator can cleave both the Arg323-lle324 and Arg274-Thr275 bonds of prothrombin and is, therefore, able to convert prothrombin into thrombin. The formation of two different intermediates (prethrombin 2 and meizothrombin) is observed. This shows that the venom activator can activate prothrombin via two pathways, which 
are distinguished by the order at which the Arg323-lle324 and Arg274-Thr275 bonds are cleaved during prothrombin activation. The prothrombin activator from Notechis scutatus has a molecular weight of 54,000. Like factor $\mathrm{Xa}$, this venom activator consists of a light chain and a heavy chain linked to each other by a disulfide bridge. The activator is classified as a serine protease since its prothrombin-converting activity is inhibited by soy-bean trypsin inhibitor, diisopropylfluorophosphate and dansyl-GGACK chloromethyl ketone. The venom activator from Notechis scutatus scutatus is stimulated by the accessory components factor $\mathrm{Va}$ and phospholipids. The stimulating effect of phospholipids has led to the discovery of $\gamma$-carboxy-glutamic acid residues (Gla's) in the polypeptide chain of the snake venom prothrombin activator. The mechanism by which this venom activator binds to procoagulant membranes may therefore be similar to that by which vitamin $\mathrm{K}$-dependent coagulation factors bind. It also indicates that this snake possesses a carboxylation system which converts the amino acid Glu into Gla in a posttranslational modification.

The presence of $\gamma$-carboxyglutamic acid residues in the polypeptide chains of coagulation factors is essential for the binding of these proteins to the phospholipid surface. But the procoagulant membrane also has to meet a number of requirements. Membranes, which contain the negatively charged phosphatidylserine have the highest prothrombin-converting activity. The high activity of phosphatidylserine-containing membranes in prothrombin activation is attributed to the important role of the amino group of phosphatidylserine in the binding of the vitamin K-dependent coagulation factors to the membrane. The formation of a chelate complex, with a structure that resembles the calcium-EDTA complex, has been proposed as a model for the vitaminK-dependent protein-Ca2+-membrane complex when the procoagulant membrane contains phosphatidylserine.

This model is supported by the experiments that are reported in chapter 6 . In this chapter the influence of the chemical structure of the polar headgroup of the phospholipid molecules on prothrombin activation is described. Not only the surface charge appears to be important for the binding of coagulation factors, but also the chemical nature of the negatively charged phospholipid molecule. Membranes, which derive their negative charge from phospholipid molecules with different polar headgroups, e.g. phosphatidylglycerol, phosphatidylethanolamine and phosphatidic acid have a less stimulating effect upon prothrombin activation than membranes which contain phosphatidylserine. In chapter 6 it is also shown that the stimulating effect of negatively charged membrane surfaces on prothrombin activation is 
not strictly dependent on the presence of a phosphate group. Membranes which contain a carboxyl- or a sulfate group instead of a phosphate group as anionic moiety are also able to promote the formation of a functionally active prothrombinase complex. However, the prothrombin-converting activity of these membranes is inhibited at high ionic strength and the stimulation of prothrombin activation by these membranes is less than in the case of membranes which contain phosphatidylserine. Both higher lipid concentrations and a higher anionic lipid content are required for optimal activity. It has been postulated that electrostatic interactions between prothrombin, factor $\mathrm{Xa}$ and the membrane significantly contribute to the assembly of a catalytically active prothrombinase complex on membranes which contain anionic lipids other than phosphatidylserine. In the presence of factor $\mathrm{Va}$, the structure of the negatively charged (phospho)lipid molecule becomes less important and the sensitivity towards ionic strength variation is less. Factor $\mathrm{Va}$ apparently compensates for the weak electrostatic proteinlipid interactions, presumably by additional interactions with prothrombin and factor Xa.

For many years it has been assumed that procoagulant membanes derive their functional activity from the presence of negatively charged phospholipids. The experiments presented in chapter 7, however, demonstrate that neutrally charged surfaces can also exhibit prothrombinconverting activity. Stimulation of prothrombin activation by neutral phosphatidylcholine membranes is particularly observed: (1) at low ionic strength, (2) in the presence of factor $\mathrm{Va},(3)$ when the phosphatidylcholine molecules contain unsaturated fatty acyl side chains and, (4) in the presence of calcium ions. Both the actiyation of prethrombin 1 by factor $\mathrm{Xa}$ and the activation of prothrombin by Gla-domainless factor $X a$ are not stimulated by DOPC vesicles. The dependence on calcium as well as the requirement for the presence of Gla-domains in the vitamin K-dependent coagulation factors suggests that calcium dependent interactions between the Gla-domains of prothrombin and factor $\mathrm{Xa}$ and the DOPC surface are essential for the expression of the prothrombin-converting activity of DOPC membranes.

In chapter 8 the effect of variation of the physical properties of the procoagulant membranes on prothrombin activation is described. The composition of the hydrophobic part of the membrane, which is formed by the fatty acyl side chains of the phospholipid molecules, determines the fluidity of the membrane. Fluid membranes exhibit a higher prothrombinconverting activity than solid membranes both in the initial and steady state phase of prothrombin activation. In the initial phase of prothrombin 
activation, a considerable lag in thrombin formation is observed on solid membranes (chapter 8). This lag phase is caused by the slower assembly of the factor XaVa complex on solid membranes. Compared with fluid membranes, prothrombin activation on solid membranes is not only impeded in the initial phase of prothrombin activation but also in the so-called steady state phase. From determination of the kinetic parameters it appears that this is due to a decrease of $k_{\text {cat }}$ of prothrombin activation on solid membranes. The decrease of the $k_{c a t}$ is, however, not due to an effect of membrane fluidity on the active site of factor $X a$ since the activation of prethrombin 1 is stimulated to the same extent on solid and fluid membranes. Gelelectrophoretic analysis of product formation during prothrombin activation on solid membranes shows that the main reaction product formed is prethrombin 2. This observation is in contrast with prothrombin activation on fluid membranes on which only meizothrombin is formed as prothrombin activation intermediate. These data demonstrate that membrane fluidity influences the order of peptide bond cleavage in the prothrombin molecule. Solid membranes apparently cause a shift in the pathway of prothrombin activation. The non-active prethrombin 2 is formed and this results in a decreased rate of thrombin formation on solid membranes. A possible explanation for the observed shift in the pathway of prothrombin activation may be that the proteins involved in the prothrombin activation do not properly juxtapose after binding to a solid membrane, which may result in a decreased rate of thrombin formation.

The fatty acyl side chains of the phospholipid molecules not only determine the fluidity of the membrane, but also influence the packing density of a membrane. The distance between the phospholipid molecules in a membrane is increased when cis double bonds are present in the fatty acyl side chains. PS/PC membranes which are in the liquid crystalline phase (i.e. above the phase transition temperature) and which contain a low percentage PS, exhibit less prothrombin-converting activity when the phospholipid molecules contain saturated fatty acyl side chains. The reduced activity of saturated membranes appears to be caused by impeded factor $\mathrm{XaVa}$ complex formation. This difference between saturated and non-saturated membranes dissappears either by introducing more PS in the membrane or by increasing the factor $\mathrm{Va}$ concentration. Since factor $\mathrm{Va}$ binding to membrane surfaces involves both hydrophobic and electrostatic interactions this suggests that a) the hydrophobic interaction of factor $\mathrm{Va}$ with the inner core of the membrane is hampered on membranes composed of phospholipid molecules with saturated fatty acyl side chains and that $b$ ) this 
effect disappears on membranes with more phosphatidylserine is due to an increased contribution of electrostatic interactions, which compensate for the weak hydrophobic interactions. 


\section{Hoofdstuk 9}

Samenvatting en Slotopmerkingen 
De omzetting van protrombine in trombine is de centrale reactie in de bloedstolling. Deze reactie wordt gecatalyseerd door het protrombinasecomplex, wat bestaat uit het enzym factor $\mathrm{Xa}$, de eiwit cofactor $\mathrm{Va}$, een stollingsbevorderend fosfolipide-oppervlak en calcium ionen. De eiwitten protrombine, factor $\mathrm{Xa}$ en factor $\mathrm{Va}$ binden met hoge affiniteit aan stollingsbevorderende membranen. Deze binding verhoogt de locale concentraties van de eiwitten aan het membraanoppervlak wat de vorming van het enzym-cofactor-substraatcomplex bevordert en wat resulteert in een verhoogde snelheid van protrombine-activering.

De specifieke eiwit-lipide interacties stellen zowel voorwaarden aan de eiwitten als aan het stollingsbevorderende oppervlak. Dit proefschrift behandelt een studie naar het belang van eiwit-membraan-interacties voor protrombine-activering in modelsystemen en naar het werkingsmechanisme van het protrombinase complex. In het eerste gedeelte van het proefschrift vindt benadering van de vraagstelling plaats via de eiwitcomponenten van dit complex en in het tweede deel wordt ingegaan op het belang van de fysische en chemische eigenschappen van membraanoppervlakken voor hun activiteit in de protrombine-activering.

In hoofdstuk 3 van dit proefschrift wordt de structurele en functionele karakterisering beschreven van een protrombine-activator uit het gif van de slang Bothrops neuwiedi. Dit blijkt een effectieve protrombine-activator te zijn, die uitsluitend de peptidebinding Arg323-lle324 in het protrombinemolecuul kan splitsen. Onder invloed van dit enzym wordt protrombine omgezet in meizotrombine en verdere activering stopt op dit niveau. De activiteit van deze protrombine-activator uit slangegif wordt niet beïnvloed door de aanwezigheid van de cofactoren van het protrombinasecomplex, fosfolipiden en factor $V a$. De protrombine-activator bestaat uit een polypeptideketen en heeft een relatief molecuulgewicht van ongeveer 60.000. Het is een metallo-protease en derhalve behoort het tot een andere enzymklasse als de fysiologische protrombine-activator factor $\mathrm{Xa}$, wat een serineprotease is. De protrombine-activator van Bothrops neuwiedi blijkt echter zowel structureel als functioneel grote overeenkomst te vertonen met de protrombine-activatoren aanwezig in de giffen van Echis carinatus en Dispholidus typus.

Hoofdstuk 4 behandelt de zuivering en karakterisering van de protrombineactivator uit het gif van de slang Notechis scutatus scutatus. Dit enzym vertoont grote overeenkomst met factor $\mathrm{Xa}$. Deze protrombine-activator kan protrombine zowel op de Arg323-lle324 als op de Arg274-Thr275 plaats splitsen en kan protrombine dus omzetten in trombine. Twee verschillende 
tussenprodukten kunnen worden aangetoond: pretrombine 2 en meizotrombine. Dit houdt in dat er twee activeringsroutes gevolgd kunnen worden, die bepaald worden door de volgorde van splitsing van de peptidebindingen tijdens de activering van protrombine. De protrombineactivator van Notechis scutatus scutatus heeft een molecuulgewicht van 54.000 en bestaat evenals factor Xa uit een lichte en uit een zware keten, die geassocieerd zijn via een zwavelbrug. Op grond van remming door een trypsineremmer, door diisopropylfosfofluoridaat en door het chloromethylketon dansyl-GGACK is geconcludeerd dat dit enzym, evenals factor Xa, tot de serineproteasen behoort. De gifactivator van Notechis scutatus scutatus wordt gestimuleerd door aanwezigheid van de cofactoren factor $\mathrm{Va}$ en fosfolipiden. De stimulering door fosfolipiden heeft geleid tot de ontdekking van $\gamma$-carboxyglutaminezuurresiduen (Gla's) in de eiwitketen van de slangegif protrombine-activator. Het bindingsmechanisme van de vitamine K-afhankelijke stollingsfactoren geldt daarom misschien ook voor de binding van deze gifactivator aan het oppervlak. Tevens houdt het in dat deze slang een carboxyleringssysteem bezit dat het aminozuur Glu via een posttranslationele modificatie omzet in Gla.

De aanwezigheid van $\gamma$-carboxyglutaminezuur in de eiwitketen van stolfactoren blijkt essentiëel te zijn voor de binding van deze eiwitten aan fosfolipiden. Maar ook het stollingsbevorderend oppervlak moet aan een aantal eisen voldoen. Membranen, die het negatief geladen fosfatidylserine bevatten, vertonen de hoogste protrombinase-activiteit. De unieke stimulering van protrombine-activering door fosfatidylserine bevattende membranen wordt toegeschreven aan een belangrijke functie van de aminogroep van fosfatidylserine in de binding van vitamine $\mathrm{K}$-afhankelijke stollingsfactoren aan het fosfolipide-oppervlak. De vorming van een chelaatcomplex, welke overeenkomst vertoont met de structuur van het calcium-EDTA-complex, is voorgesteld als model voor het vitamine $\mathrm{K}$ afhankelijke eiwit-Ca2+-membraancomplex voor het geval dat fosfatidylserine deel uitmaakt van het stollingsbevorderend oppervlak.

Dit model wordt ondersteund door de experimenten die gerapporteerd worden in hoofdstuk 6 . In dit hoofdstuk wordt de invloed beschreven van de chemische structuur van de polaire kop van de fosfolipidemoleculen waaruit het membraan is opgebouwd op protrombine-activering. Niet alleen de lading van het membraanoppervlak maar ook de chemische structuur van de negatief geladen fosfolipidemoleculen blijkt van belang te zijn voor de binding van de stolfactoren. Membranen die negatief geladen zijn door de aanwezigheid van fosfolipidemoleculen met verschillende polaire koppen, 
zoals fosfatidylglycerol, fosfatidylethanolamine of fosfatidezuur zijn minder effectief in protrombine-activering dan fosfatidylserine-bevattende membranen. In hoofdstuk 6 wordt tevens aangetoond dat de stimulerende werking van negatief geladen membraanoppervlakken op de activering van protrombine niet noodzakelijkerwijs afhankelijk is van de aanwezigheid van een fosfaatgroep. Membranen met lipidemoleculen, die in plaats van een fosfaatgroep een carboxyl- of een sulfaatgroep bevatten, zijn ook in staat de vorming van een functioneel actief protrombinase-complex te bevorderen. De protrombine-activering op deze membranen is echter ionsterkte gevoelig en veel minder effectief dan PS-bevattende membranen. Tevens zijn zowel een hogere lipideconcentratie als een hoger percentage van deze anionische lipiden vereist voor optimale procoagulante activiteit. Er is gepostuleerd dat electrostatische interacties tussen protrombine, factor $\mathrm{Xa}$ en het membraan een belangrijke rol spelen in de assemblage van een catalytisch actief complex op membranen die een ander anionisch lipide bevatten dan fosfatidylserine. In aanwezigheid van factor $\mathrm{Va}$, wordt de structuur van het negatief geladen (fosfo)lipidemolecuul echter minder belangrijk en neemt de zoutgevoeligheid ook sterk af. Factor Va compenseert klaarblijkelijk voor de zwakke electrostatische eiwit-lipideinteracties, mogelijk door additionele interacties met protrombine en factor $\mathrm{Xa}$.

Jarenlang is men er vanuit gegaan dat stollingsbevorderende oppervlakken hun functionele activiteit verkrijgen door de aanwezigheid van negatief geladen fosfolipiden. Het onderzoek beschreven in hoofdstuk 7 toont echter aan dat neutraal geladen oppervlakken ook in staat zijn de omzetting van protrombine in trombine te bevorderen. Stimulering van protrombine-activering door neutrale phosphatidylcholinemembranen treedt met name op: (1) bij lage ionsterkte, (2) in aanwezigheid van factor $\mathrm{Va}$, (3) wanneer de phosphatidylcholinemoleculen onverzadigde vetzuurstaarten bevatten en, (4) in aanwezigheid van calcium-ionen. Zowel de activering van pretrombine 1 door factor $\mathrm{Xa}$ als de activering van protrombine door factor $\mathrm{Xa}$ zonder Gla-domein worden echter niet gestimuleerd door phosphatidylcholinevesicles. De calcium-afhankelijkheid in combinatie met de noodzakelijke aanwezigheid van Gla-domeinen in de vitamine $\mathrm{K}$ afhankelijke stolfactoren wijst erop dat calcium-afhankelijke interacties tussen de Gla-domeinen van protrombine en factor $\mathrm{Xa}$ en het phosphatidylcholine oppervlak essentieel zijn voor de expressie van protrombine-activering op PC-membranen. 
In hoofdstuk 8 wordt het belang beschreven van de fysische eigenschappen van de stollingsbevorderende oppervlakken voor de protrombine-activering. De samenstelling van het hydrofobe deel van het membraan, gevormd door de vetzuurstaarten van de fosfolipidemoleculen, bepaalt de vloeibaarheid van het membraan. Vloeibare membranen vertonen een hogere activiteit in protrombine-activering dan vaste membranen. In de beginfase van protrombine-activering op vaste membranen (hoofdstuk 8), wordt een toenemende omzettingssnelheid waargenomen. Deze blijkt veroorzaakt te worden door een vertraagde vorming van het factor Xa-factor $\mathrm{Va}$ complex op vaste membranen. In vergelijking met vloeibare membranen is protrombine-activering op vaste membranen niet alleen langzamer in de initiële fase, maar ook in de zogenaamde steady state fase. Uit bepaling van de kinetische parameters blijkt dat de $k_{\text {cat }}$ op vaste membranen is verlaagd. Deze verlaging van de $k_{c a t}$ is echter niet het gevolg van een direct effect van membraanvloeibaarheid op het actieve centrum van factor $X a$. Pretrombine 1 activering wordt door vaste en vloeibare membranen namelijk evenveel gestimuleerd. Analyse van produktvorming tijdens protrombine-activering op vaste membranen met behulp van gelelectroforetische technieken laat zien dat er voornamelijk pretrombine 2 gevormd wordt. Dit is in tegenstelling tot protrombine-activering op vloeibare membranen waarop in de initiële fase meizotrombine gevormd wordt. Deze resultaten tonen aan dat membraanvloeibaarheid van invloed is op de volgorde van splitsing van de peptidebindingen in het protrombinemolecuul. Membranen in de vaste fase veroorzaken een verandering van de activeringsroute van protrombine. Het niet actieve pretrombine 2 wordt gevormd, en dit heeft een verlaging van de trombinevormingssnelheid op vaste membranen tot gevolg. Een mogelijke verklaring voor de verandering van de activeringsroute zou kunnen zijn dat de bij de protrombine-activering betrokken eiwitten na binding aan een vast membraan niet de juiste positie ten opzichte van elkaar innemen, hetgeen een verlaging van de trombinevormingssnelheid van het enzym tot gevolg kan hebben.

De vetzuurstaarten van de fosfolipidemoleculen beïnvloeden niet alleen de vloeibaarheid, maar ook de pakkingsdichtheid van een membraan. De onderlinge afstand van de fosfolipidemoleculen in een membraan wordt verhoogd wanneer er cis-dubbele bindingen in de vetzuurstaarten aanwezig zijn. Vloeibare PS/PC-membranen, die een laag percentage PS bevatten, geven minder stimulering van protrombine-activering wanneer de vetzuurstaarten verzadigd zijn. De factor XaVa complexvorming blijkt 
bemoeilijkt te zijn op verzadigde membranen met een laag percentage PS. De lagere snelheid van protrombine-activering op verzadigde membranen kan worden verhoogd, wanneer er meer PS geïntroduceerd wordt in het membraan of wanneer de factor $\mathrm{Va}$ concentratie in het activeringsmengsel verhoogd wordt. De factor $\mathrm{Va}$ binding aan het membraan is zowel afhankelijk van hydrofobe- als ionogene interacties. Membranen opgebouwd uit fosfolipide-moleculen met verzadigde vetzuurstaarten lijken de interactie van factor $\mathrm{Va}$ met het hydrofobe binnenste van het membraan te bemoeilijken. De invloed van de verzadigingsgraad van het membraan op de protrombine-activering neemt echter af, wanneer het PS-gehalte van het membraan wordt verhoogd. Dit effect is mogelijk te verklaren door een toenemende bijdrage van electrostatische interacties die de verminderde hydrofobe interacties compenseren. 


\section{List of publications}

- Vermeer C., Soute B.A.M., Govers-Riemslag J.W.P. and Hemker H.C. (1976) In vitro prothrombin synthesis from a purified precursor protein. I. Development of a bovine cell-free system, Biochim. Biophys. Acta 444, 926-930

- Vermeer C., Govers-Riemslag J.W.P., Soute B.A.M., Lindhout M.J., Kop J. and Hemker H.C. (1978) The role of blood clotting factor $V$ in the conversion of prothrombin and a decarboxy prothrombin into thrombin, Biochim. Biophys. Acta 538, 521-533

- Rosing J., Tans G., Govers-Riemslag J.W.P., Zwaal R.F.A. and Hemker H.C. (1980) The role of phospholipids and factor $\mathrm{Va}$ in the prothrombinase complex, J. Biol. Chem. 255 274-283

- Lindhout T., Govers-Riemslag J.W.P., van de Waart P., Hemker H.C. and Rosing J. (1982) Factor Va-factor Xa interaction. Effects of phospholipid vesicles of varying composition, Biochemistry 21 5494-5502

- van Rijn J.L.M.L., Govers-Riemslag J.W.P., Zwaal R.F.A., and Rosing J. (1984) Kinetic studies of prothrombin activation: Effect of factor Va and phospholipids on the formation of the enzyme substrate complex, Biochemistry 23 4557-4564

- Govers-Riemslag J.W.P., Speijer H., Zwaal, R.F.A. and Rosing J. (1985) The effects of bovine prothrombin fragment 1 and fragment 1.2 on prothrombin activation Thromb. Res. 38 (4), 375-388

- van Dieijen G., van Rijn, J.L.M.L., Govers-Riemslag, J.W.P., Hemker, H.C. and Rosing, J. (1985) Assembly of the intrinsic factor $X$ activating complexinteractions between factor IXa, factor VIIla and phospholipid, Thromb. Haemostas. 53 (3), 396-400

- Tans G., Govers-Riemslag J.W.P., van Rijn J.L.M.L., and Rosing J. (1985) Purification and properties of a prothrombin activator from the venom of Notechis Scutatus Scutatus, J. Biol. Chem. 260, 9366-9372

- Speijer H., Govers-Riemslag J.W.P., Zwaal R.F.A. and Rosing J. (1986) Prothrombin activation by an activator from the venom of Oxyuranus Scutellatus (Taipan Snake), .J. Biol. Chem. 261, 13258-13267

- Speijer H., Govers-Riemslag J.W.P., Zwaal R.F.A. and Rosing J. (1987) Platelet procoagulant properties studied with snake venom prothrombin activators, Thromb. Haemostas. 57, 349-355

- Govers-Riemslag J.W.P., Knapen M.J.H., Tans G., Zwaal R.F.A. and Rosing J. (1987) Structural and functional characterization of a prothrombin activator from the venom of Bothrops Neuwiedi, Biochim. Biophys. Acta 916, 388-401

- Tans G., Govers-Riemslag J.W.P., van Rijn J.L.M.L., and Rosing J. (1988) Prothrombin activation by an activator purified from the venom of the Mainland Tiger snake (Notechis Scutatus Scutatus), Hemostasis and animal venoms (Pirkle, H. and Markland, F.S., eds.) Marcel Dekker, Inc., New York, pp 29-40 
- Govers-Riemslag J.W.P. Speijer H., Zwaal, R.F.A. and Rosing J. (1988) Purification and characterization of the prothrombin activator from Oxyuranus Scutellatus (Taipan Snake), Hemostasis and animal venoms (Pirkle, $\mathrm{H}$. and Markland, F.S., eds.) Marcel Dekker, Inc., New York, pp 41-53

- Gerads I., Govers-Riemslag J.W.P., Tans G., Zwaal R.F.A., and Rosing J. (1990) Prothrombin activation on membranes with anionic lipids containing phosphate, sulfate, and/or carboxyl groups, Biochemistry 29, 7967-7974

- Govers-Riemslag J.W.P., Janssen M.P., Zwaal R.F.A. and Rosing J. (1992) Effect of membrane fluidity and fatty acid composition on the prothrombinconverting activity of phospholipid vesicles, Biochemistry 31, 10000-10008

- Govers-Riemslag J.W.P., Janssen M.P., Zwaal R.F.A. and Rosing J. (1994) Prothrombin activation on dioleoylphosphatidylcholine membranes, Eur. J. Biochem. 220, 131-138 


\section{Curriculum vitae}

José Govers-Riemslag werd geboren op 17 maart 1953 te Arnhem. Zij behaalde het HBS-B diploma aan het Katholiek Gelders Lyceum te Arnhem. Hierna studeerde zij aan de Hogere Laboratorium School te Oss. In 1974 behaalde zij het getuigschrift HBO-B Biochemie. In oktober 1974 werd zij aangesteld als analiste bij de vakgroep Biochemie van de Medische Faculteit Limburg in oprichting en was tijdelijk werkzaam in Leiden. Vervolgens kwam zij in dienst van de Faculteit der Geneeskunde van de Rijksuniversiteit Limburg te Maastricht. In 1990 inmiddels werkzaam als laboratoriumhoofdassistente begon zij een aanvullende studie aan de Hogeschool Heerlen. In januari 1992 werd dit HLO-diploma Chemie behaald en werd toelating verkregen tot promotie. 


\section{Dankwoord}

Als afsluiting een woord van dank aan al diegenen, die direct of indirect een bijdrage hebben geleverd aan de totstandkoming van dit proefschrift.

Op de afdeling Biochemie heb ik een groot aantal collega's getroffen die met hart en ziel onderzoek verrichten en daardoor een werksfeer creëren, die stimulerend en motiverend is voor elkaar. Een aantal mensen wil ik in het bijzonder noemen.

Allereerst gaat mijn dank uit naar mijn copromotor Jan Rosing. Tijdens onze veelvuldige gesprekken in de afgelopen jaren heb ik mijn ideeën steeds kunnen toetsen aan jouw bewonderingswaardige kennis, en je hebt mij vaak bijgestuurd in de ingewikkelde weg die ik meestal lijk te kiezen. Jan, de heldere uitleg die jij mij steeds gegeven hebt en de veelvuldige discussies die wij gevoerd hebben, daar kijk ik met veel plezier op terug.

Mijn promotor, professor R.F.A. Zwaal, wil ik bedanken voor de gelegenheid die hij mij geboden heeft om dit proefschrift te schrijven.

Mijn dank gaat ook in het bijzonder uit naar professor H.C. Hemker, die al vroeg vertrouwen in mij schonk en mij mijn eigen weg liet gaan.

De mede-auteurs van de artikelen wil ik bedanken voor de plezierige samenwerking en vooral Rita voor haar bijdrage in de experimenten.

Guido, Stella, Gerry; de gezellige sfeer op het lab zijn van onschatbare waarde geweest voor het doen van de experimenten.

Met Cees en Berry heb ik mijn eerste onderzoekservaring opgedaan en veel heb ik aan hen te danken.

Theo, Bemadette en Jos wil ik ook nog in het bijzonder vermelden.

Trees en Mariet bedank ik voor de secretariële ondersteuning en Enny Beerden voor de lay-out adviezen van dit proefschrift.

De mensen van ICA, RL design, de bibliotheek, de technische dienst en het magazijn bedank ik voor de altijd prettige samenwerking.

In dit dankwoord ook nog een "second pathway", die tot de totstandkoming van dit proefschrift geleid heeft: het thuisfront.

Mijn ouders dank ik voor het doorzettingsvermogen, dat ik van hen heb meegekregen.

Frans, ondanks de wat lijdzame weg die partners van promovendi nou eenmaal doormaken, heb jij door jouw voortdurende geduld en begrip wezenlijk aan de voltooiing van dit proefschrift bijgedragen. 
Ook Pim en Birgit hebben mij soms moeten missen, omdat ik veel achter de computer zat.

Mariet Bours, zonder jouw uitstekende opvang van de kinderen was het mij nooit gelukt dit proefschrift te schrijven.

Tot slot wil ik mijn paranimfen, Francien en Anneke bedanken voor het verlichten van de laatste loodjes.

Maastricht, 10 juni 1994

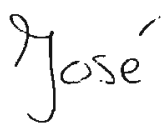


